ADVANCED STEEL CONSTRUCTION

\section{An International Journal}

Volume 6 Number 4

December 2010

CONTENTS

Technical Papers

Progressive Collapse of Steel-Framed Buildings: Influence of Modelling Approach

Hang Yu, Bassam A. Izzuddin and Xiao-Xiong Zhe

Theoretical Analysis and Experimental Research on Stability Behavior of Structural Steel Tube and Coupler Falsework with X-Bracing

Hongbo Liu, Zhihua Chen, Xiaodun Wang and Ting Zhou

Experimental Behavior of High Strength Concrete-Filled Square Steel Tube under Bi-Axial Eccentric Loading

GuoChang Li, Zhijian Yang and Yan Lang

Load-Carrying Capacity and Practical Design Method of Welded Hollow Spherical Joint in Space Latticed Structures

Xing $L i$

Bond Tests of Partially Encased Composite Column

Marisa Pecce and Francesca Ceroni

Advanced Analysis and Performance Based Evaluation of Concrete Filled Tube (CFT) Columns Jong Wan Hu, Joonam Park and Roberto T. Leon

Tensile Behavior of Welded Tee End Connection for Circular Hollow Members Vittorio Nascè and Francesco Tondolo

Copyright $\odot 2010$ by :

The Hong Kong Institute of Steel Construction

Website: $h t t p: / / w w w . h k i s c . o r g$

ISSN 1816-112X

Science Citation Index Expanded, Materials Science Citation Index and ISI Alerting

Cover: Curved Roof of the New Wuhan Bullet Train Station in China

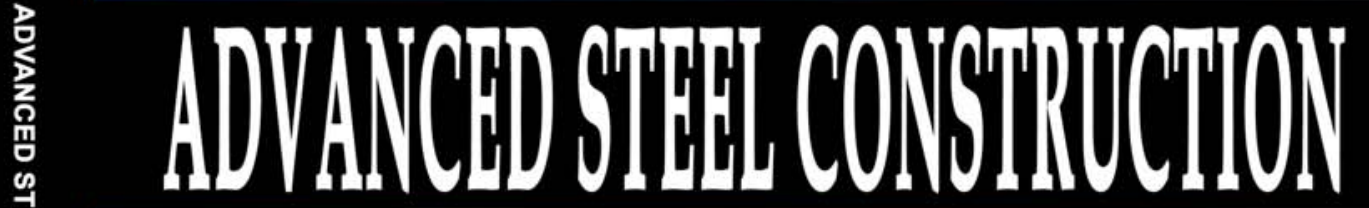

an International Jounal ISSN 1816-112X

Volume 6 Number 4

December 2010

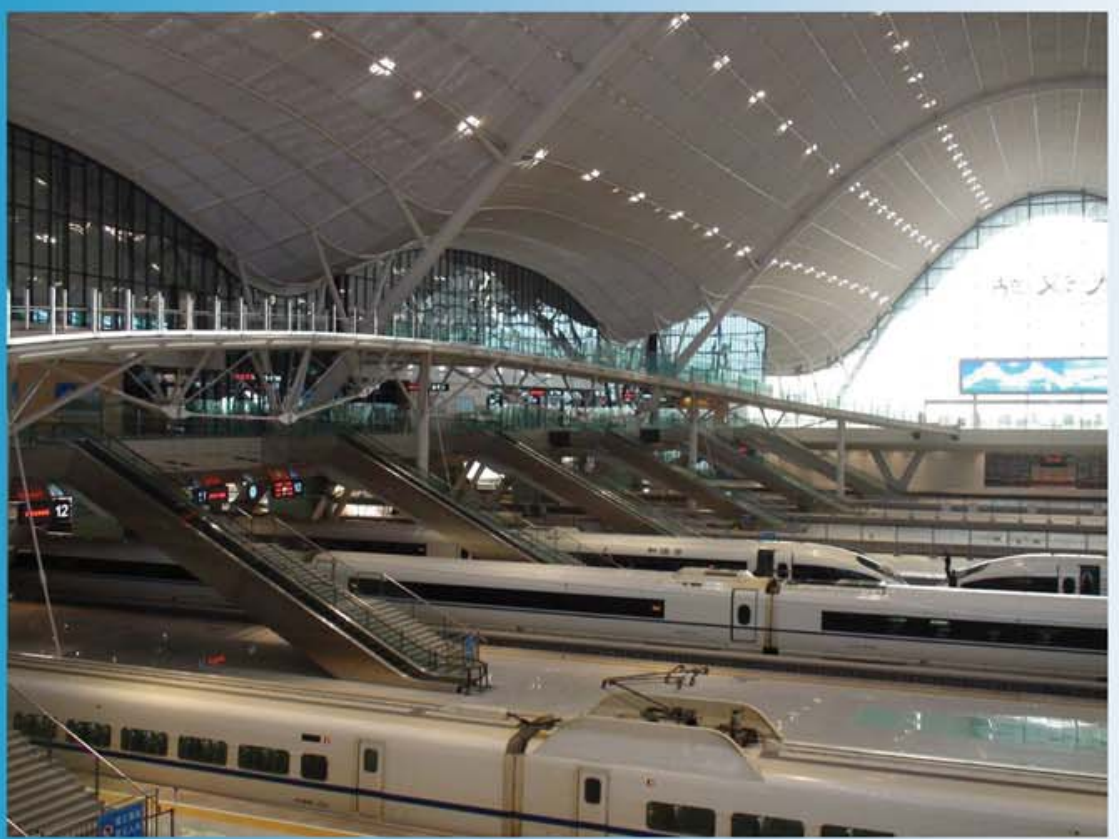

Editors-in-Chief

S.L. Chan, The Hong Kong Polytechnic University, Hong Kong

W.F. Chen, University of Hawaii at Manoa, USA

R. Zandonini, Trento University, Italy 


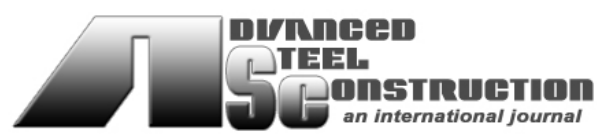

ISSN 1816-112X

Science Citation Index Expanded, Materials Science Citation Index and ISI Alerting

\section{EDITORS-IN-CHIEF}

Asian Pacific, African and organizing Editor

S.L. Chan

The Hong Kong Polyt. Univ., Hong Kong

\section{American Editor \\ W.F. Chen \\ Univ. of Hawaii at Manoa, USA}

\section{European Editor}

R. Zandonini

Trento Univ., Italy

\section{INTERNATIONAL} EDITORIAL BOARD

F.G. Albermani

The Univ. of Queensland, Australia

I. Burgess

Univ. of Sheffield, UK

F.S.K. Bijlaard

Delft Univ. of Technology, The Netherlands

R. Bjorhovde

The Bjorhovde Group, USA

M.A. Bradford

The Univ. of New South Wales, Australia

D. Camotim

Technical Univ. of Lisbon, Portugal

C.M. Chan

Hong Kong Uni v. of Science \& Technolog Hong Kong

T.H.T. Chan

Queensland Univ. of Technology, Australia

S.P. Chiew

Nanyang Technological Univ., Singapore

W.K. Chow

The Hong Kong Polyt. Univ., Hong Kong

K.F. Chung

The Hong Kong Polyt. Univ., Hong Kong

G.G. Deierlein

Stanford Univ., California, USA

\section{Advanced Steel \\ Construction an international journal}

L. Dezi

Univ. of Ancona, Italy

D. Dubina

The Politehnica Univ. of Tim

Romania

R. Greiner

Technical Univ. of Graz, Austria

L.H. Han

Tsinghua Univ. China

G.W.M. Ho

Ove Arup \& Pa rtners Hong Kon g Ltd., Hong Kong

B.A. Izzuddin

Imperial College of Science, Technology

and Medicine, UK

J.P. Jaspart

Univ. of Liege, Belgium

S. A. Jayachandran

IIT Madras, Chennai, India

S. Kitipornchai

City Univ. of Hong Kong, Hong Kong

D. Lam

Univ. of Bradford, UK

G.Q. Li

Tongji Univ., China

J.Y.R. Liew

National Univ. of Singapore, Singapore

E.M. Lui

Syracuse Univ., USA

Y.L. Mo

Univ. of Houston, USA

J.P. Muzeau

y, CUST, Clermont Ferrand, France

D.A. Nethercot

Imperial College of Science, Technology and Medicine, UK

Y.Q. Ni

The Hong Kong Polyt. Univ., Hong Kong

D.J. Oehlers

The Univ, of Adelaide, Australia

K. Rasmussen

The Univ. of Sydney, Australia

J.M. Rotter

The Univ. of Edinburgh, UK
C. Scawthorn

Scawthorn Porter Associates, USA

P. Schaumann

osoara, Univ. of Hannover, Germany

G.P. Shu

Southeast Univ. China

J.G. Teng

The Hong Kong Polyt. Univ., Hong Kong

G.S. Tong

Zhejiang Univ., China

K.C. Tsai

National Taiwan Univ., Taiwan

C.M. Uang

Univ. of California, USA

B. Uy

University of Western Sydney

M. Veljkovic

Univ. of Lulea, Sweden

F. Wald

Czech Technical Univ. in Prague, Czech

Y.C. Wang

The Univ. of Manchester, UK

Y.L. Xu

The Hong Kong Polyt. Univ., Hong Kong

D. White

Georgia Institute of Technology, USA

E. Yamaguchi

Kyushu Institute of Technology, Japan

Y.B. Yang

National Taiwan Univ., Taiwan

B. Young

The Univ. of Hong Kong, Hong Kong

X.L. Zhao

Monash Univ., Australia

Z.H. Zhou

Alpha Consultant Ltd., Hong Kong 



\begin{tabular}{ll}
\hline \hline & General Information \\
& Advanced Steel Construction, an international journal \\
\hline \hline Aims and scope
\end{tabular}

\section{Aims and scope}

The International Journal of Advanced Steel Construction provides a platform for the publication and rapid dissemination of ori ginal and up-to-date research and tec hnological developments in steel c onstruction, design and anal ysis. Scope of research $p$ apers published in this journal includes but is not limite $d$ to theor etical and expe rimental research on elements, assemblages, sy stems, material, design philosophy and codification, standards, fabrication, projects of innov ative nature an d computer tech niques. The journal is specifically $t$ ailored to channel the e xchange of tec hnological know-ho $w$ bet ween $r$ esearchers an d practitioners. Contributions from all aspects related to the recent developments of advanced steel construction are welcome.

\section{Instructions to authors}

Submission of the manuscript. Authors may submit double-spaced manuscripts preferably in MS Word by emailing to one of the chief editors as follows for arrangement of review. Alternatively papers can be submitted on a diskette to one of the chief editors.

Asian Pacific, African and organizing editor: Professor S.L. Chan, Email: ceslchan@polyu.edu.hk

American editor :

European editor:

Professor S.L. Chan, Email: ceslchan@polyu.edu

Professor R. Zandonini, Email: riccardo_zandonini@ing.unitn.it

All manuscripts submitted to the journal are recommended to accompany with a li st of four potential reviewers suggested by the author(s). This list should include the complete name, add ress, telephone and fax num bers, em ail address, and at least five keywords that identify the expertise of each reviewer. This scheme will improve the process of review.

Style of manuscript

General. Author(s) should provide full postal and email addresses and fax number for correspondence. The manuscript including abstract, keywords, references, figures and tables should be in English with pages numbered and typed with double line spacing on single side of A4 or letter-sized paper. The front page of the article should contain:

a) a short title (reflecting the content of the paper);

b) all the name(s) and postal and email addresses of author(s) specifying the author to whom correspondence and proofs should be sent;

c) an abstract of $100-200$ words; and

d) 5 to 8 keywords.

The paper must contain an introduction and a conclusion. The length of paper should not exceed 25 journal pages (approximately 15,000 words equivalents).

Tables and figures. Tables and figures including photographs should be typed, numbered consecutively in Arabic numerals and with short titles. They should be referred in the text as Figure 1, Table 2, etc. Originally drawn figures and photographs should be provided in a form suitable for photographic reproduction and reduction in the journal.

Mathematical expressions and units. The Systeme Internationale (SI) should be followed whenever possible. The numbers identifying the displayed mathematical expression should be referred to in the text as Eq. (1), Eq. (2).

References. References to published literature should be referred in the text, in the order of citation with Arabic numerals, by the last name(s) of the author(s) (e.g. Zandonini and Zanon [3]) or if more than three authors (e.g. Zandonini et al. [4]). References should be in English $w$ ith occasional allow ance of 1-2 e xceptional referenc es in local lang uages and $r$ eflect the curren $t$ state-of-technology. Journal titles should be abbreviated in the style of the Word List of Scientific Periodicals. References should be cited in the following style $[1,2,3]$.

Journal: [1] Chen, W.F. and Kishi, N., "Semi-rigid Steel Beam-to-column Connections, Data Base and Modellin g", Journal of Structural Engineering, ASCE, 1989, Vol. 115, No. 1, pp. 105-119.

Book: [2] Chan, S.L. and Chui, P.P.T., "Non-linear Static and Cyclic Analysis of Semi-rigid Steel Frames", Elsevier Science, 2000 .

Proceedings: [3] Zandonini, R. a nd Zanon, P., "Experimental Analy sis of S teel Beams with Semi -rigid Joint s", Proceedings of International Conference on Advances in Steel Structures, Hong Kong, 1996, Vol. 1, pp. 356-364.

Proofs. Proof will be sent to the c orresponding author to correct an y typesetting errors. Alternations to the original manuscript at this stage will not be accepted. Proofs should be returned within 48 hours of receipt by Express Mail, Fax or Email.

Copyright. Submission of an article to "Advanced Steel Construction" implies that it presents the original and unpublished work, and not under consideration for publication nor published elsewhere. On acceptance of a manuscript submitted, the copyright thereof is transferred to the publisher $b y$ the Transfer of $C$ opyright Agreement and upon $t$ he acceptance of publication for the $p$ apers, the corresponding author must sign the form for Transfer of Copyright.

Permission. Quoting from this journal is granted provided that the customary acknowledgement is given to the source.

Page charge and Reprints. There will be no page charges if the length of paper is within the limit of 25 journal pages. A total of 30 free offprints will be supplied free of charge to the corresponding author. Purchasing orders for additional offprints can be made on order forms which will be sent to the authors. These instructions can be obtained at the Hong Kong Institute of Steel Construction, Journal website: http://www.hkisc.org

The International Journal of Advanced Steel Construction is published quarterly by non-profit making learnt society, The Hong Kong Institute of Steel Construction, c/o Department of Civil \& Structural Engineering, The Hong Kong Polytechnic University, Hung Hom, Kowloon, Hong Kong.

Disclaimer. No responsibility is assumed for a ny injury and / or damage to per sons or property as a matter of products liability, negligence or otherwise, or from any use or operation of any methods, products, instructions or ideas contained in the material herein.

Subscription inquiries and change of address. Address all subscription inquiries and correspondence to Member Records, IJASC. Notify an address change as soon as possible. All communications should include both old and new addresses with zip codes and be accompanied by a mailing label from a recent issue. Allow six weeks for all changes to become effective.

The Hong Kong Institute of Steel Construction

HKISC

c/o Department of Civil and Structural Engineering,

The Hong Kong Polytechnic University,

Hunghom, Kowloon, Hong Kong, China.

Tel: 852- 27666047 Fax: 852- 23346389

Email: ces/chan@polyu.edu.hk Website: http://www.hkisc.org/

ISSN 1816-112X

Science Citation Index Expanded, Materials Science Citation Index and ISI Alerting

Copyright $\odot 2010$ by:

The Hong Kong Institute of Steel Construction. 



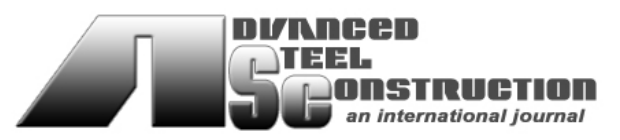

ISSN 1816-112X

Science Citation Index Expanded, Materials Science Citation Index and ISI Alerting

\section{EDITORS-IN-CHIEF}

\section{Asian Pacific, African and organizing Editor}

S.L. Chan

The Hong Kong Polyt. Univ., Hong Kong

Email: ces/chan@polyu.edu.hk

\section{American Editor \\ W.F. Chen}

Univ. of Hawaii at Manoa, USA

Email:waifah@hawaii.edu

\section{European Editor}

R. Zandonini

Trento Univ., Italy

Email: riccardo.zandonini@ing.unitn.it

\section{Advanced Steel Construction an international journal}

\begin{tabular}{lll}
\hline VOLUME 6 & NUMBER 4 & DECEMBER 2010 \\
\hline
\end{tabular}

Technical Papers

Progressive Collapse of Steel-Framed Buildings:

Influence of Modelling Approach

Hang Yu, Bassam A. Izzuddin and Xiao-Xiong Zha

Theoretical Analysis and Experimental Research on Stability Behavior of Structural Steel Tube and Coupler

Falsework with X-Bracing

Hongbo Liu, Zhihua Chen, Xiaodun Wang and Ting Zhou

Experimental Behavior of High Strength Concrete-Filled Square Steel Tube under Bi-Axial Eccentric Loading GuoChang Li, Zhijian Yang and Yan Lang

Load-Carrying Capacity and Practical Design Method of Welded Hollow Spherical Joint in Space Latticed Structures Xing $L i$

Bond Tests of Partially Encased Composite Columns Marisa Pecce and Francesca Ceroni

Advanced Analysis and Performance Based Evaluation of Concrete Filled Tube (CFT) Columns

Jong Wan Hu, Joonam Park and Roberto T. Leon

Tensile Behavior of Welded Tee End Connection for Circular Hollow Members

Vittorio Nascè and Francesco Tondolo 



\title{
PROGRESSIVE COLLAPSE OF STEEL-FRAMED BUILDINGS: INFLUENCE OF MODELLING APPROACH
}

\author{
Hang $\mathrm{Yu}^{1, *}$, Bassam A. Izzuddin ${ }^{2, *}$ and Xiao-Xiong $\mathrm{Zha}^{3}$ \\ ${ }^{I}$ PhD Candidate, Shenzhen Graduate School, Harbin Institute of Technology, Shenzhen 518055, China \\ ${ }^{2}$ Professor, Department of Civil and Environmental Engineering, Imperial College London, United Kingdom \\ ${ }^{3}$ Professor, Department of Urban and Civil Engineering, Shenzhen Graduate School, \\ Harbin Institute of Technology, China \\ *(Corresponding author: E-mail: yuh119@gmail.com and b.izzuddin@imperial.ac.uk)
}

Received: 8 December 2009; Revised: 1 March 2010; Accepted: 2 March 2010

\begin{abstract}
This paper compares the influence of several modelling approaches for progressive collapse assessment of steel-framed buildings, considering sudden column loss as a design scenario. A typical steel moment frame structure is modelled at various levels of structural idealization, including assembled beam models, grillage models and frame models with the reinforced concrete slab. Both peripheral and corner column loss scenarios are investigated, where the maximum dynamic response of the above floors is regarded as a key factor defining the structural robustness. Both nonlinear dynamic finite element analysis and a novel simplified dynamic assessment method are employed, where it is confirmed that the simplified approach has good accuracy considering various structural idealizations. The influence of the level of structural idealisation is investigated, where it is shown that grillage models using a simplified assembly procedure predict the response of a frame idealisation under sudden column loss quite well. On the other hand, the incorporation of the reinforced concrete floor slab can significantly affect the structural response to sudden column loss beyond the predictions of grillage models due to 2D slab effects. It is recommended that progressive collapse assessment of multi-storey buildings under sudden column loss is performed using the simplified dynamic assessment procedure, and that grillage models can be used as a conservative representation in the absence of detailed slab models.
\end{abstract}

Keywords: Progressive collapse; modelling approach; simplified analysis method; column failure; steel frame building; pseudo-static analysis

\section{INTRODUCTION}

Since the Ronan Point collapse in 1968, progressive collapse of multi-storey buildings has attracted the attention of several researchers. Several related design codes have since been developed, where most of these, such as GSA 2003 [1], DoD 2005 [2] and ACI [3], consider three types of requirement, namely, interconnection or continuity via tying forces, alternate load path, and local resistance of key elements. However, there are still numerous issues that remain to be resolved, including the treatment of dynamic amplification for sudden column loss, which has been recently adopted as an even-independent scenario for the assessment of structural robustness [4]. Williamson et al [5] suggested decreasing the dynamic amplification factor to 1.5 for the static nonlinear analysis of steel structures, and they argued that none of the parameters as the number of bays, stories and so on significantly affected the dynamic multiplier. Marjanishvili and Agnew [6] compared four methods for progressive collapse analysis by analyzing steel moment-resistant frame with linear elastic static, non-linear static, linear-elastic dynamic and non-linear dynamic method. They supposed that 2 is a good estimate of the amplification factor. Rather than providing a determinate amplification factor, Izzuddin et al. [7, 8] proposed a novel simplified framework, which enables the evaluation of dynamic response to be predicted using pseudo-static analysis method. In the case study of this paper, the dynamic amplification factor estimated with this method proved to be accurate enough compared with the nonlinear dynamic analysis results. More recently, the effect of available ductility on dynamic amplification has been incorporated in an empirical manner within the recommendations for the new DoD design code [12], though Izzuddin $[13,14]$ has shown that these recommendations ignore the nature of the nonlinear static response 
and can be unsafe, Izzuddin $[13,14]$ proposed that the simplified dynamic assessment procedure used in this work, resulting in the so-called ductility centred approach, offers a more rational approach for progressive collapse assessment under sudden column loss scenarios.

In addition to the issue of dynamic amplification, and although computing power is now order of magnitude more than decades ago, it is still impractical for structural engineers to set up detailed FEM models for real building structures. Accordingly, research efforts have been dedicated towards the development of simplified structural modelling approaches, which satisfy both accuracy and efficiency requirements, for example utilising and improving the component method in EC3 to simulate the response of beam-to-column connections $[8,15]$. However, physical testing is still necessary to validate these connection models, since the ductility of connections is still not very well understood and cannot be simply derived from FEM modelling. Besides the beam-to-column connections, the modelling of the floor slab is also of great concern, since it can play a significant role in the structural resistance to progressive collapse. Khandelwal et al $[9,10]$ and Sadek et al, [11] developed a reduced component connection model and simulated the composite slab in detail using LS-DYNA, which provided a useful insight into structural pushdown behaviour. However, this modelling approach is too complicated and computationally demanding for practical application in the design and assessment of structure for robustness.

In the current paper, several modelling approaches at various levels of idealisation are compared with reference to a typical seismically-design steel moment-resisting framed building, considering the sudden loss of middle peripheral corner columns. Since the floor of the structure is crucial in assessing the robustness of the structure, a composite beam frame model is firstly adopted for idealization rather than the bare steel frame, which neglects composite action between the steel beam and the concrete slab. This is compared to a simpler grillage model for which the response is obtained using a simplified assembly procedure [7], where good agreement has been achieved. In order to consider the contribution of the floor slab more realistically, a plate element is also utilized at the higher level of idealisation, where it is shown that the more complete structural system is typically less prone to progressive collapse than the grillage models. In considering the effect of the structure surrounding the affected bay, various representative boundary conditions have also been applied to the affected bay. It is found that when the edges of the slab are rotationally restrained, the structure behaves similarly to a full structural model with the entire floor slab. In all of the idealisations, the novel simplified dynamic assessment method proposed by Izzuddin [7] is utilised, which evaluates the dynamic response as a pseudo-static response, and this is shown in this paper to be quite accurate compared to detailed nonlinear dynamic analysis at the various levels of structural idealisation.

\section{FRAMEWORK OF STRCTURAL PROGRESSIVE COLLAPSE ASSESSMENT APPROACH}

When the scenario of sudden loss of a single vertical member is considered, the vertical support of the affected bay is lost. The floor begins to deflect towards the damaged column under the action of the unbalanced gravity load, which will lead to a considerable concentration of deformations in the connections within the floors above, provided the redistributed gravity load can be sustained by the adjacent columns, and thus the vulnerability of the structure is largely determined by the maximum deformation demands on the connections in relation to their ductility supply.

The framework of structural progressive collapse assessment approach, which is presented by Izzuddin et al. [7, 8], is based on this typical failure mode. It utilises three main stages for assessing this limit state: 
a) non-linear static response, which considers the damaged structure under gravity loading,

b) simplified dynamic assessment, in which the maximum dynamic response can be evaluated on the basis of the energy conservation, and

c) ductility assessment, which compares the ductility supply against the ductility demand with at the maximum dynamic response.

In the nonlinear static analysis stage, this framework can be applied at various levels of idealisation [7], such as the individual beam level, grillage/floor model level provided that the affected floors are identical in terms of structure and loading, and the level of several floors. On the beam level, the beams are simulated with elasto-plastic beam-column elements. The semi-rigid beam-to-column connections can be modelled as a series of springs according to the component method introduced in EC3 [17]. This level also has the additional benefit of enabling the realistic representation of composite action between the steel beam and the floor slab, including the influence of partial/full shear connection. In the cases that the arching and 2D slab action of the slab are significant, the resistance provided by the floor slab can be modelled with shell elements. The framework proposed by Izzuddin et al. [7] is based on the simplifying assumption that the maximum dynamic response can be estimated from the nonlinear static response under amplified gravity loading $\left(\lambda \mathrm{P}_{0}\right)$, where $\lambda$ is the dynamic amplification factor, and $\mathrm{P}_{0}$ is the designed gravity loading. Moreover, this nonlinear static response also forms the basis for simplified dynamic assessment method without the need for detailed non-linear dynamic analysis.

In the simplified dynamic assessment stage, the energy conservation is utilized to predict the maximum dynamic response using only the nonlinear static response. In the initial stage of dynamic response, the differential work done over the incremental deformation by the unbalanced gravity load is transformed into additional kinetic energy. As the deformation increase, the static resistance exceeds the gravity loading, and hence the velocities are decreased until the kinetic energy is reduced back to zero, provided the beam-to-column connections satisfy the ductility demand. Therefore, at the maximum dynamic deformed configuration (i.e. at rest), the work done by the gravity loads become identical with the energy absorbed by the structure, and the dynamic equilibrium is achieved.

In order to evaluate the total energy absorbed by the structure, a dominant deformation mode is assumed. The equivalence between external work and internal energy is obtained when the two depicted hatched areas become identical [7], as illustrated in Figure $1(\mathrm{a}-\mathrm{b})$, where the nonlinear static load-deflection response is employed for two levels of suddenly applied gravity loading $\left(P=\lambda_{1} P_{0} P=\lambda_{2} P_{0}\right)$. The level of suddenly applied gravity loading $\left(P_{n}=\lambda_{n} P_{0}\right)$ that leads to a specific maximum dynamic displacement $\left(u_{d, n}\right)$ is therefore easily obtained from Eq. 1 [6]:

$P_{n}=\lambda_{n} P_{0}=\frac{1}{u_{d, n}} \int_{0}^{u_{d, n}} P d u_{s}$

In the final ductility assessment stage, the ductility capacity of the structural system is checked and compared to the ductility demand, which is established from the maximum dynamic displacement $\left(u_{d}\right)$ obtained from the pseudo-static response. It is noted that, in order to establish the ductility supply of various connection types under general deformation conditions, more experimental work is required, since their ductility under the combination of axial force and bending moment is still not very well understood. 


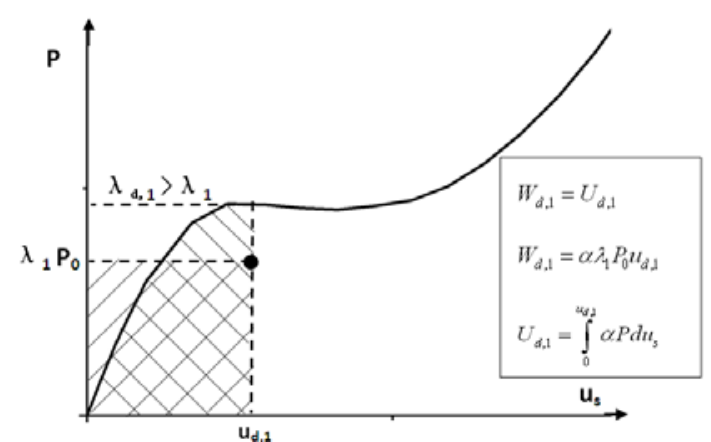

(a)

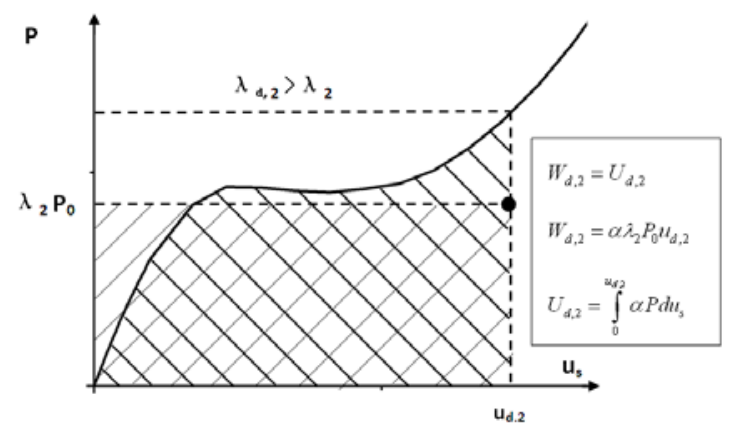

(b)

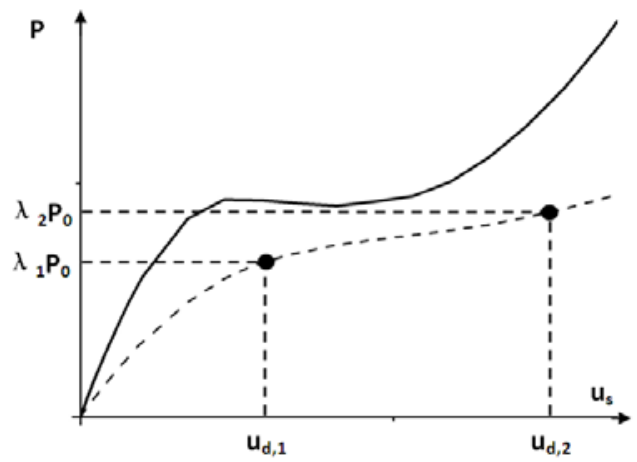

(c)

Figure 1. Simplified Dynamic Assessment and Definition of Pseudo-Static Response (Izzuddin et al. [7])

(a) Dynamic Response $\left(\mathrm{P}=\lambda_{1} \mathrm{P}_{0}\right)$; (b) Dynamic Response $\left(\mathrm{P}=\lambda_{2} \mathrm{P}_{0}\right)$; (c) Pseudo-Static Response

\section{INFLUENCE OF DIFFERENT MODELLING APPROACHES}

In order to compare and verify the various modelling approaches with this simplified assessment method, a steel moment frame is designed. Considering the case that the affected floors are identical in terms of structure and loading, the axial force in the columns above the lost column immediately becomes negligible. A typical level of the steel framed structure investigated is illustrated in Figure 2. For the purpose of introducing great damage caused by the sudden column loss, the steel frame members are deliberately selected as small as possible, while still satisfying the design requirements under normal loading. All the steel members are Grade S275 steel and the slab is Grade 30 normal weight concrete of $120 \mathrm{~mm}$ thick with reinforcement ratio $\rho=2.09 \%$ in long span and $\rho=1.038 \%$ in short span. The steel section sizes and dimensions are summarized in Table 1 , and the total floor load at accidental limit state is assumed $7.25 \mathrm{kN} / \mathrm{m}^{2}$. In order to focus on the influence of the modelling approach, the beam-to-column connections are designed as rigid connections as appropriate to design in a seismic area. However, the model can be extended without great difficulty to semi-rigid connections in non-seismic areas by introducing a series of springs according to the EC3 [17] component method.

As shown in Figure 2, two sudden column loss scenarios are investigated for the considered building structure, specifically the loss of a peripheral middle column and the loss of a corner column. At the floor level of structural idealisation, the lower ends of the remaining columns are all fixed, while the upper ends are rotationally restrained, assumed as the restraints provided by the upper floor. 


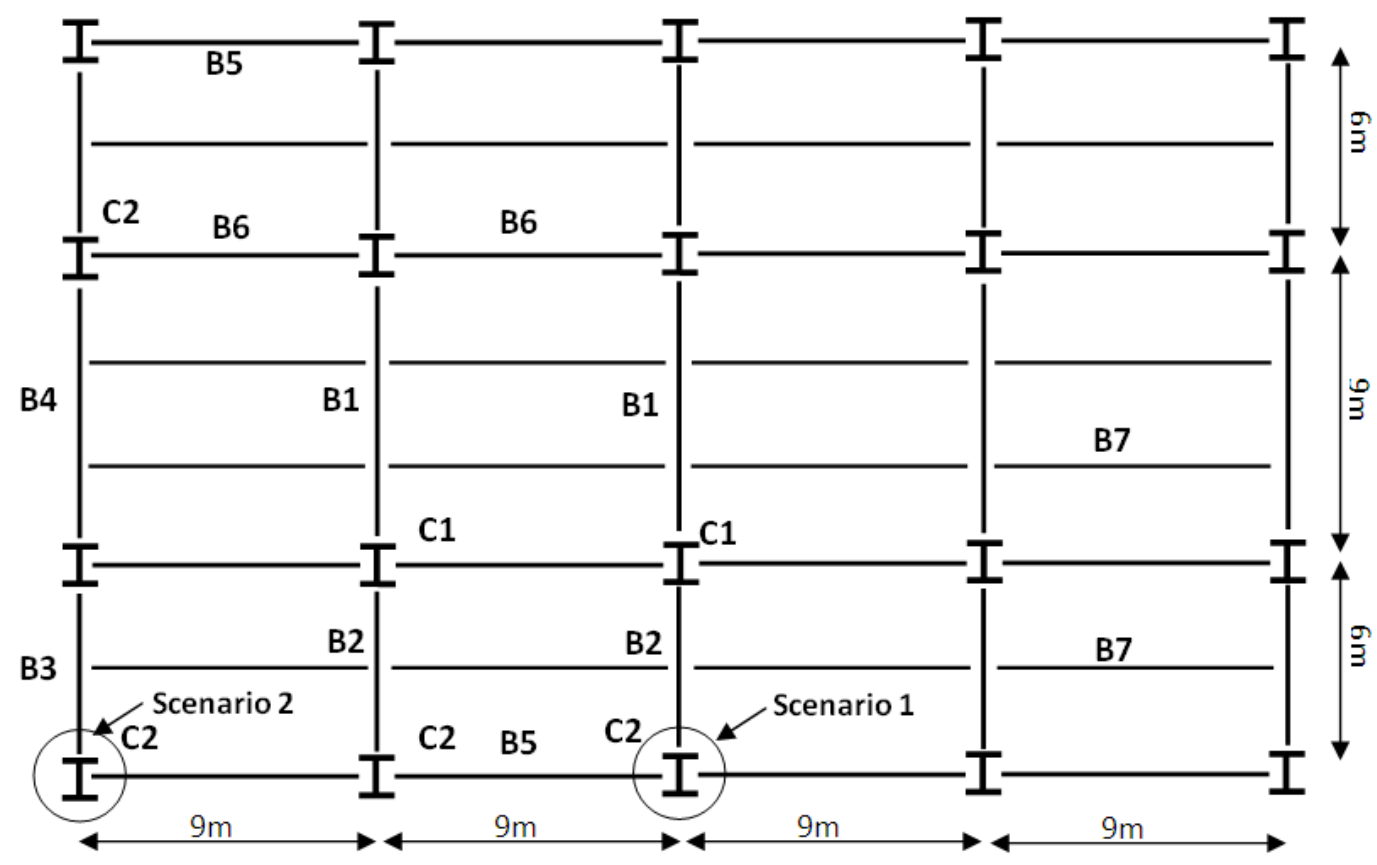

Figure 2. Layout of Steel-Framed Building Structure

Table 1. Structural Member Cross-Sections

\begin{tabular}{cccc}
\hline Beams & Section & Columns & Sections \\
\hline B1 & UB $305 \times 127 \times 48$ & & \\
B2 & UB $178 \times 102 \times 19$ & C1 & UC 356 $\times 406 \times 287$ \\
B3 & UB $127 \times 78 \times 13$ & & \\
B4 & UB $178 \times 102 \times 19$ & & \\
B5 & UB $127 \times 78 \times 13$ & C2 & UC 356 $\times 358 \times 153$ \\
B6 & UB $178 \times 102 \times 19$ & & \\
B7 & UB $203 \times 102 \times 23$ & & \\
\hline
\end{tabular}

\subsection{Case Study: Scenario 1}

\subsubsection{Simplified assembly of beam models}

To evaluate the vulnerability of the structure to progressive collapse as a consequence of the sudden column loss as well as to obtain an insight into the relative contribution of the affected beam members, the beam level of structural idealisation is firstly considered, in which the affected beam members are individually modelled. Since the composite action between the concrete slab and the steel beams is critical, and the beams are designed as composite beams, the concrete slab on the steel beam is simulated with elasto-plastic beam-column elements as a flange using the nonlinear structural analysis program ADAPTIC developed by Izzuddin [16], which can also include the sla reinforcement, where an effective width of L/4 simplicities chosen. Composite action between the concrete slab and the steel beam is realised by connecting the centroids of the concrete slab and the steel beam cross-sections through rigid links.

In Scenario 1, two bays of the structure are directly affected, in which the peripheral edge beam, secondary beam and transverse beam are assumed to deform according to the compatibility mode depicted in Figure 3. The nonlinear static responses of these individual beams are obtained as part of the first stage of progressive collapse assessment. 
Considering the affected double-span peripheral edge beam illustrated in Figure 4, the nonlinear static analysis is carried with ADAPTIC. The steel members and reinforcement bars are simulated using a bilinear steel model with kinematic strain-hardening. The concrete is simulated using a trilinear concrete model with tensile response. Proportional point loading is applied on the middle node of peripheral edge beams, and full axial restraint is assumed from the surrounding structure, while rotational restraint is assumed for the peripheral end node of the transverse beam. The nonlinear static response of the middle node of the peripheral edge beam is obtained as a sequence of values $\left(\mathrm{u}_{\mathrm{d}, \mathrm{i}}, \mathrm{P}_{\mathrm{d}, \mathrm{i}}\right)$ with small increments and depicted in Figure 5, in which $1 \leq \mathrm{i} \leq \mathrm{n}$. In order to obtain the pseudo-static response, the algorithm proposed by Izzuddin et al. [7] is applied as follow:

a) For $\mathrm{i}=1,\left(\mathrm{u}_{\mathrm{d}, 1}, \mathrm{P}_{\mathrm{d}, 1}\right)$ is $(0,0)$, and the absorbed strain energy is $\mathrm{U}_{\mathrm{d}, 1}=0$. Thus the pseudo-static response $\left(\mathrm{u}_{\mathrm{d}, 1}, \mathrm{P}_{1}\right)$ is also $(0,0)$.

b) For $\mathrm{i}=2$, the static response is obtained as $\left(\mathrm{u}_{\mathrm{d}, 2}, \mathrm{P}_{\mathrm{d}, 2}\right)$, and the absorbed strain energy is $\mathrm{U}_{\mathrm{d}, 2}=\mathrm{U}_{\mathrm{d}, 1}+\left(\mathrm{P}_{\mathrm{d}, 1}+\mathrm{P}_{\mathrm{d}, 2}\right)\left(\mathrm{u}_{\mathrm{d}, 2}-\mathrm{u}_{\mathrm{d}, 1}\right) / 2$.

c) On the basis of Eq. 1, the pseudo-static load corresponding to $u_{d, 2}$ can be obtained as $\mathrm{P}_{2}=\mathrm{U}_{\mathrm{d}, 2} / \mathrm{u}_{\mathrm{d}, 2}$, and thus the pseudo-static response is obtained as $\left(\mathrm{u}_{\mathrm{d}, 2}, \mathrm{P}_{2}\right)$.

d) Similarly for $\mathrm{i}=\mathrm{m} \leq \mathrm{n}$, the static response is $\left(\mathrm{u}_{\mathrm{d}, \mathrm{m}}, \mathrm{P}_{\mathrm{d}, \mathrm{m}}\right)$, the strain energy is obtained as $\mathrm{U}_{\mathrm{d}, \mathrm{m}}=\mathrm{U}_{\mathrm{d}, \mathrm{m}-1}+\left(\mathrm{P}_{\mathrm{d}, \mathrm{m}-1}+\mathrm{P}_{\mathrm{d}, \mathrm{m}}\right)\left(\mathrm{u}_{\mathrm{d}, \mathrm{m}}-\mathrm{u}_{\mathrm{d}, \mathrm{m}-1}\right) / 2$, and the pseudo-static load is determined as $\mathrm{P}_{\mathrm{m}}=\mathrm{U}_{\mathrm{d}, \mathrm{m}} / \mathrm{u}_{\mathrm{d}, \mathrm{m}}$, thus the pseudo-static response is established as $\left(\mathrm{P}_{\mathrm{m}}, \mathrm{u}_{\mathrm{d}, \mathrm{m}}\right)$.

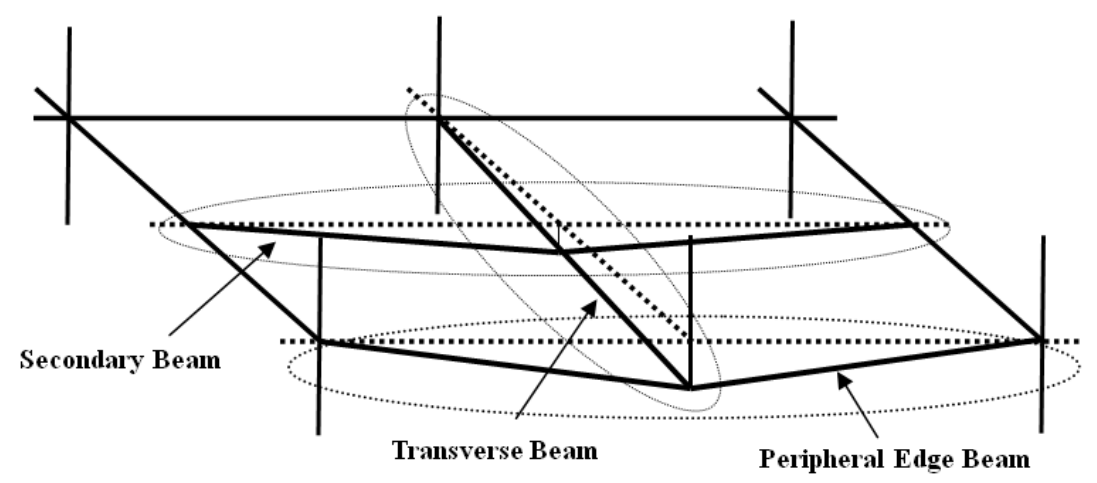

Figure 3. Affected Members in Scenario 1

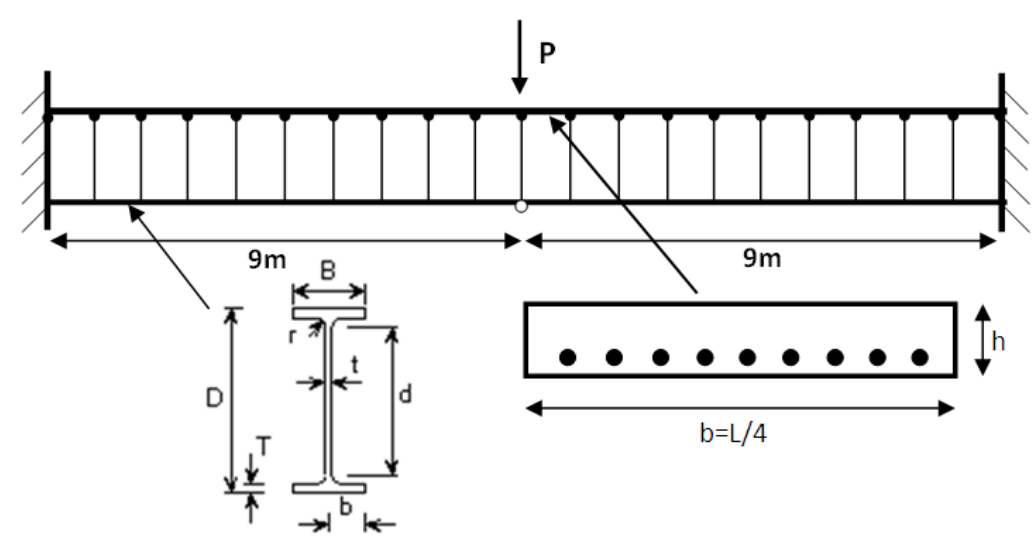

Figure 4. Modelling of Peripheral Edge Beam 


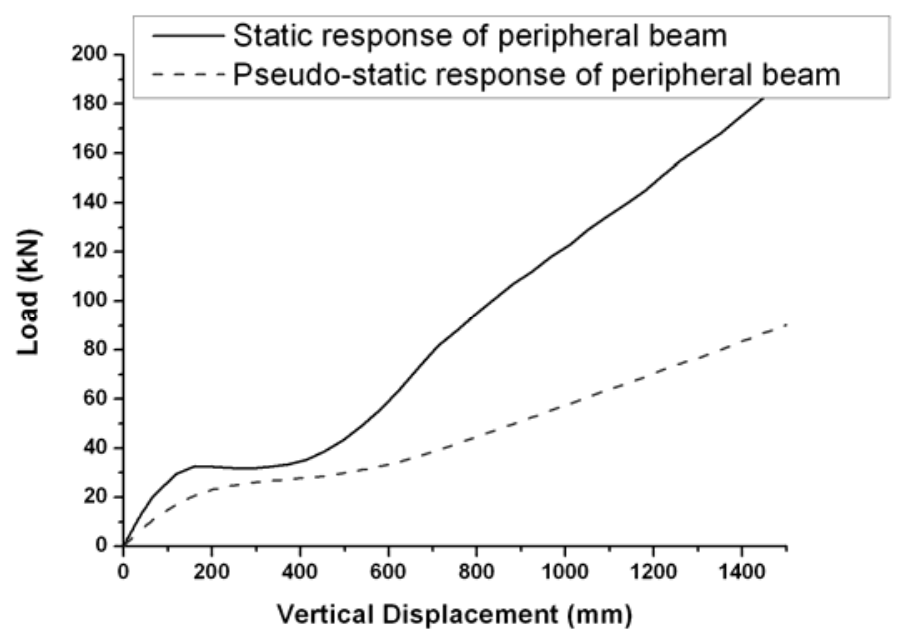

Figure 5. Nonlinear Static and Pseudo-Static Responses of Peripheral Edge Beam

Noting that the secondary beams undergo a similar deformation mode to the peripheral edge beam, they are idealised and simulated in a similar way, where the nonlinear static and pseudo-static responses are shown in Figure 6. It is observed that the catenary effect of the beams plays a significant role when the deformation becomes large both in the edge beam and the secondary beam, provided that the ductility supply and axial restraint contributed by the surrounding structure are sufficient.

For the transverse beam, this is modelled as a cantilever beam with one end fixed, while the other end is rotationally restrained. A point load is applied on the outer end of the beam to obtain the nonlinear static response. It is noted that the specific distribution of loading is not very important in the context of an assumed mode approach [7], since this is only required for obtaining the internal energy that is more dependent on the deformations than the applied load. The static and pseudo-static responses are shown in Figure 7, where the catenary effect is much smaller than for the previous two beams due to the absence of axial restraint. Accordingly, the contribution to the overall resistance provided by this beam is obviously lower than that of the other two beams.

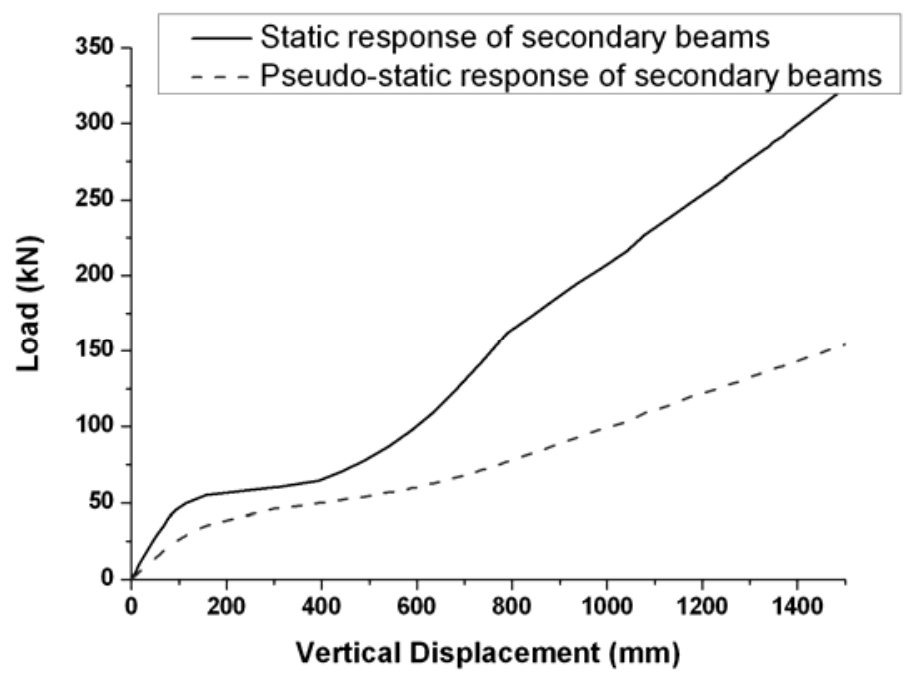

Figure 6. Static and Pseudo-Static Responses of Secondary Beam 


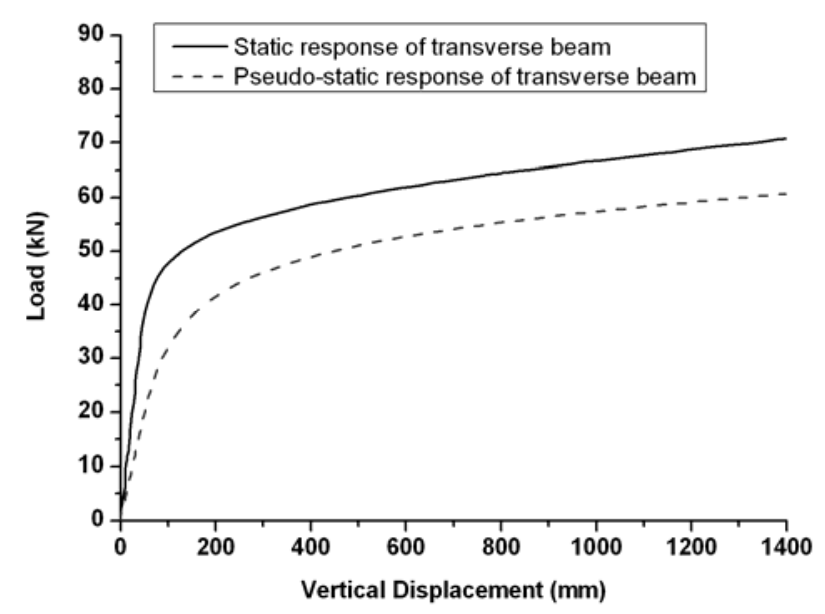

Figure 7. Static and Pseudo-Static Response of Transverse Beam

Considering the deformation compatibility of the beams, the displacement of middle node of the double-span edge beam is equal to that of the end node of transverse beam and to twice the displacement of middle node of the double-span secondary beam. In order to estimate the relationship between the total load applied on the system and the structural deformation, a set of displacement value are selected at the location of the lost column, varying between $200 \mathrm{~mm}$ and $1400 \mathrm{~mm}$. From the previous results, the corresponding static and pseudo-static load resistances are provided in Table 2 .

According to the layout at the floor level of idealisation, the deformation compatibility factors are given by:

$\beta_{1}=1, \beta_{2}=0.5, \beta_{3}=1$,

By assembling the responses of individual beams in accordance with the simplified assembly approach proposed by Izzuddin et al. [7], the equivalent point load at the location of the lost column resisted by the overall system is illustrated in Eq. 2:

$P=\frac{1}{\alpha} \sum_{i} \alpha_{i} \beta_{i} P_{i}=\frac{1}{1}\left(1 \times 1 \times P_{1}+1 \times 0.5 \times P_{2}+1 \times 1 \times P_{3}\right)$

in which $\alpha_{i}$ are non-dimensional weighting factors which depend on the assumed load distribution on the beams, where all $\alpha_{i}$ values in this case are 1 .

Table 2. Static and Pseudo-Static Resistance of Affected Beams

\begin{tabular}{|c|c|c|c|c|c|c|c|c|c|}
\hline \multirow[b]{2}{*}{$\begin{array}{c}\mathrm{u}_{\mathrm{s}} \\
(\mathrm{mm})\end{array}$} & \multicolumn{3}{|c|}{ Edge Beam } & \multicolumn{3}{|c|}{ Secondary Beam } & \multicolumn{3}{|c|}{ Transverse Beam } \\
\hline & $\begin{array}{c}\mathrm{u}_{1} \\
(\mathrm{~mm})\end{array}$ & $\begin{array}{l}\text { Static } \\
(\mathrm{kN})\end{array}$ & $\begin{array}{c}\text { Pseudo-Static } \\
\mathrm{P}_{1}(\mathrm{kN})\end{array}$ & $\begin{array}{c}\mathrm{u}_{2} \\
(\mathrm{~mm})\end{array}$ & $\begin{array}{l}\text { Static } \\
(\mathrm{kN})\end{array}$ & $\begin{array}{c}\text { Pseudo-Static } \\
\mathrm{P}_{2}(\mathrm{kN})\end{array}$ & $\begin{array}{c}\mathrm{u}_{3} \\
(\mathrm{~mm})\end{array}$ & $\begin{array}{l}\text { Static } \\
(\mathrm{kN})\end{array}$ & $\begin{array}{c}\text { Pseudo-Static } \\
\mathrm{P}_{3}(\mathrm{kN})\end{array}$ \\
\hline 200 & 200 & 32.9 & 22.8 & 100 & 46.4 & 26.3 & 200 & 53.5 & 41.7 \\
\hline 400 & 400 & 34.3 & 28.2 & 200 & 57.5 & 38.3 & 400 & 58.6 & 49.0 \\
\hline 600 & 600 & 59.2 & 33.6 & 300 & 45.6 & 59.7 & 600 & 61.8 & 52.7 \\
\hline 800 & 800 & 95.5 & 44.6 & 400 & 50.3 & 65.6 & 800 & 64.6 & 55.6 \\
\hline 1000 & 1000 & 121.6 & 57.7 & 500 & 78.8 & 54.0 & 1000 & 67.0 & 57.4 \\
\hline 1200 & 1200 & 149.1 & 70.7 & 600 & 101.2 & 58.8 & 1200 & 68.9 & 59.0 \\
\hline 1400 & 1400 & 176.2 & 83.8 & 700 & 129.7 & 68.4 & 1400 & 70.9 & 60.6 \\
\hline
\end{tabular}


$\mathrm{u}_{\mathrm{s}}$ : reference vertical displacement at the location of the lost column

$\mathrm{u}_{1}$ : vertical displacement of the middle of the edge beam

$\mathrm{u}_{2}$ : vertical displacement of the middle of the secondary beam

$\mathrm{u}_{3}$ : vertical displacement of the outer end of the transverse beam

On the basis of Table 2, the equivalent point load resistance corresponding to various levels of maximum dynamic displacement can be obtained, as provided in Table 3.

Table 3. Equivalent Point Load Pseudo-Static Resistance of Floor System

\begin{tabular}{cccccccc}
\hline $\mathbf{u}_{\mathbf{s}}$ & $\mathbf{2 0 0}$ & $\mathbf{4 0 0}$ & $\mathbf{6 0 0}$ & $\mathbf{8 0 0}$ & $\mathbf{1 0 0 0}$ & $\mathbf{1 2 0 0}$ & $\mathbf{1 4 0 0}$ \\
\hline $\mathrm{P}(\mathrm{kN})$ & 77.65 & 96.35 & 116.15 & 133 & 142.1 & 159.1 & 178.6 \\
\hline
\end{tabular}

As previously noted, the gravity load is assumed to be $7.25 \mathrm{kN} / \mathrm{m}^{2}$, hence the equivalent line load of the beams is obtained as $10.875 \mathrm{kN} / \mathrm{m}$ for the peripheral edge beam and $21.75 \mathrm{kN} / \mathrm{m}$ for the secondary beam. The equivalent point load at the top of column can then be determined on the basis of work equivalence as Eq. 3:

$$
P_{0}=\frac{1}{2} q_{1} \times 2 l+\frac{1}{4} q_{2} \times 2 l=\frac{1}{2} \times 10.875 \times 18+\frac{1}{4} \times 21.75 \times 18=195.75 \mathrm{kN}
$$

The equivalent point load pseudo-static resistance obtained previously can be normalised relative to the corresponding gravity load given by Equation (3), where the resistance/load unity factors are provided in Table 4 at various levels of reference vertical displacement. These values allow the determination of the level of anticipated maximum dynamic displacement for various levels of gravity loading (ie. the displacements at $50 \%$ of the above gravity load correspond to a unity load factor of 0.5).

Table 4. Resistance/Load Unity Factors for the Floor System

\begin{tabular}{cccccccc}
\hline Displacement $(\mathbf{m m})$ & $\mathbf{2 0 0}$ & $\mathbf{4 0 0}$ & $\mathbf{6 0 0}$ & $\mathbf{8 0 0}$ & $\mathbf{1 0 0 0}$ & $\mathbf{1 2 0 0}$ & $\mathbf{1 4 0 0}$ \\
\hline Fully restraint & 0.397 & 0.492 & 0.593 & 0.679 & 0.726 & 0.813 & 0.912 \\
\hline
\end{tabular}

In order to verify the accuracy of the design-oriented approach based on simplified assembly of beam responses into an overall floor system response, a detailed grillage model is considered in the next section.

\subsubsection{Detailed Grillage Model}

Based on the same multi-level assessment framework [7], the assessment is undertaken here directly at the floor level using a grillage model with composite beams as shown in Figure 8. For the purpose of verifying the accuracy of the proposed simplified dynamic assessment method, detailed nonlinear dynamic analysis method is first performed to evaluate the dynamic response. Figure 9 depicts the structural dynamic response after the sudden column loss under the assumed gravity load. The maximum dynamic responses corresponding to a series of gravity load factors, including $0.1,0.2,0.3 \ldots 1.1$, are obtained and provided in Table 5.

Table 5. Maximum Dynamic Response of Grillage Model from Nonlinear Dynamic Analysis

\begin{tabular}{cccccccccccc}
\hline Gravity Load Factor & $\mathbf{0 . 1}$ & $\mathbf{0 . 2}$ & $\mathbf{0 . 3}$ & $\mathbf{0 . 4}$ & $\mathbf{0 . 5}$ & $\mathbf{0 . 6}$ & $\mathbf{0 . 7}$ & $\mathbf{0 . 8}$ & $\mathbf{0 . 9}$ & $\mathbf{1 . 0}$ & $\mathbf{1 . 1}$ \\
\hline $\begin{array}{c}\text { Vertical Displacement } \\
(\mathbf{m m})\end{array}$ & 32.1 & 69.8 & 138 & 267 & 538 & 788 & 968 & 1100 & 1230 & 1380 & 1510 \\
\hline
\end{tabular}


For comparison with the simplified dynamic analysis procedure proposed by Izzuddin [7], nonlinear static analysis is also performed as the first stage of assessment approach, and the pseudo-static response is subsequently obtained. It is noted that the relationship between the load factor and the maximum dynamic response has been established with three simplified modelling approaches for the same frame structure, namely the assembled beam model with fixed boundary condition, assembled beam model with more realistic boundary conditions and the grillage model. The dynamic response obtained from the nonlinear dynamic analysis method is hence compared against these responses in Figure 10. It is observed that the pseudo-static responses predicted by the three models are quite accurate compared with the results obtained from nonlinear dynamic analysis of the full grillage model. It is therefore evident from this comparison that the simplified dynamic assessment method [7] is applicable to different types of simplified model and provides an accurate prediction of the maximum dynamic displacements much more effectively than detailed nonlinear dynamic analysis.

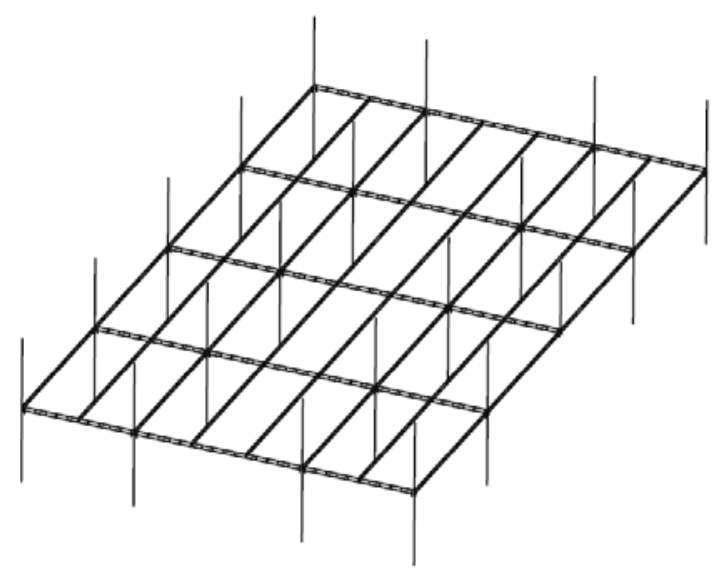

Figure 8. Grillage Model of Floor System

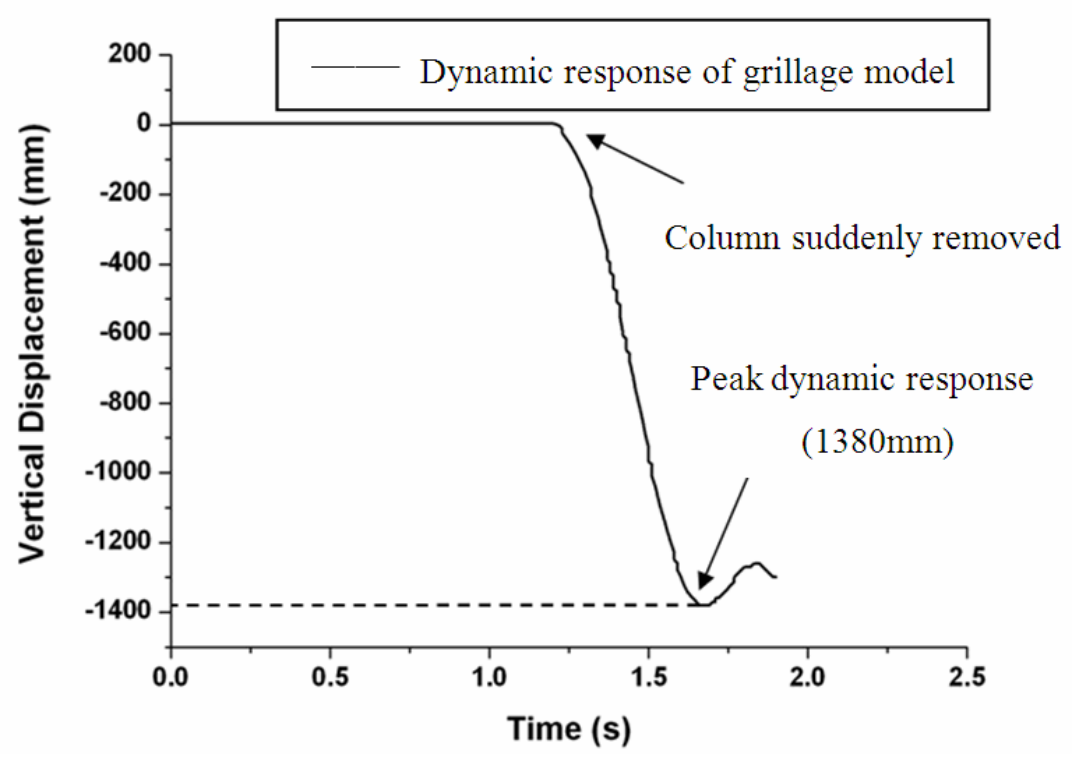

Figure 9. Nonlinear Dynamic Response Predicted for Full Gravity Loading $($ Load Factor $=1.0)$ 


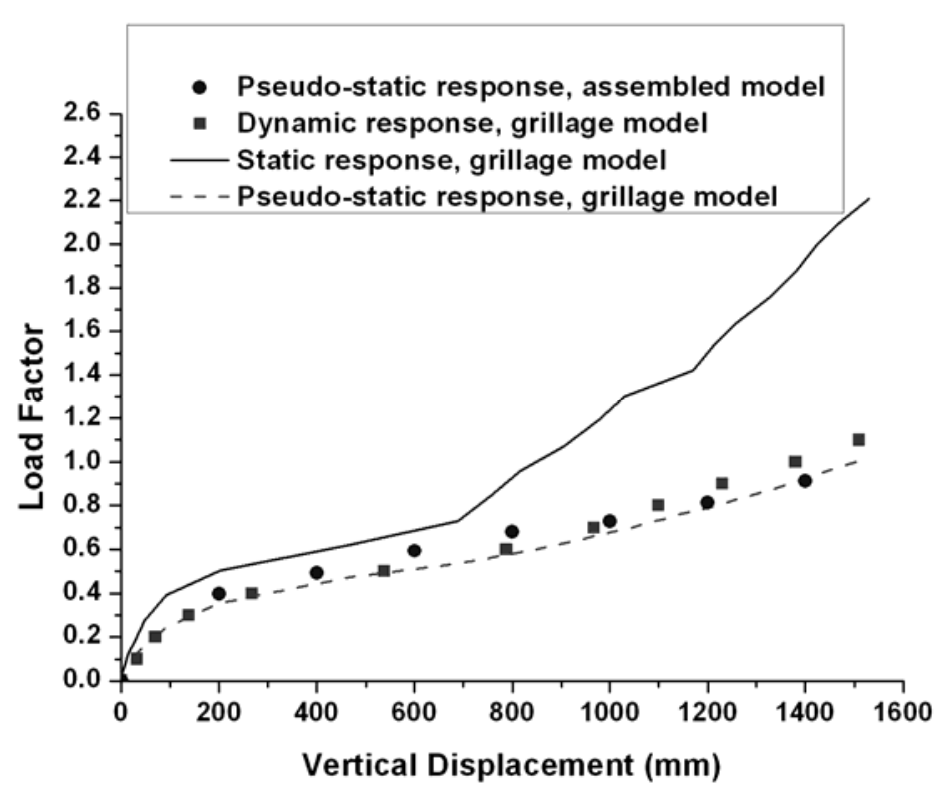

Figure 10. Maximum Dynamic Responses Predicted by Different Modelling Approaches

\subsubsection{Detailed Slab Model}

Since the 2D slab action may play a critical part in the structural resistance to progressive collapse, the floor slab model is modelled here with shell elements to address this issue, as shown in Figure 11. The same boundary conditions at the column ends as the grillage model are adopted, and the tensile softening is ignored in the slab model. The nonlinear static, nonlinear dynamic and pseudo-static responses are also obtained in a similar way, where the corresponding maximum dynamic displacements for different levels of gravity loading are compared in Figure 12. Compared with the responses obtained using the grillage model, it is clear that the slab reduces the maximum dynamic response significantly for the considered building structure due to 2D slab action and the ignorance of concrete cracking in slab model. Despite ignoring 2D slab action, the assembled beam models and the grillage model are still useful since they provide a conservative prediction of the structural response under sudden column loss.

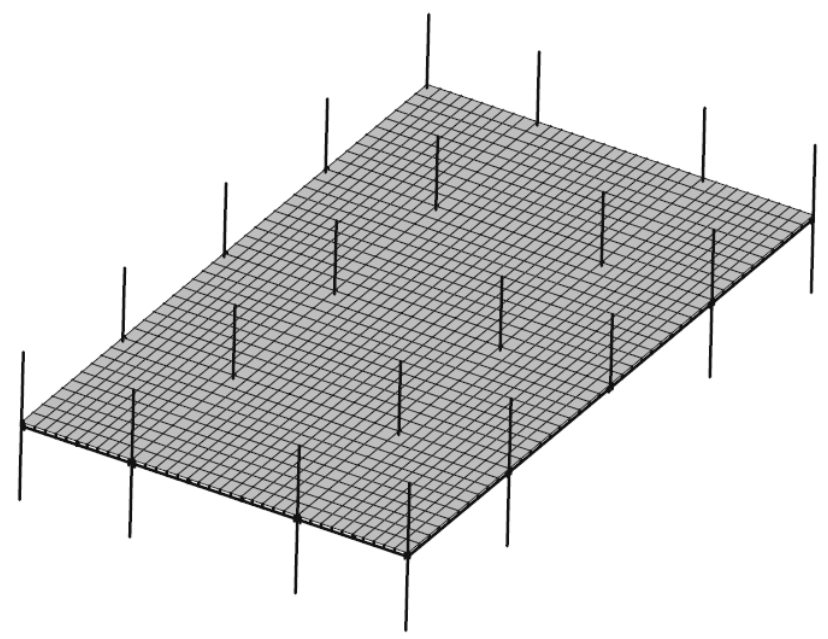

Figure 11. Steel Frame Model with Concrete Slab 


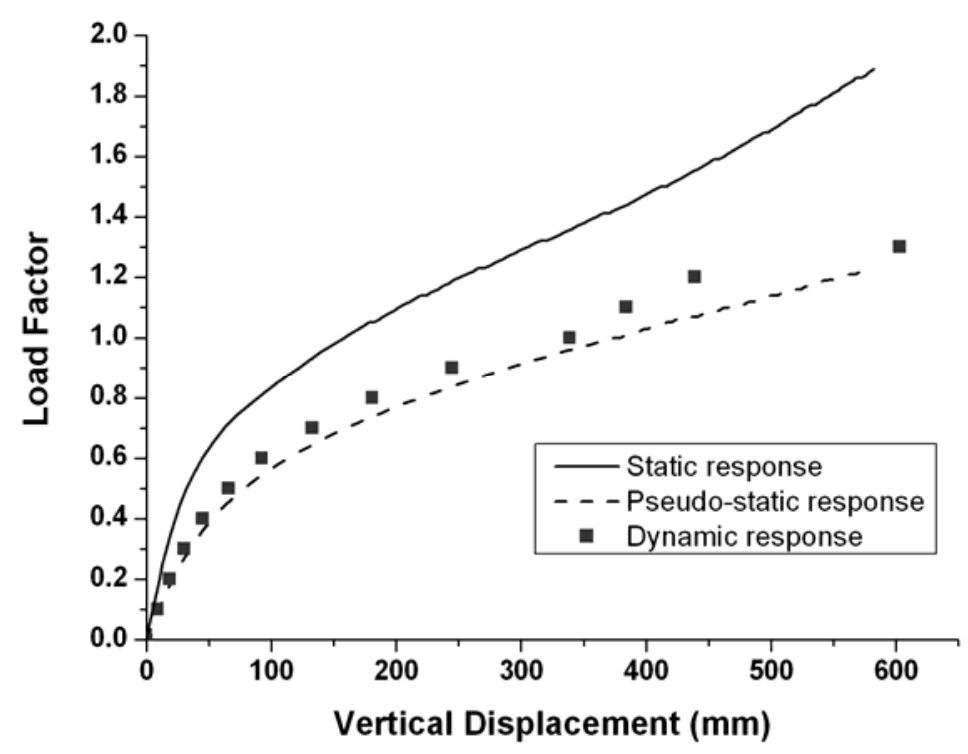

Figure 12. Pseudo-Static and Dynamic Responses of Frame Model with Slab

Considering the fact that the shell element is computationally demanding, and that the adjacent bay of the floor does not affect the response in a direct way, it is next assumed that the adjacent floor slab only provides planar and rotational restraints. Consequently, another idealised model is set up based on this assumption, where the adjacent floor slab is omitted as in Figure 13. No planar and rotational restraints are initially applied at the edges of the slabs. The nonlinear static, pseudo-static and dynamic responses are obtained in Figure 14. It is worth noting that the dynamic response predicted by the simplified dynamic assessment method also shows very good accuracy compared with the results of nonlinear dynamic analysis, which confirms that the dynamic and amplified static loads are associated with a similar dominant deformation mode under sudden column loss.

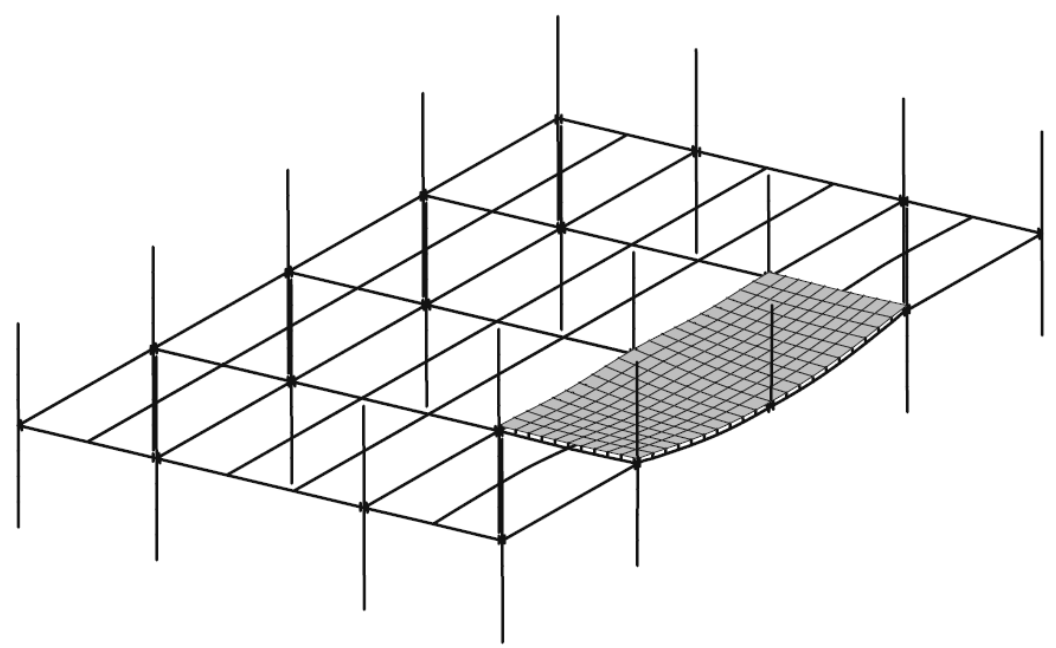

Figure 13. Floor Model with Partial Concrete Slab in Affected Bay 


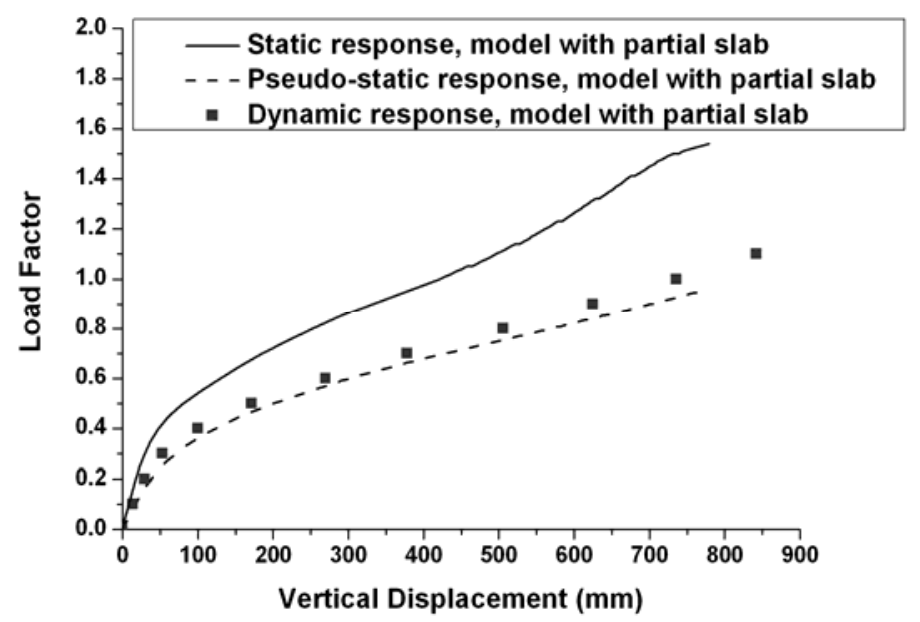

Figure 14. Pseudo-Static and Dynamic Response of Floor Model with Partial Slab

Although the above model hugely reduced the computational demand by ignoring the unaffected floor slab, the influence of the restraints provided by the surrounding floor slabs appear to be significant. Therefore, different kinds of boundary conditions, namely rotational restraint, planar restraint, and both rotational/planar restraints, are applied on the edge of the slabs of the affected bay, representing the assumed restraints provided by the surrounding floor slab. The pseudo-static responses of these models are compared in Figure 15. It is noted that the planar restraints have limited influence on the damaged bay, while the rotational restraints at the edge of the slab may lead to similar response as obtained from the realistic whole slab model. The adjacent concrete floor normally provide hogging moment at the boundary of the affected floor, which significantly increases the robustness of the structure, and hence applying the rotational restraints plays the same role in this idealised model.

Since the tensile cracking of concrete in the slab is also a key factor which should be considered in assessment of structural progressive collapse, a concrete softening modulus of $500 \mathrm{~N} / \mathrm{mm}^{2}$ is introduced in the whole slab model to address this issue. The pseudo-static responses of the structure with and without consideration of tensile cracking are given in Figure 16. It is observed that concrete cracking does not have a significant influence in this case, which is attributed to the fact that the reinforcement plays an important role in reinforced concrete slabs in both bending and 2D slab action. However, cracking affects the onset of rupture of the reinforcement bar, and this should be further investigated with more detailed models accounting for bond-slip effects.

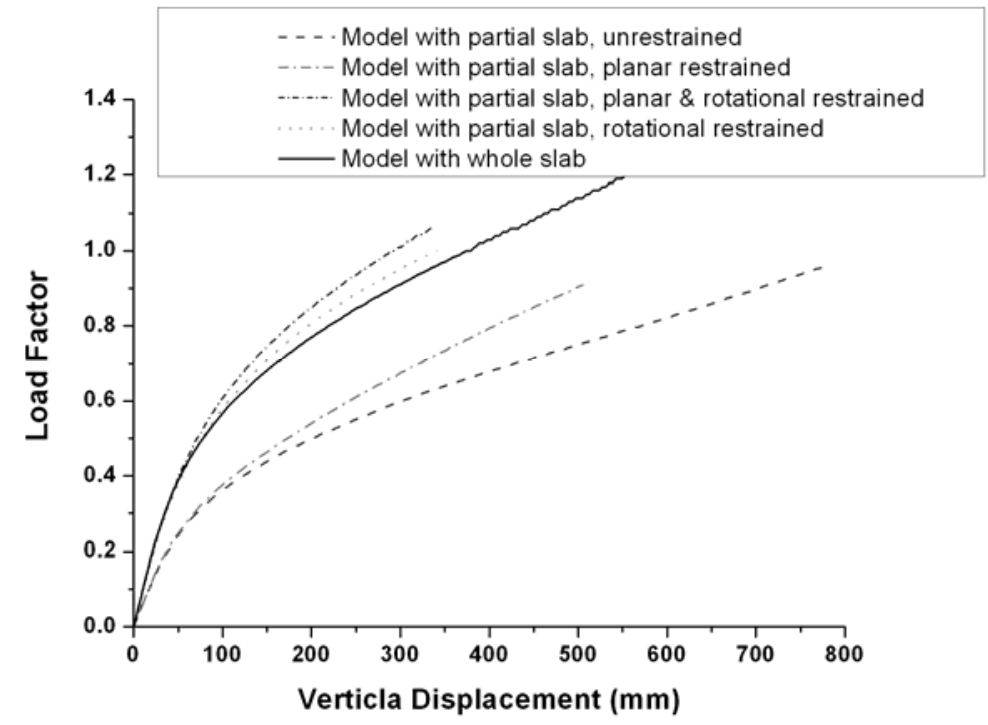

Figure 15. Pseudo-Static Response of Floor System with Different Restraints 


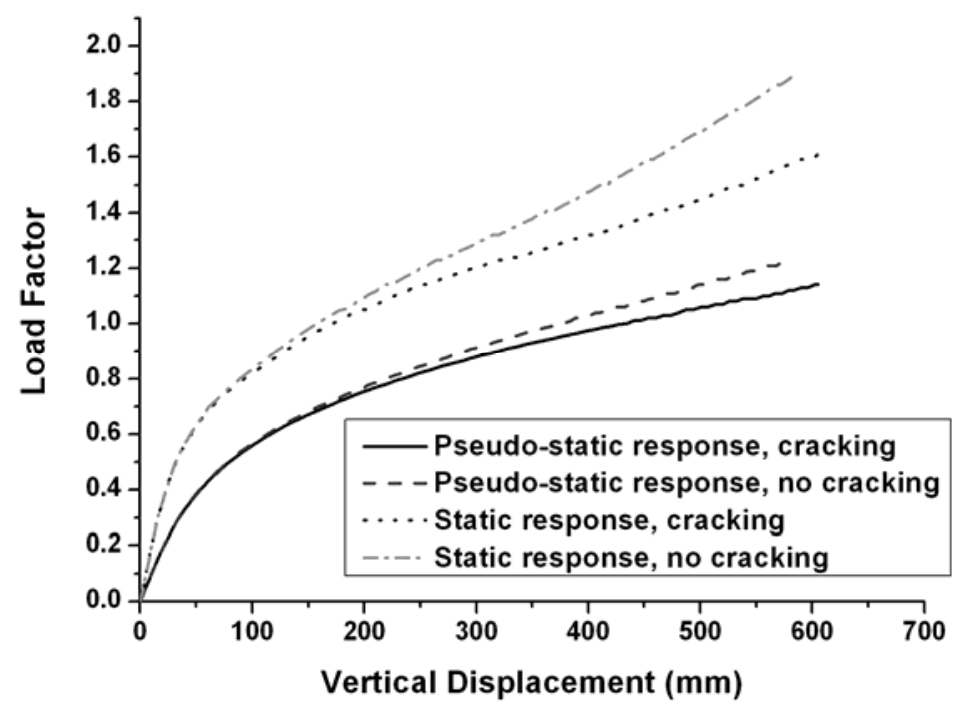

Figure 16. Pseudo-Static Response of Floor System with/without Cracking of Concrete Slab

\subsubsection{D Slab Action Resistance Amplification Factor}

Having shown that 2D slab action affects the level of deformation sustained by the bay affected by column loss, the pseudo-static responses obtained from the grillage model and the floor system model including the slab are compared. A 2D slab action resistance amplification factor $\delta$ is defined as Eq. 4:

$$
\delta=\frac{\lambda_{s, c o}}{\lambda_{s, s l a b}}
$$

where $\lambda_{s, c o}$ is the load resistance factor of the composite grillage model and $\lambda_{s, s l a b}$ is the load resistance factor of the floor model with concrete slab corresponding to the same maximum dynamic response $u_{s}$.

The relationship between displacement and resistance amplification factor is depicted in Figure 17 for Scenario 1, where the amplification factor varies little around 2.3 in this case. Clearly, the 2D action of reinforced concrete slabs has a significant effect on the pseudo-static resistance, increasing it by more than two fold.

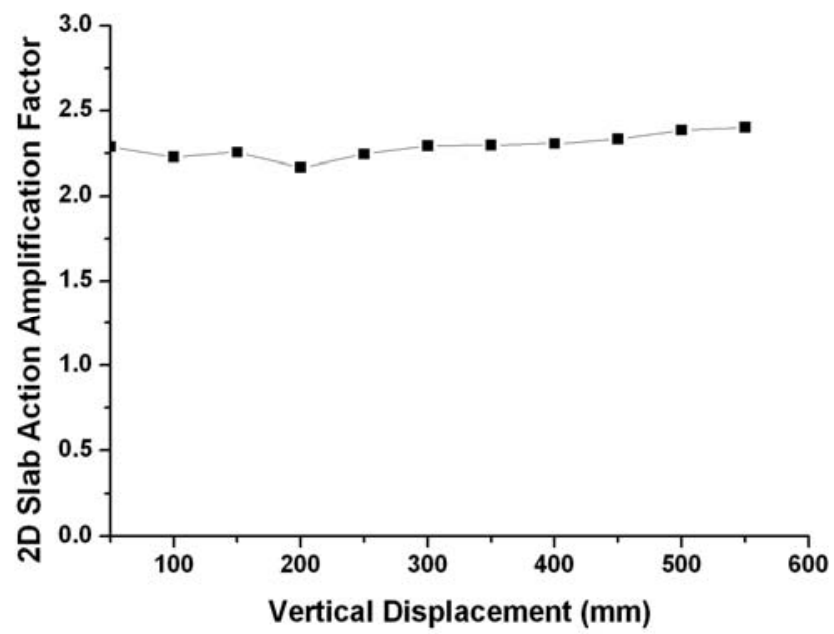

Figure 17. 2D Slab Action Resistance Amplification Factor in Scenario 1 


\subsection{Case Study: Scenario 2}

Here, the second scenario involving of the sudden loss of a corner column is investigated, where again various levels of idealisation are considered. The nonlinear static, pseudo-static and dynamic responses of these models are obtained using the same modelling approach as for Scenario 1, as depicted in Figure 18. The simplified dynamic assessment approach [7] again shows great accuracy in predicting the maximum dynamic response. It is also observed that the grillage model is again conservative compared with the slab model. The $2 \mathrm{D}$ slab action amplification factor is also employed to evaluate the contribution of the $2 \mathrm{D}$ slab action of the floor slab, and is depicted in Figure 19.

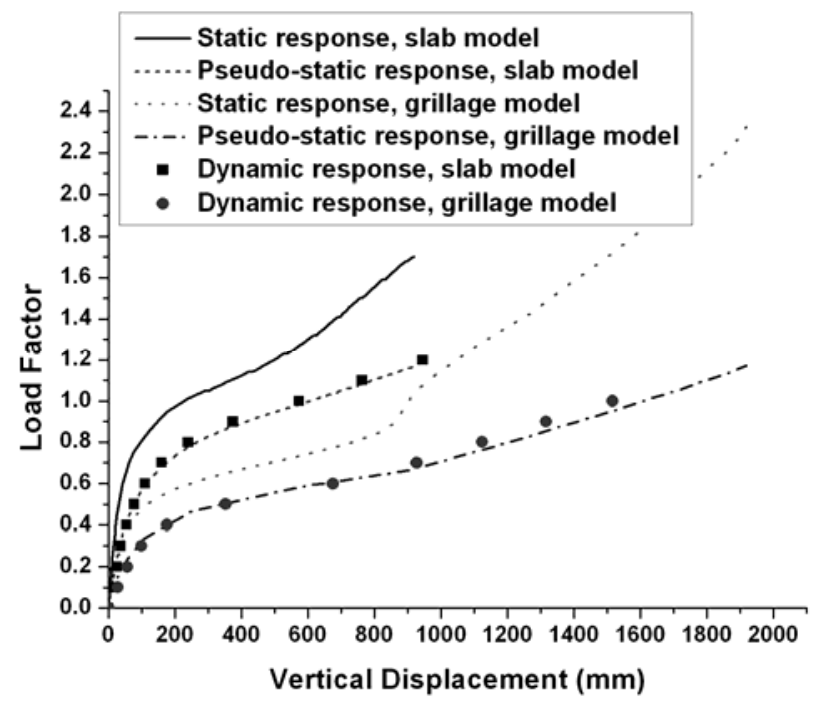

Figure 18. Nonlinear Static, Pseudo-Static and Dynamic Response for Scenario 2

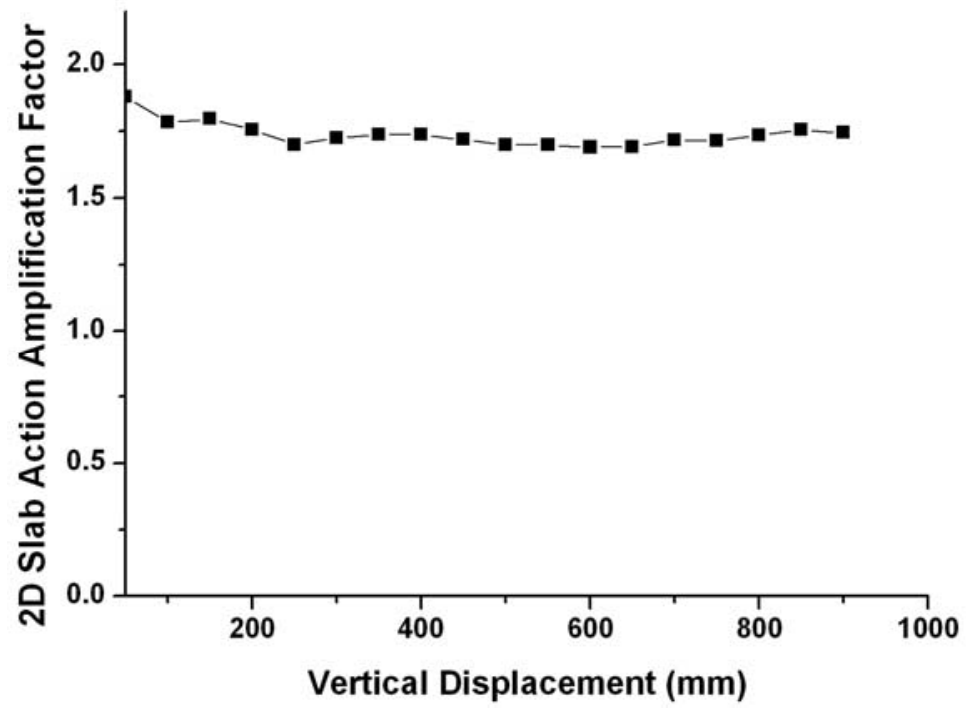

Figure 19. 2D Slab Action Resistance Amplification Factor in Scenario 2

It is observed that the 2D slab action resistance amplification factor also varies little with displacement, and is smaller than the factor obtained in Scenario 1, as expected due to reduced continuity of the slab in Scenario 2. Despite the variation of the amplification factor in different bays, it still provides an insight on the contribution of the 2D slab effect towards the resistance to structural progressive collapse. Further research should be carried out to establish whether a generalisation of these findings can be made so as to provide practical robustness design guidance for buildings of different structural configurations. 


\section{CONCLUSIONS}

A typical steel moment-resisting framed building structure is investigated for robustness under sudden column loss considering several modelling approaches and employing the simplified framework for progressive collapse assessment previously proposed by Izzuddin and co-workers at Imperial College London. The first and second stages of this framework, consisting of the nonlinear static response under gravity loading and the pseudo-static resposne, are utilised in the current paper, where the latter is compared with the the maximum dynamic response obtained from detailed nonlinear dynamic analysis. Two scenarios are investigated for the chosen building structure, including the removal of a peripheral middle column and a corner column. It is evident from the undertaken analysis that the simplified dynamic analysis approach can be used to evalute the maximum dynamic response with very good accuracy, thus offering an effective design-oriented approach for the assessment of maximum dynamic deformations due to sudden column loss.

With the consideration of the required modelling detail and the feasibility of model reduction, the structure is considered at the floor system level, and is idealised starting from different levels, including the simplified assembly of composite beam models, grillage floor models, and a floor model inclduing the $2 \mathrm{D}$ influenece of the reinforced concrete slab. In the process, some important modelling related findings are made. When using the assembled beam model, significant benefits arise from the evaluation of the contributions of individual members, as this sheds significnat light on their relative contribution to the overall system response. Importantly, the dynamic response evaluated with the assembled model using the simplified dynamic assessment approach agrees well with the results obtained from detailed nonlinear dynamic analysis of the grillage model, which can be used as a conservative assessment method that ignores the $2 \mathrm{D}$ slab action.

With the consideration of 2D slab action, it is evident from the obtained results that this action plays a significant role in resisting progressive collapse under sudden column loss. In order to evaluate nonlinear static and dynamic structural response more efficiently, reduced slab models are employed by omitting the floor slab surrounding the affected bay. Various types of boundary condition are introduced to substitute for the effect of the omitted slab. It is found that employing rotational restraints on the edges of the affected bay is a reasonably accurate way to represent the restraints provided by the adjacent structure, which can thus be utilised to reduce the computational demand. Furthermore, cracking in the concrete slab is also considered and shown to have limited influence on progressive collapse resistance, since the reinforcement plays a relatively more critical role.

In order to determine the contribution of the 2D slab action, an amplification resistance factor is introduced in this paper, by dividing the load factor in slab model with that or the grillage model corresponding to the same maximum dynamic displacement. It is found that this amplification is larger for sudden column loss in the middle bay than in the corner bay, since there are more restraints provided by the surrounding structures in the former case.

In conclusion, the framework proposed by Izzuddin and co-workers at Imperial College London can be used as a practical approach for progressive collapse assessment of multi-storey buildings. The simplified dynamic assessment method leads to a new and practical method for addressing the relatively complicated issue of nonlinear dynamic response under sudden column loss. By investigating the different levels of structural idealisation, it is shown that simplified assembly of beam contributions into the pseudo-static response of the floor system is similar to grillage modelling, and can provide efficient and conservative prediction of resistance to progressive collapse. On the other hand, full floor models including the 2D reinforced concrete slab can enhance the resistance by over two fold, though the computational demands are typically much more extensive than those of the assembled beam and grillage models. 


\section{REFERENCES}

[1] GSA., "Progressive Collapse Analysis and Design Guidelines for New Federal Office Buildings and Major Modernization Projects", The US General Services Administration, 2003.

[2] DoD., "Design of Buildings to Resist Progressive Collapse", Unified Facilities Criteria (UFC), 2005.

[3] ACI., "Building Code Requirements for Structural Concrete (ACI 318-05) and Commentary (ACI 318R-05)", American Concrete Institute, Farmington Hills, MI, 2005.

[4] Gudmundsson, G.V. and Izzuddin, B.A., "The 'Sudden Column Loss' Idealisation for Disproportionate Collapse Assessment", The Structural Engineer, 2010 (Accepted for publication).

[5] Peter Ruth, S.M., Kirk A. Marchand, P.E., and Eric B. Williamson, P.E., "Static Equivalency in Progressive Collapse Alternate Path Analysis: Reducing Conservatism While Retaining Structural Integrity", Journal of Performance of Constructed Facilities, 2006, Vol. 20, No. 4, pp. 349-364.

[6] Shalva Marjanishvili, P.E. and Elizabeth Agnew, "Comparison of Various Procedures for Progressive Collapse Analysis", Journal of Performance of Constructed Facilities, Vol. 20, No. 4, pp.365-374.

[7] Izzuddin, B.A., Vlassis, A.G., Elghazouli, A.Y. and Nethercot, D.A., "Progressive Collapse of Multi-Storey Buildings Due to Sudden Column Loss - Part I: Simplified Assessment Framework", Engineering Structures, 2008, Vol. 30, No. 5, pp.1308-1318.

[8] Vlassis, A.G., Izzuddin, B.A., Elghazouli, A.Y. and Nethercot, D.A., "Progressive Collapse of Multi-Storey Buildings Due to Sudden Column Loss - Part II: Application", Engineering Structures, 2008, Vol. 30, No. 5, pp.1424-1438.

[9] Kapil Khandelwal and Sherif EI-Tawil, "Collapse Behavior of Steel Special Moment Resisting Frame Connections", Journal of Structural Engineering, 2007, Vol. 133, No. 5, pp.646-655.

[10] Kapil Khandelwal, Sherif EI-Tawil, Sashi K.Kunnath and Lew, H.S., "Macromodel-Based Simulation of Progressive Collapse: Steel Frame Structures", Journal of Structural Engineering, 2008, Vol. 134, No. 7, pp. 1070-1078.

[11] Fahim Sadek, Sherif EI-Tawil and Lew, H.S., "Robustness of Composite Floor Systems with Shear Connections: Modeling, Simulation, and Evaluation", Journal of Structural Engineering, 2008, Vol.134, No. 11, pp. 1717-1725.

[12] Department of Defense, "Unified Facilities Criteria, Design of Buildings to Resist Progressive Collapse", UFC 4-023-03, Washington, DC, USA, 2009.

[13] Izzuddin, B.A. and Nethercot, D.A., "Design-Oriented Approaches for Progressive Collapse Assessment: Load-Factor vs Ductility-Centred Methods”, Structures Congress'09, Austin, Texas, 2009, Vol. 341, pp. 198-198.

[14] Izzuddin, B.A., "Mitigation of Progressive Collapse in Multi-Storey Buildings", Journal of Advances in Structural Engineering, 2009, (Accepted for publication).

[15] Stylianidis, P.M., Nethercot D.A., Izzuddin, B.A. and Elghazouli, A.Y., "Progressive Collapse: Failure Criteria Used in Engineering Analysis", Structures Congress'09, Austin, Texas, 2009, Vol. 341, pp. 200-200.

[16] Izzuddin, B.A., "Nonlinear Dynamic Analysis of Framed Structures", PhD Thesis, Imperial College, University of London, 1991.

[17] Eurocode 3, "Design of steel structures - Part 1-8: Design of joints", European Committee for Standardization, 2005. 


\title{
THEORETICAL ANALYSIS AND EXPERIMENTAL RESEARCH ON STABILITY BEHAVIOR OF STRUCTURAL STEEL TUBE AND COUPLER FALSEWORK WITH X-BRACING
}

\author{
Hongbo Liu ${ }^{1}$, Zhihua Chen ${ }^{1,2 *}$, Xiaodun Wang ${ }^{1}$ and Ting Zhou ${ }^{1}$ \\ ${ }^{1}$ Department of Civil Engineering, Tianjin University, Tianjin, 300072, China \\ ${ }^{2}$ Tianjin Key Laboratory of Civil Engineering Structure \& New Materials, Tianjin University, \\ Tianjin, 300072, China \\ *(Corresponding author: E-mail: zhchen@tju.edu.cn)
}

Received: 9 December 2009; Revised: 12 March 2010; Accepted: 18 March 2010

\begin{abstract}
This paper presents a systematic study on stability of the structural steel tube and coupler falseworks with X-bracing (hereinafter referred to as STCF with X-bracing) through experimental and analytical investigations. Two full-scale STCF specimens were constructed and static tests were conducted in the lab in order to get the strength and failure modes of typical STCF with X-bracing. Test data from literature on two full-scale STCF specimens with same geometric parameters but without X-bracing are also adopted for comparison to investigate the effect of X-bracing on its structural property. Advanced nonlinear finite element analysis was conducted on the specimen models using ANSYS in order to study the capacity and failure modes of the tested specimens. Based on the FEA results, parametric studies were carried out in order to investigate the influence of various geometric parameters on the capacity of STCF with X-bracing.

Based on the experimental and analytical results, it seemed that the typical failure mode of STCF with X-bracing was that only upper two storey posts and the U-head buckled evidently about the short axis, and other lower posts deformed little which can be negligible, and the findings reveal that the existence of X-bracing causes an evident increase to the load carrying capacities of STCF, especially of STCF without additional spans. It is clear that the strength of the STCF with X-bracing system would 1) increase linearly with the right-angle coupler rotational stiffness, thickness of steel tube to a certain extent; 2) decrease linearly with post spacing, initial imperfection, the storey height to a certain extent; 3) decrease nonlinearly with the U-head height, the sweeping staff height, which has little effect on the failure load of STCF with X-bracing at initial stage and large effect at later stage.
\end{abstract}

Keywords: Steel tube and coupler falsework, X-bracing, experimental research, numerical modeling method, parametric analyses

\section{INTRODUCTION}

Due to the ease of fabrication, installation and dissemination, the structural steel tube and coupler falseworks (referred to hereinafter as STCF) are widely used in the construction of large-span spatial structures such as gymnasiums, train stations, garages, bridges, etc, especially in developing countries, such as China. However, structural failure of these systems often occurred on the construction site due to inadequate design, poor installation and over-loads, which would cause not only project delays but also more serious injuries and casualties of the construction workers [1]. A picture of the steel falsework collapse is shown in Figure 1.

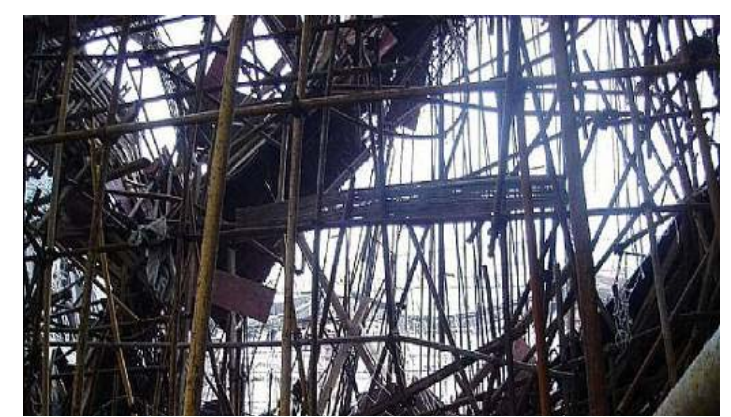

Figure 1. A Collapse Example of STCF using as Shoring Systems 
Currently, most researches on falseworks have focused on the door-type steel falseworks [2 6], high clearance falsework systems [7 8], single-wall and two-wall steel tube and coupler falseworks [9 12], but very few has referred to the STCF. However, many disastrous collapses of STCF have happened during the construction because of no rational design rules for STCF available currently in the national standards in China, Japan, UK and USA [13 17]. As a result, there is a growing concern in many countries on the structural properties of this type of system. Semi-rigid behavior of couplers in STCF was investigated through experiments by R.G. Beale [9], Li Guoqiang [11], Jin Weiliang [12] and Chen Zhihua [18]. Moreover, the stability behavior of STCF without X-bracing was also studied through both numerical simulation and experimental research [18].

It should be noted that there is remarkable difference in the stability behavior between STCF with $\mathrm{X}$-bracing and STCF without X-bracing, so the stability behavior of STCF with X-bracing must be studied. Due to the high slenderness of posts, existence of $\mathrm{X}$-bracing, unloading area, and the semi-rigid properties of couplers, it is important for the researchers to understand the structural behaviors of STCF through both experimental and analytical studies.

\section{OBJECTIVES AND SCOPE OF INVESTIGATION}

An extensive study has been conducted on the stability behavior of STCF with X-bracing through both experimental and analytical investigations. Here the STCF with X-bracing system consists of steel beams (horizontal members), steel posts (vertical members), X-bracing members, right-angle coupler at the intersection of beams and posts, swivel coupler at the intersection of posts and $\mathrm{X}$-bracing member etc. The objectives of the study included:

- Indentify the strength and failure modes of STCF with X-bracing through experiments.

- Present an effective numerical modeling method considering the semi-rigid nature of the couplers to analyze the structural properties of STCF with X-bracing and verify it by full-scale tests.

- Investigate the effect of various geometric parameters on the stability of STCF with X-bracing.

The following tasks have been undertaken to achieve the research objectives:

Task 1 - Two full-scale tests were carried out to provide not only insights into the structural behavior of STCF with X-bracing, but also data to compare with and verify the numerical results obtained from subsequent finite element analyses. Test result of two full-scale tests from literature is also adopted for comparison.

Task 2 - Establish FEM model based on the characteristics of STCF with X-bracing system and verify it by results of full-scale tests.

Task 3 - A series of parametric analysis were carried out to investigate the effect of various geometric characters on system stability. 


\section{EXPERIMENTAL INVESTIGATION}

\subsection{Test Specimens}

Two full-scale static tests, both of which were over $8 \mathrm{~m}$ high, were carried out in order to examine the strength and failure modes of tall STCF with X-bracing. During the static tests, vertical loads were applied to the top of the STCF specimens at a very low loading rate until the specimens failed. The layouts of the two specimens are shown in Figure 2 and Figure 3. The geometric properties are summarized in Table 1. The steel tubes used in the test specimens had a diameter of $48 \mathrm{~mm}$ and a thickness of $3.5 \mathrm{~mm}$. In order to guarantee that the tests realistically reflected the actual structural behavior of STCF on the construction site, the following actions were taken:

(1) All the steel tubes, couplers and U-heads used in the test specimens were acquired randomly from the falsework market;

(2) All the test specimens were built by actual workers from the construction site;

(3) The torque applied to the coupler bolts were controlled to be $40 \mathrm{~N} \cdot \mathrm{m}$

(4) All intersections between X-bracing and vertical posts were set a joint to fix them together using swivel couplers.

(5) The X-bracings were not only fixed on the four edges, but also on all intersection between them and vertical posts.

Therefore, the tests would provide an insight into the behavior of STCF in practice and also important references for future study and design.

Table 1. Parameters for the Four Specimens

\begin{tabular}{cccccccc}
\hline Spec \# & Num & $\begin{array}{c}\text { H_1 } \\
(\mathrm{m})\end{array}$ & $\begin{array}{c}\mathrm{H} \_3 \\
(\mathrm{~m})\end{array}$ & $\begin{array}{c}\text { H_4 } \\
(\mathrm{m})\end{array}$ & $\begin{array}{c}\text { S_1 } \\
(\mathrm{m})\end{array}$ & X-bracing & $\begin{array}{c}\mathrm{P}_{\mathrm{T}} \\
(\mathrm{kN})\end{array}$ \\
\hline TF1 & 8 & 0.9 & 0.4 & 0.5 & $0.6 \times 0.6$ & yes & 32.5 \\
\hline TF2 [18] & 8 & 0.9 & 0.4 & 0.5 & $0.6 \times 0.6$ & no & 21.17 \\
TS1 & 5 & 1.5 & 0.2 & 0.5 & $0.9 \times 0.94$ & yes & 28.38 \\
TS2 [18] & 5 & 1.5 & 0.2 & 0.5 & $0.9 \times 0.94$ & no & 23.22 \\
\hline
\end{tabular}

Note: Num stands for the number of stories in the test specimen. 


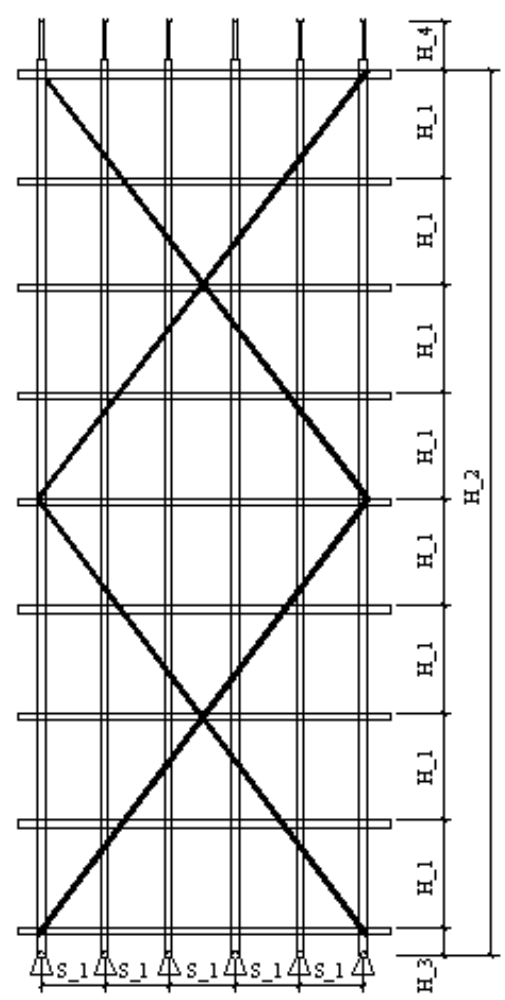

(a) Elevation View from South

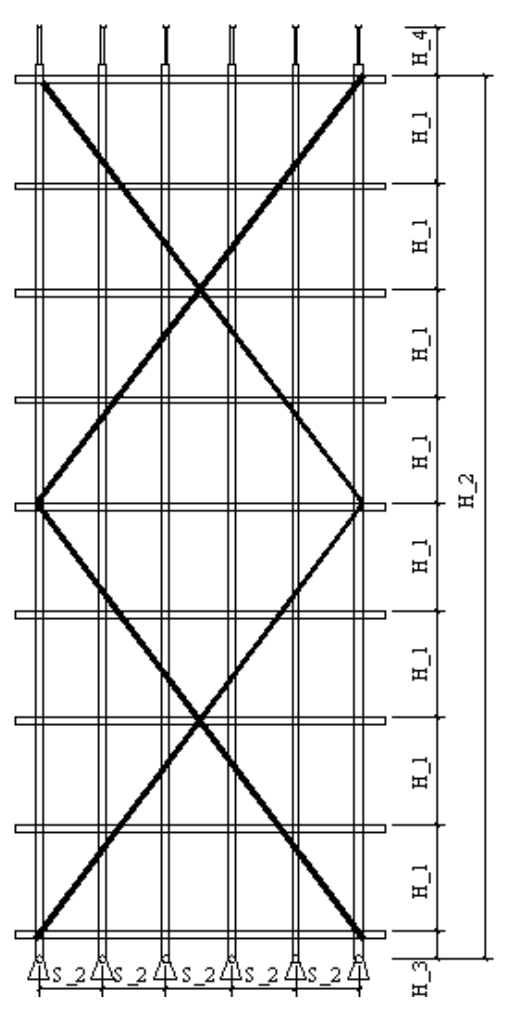

(b) Elevation View from West

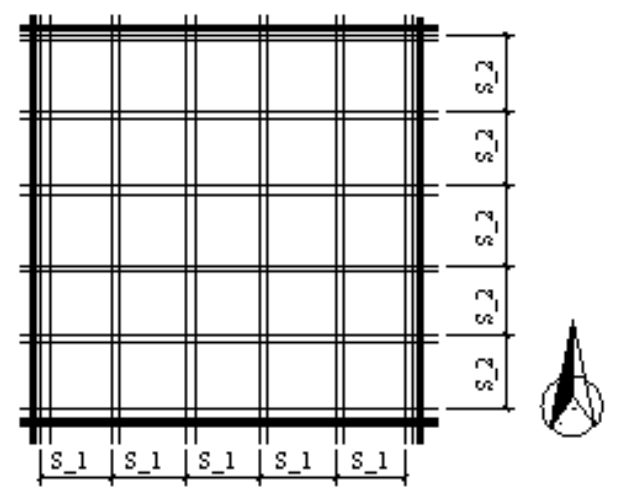

(c) Plan View

Figure 2. General Arrangement of TF1 


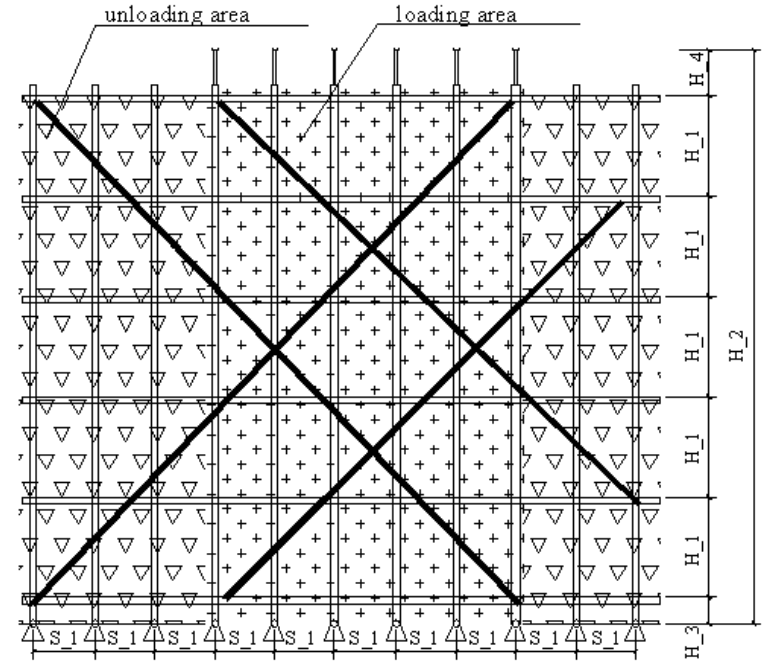

(a) Elevation View from South

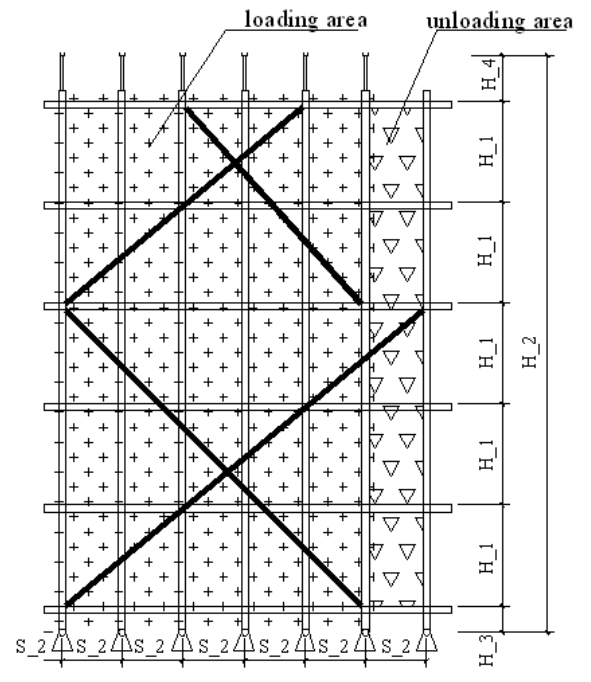

(b) Elevation View from West

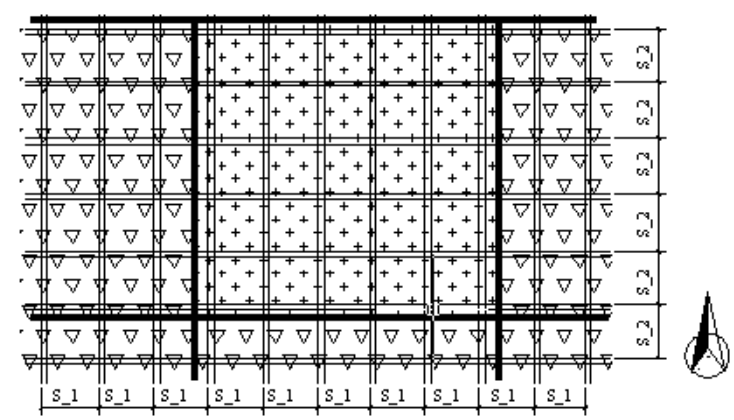

(c) Plan View

Figure 3. General Arrangement of TS1

\subsection{Loading Mechanism and Test Set-Up}

Four loading frames with a height of $10 \mathrm{~m}$ were fabricated for the tests. Two 50-ton hydraulic jacks were fastened to the top of each loading frame, and vertical loads were firstly applied by the hydraulic jacks to the two top steel distribution beams, and then transferred to the group of bottom steel distribution beams in the perpendicular direction, and finally to the falsework system, as is shown in Figure 4. In this way, the vertical concentrated loads applied by the hydraulic jacks would be converted into a vertical uniform load applied to the top of the falsework system through two steel tubes with same diameter with post of specimen right below the bottom distribution beams and the U-heads, as is shown in Figure 4(b). Because there are four loading frames, there are eight 50-ton hydraulic jacks used in each test, and they were fixed under loading frames simultaneously and not gradually. Moreover, all hydraulic jacks were connected with each other by oil tube in order to make them bring pressure simultaneous. 


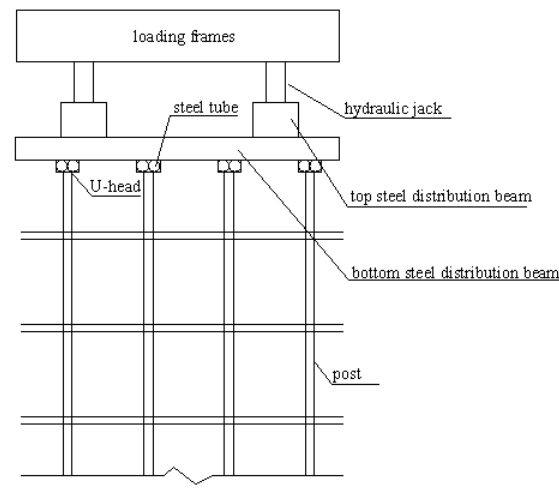

(a) Elevation View from West

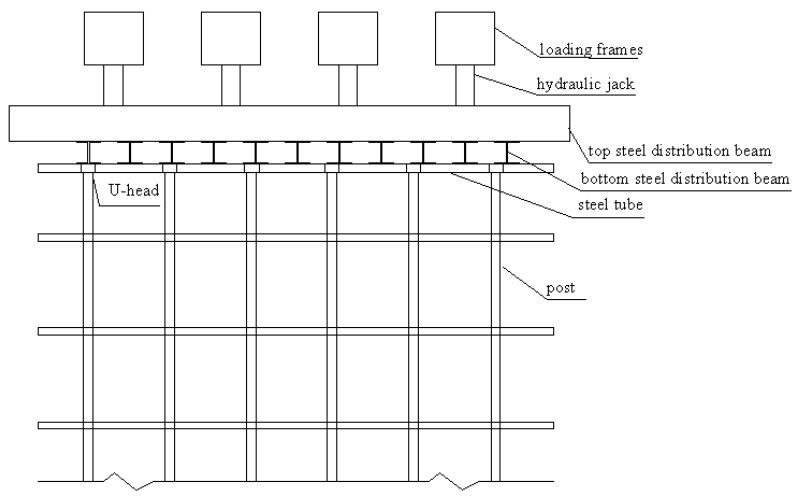

(b) Elevation View from South

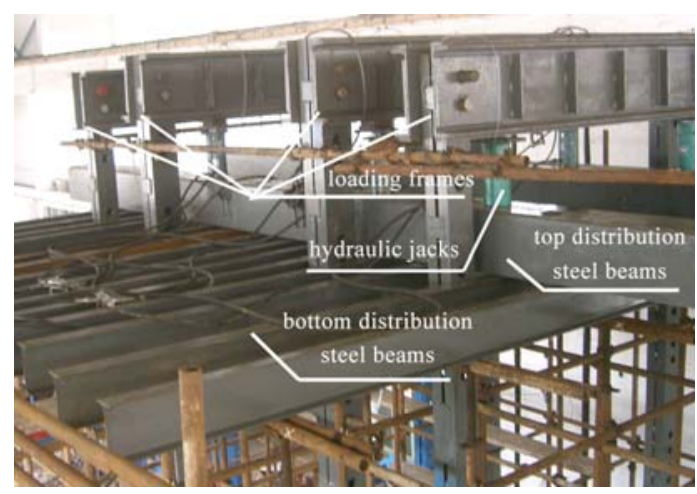

(c)

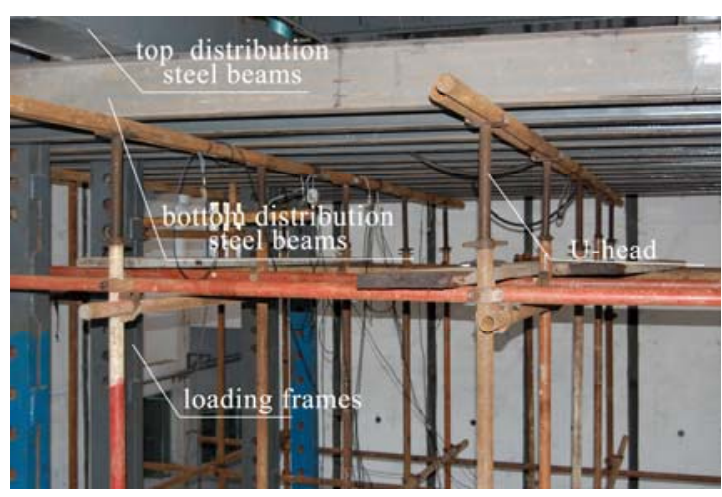

(d)

Figure 4. Loading Mechanism and Test Set-Up

For these falseworks, it is clear from Figure 5 that the bottom end of the falsework system was not restrained in the horizontal directions, so theoretically it is free. However, during the tests as well as in common practices, there were no horizontal displacements observed at this location, therefore the boundary condition here would be considered pinned. On the top end of the falsework system, the boundary condition there would be considered as a roller condition, since the horizontal friction force between the two steel tubes and the bottom surface of the distribution steel beams was very small, as is shown in Figure 4(b).

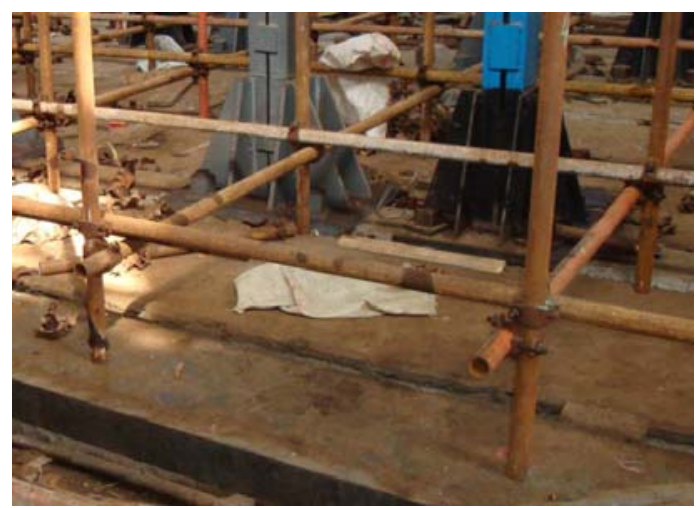

Figure 5. Bottom of the Falsework System

Considering the safety of the experiments, the collapse of the falsework system was not allowed. Since the pressure induced by the hydraulic jacks will decrease once the STCF specimen reached its peak load and start unloading due to instability, the specimen would be considered "failed" at this point and the test will be stopped. 


\subsection{Test Results of Tested Specimens}

It is interesting to note that two specimens of STCF, which have all same geometric parameters, material properties but not X-bracing, were reported, which were tested at the same time with the specimens presented in this paper [18], therefore, it can be compared with the test results obtained in this paper to get the effect of X-bracing on the stability of STCF. Consequently, it is considered to be appropriate to adopt the tests results and re-presented as TF2 and TS2 for direct comparison with the test results in this paper.

Typical deformed shapes of both TF1 and TS1 with X-bracing at failure are shown in Figure 6(a) and Figure 6(b). Considering failure modes are not clearly enough in the Figure 6(a) and Figure 6(b), a sketch view of failure mode is provided to give a clear view as is shown in Figure 6(c). There only a failure mode for a single post is given in the Figure 6(c) because all posts of both TF1 and TS1 have the same failure mode. From Figure6 it can be seen that only upper two storey posts and the U-head buckled evidently about the short axis (that is south-north axis, and the long axis is east-west axis.), and other lower posts deformed little which can be negligible. but Typical deformation of both TF2 and TS2 without X-bracing at failure is that the posts buckled about the short axis, since the system flexural stiffness about this axis would be lower than the long axis are shown in Figure 7(a) and Figure 7(b). Therefore, it is clear that the failure mode of STCF with $\mathrm{X}$-bracing is different from that of STCF without X-bracing.

For STCF with X-bracing, the system below U-head has evident lateral stiffness due to the existence of X-bracing, and there is a little lateral stiffness for the top end of U-head, therefore, there is a large bending moment at bottom end of U-head under effect of vertical load and initial imperfection. Hence, the two top stories will easily buckle under interaction of bending moment and axial force induced by vertical load and initial imperfection.

It should be noted that both deformation and maximum displacement of all posts of TF2, which is absence of both unloading area and X-bracing, are similar, but for all posts in each specimen of TF1, TS2 and TS1, only deformation are similar and maximum displacement is different due to the existence of either unloading area or X-bracing. Moreover, for TF1, TS2 and TS1, the maximum displacement occurs in the middle posts of loading area along long axis.

From the load-displacement curves shown in Figure 8 obtained from tests, it is clear that when applied load on the per post reach the maximum load, the load carrying capacity of TF2 and TS2 reduce evidently, but for TF1 and TS1 it changes little. Here, the applied load on per post can be calculated by following method: all load applied on the falseworks (including pressure of hydraulic jacks, weight of hydraulic jacks, weight of steel distribution beams and so on) divided by the number of post in the loading area of falseworks.

Table 2 summarizes the $\mathrm{P}_{\mathrm{T}}$ at failure, which is maximum applied load per post in the load-displacement curve when the capacity of the specimen started to decrease. It is shown that the average applied loads per post $\mathrm{P}_{\mathrm{T}}$ at failure are $32.5 \mathrm{kN}$ and $28.38 \mathrm{kN}$ for TF1 and TS1 respectively, and hence, the axial buckling resistances of the posts are only $23.44 \%$ and $20.46 \%$ of their section capacities $\mathrm{P}_{\mathrm{C}}$ respectively. Moreover, it should be noted that the load carrying capacities of TF1 and TS1 are $53.52 \%$ and $22.22 \%$ higher than those of TF2 with $\mathrm{P}_{\mathrm{T}}$ of $21.17 \mathrm{kN}$ and TS2 with $\mathrm{P}_{\mathrm{T}}$ of $23.22 \mathrm{kN}$ due to the existence of $\mathrm{X}$-bracing. The findings reveal that the existence of $\mathrm{X}$-bracing causes a evident increase of the load carrying capacities of STCF, especially for STCF without unloading area such as TF2. 


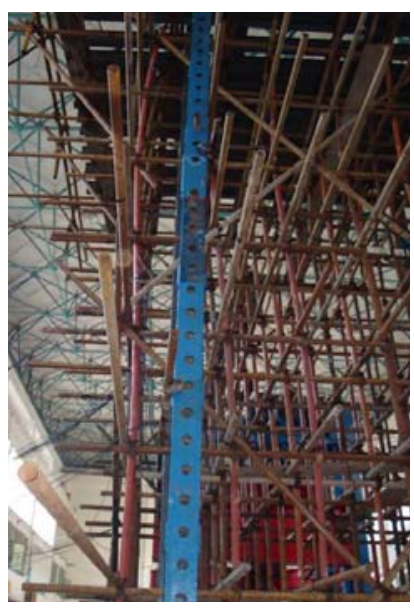

(a) Specimen TF1

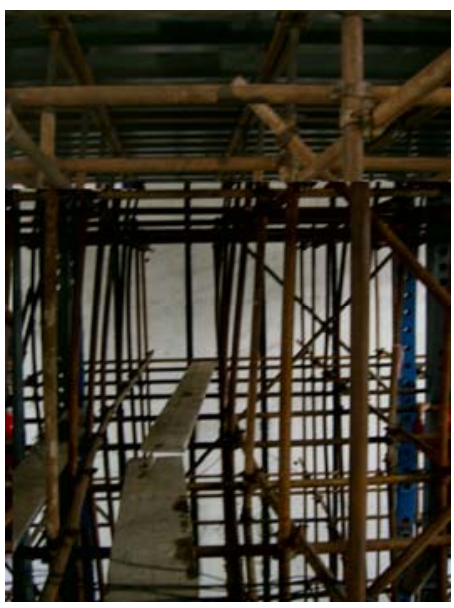

(b) Specimen TS1 (c) Sketch View of

Failure Mode of Post

Figure 6. Failure Modes for TF1, TS1 Observed from Full-Scale Tests

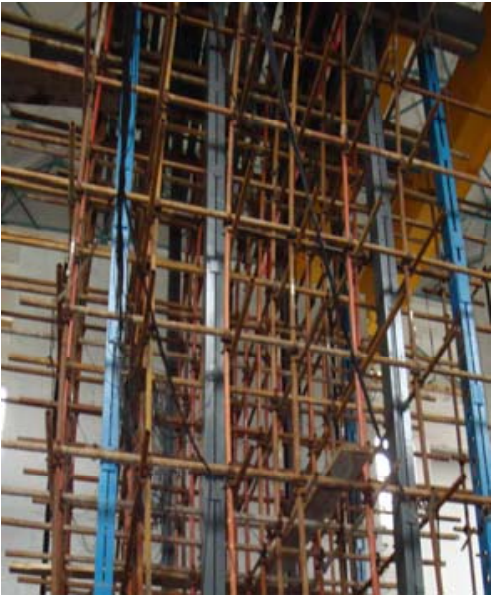

(a) Specimen TF2

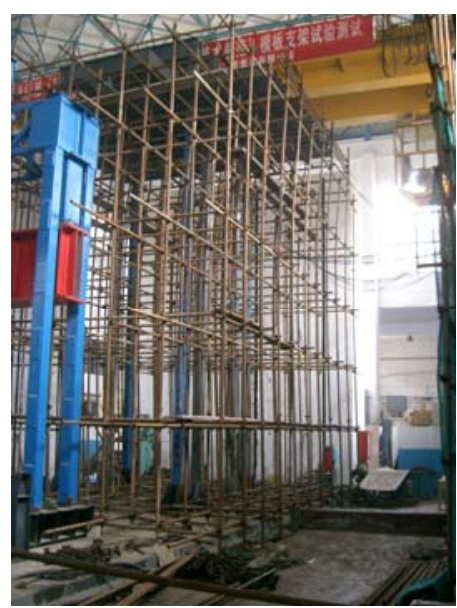

(b) Specimen TS2

Figure 7. Failure Modes for TF2, TS2 Observed from Full-Scale Tests

Table 2. Both Experimental and FEM Results of Specimens

\begin{tabular}{ccccccccc}
\hline $\begin{array}{c}\text { Spec } \\
\#\end{array}$ & $\begin{array}{c}\mathrm{P}_{\mathrm{C}} \\
(\mathrm{kN})\end{array}$ & $\begin{array}{c}\mathrm{P}_{\mathrm{L}} \\
(\mathrm{kN})\end{array}$ & $\begin{array}{c}\mathrm{P}_{\mathrm{NL}} \\
(\mathrm{kN})\end{array}$ & $\begin{array}{c}\mathrm{P}_{\mathrm{T}} \\
(\mathrm{kN})\end{array}$ & $P_{T} / P_{C}$ & $P_{L} / P_{N L}$ & $\left(P_{L}-P_{t}\right) / P_{t}$ & $\left(P_{N L}-P_{t}\right) / P_{t}$ \\
\hline TF1 & 138.68 & 77.22 & 34.13 & 32.5 & 0.2344 & 2.26 & 137.60 & 5.02 \\
TS1 & 138.68 & 68.56 & 30.32 & 28.38 & 0.2046 & 2.26 & 141.58 & 6.84 \\
\hline
\end{tabular}

Note: $\mathrm{P}_{\mathrm{C}}$ stands for the strength of specimens calculated using section area.

$\mathrm{P}_{\mathrm{L}}$ stands for the strength of specimens obtained from eigenvalue buckling analysis.

$\mathrm{P}_{\mathrm{NL}}$ stands for the strength of specimens obtained from nonlinear buckling analysis.

$\mathrm{P}_{\mathrm{T}}$ stands for the strength of specimens obtained from test. 


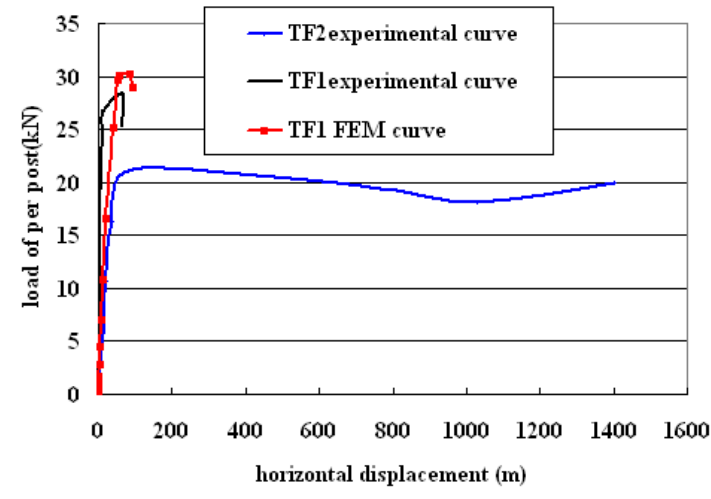

(a) Results of Specimen TF1and TF2

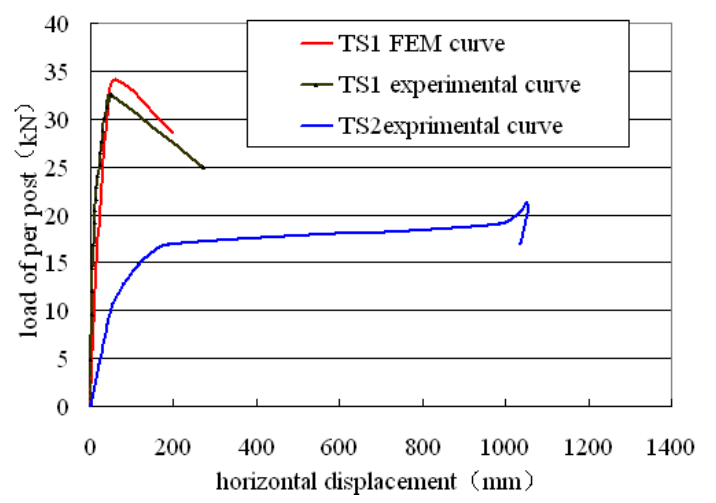

(b) Results of Specimen TS1and TS2

Figure 8. Typical Load-Displacement Curve of Specimens

\section{NUMERICAL ANALYSIS}

In order to predict the structural behavior and the load deformation characteristics of STCF with X-bracing up to maximum applied loads, non-linear analysis is required. In the present study, an advanced non-linear analysis software ANSYS is used to evaluate the load carrying capacities of STCF with X-bracing.

Since the beams (horizontal member) and posts (vertical member) are continuous in the longitudinal direction and there is no disconnection of the members at the right-angle coupler location in practice, three-dimensional beam element (BEAM188) was used to model the horizontal beams and vertical posts. At the intersection between a post and two beams in perpendicular directions, three nodes $\mathrm{N}_{\mathrm{Vi}}, \mathrm{N}_{\mathrm{Hi}}, \mathrm{N}_{\mathrm{Li}}$ were defined at this location with the same coordinates as it shown in Figure 9(a), where one $\mathrm{N}_{\mathrm{Vi}}$ belongs to the post element, and the other two $\mathrm{N}_{\mathrm{Hi}}, \mathrm{N}_{\mathrm{Li}}$ belong to the beam elements in perpendicular directions. Coupling was defined for the three nodes so that the nodes would have the same displacement in all directions and the same rotation about the vertical axis. In order to simulate the semi-rigid behavior of the right-angle couplers, spring-damper element (COMBIN14) was used with a spring constant of $16.0 \mathrm{kN}-\mathrm{m} / \mathrm{rad}$, which was the mean initial rotational stiffness obtained from previous right-angle coupler tests[18]. The COMBIN14 element was added between the node on the post and the node on each beam, in order to simulate the in-plane rotational restraints provided by the right-angle couplers. Since the X-bracing members are continuous in the longitudinal direction and there is no disconnection of the members at the swivel coupler location in practice, three-dimensional beam element (BEAM188) was used to model the X-bracing. In order to simulate the connection between post and X-bracing, two nodes $\mathrm{N}_{\mathrm{bi}}, \mathrm{N}_{\mathrm{Vmi}}$ are defined at the location of swivel coupler as it shown in Figure 9 (b), where one $\mathrm{N}_{\mathrm{bi}}$ belongs to the $\mathrm{X}$-bracing elements and the other one $\mathrm{N}_{\mathrm{Vmi}}$ belong to the post elements. Coupling was defined for the two nodes so that the nodes would have the same displacement in all directions. 


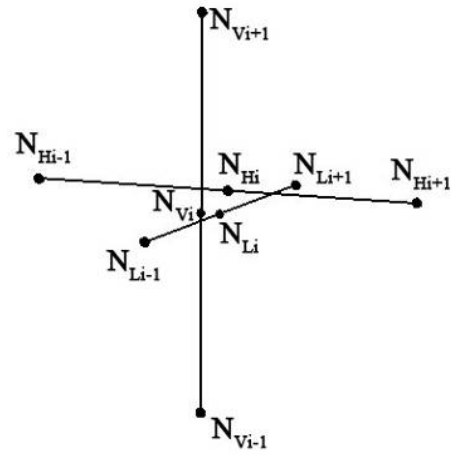

(a) Intersection of Posts and Beams

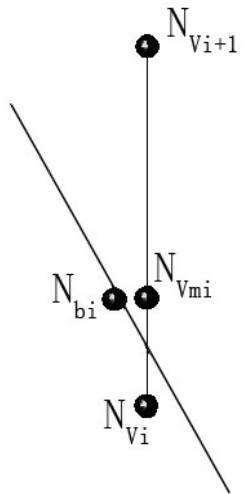

(b) Intersection of Post and X-Bracing

Figure 9. Method for Building the FEM Model

A concentrated load was applied to the top end of each post of STCF. For the boundary conditions, the top of the falseworks was assumed free with only vertical loads applied from the bottom distribution beam, since the rolling friction between the falseworks and the bottom distribution beams is very small. The bottom of the falseworks was considered pinned, since no displacement at the bottom was observed during the tests. FEM model built in ANSYS for two specimens are shown in Figure 10.

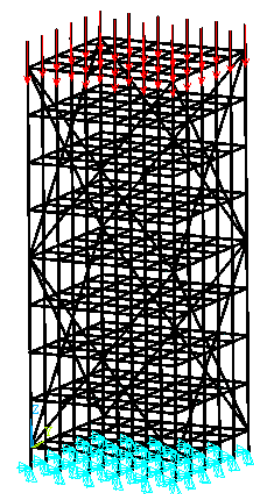

(a)TF1

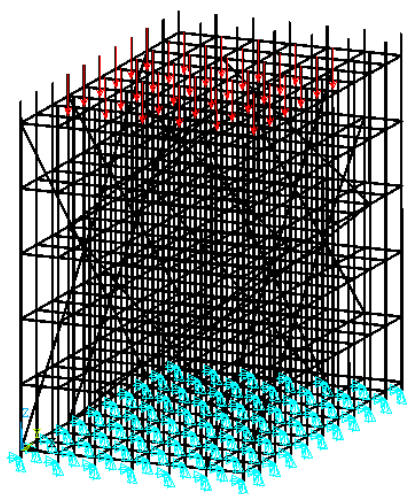

(b)TS1

Figure 10. Axonometric Projections of FEM Model of Specimens

As the first step, eigenvalue buckling analysis was carried out in order to indentify the upper limit of the critical buckling load as well as the failure modes for the nonlinear buckling analysis in later steps. Note that neither the material nonlinearity nor the geometric imperfections were considered in the eigenvalue buckling analysis, therefore the results could not be used directly, but it would provide useful information for later nonlinear buckling analysis. The critical buckling load $\mathrm{P}_{\mathrm{L}}$ obtained from the eigenvalue buckling analysis of each specimen was listed in Table 2.

Nonlinear buckling analysis was then carried out based on the results from the previous eigenvalue buckling analysis. Material nonlinear was considered using perfect elastic-plastic model in ANSYS with elastic modulus of $184 \mathrm{kN} / \mathrm{mm}^{2}$ and yield strength of $374 \mathrm{~N} / \mathrm{mm}^{2}$, and the stress-strain curve obtained from coupon test were shown in Figure11. A group of concentrated load was applied incrementally to the top of the model until the STCF becomes unstable and the solution cannot converge. The first buckling mode identified from the eigenvalue buckling analysis was generally considered as the most critical one, which was used as the initial imperfection in the nonlinear buckling analysis. According to literature, the maximum imperfection allowed in practice is $0.05 \mathrm{~m}$ for STCF with height less than $10 \mathrm{~m}$ [13]. Therefore an initial geometric imperfection was applied by scaling the first buckling mode from the eigenvalue buckling analysis so that the maximum imperfection would be $0.05 \mathrm{~m}$. 


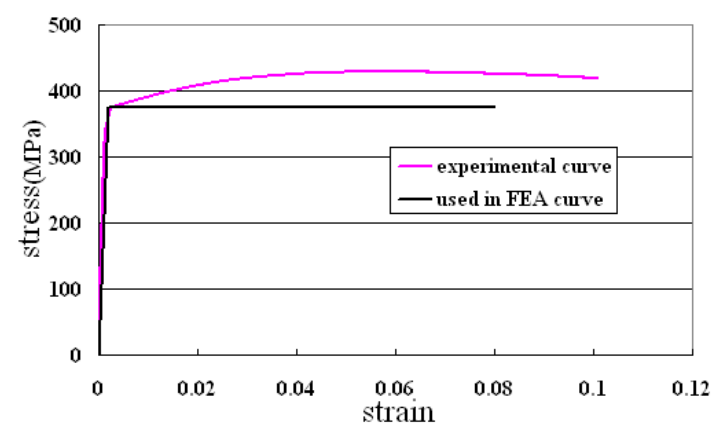

Figure 11. Strain-Stress Curve of Steel Tubes

From the result of the nonlinear buckling analysis, some typical conclusions can be obtained as follows:

1) Only upper two storey posts and the U-head buckling significantly about the longitudinal weak axis, and the other lower posts deformed little that can be negligible for specimens STF2, STS2 as shown in Figure 12;

2) Typical failure modes for two specimens obtained from the nonlinear buckling analysis are shown in Figure 12, which were quite consistent with the full-scale test observations.

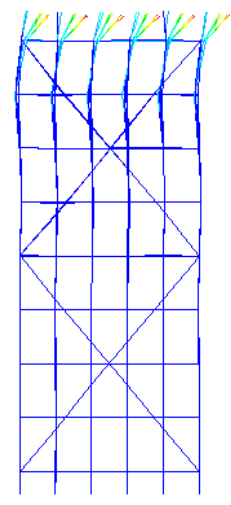

(a) TF1

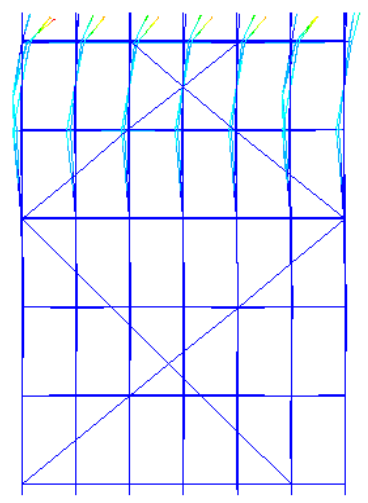

(b) TS1

Figure 12. Failure Modes of Specimens Obtained from FEM Model

The strength $\mathrm{P}_{\mathrm{NL}}$ obtained from the nonlinear buckling analysis of each specimen was also listed in Table 2, where it is clear that $\mathrm{P}_{\mathrm{NL}}$ was generally less than $\mathrm{P}_{\mathrm{L}}$ from the elastic eigenvalue buckling analysis by a factor of 2.26. Therefore, it can be concluded that the strength of STCF is sensitive to the initial imperfection and material nonlinearity.

It is also clear from table 2 that the strength $\mathrm{P}_{\mathrm{NL}}$ obtained from the nonlinear buckling analysis of each specimen was generally consistent with the full-scale test results, with a maximum difference of $6.84 \%$. Reasons attributing to the error could include variance in the rotational stiffness of couplers, variance in the mechanical properties of steel tubes, initial imperfections of the steel tubes, etc. The FEM simulation results for the STCF test specimens were then considered precise to a reasonable degree and could be used for future parametric studies. 


\section{PARAMETRIC STUDIES}

Parametric studies were conducted in order to indentify the controlling factors for the critical buckling load of the STCF with X-bracing system. The parameters investigated included the rotational stiffness of the right-angle couplers, the storey height, the sweeping staff height (that is the height of H_3 illustrated in Figure 2 and Figure 3), the post spacing, the U-head height, thickness of steel tubes and initial imperfection. The primary layout of the FE model here is as same as specimen TF1.

Results from the parameter studies are shown in Figure 13. From the Figure 13, it is clear that the critical buckling load of the STCF with X-bracing system would 1) increase linearly with the right-angle coupler rotational stiffness, thickness of steel tube to a certain extent as it shown in Figure 13(a) (b); 2) decrease linearly with post spacing, initial imperfection, the storey height to a certain extent as it shown in Figure 13(c) (e); 3) decrease nonlinearly with the U-head height, the sweeping staff height as it shown in Figure 13(f) (g), which has little effect on the failure load of STCF with X-bracing at initial stage and large effect at later stage.

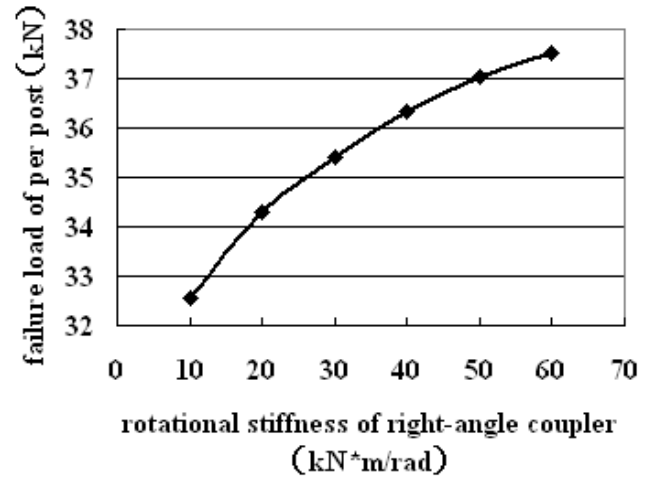

(a) Influence of Rotational Stiffness of Right-Angle Coupler

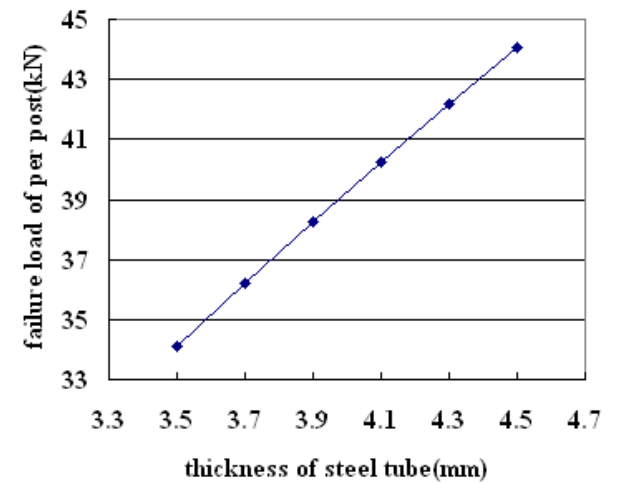

(b) Influence of Thickness of Steel Tube

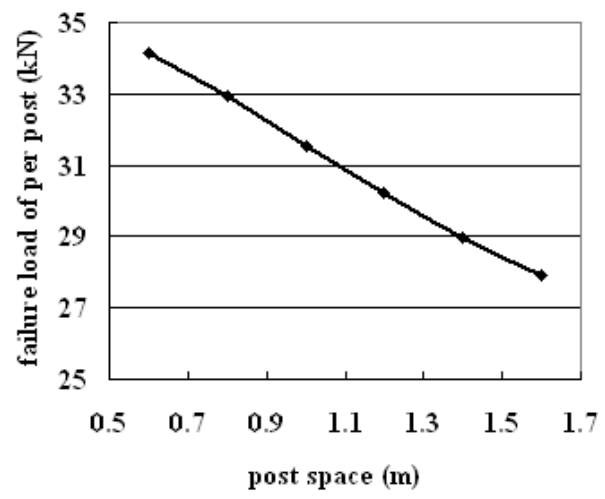

(c) Influence of Post Space

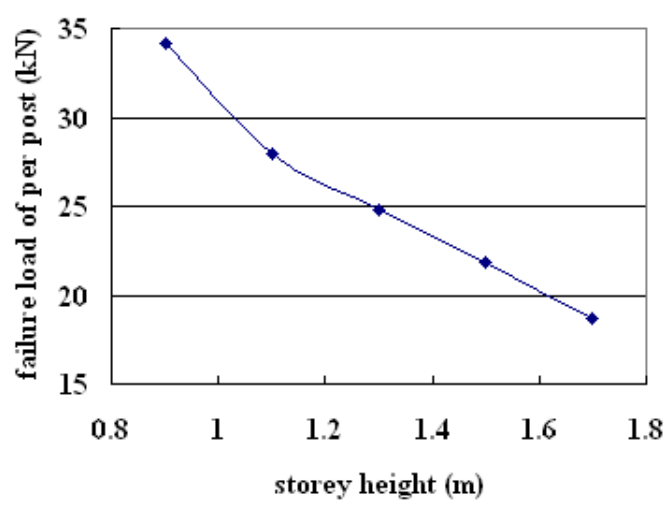

(e) Influence of Storey Height

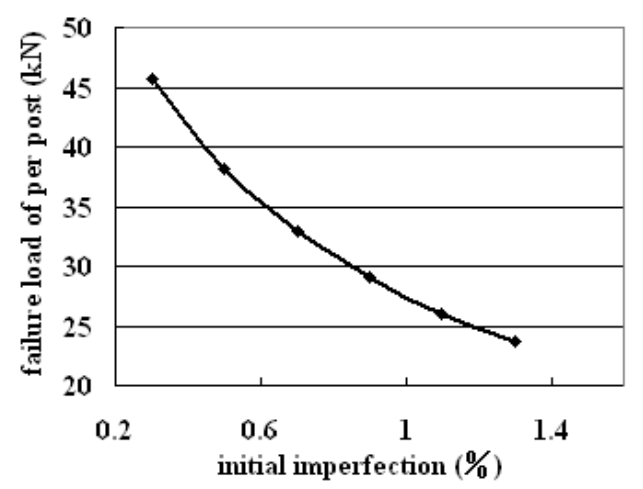

(d) Influence of Initial Imperfection

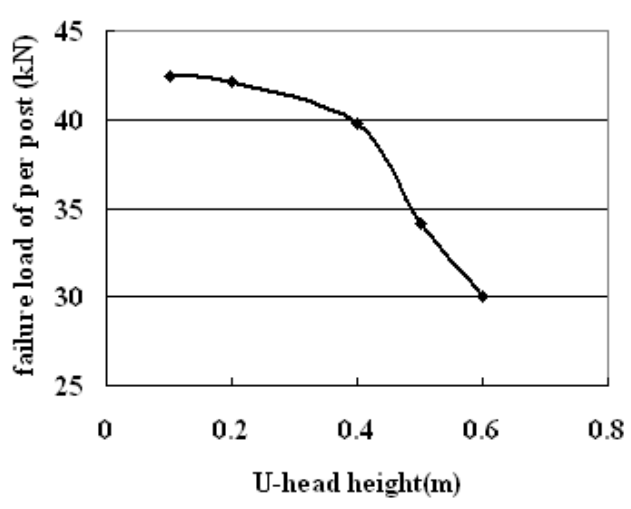

(f) Influence of U-Head Height 


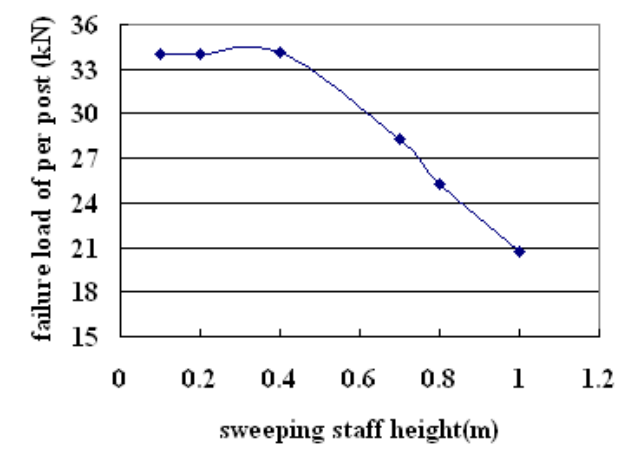

(g) Influence of Sweeping Staff Height

Figure 13. Results of Parameter Studies on STCF with X-Bracing by FEM

\section{CONCLUSIONS}

This paper presents an extensive study on the stability behavior of STCF with X-bracing through full-scale tests as well as numerical investigations. It is demonstrated that:

1) The failure mode of STCF with X-bracing is different from that of STCF without X-bracing. Typical deformed shapes for STCF without X-bracing at failure is that the posts buckled about the short axis, since the system flexural stiffness about this axis would be lower than the long axis. But typical deformed shapes for STCF with X-bracing at failure is that only upper two storey posts and the U-head buckled significantly about the short axis, and other lower posts deformed little which can be negligible;

2) Both deformed shapes and maximum displacement of all posts of TF2, which is absence of both unloading area and X-bracing, are similar, but for all posts in each specimen of TF1, TS2 and TS1, only deformed shapes are similar and maximum displacement is different due to the existence of either unloading area or X-bracing. Moreover, for TF1, TS2 and TS1, the maximum displacement occurs in the middle posts of loading area along long axis;

3) Axial buckling resistances of the column members are only $23.44 \%$ and $20.46 \%$ of their section capacities respectively, so the stability is the control factor for failure;

4) The load carrying capacities of TF1 and TS1 are 53.52\% and $22.22 \%$ higher than those of TF2 and TS2 due to the existence of X-bracing. The findings reveal that the existence of $\mathrm{X}$-bracing causes a significant increase to the load carrying capacities of STCF, especially of STCF without unloading area such as TF2;

5) The FEM simulation results for the STCF test specimens were then considered precise to a reasonable degree and could be used for future parametric studies;

6) It is clear that the critical buckling load of the STCF with X-bracing system would 1) increase linearly with the right-angle coupler rotational stiffness, thickness of steel tube to a certain extent; 2) decrease linearly with post spacing, initial imperfection, the storey height to a certain extent; 3) decrease nonlinearly with the U-head height, the sweeping staff height, which has little effect on the failure load of STCF with X-bracing at initial stage and large effect at later stage.

\section{ACKNOWLEDGEMENTS}

The authors sincerely thank the Tianjin Municipal Science and Technology Commission for the financial support provided to this research project (Research Project No.08JCZDJC19600). The authors also thank the China Academy of Building Research for their partial support on the experiment research and are especially grateful to Mr. Qun Liu, chief engineer, for his advices and support during the process. 


\section{REFERENCES}

[1] Milojkovic, B., Beale, R.G. and Godley, M.H.R., "Determination of the Factors of Safety of Standard Scaffold Structures”, Proceedings of International Conference on Advances in Steel Structures, 2002, Vol. 1, pp. 303-10.

[2] Chan, S.L., Zhou, Z.H., Chen, W.F., Peng, J.L. and Pan, A.D., "Stability Analysis of Semi-Rigid Steel Scaffolding”, Eng. Struct., 1995, Vol. 17, pp. 568-74.

[3] Peng, J.L., Pan, A.D.E. and Chan, S.L., "Simplified Models for Analysis and Design of Modular Falsework”, J. Construct. Steel Res. 1998, Vol. 48, pp. 189-209.

[4] Peng, J.L., Pan, A.D.E. and Chen, W.F., "Approximate Analysis Method for Modular Tubular Falsework”, ASCE, J. Struct. Engng., 2001, Vol. 127, pp. 256-63.

[5] Weesner, L.B. and Jones, H.L., "Experimental and Analytical Capacity of Frame Scaffolding”, Eng. Struct., 2001. Vol. 23, pp. 592-99.

[6] Yu, W.K., Chung, K.F. and Chan, S.L., "Structural Instability of Multi-Storey Door-Type Modular Steel Scaffolds”, Eng. Struct., 2004, Vol. 26, pp. 867-61.

[7] Peng, J.L., Pan, A.D., Rosowsky, D.V., Chen, W.F., Yen, T. and Chan, S.L., "High Clearance Scaffold Systems during Construction-1: Structural Modeling and Modes of Failure”, Eng. Struct., 1996, Vol. 18, pp. 247-57.

[8] Peng, J.L., Pan, A.D., Rosowsky, D.V., Chen, W.F., Yen, T. and Chan, S.L., "High Clearance Scaffold Systems During Construction - 2: Structural Analysis and Development of Design Guidelines”, Eng. Struct., 1996, Vol. 18, pp. 258-67.

[9] Beale, R.G. and Godley, M.H.R., "Numerical Modeling of Tube and Fitting Access Scaffold Systems”, Advanced Steel Construction, 2006, Vol. 2, pp. 199-223.

[10] Xu, C.B., Zhang, T.Z. and Pan, J.L., et al., "Theoretical and Experimental Studies on the Structural Behavior of Two-Wall Steel Tube and Coupler Scaffold”, Journal of Harbin Architectural and Civil Engineering Institution, 1989, Vol. 2, pp. 38-55. (In Chinese)

[11] Ao, H.F. and Li, G.Q., "Investigation of Overall Load-Bearing Stability Capacity of Tube-and-Coupler Scaffolds”, Chinese Quarterly of Mechanics, 2004, Vol. 25, pp. 213-218. (In Chinese)

[12] Yuan, X.X., Jin, W.L., Lu, Z., Liu, X. and Chen, T.M., “A Study on the Stability Bearing Capacity of Fastener-Style Tubular Steel Formwork-Supports”, J. China Civil Engineering Journal, 2006, Vol. 39, No. 5, pp. 43-50. (In Chinese)

[13] Chinese Standards Institution, GJG 130-2001: Technical Code for Safety of Steel Tubular Scaffold with Couplers in construction: 2001. (In Chinese)

[14] British Standards Institution, BS EN 12811: Temporary Works Equipment: 2003.

[15] British Standards Institution, BS EN 12812: Falsework-Performance Requirements and General Design: 2004.

[16] American National Standards Institution. ANSI/ASSE A10.8-2001: Safety Requirements for Scaffolding: 2001.

[17] Japanese Industrial Standards Committee. JIS A 8951-1995: Tubular Steel Scaffolds: 1995.

[18] Liu, H.B, Zhao, Q.H, Wang, X.D., et al., "Experimental and Analytical Studies on Stability of Structural Steel Tube and Coupler Scaffold without X-Bracing”, Eng. Struct., 1996, Vol. 32, pp. 1003-1015.

[19] Chen, Z.H., Liu, H.B. and Zhou, T., et al., "Parametric Analysis of Spatial Steel Structures Using APDL Language”, Beijing: China WaterPower Press, 2009. (In Chinese) 


\title{
EXPERIMENTAL BEHAVIOR OF HIGH STRENGTH CONCRETE-FILLED SQUARE STEEL TUBE UNDER BI-AXIAL ECCENTRIC LOADING
}

\author{
GuoChang $\mathrm{Li}^{*}$, Zhijian Yang and Yan Lang \\ School of Civil Engineering, Shenyang Jianzhu University, Shenyang, China \\ *(Corresponding author: E-mail: cegcli@sjzu.edu.cn)
}

Received: 31 January 2010; Revised: 7 June 2010; Accepted: 25 June 2010

\begin{abstract}
An experimental investigation on the behaviour of square steel tube columns filled with high-strength concrete in this study was done. A total of six high strength concrete-filled square steel tube (HCFST) columns subjected to bi-axial eccentric loading were constructed and tested. The primary test parameters were the slenderness ratios (varied from 13.9 to 27.7 ), steel ratios(7\% and $13 \%$ ), and eccentricity along major axis was $71 \mathrm{~mm}$. The test results demonstrate the influence of these parameters on the strength and behavior of concrete-filled square steel tube columns. As what shows in the experiment, the steel ratio is an important factor which influences the bearing capacity of the specimens, and the stable bearing capacity of the specimens decreased rapidly with the increasing slenderness ratio. The specimens failed to work out of instability. Proper material constitutive models for HCFST columns are applied and verified by the nonlinear finite element software ABAQUS against experimental data. A comparison of experimental failure loads with the predicted failure loads in accordance with the method described in the reference showed good agreement.
\end{abstract}

Keywords: Square steel tube, High strength concrete, Bi-axial eccentric loading, Finite element analysis, Slenderness ratio, Steel ratio

\section{INTRODUCTION}

Concrete-filled steel tube columns have recently undergone increased usage throughout the world, which has been influenced by the development of high-strength concrete. With the ever-increasing application of high-strength concrete in civil engineering, the research on steel tube filled with high-performance concrete columns is imperative nowadays. Concrete-filled square steel tube (CFST) column has a high bearing capacity, good plasticity, toughness, fatigue resistance and other superior mechanical properties, but it also has unique characteristics, (1) simple form of beam-to-column connection, (2) flexible building layout, (3) good stability behavior with large cross-section moment of inertia, (4) convenient construction (Han [1], Shosuke [2]). Thus, in recent years CFST columns have been widely applied in practical project, such as, the cross-section of $1400 \mathrm{~mm} \times 1400 \mathrm{~mm}$ concrete filled square steel tube columns were used in Wuhan International Stock Exchange Building with 68 stories and a height of $243 \mathrm{~m}$.

When subjected to the load of horizontal wind or earthquake, frame columns of high-rise building structures usually tend to be bi- axial bending, especially the corner columns of the structures. It is very important to describe the behavior of such columns for rational analysis and design, but most of studies on CFST at home or abroad mainly focused on axial compression and uniaxial eccentric compression(Toshiaki [3], Han [4], Campione [5]). Some theoretical and experimental studies have been conducted for the determination of the behavior of eccentrically loaded CFST columns (Zegbicbe [6]). Mursi and Uy have presented experimental and theoretical studies of fabricated high strength steel columns subjected to biaxial bending (Mursi [7], Uy [8]). Serkan Tokgoz constructed a experimental investigation on the structural behavior of steel tubular columns in-filled plan and steel reinforced concrete subjected biaxial bending and axial load (Serkan and Cengiz [9]). Su-Mei Zhang has done a lot of research on concrete-filled rectangular hollow section (RHS) steel tubes subjected to axial compression combined with bi- axial bending, and achieved a few success (Guo [10]). Bridge, R studied on four concrete-filled rectangular hollow section(RHS) 
steel tubes subjected to bi-axial eccentric loading, and showed that the bearing capacity of the specimen has a close relationship with the eccentric angle (Bridge [11]). Shakir-Khalil H conducted a test of nine concrete-filled rectangular hollow section(RHS) steel tube columns subjected to bi-axial eccentric loading, with a eccentric angle of $45^{\circ}$ and concrete strength of $94.1 \mathrm{MPa}$ (Shakir-Khalil [12]).

The main objective of this study is to investigate the behavior and strength of high strength concrete-filled square steel tube (HCFST) columns. For this purpose, several HCFST columns were constructed and tested subjected to bi-axial eccentric loading. The test results of HCFST column specimens have been compared with the analysis results and discussed in this paper.

\section{EXPERIMENTAL INVESTIGATION}

\subsection{Specimens and Parameters}

A total of six CFST column specimens were constructed with high-strength concrete. The cross-section of the specimen was $200 \mathrm{~mm} \times 200 \mathrm{~mm}$ with a wall thickness of $4 \mathrm{~mm}$ or $6 \mathrm{~mm}$. The length of the columns varied from $800 \mathrm{~mm}$ to $1600 \mathrm{~mm}$ in increments of $400 \mathrm{~mm}$ and the steel tube was cold-formed Q235 square tube. The eccentricity along major axis was $71 \mathrm{~mm}$, and eccentric angle was $45^{\circ}$. The primary test parameters were slenderness ratios and steel ratios, Table 1 gives the details of the specimens.

Ready-mixed concrete with a designed strength of C60 was used in the test. Three $150 \mathrm{~mm}$ cubes were cast and cured in conditions similar to the related specimens. The 28 day cube strength $\left(f_{c u}\right)$ was $65 \mathrm{MPa}$ and slightly increased on the column test day that was $79.7 \mathrm{MPa}$ (shown as in the Table 1). The modulus of elasticity $\left(E_{c}\right)$ of concrete was $3.81 \times 10^{4}$. Where $B$ is cross section height of steel tube, $t$ is nominal thickness of steel tube; $t$ 'is measured thickness of steel tube. $f_{y}$ is yield strength of steel; $f_{u}$ is ultimate tensile strength of steel; $E_{s}$ is elasticity modulus of steel.

Table1. Specimens in Details

\begin{tabular}{|c|c|c|c|c|c|c|c|}
\hline $\begin{array}{c}\text { Specimen } \\
\text { Number }\end{array}$ & $\begin{array}{c}B \\
(\mathrm{~mm})\end{array}$ & $\begin{array}{c}L \\
(\mathrm{~mm})\end{array}$ & $\begin{array}{c}t \\
(\mathrm{~mm})\end{array}$ & $\begin{array}{c}t^{\prime} \\
(\mathrm{mm})\end{array}$ & $\begin{array}{c}f_{y} \\
(\mathrm{MPa})\end{array}$ & $\begin{array}{c}f_{u} \\
(\mathrm{MPa})\end{array}$ & $\begin{array}{c}E_{s} \\
(\mathrm{Gpa})\end{array}$ \\
\hline ES4-4-71 & 200 & 800 & 4 & 3.5 & 306 & 430 & 200 \\
\hline ES4-6-71 & 200 & 800 & 6 & 5.8 & 340 & 440 & 206 \\
\hline ES6-4-71 & 200 & 1200 & 4 & 3.5 & 306 & 430 & 200 \\
\hline ES6-6-71 & 200 & 1200 & 6 & 5.8 & 340 & 440 & 206 \\
\hline ES8-4-71 & 200 & 1600 & 4 & 3.5 & 306 & 430 & 200 \\
\hline ES8-6-71 & 200 & 1600 & 6 & 5.8 & 340 & 440 & 206 \\
\hline
\end{tabular}

To determine the steel properties, three specimens were cut from randomly selected steel sheet. The specimens were tested in tension. From these tests, the average yield strength $\left(f_{y}\right)$, ultimate tensile strength $\left(f_{u}\right)$ as well as Young's modulus of elasticity $\left(E_{s}\right)$ were got. They are shown in Table 1 .

First of all, the bearing plate was welded at the bottom end of each CFST column specimen. Then, the concrete was casted into steel tubes. Progress vibration was employed in order to eliminate air pockets in the concrete and give a homogeneous mix. The CFST specimens were left with top open to the air for two weeks for the concrete to set. Prior to testing, the top surfaces of the concrete-filled steel tubes were ground smooth and flat using a grinding wheel with diamond cutters to ensure that the load was able to be applied evenly across the cross-section and simultaneously to the steel and concrete. Finally, the base plate was welded at the top end of each CFST specimen. 


\section{$2.2 \quad$ Testing Equipment}

All of the columns were carried out on a $5000 \mathrm{kN}$ capacity loading jack in the Structural Engineering Laboratory of Shenyang Jianzhu University. Knife edges were used on either end to ensure that pinned ends were achieved in all the experiments conducted. The test setup is illustrated in Figure 1 and Figure 3. A number of linear varying displacement transducers (LVDT's) were used to measure the out-of-plane deflections of the column at the mid-height and quarter points of the column (two for short column, six for long column ), and two LVDT's were set up at the bottom to observe the total vertical deformation of the specimen.

Strain gauges were used to measure the surface strains of the steel tube at the mid-height section at various locations. Each column was instrumented with twenty-two strain gauges. Figure 2 shows the strain gauge location and numbering scheme for the columns. The transducers were calibrated before they were used in the test. The U-CAM 70A static data acquisition system was arranged to collect the load, the lateral deflections, and the strain measurements.

\section{$2.3 \quad$ Testing Method}

At each load increment, the strain readings and the deflection measurements were recorded. Special attention was given to verifying the correct position of the column before loading. The load was applied in small increment. Each load interval was maintained for 1 minute. Each of the first few increments of load was about $10 \%$ of the predicted failure load. For the first increment, a complete check of displacement, strains and load was carried out. Several loading and unloading cycles were performed at this stage. When the results were satisfactory, began to load in increments of $10 \%$ estimated ultimate load each step. After steel tube yielded, each step was about 1/15 of estimated ultimate load. Every load lasts about $2 \sim 3$ min. Slow and continuous load was applied when the specimen approaches to destroy.

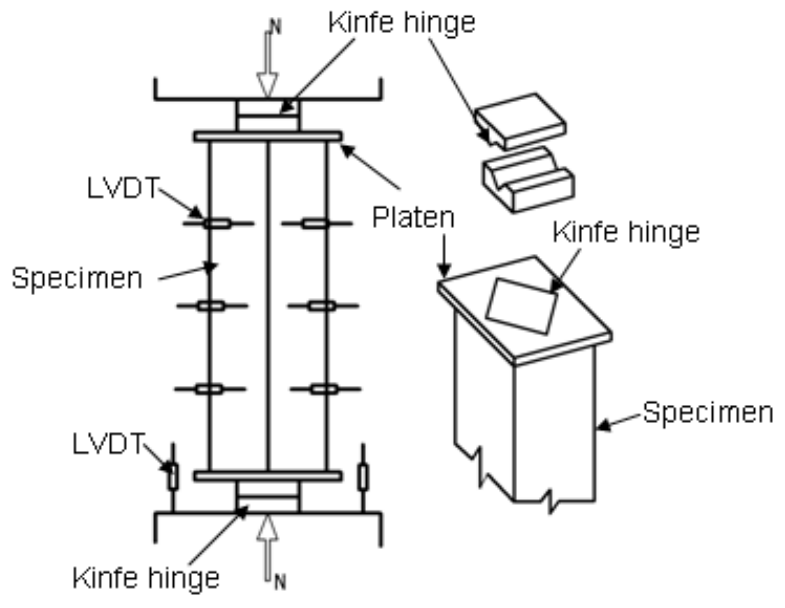

Figure 1. Experimental Equipment

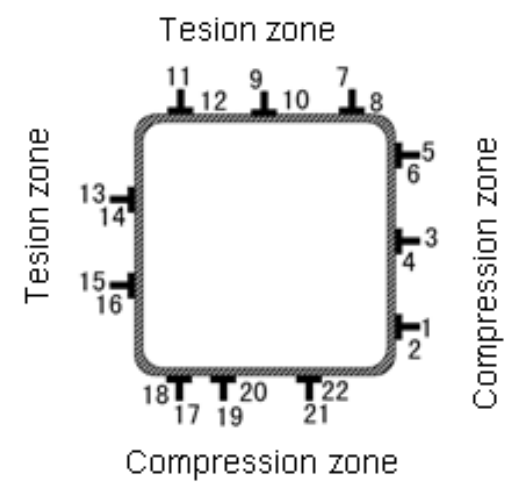

Figure 2. The Location of Strain Gauges

\subsection{Testing Phenomenon and Analysis}

It was observed in the experimental study that the column specimens tested mostly illustrate overall buckling or global instability and behaved in a ductile manner. The load carrying capacity of the columns decreased when reached the failure load. It was concluded from the test that the slenderness and steel ratio had significantly effect on the ultimate strength capacity of HCFST columns subjected to bi-axial eccentric loading. The typical failure mode of a HCFST column is illustrated in Figure 4. 


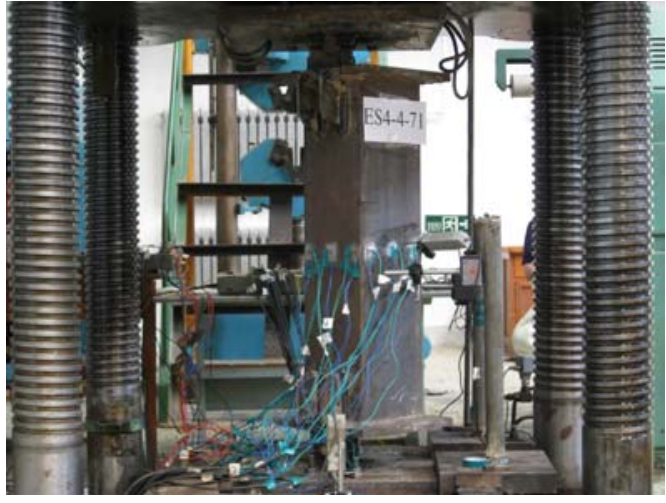

Figure 3. The Typical CFST Column Specimen before Testing

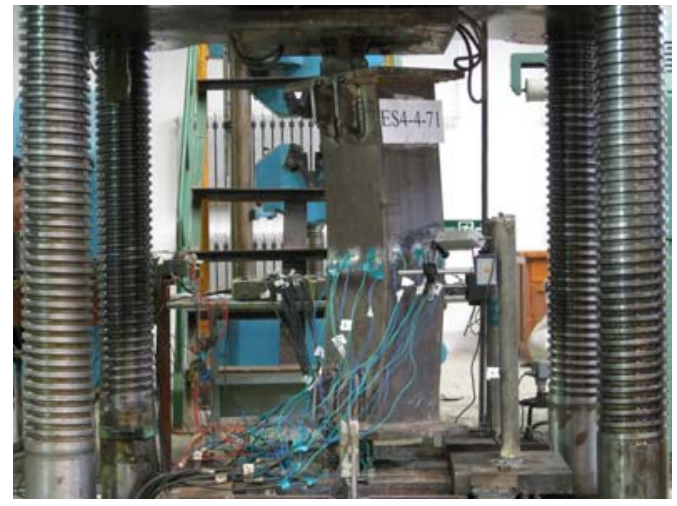

Figure 4. The Typical CFST Column Specimen after Testing

Figure 5(a) shows the specimen after failure. All column specimens failed at the mid-height by rupture of the steel casing in the tension zone and buckling of steel in the compression zone at the termination of loading. Typical failure mode was overall buckling failure. The removal of steel from the failed columns revealed crushing and cracking of concrete in the compression and tension zones, respectively, at mid-length sections, which is illustrated in Figure. 5(b) and Figure. 5(c).

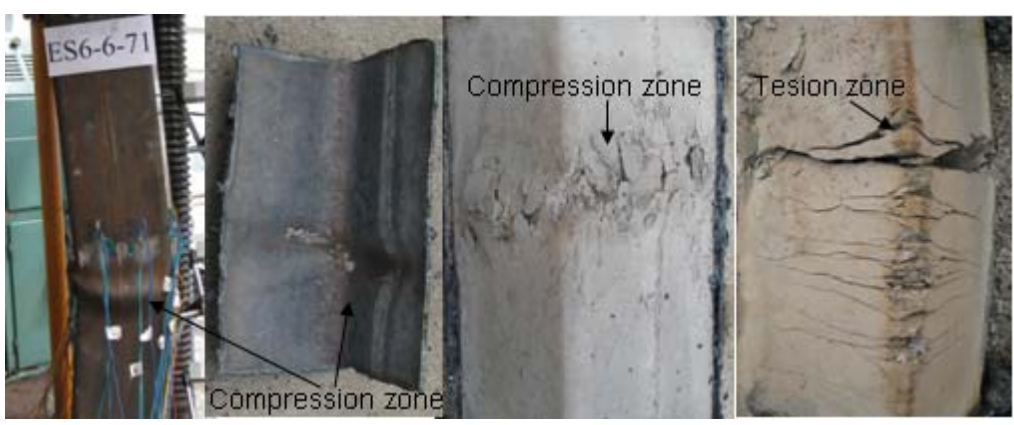

(a)

(b)

(c)

Figure 5. Specimen after Failure

The load $(N)$ versus axial strain $(\varepsilon)$ curves for the columns are presented in Figure 6 . which is the maximum absolute value of strains in the compression and tension zones. The strain value measured on the compression side of the CFST column was about 0.003 , which indicated that the steel tube yielded before the critical load was reached.

Figure 7 is the deflection curves of two typical column specimens measured in the process of load, which is compared to ideal half-sine-wave. The vertical coordinate is height $(H)$ of position on the column. The abscissa is the deflection $\left(u_{\mathrm{m}}\right)$ of different position in the process of loading. $n$ is the ratio of real-time load $(N)$ to ultimate bearing capacity $\left(N_{u}\right)$, and the dashed line is half-sine-wave in Figure 7 . The deflection $u_{\mathrm{m}}$ was calculated by the deflection of two tension face $\left(u_{m}=\sqrt{u_{x}^{2}+u_{y}^{2}}\right)$. From the deformation observed in the test and the test dates gained, the values of $u_{\mathrm{x}}$ and $u_{\mathrm{y}}$ are very close. The deflection curves of test and the ideal half-sine-wave curves fit well, and the smaller of the load, the better the curves fit. 


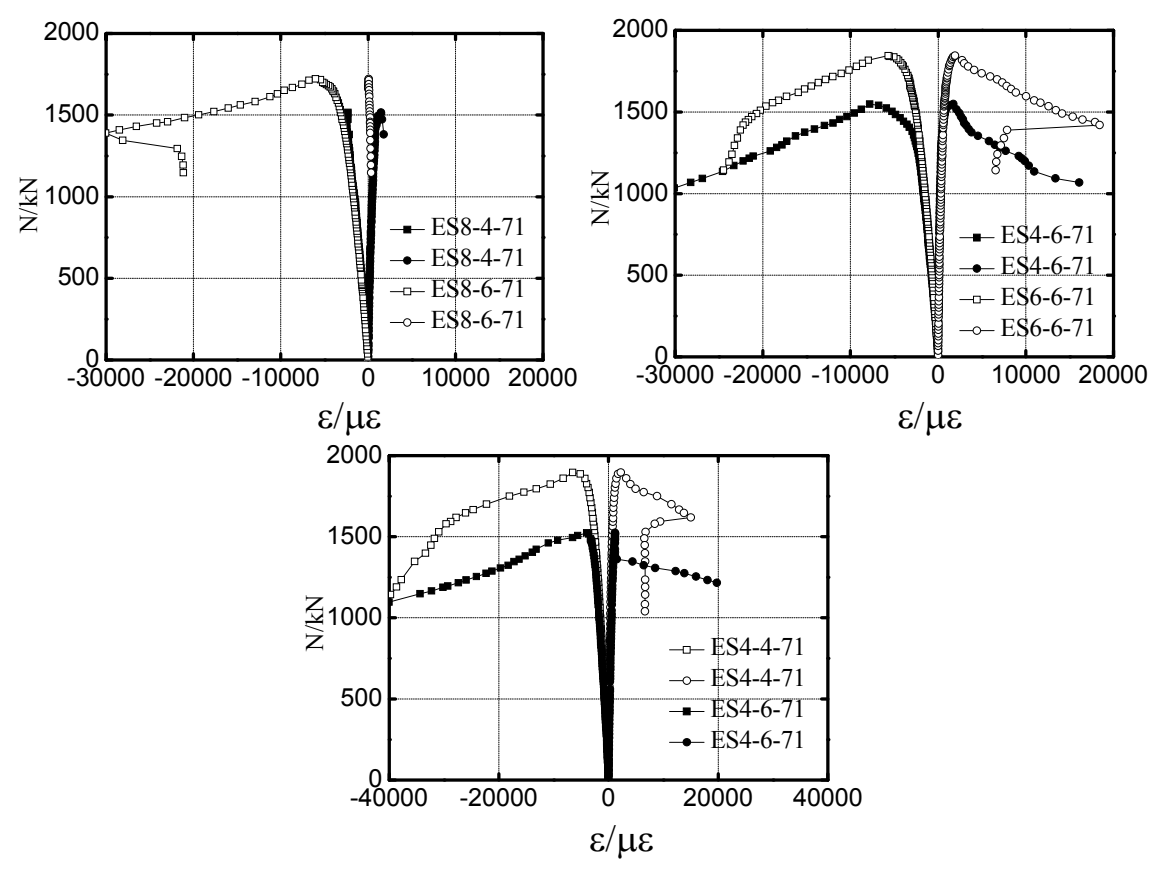

Figure 6. Load $(\mathrm{N})$ Versus Axial Strain $(\varepsilon)$ Relations

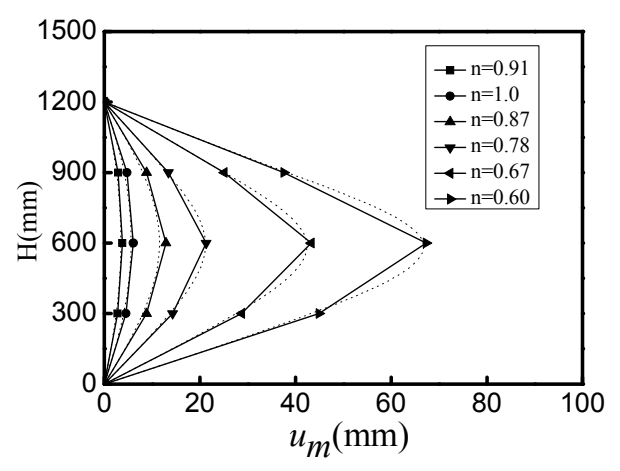

(a) ES6-6-71

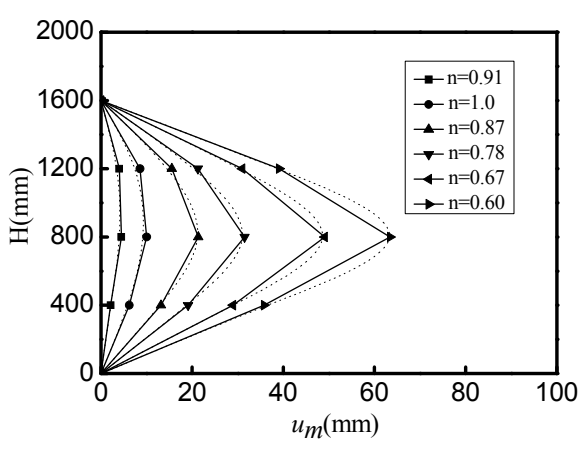

(b) ES8-6-71

Figure 7. The Deflections Curves of Specimen

When the load was small, the lateral deflection at middle height was small and approximately proportional to the applied load. However, when load reached about $70 \%$ of the ultimate load, the deflection of the mid-span increased significantly. As the deflection reached a certain value, the bearing capacity began to descend slowly, and the deflection increased quickly.

Figure 8 is the cross-sectional longitudinal strains distribution of column specimens. In order to check plane-section assumption, the strain values on $\mathrm{x}$ and $\mathrm{y}$-axis are projected to the diagonal axis. Figures 8 shows that the strains of specimen can be connected to a straight line from the beginning to the ultimate bearing capacity under different level loading and the strain distribution of cross section is consistent with plane-section assumption. 


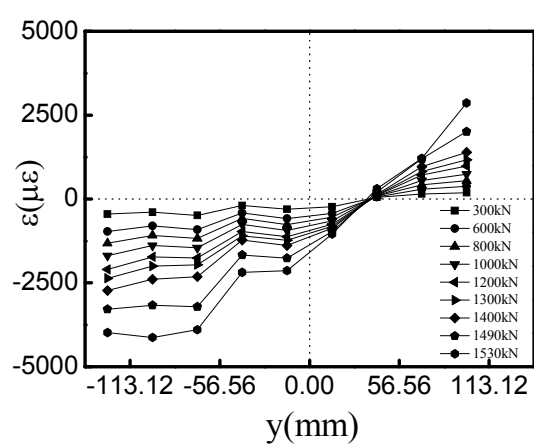

(a) ES4-4-71

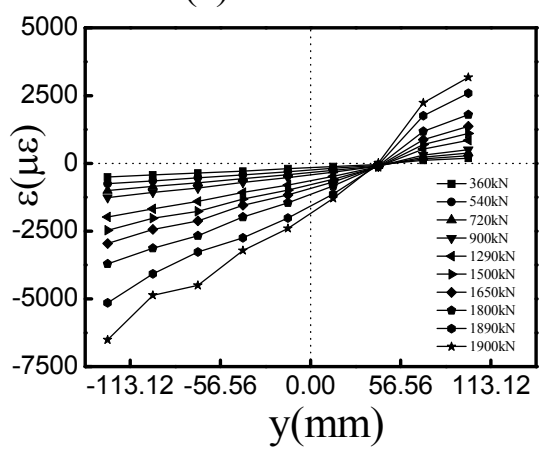

(d) ES4-6-71

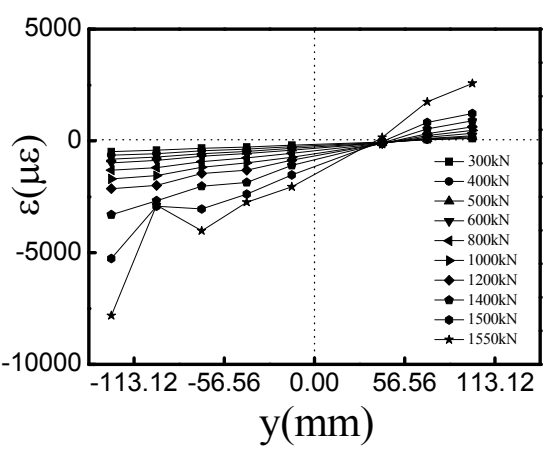

(b) ES6-4-71

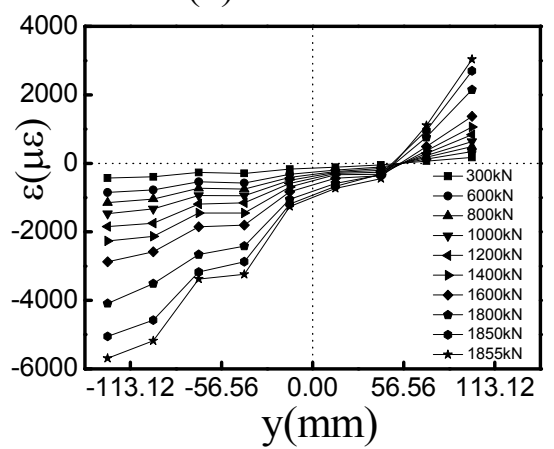

(e) ES6-6-71

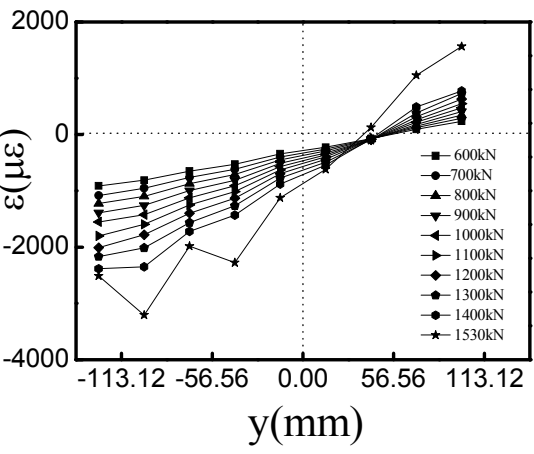

(c) ES8-4-71

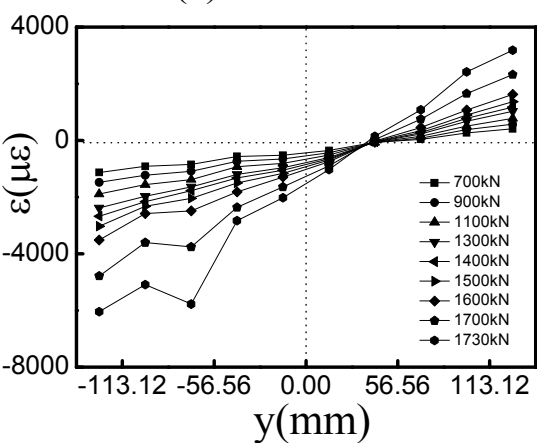

(f) ES8-6-71

Figure 8. Plane-Section Assumption

\section{FINITE ELEMENT ANALYSIS}

\subsection{Material Properties and Constitutive Models}

The nonlinear finite element program ABAQUS (Al-Rodan A [13], Hsuan-Teh Hu [14,15]) was employed to perform numerical stimulations of HCFST columns subjected to bi-axial eccentric loading. To achieve this goal, proper material constitutive models for steel tube and concrete were proposed.

In the analysis, the Poisson's ration $v$ and the elastic modulus $E_{s}$ of the steel tube are assumed to be $v=0.3$ and $E_{S}=206 \mathrm{Gpa}$. The constitutive relationship of steel adopts elastic-plastic constitutive model provided by ABAQUS to meet Von Mises yield criterion, and Isotropic strengthening rule. The steel's stress-strain relationship was shown by entering corresponding steel stress and strain point. As cold-formed steel tube was used in the test and the steel stress-strain relationship referred to four-line model suggested by Abdel-Rahman and Sivakumaran, in this analysis, the material was divided into corner area and flat area (Abdel-Rabman N [16]). The stress-strain curve is described with the following equations:

$$
\sigma= \begin{cases}E_{\mathrm{s}} \varepsilon & \left(\varepsilon \leq \varepsilon_{e}\right) \\ f_{\mathrm{p}}+E_{\mathrm{s} 1}\left(\varepsilon-\varepsilon_{e}\right) & \left(\varepsilon_{e}<\varepsilon \leq \varepsilon_{e 1}\right) \\ f_{\mathrm{ym}}+E_{\mathrm{s} 2}\left(\varepsilon-\varepsilon_{\mathrm{e} 1}\right) & \left(\varepsilon_{e 1}<\varepsilon \leq \varepsilon_{e 2}\right) \\ f_{\mathrm{y}}+E_{\mathrm{s} 3}\left(\varepsilon-\varepsilon_{\mathrm{e} 2}\right) & \left(\varepsilon_{e 2}<\varepsilon\right)\end{cases}
$$

Where $f_{y}$ is the yield strength of flat area; $E_{\mathrm{s}}$ is Young's modulus of elasticity, $E_{\mathrm{s} 1}, E_{\mathrm{s} 2}, E_{\mathrm{s} 3}$ is Slope of line, $E_{\mathrm{s} 1}=0.5 E_{\mathrm{s},} E_{\mathrm{s} 2}=0.1 E_{\mathrm{s}}, E_{\mathrm{s} 3}=0.05 E_{\mathrm{s}} ; f_{p}, f_{m}$ is stress of feature point $f_{p}=0.75 f_{y}, f_{p}=0.875 f_{y}$; $\varepsilon_{\mathrm{e}}, \varepsilon_{\mathrm{e} 1}, \varepsilon_{\mathrm{e} 2}$ is strain of feature point $\varepsilon_{\mathrm{e}}=0.75 f_{\mathrm{y}} / E_{\mathrm{s}}, \varepsilon_{\mathrm{e} 1}=\varepsilon_{\mathrm{e}}+0.125 f_{\mathrm{y}} / E_{s 1}, \quad \varepsilon_{\mathrm{e} 2}=\varepsilon_{\mathrm{e} 1}+0.125 f_{\mathrm{y}} / E_{\mathrm{s} 2}$; The yield strength of flat area $f_{y}$ was given with the following expression: 
$f_{y c}=\left[0.6 b(r / t)^{\mathrm{m}}+0.4\right] f_{\mathrm{y}}$

Where $b=3.69\left(f_{\mathrm{u}} / f_{\mathrm{y}}\right)-0.819\left(f_{\mathrm{u}} / f_{\mathrm{y}}\right)^{2}-1.79$, and $m=0.192\left(f_{\mathrm{u}} / f_{\mathrm{y}}\right)-0.068, f_{u}$ is ultimate tensile strength of steel.

Concrete used a plastic damage model provided by ABAQUS, and the model can simulate the plastic behavior of concrete well. The Poisson's ration of concrete was assumed to be $v=0.2$. When concrete is subjected to laterally confining pressure, the concrete compressive strength and the corresponding strain are much higher than those of unconfined concrete. And the softening phenomenon and ductility has also been improved compared with the case of uniaxial compression. Thus, it is difficult to simulate core concrete that is passive constrained by steel tube through entering ordinary uniaxial compression stress-strain model. Considering the confinement factor $\zeta$ and concrete strength $f_{c}$, the stress-strain relationship of the core concrete proposed by Liu Wei is applied to ABAQUS finite element analysis ( Han, L.H [1]).

In this study, fracture energy-crack displacement model was used to express tension stress-strain of concrete, which is calculated as following [17]:

$G_{f}=a \cdot\left(\frac{f_{\mathrm{c}}}{10}\right)^{0.7} \times 10^{-3}(\mathrm{~N} / \mathrm{mm})$

Where $G_{f}$ is fracture energy; coefficient $a=1.25 d_{\max }+10, d_{\max }$ is the maximum particle diameter of coarse aggregate; $f_{c}$ is mean compressive strength of concrete.

\section{2 $\quad$ Finite Element Model}

Element types of steel tube and concrete were C3D8R (an 8-node linear brick, reduced integration, hourglass control). Mapping mesh was used to mesh the element. The contact between the concrete and the steel was modeled with hard contact at normal direction and Coulomb friction at tangential direction. Coulomb friction model was used to simulate the steel tube and the mezzanine section of concrete shear force transfer. The friction coefficient used in all the analyses is 0.3 .

Due symmetry, only one fourth of the HCFST column was analyzed (Figure 9). Symmetric boundary conditions were enforced on the symmetric planes which were XSYMM and ZSYMM boundary conditions. The plate of the column was allowed to rotate at $x$-axis, and displacement was allowed to take place in the $\mathrm{z}$ direction. The analysis load was applied by displacement control, and incremental iterative method was used to solve nonlinear equations.

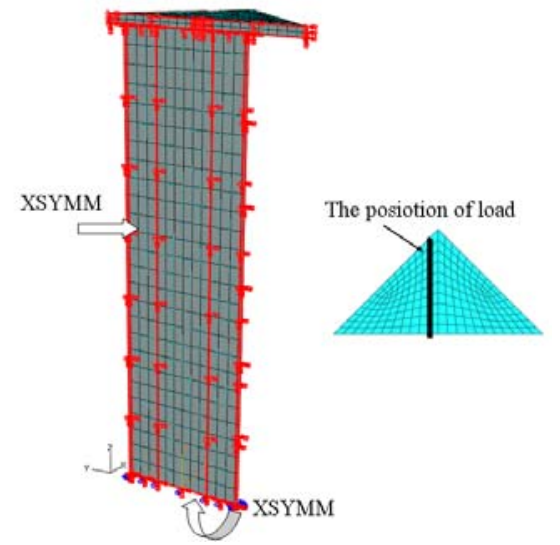

Figure 9. Boundary Condition of Analytical Model 


\subsection{Numerical Simulation}

The results of numerical simulations of HCFST are given in the Table 2 and curves of load versus lateral deflection of mid-height for these columns are plotted against the experimental data in Figures 10. The numerical results show good agreement with the experimental data.

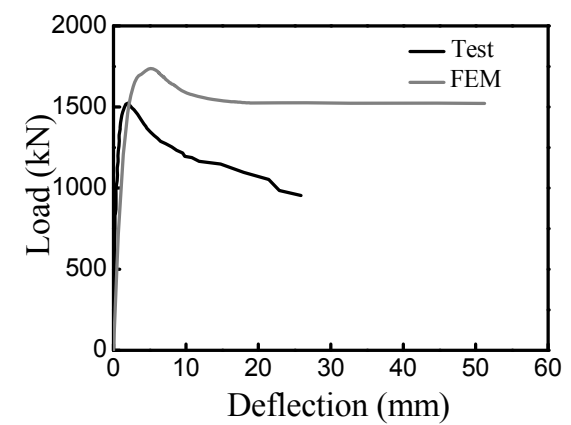

(a) ES4-4-71

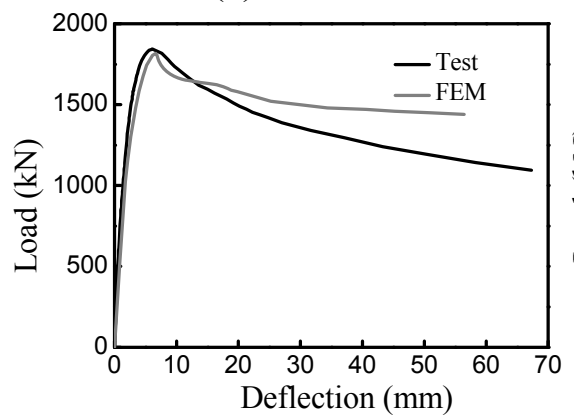

(d) ES6-6-71

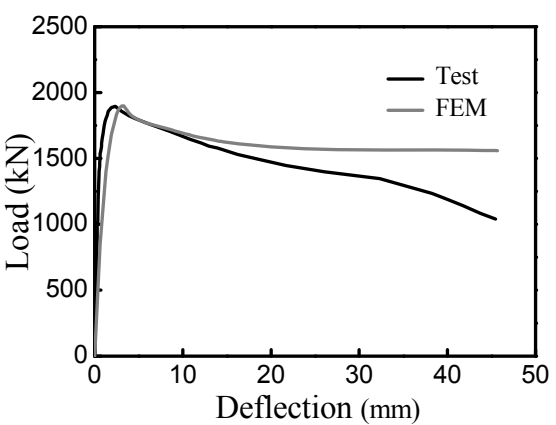

(b) ES4-6-71

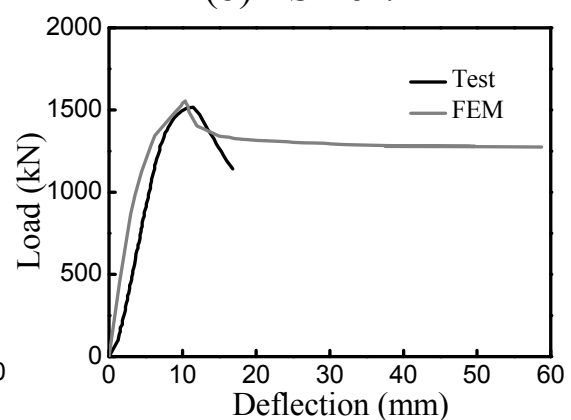

(e) ES8-4-71

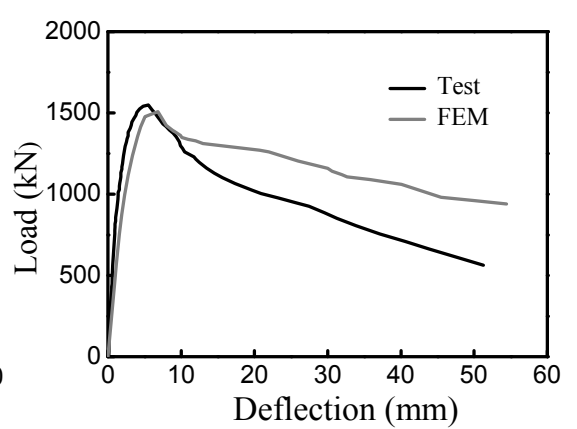

(c) ES6-4-71

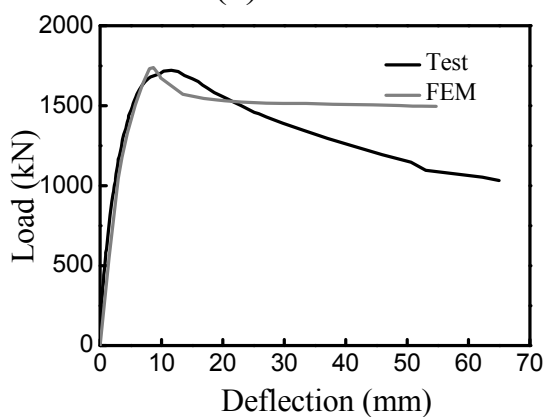

(f) ES8-6-71

Figure 10. Comparisons of Predicted Load Versus Deflection Curves of Columns with Tested Results

The concrete stress isoline of mid-height section, the longitudinal stress distribution in the core concrete section of column along the length of specimen EF6-6-71 is illustrated in Figures 11. The picture of $\mathrm{A}, \mathrm{B}$ and $\mathrm{C}$ are stress contour plots respectively corresponding to the load which is $0.75 N_{c l}$ (the ultimate bearing capacity of finite element calculation), $1.0 N_{c l}$ and $0.85 N_{c l}$. As what can be seen from Figures 11, the tension area expends and compression area reduced with the increasing of load, and the neutral axis gradually approaches to compression zone.

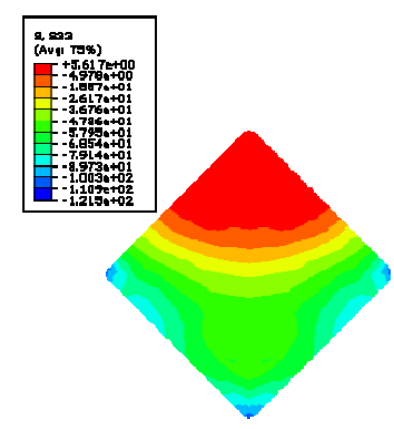

(a) A

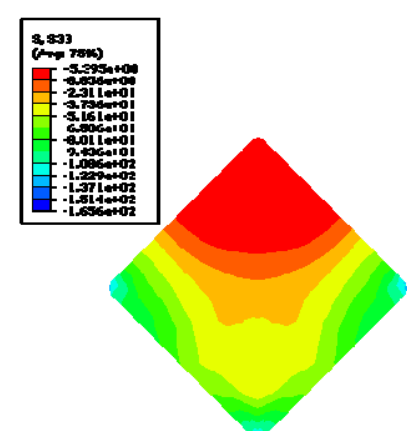

(b) B

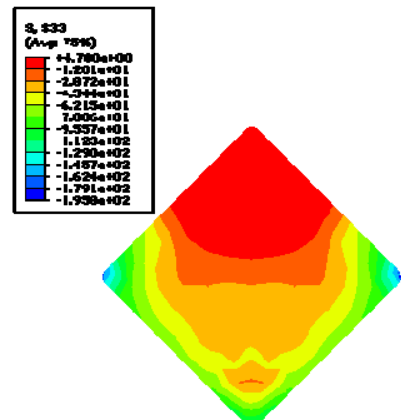

(c) $\mathrm{C}$

The Longitudinal Stress Distribution in the Core Concrete Section 


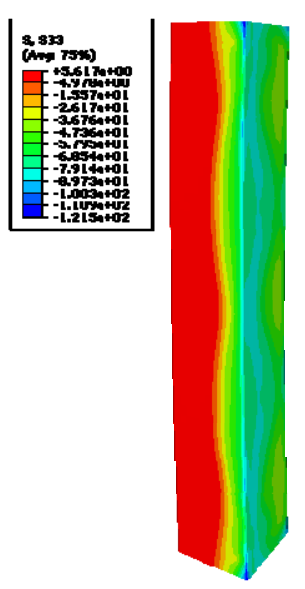

(d) A

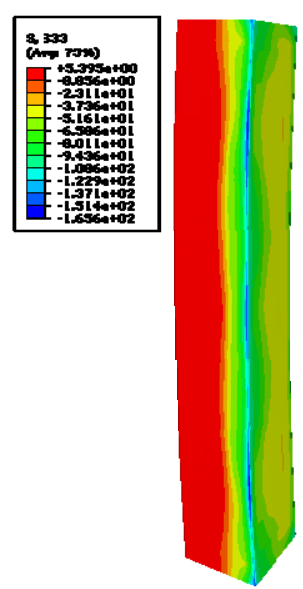

(e) B

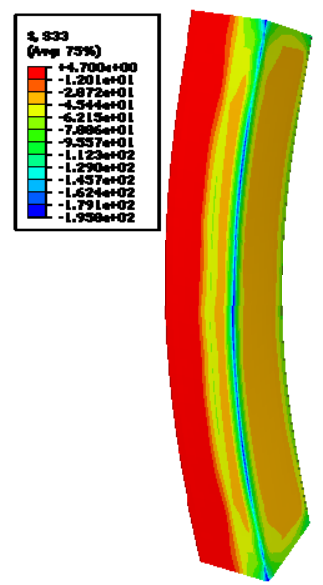

(f) $\mathrm{C}$

Figure 12. The Longitudinal Stress Distribution in the Core Concrete Section of Column along the Length

The concrete stress isoline of mid-height section is illustrated in Figures 12. The tension stress of concrete decreases from $0.0708 f^{\prime}{ }_{c}$ (Figure 12A) to $0.0583 f^{\prime}{ }_{c}$ (Figure 12C) with the increasing of the deflection. In addition, what the confined stress of compression zone corner increases constantly shows that corner confining effect is obvious.

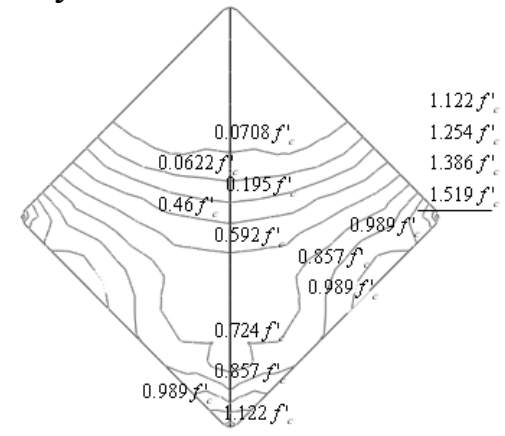

A

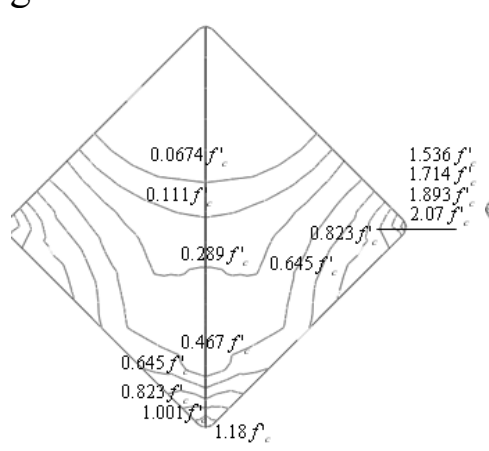

B

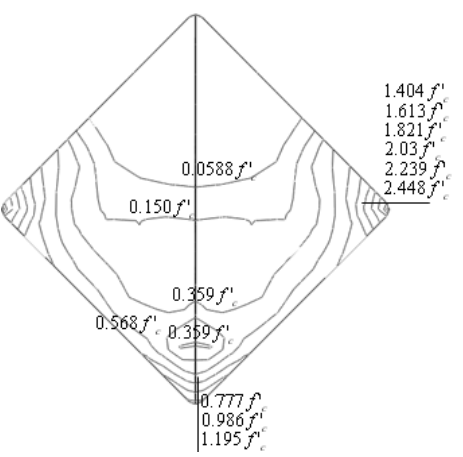

$\mathrm{C}$

Figure 12. The Longitudinal Stress Isoline in the Core Concrete Section

Figures 13 is the longitudinal stress distribution of steel tube along the length of specimen ES6-6-71. What the corner area of steel tube yielded earlier than flat area, shows that the confining effect of corner area is obvious. When the specimen reached ultimate bearing capacity the mid-length began to yield, from the mid-length to the ends.

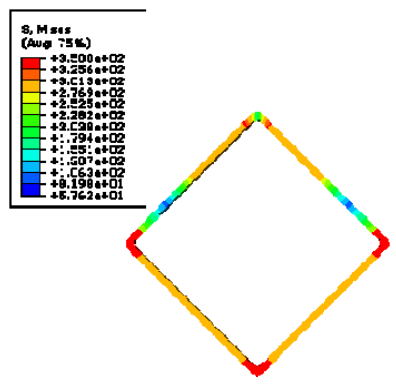

(a) $\mathrm{A}$

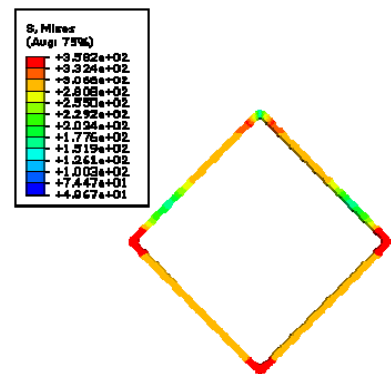

(b) B

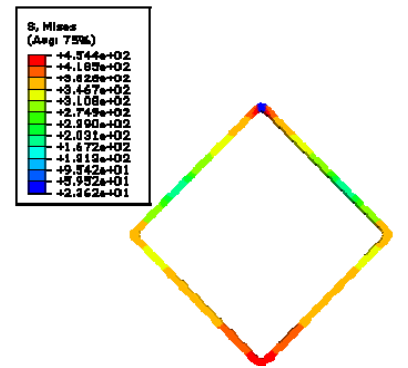

(c) $\mathrm{C}$

The Longitudinal Mises Stress Distribution of Mid-Height Section 


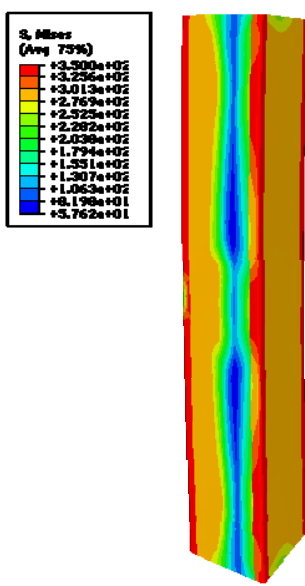

(d) A

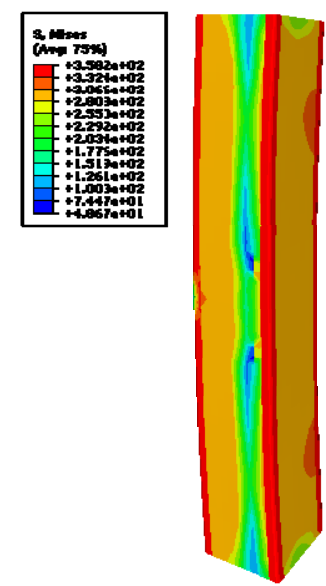

(e) B

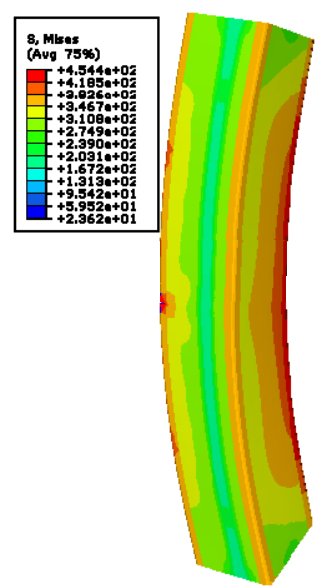

(f) $\mathrm{C}$

Figure 13. The Longitudinal Stress Distribution of Steel Tube along the Length

Figure 14 shows the ultimate bearing capacity of finite element calculation $\left(N_{c 1}\right)$ and measured values $\left(N_{e}\right)$. The ratio of $N_{c 1} / N_{e}$ is listed in Table 2 . The average is 1.005 and standard deviation is 0.038 . It can be seen that the calculation results agree well with the test data.

Table 2. Comparison of Test Results and Calculation Results

\begin{tabular}{|c|c|c|c|c|c|c|c|c|}
\hline $\begin{array}{c}\text { Specimen } \\
\text { number }\end{array}$ & $\begin{array}{c}t^{\prime} \\
(\mathrm{mm})\end{array}$ & $\begin{array}{c}f_{y} \\
(\mathrm{MPa})\end{array}$ & $\varphi_{x y}$ & $\begin{array}{c}N_{e} \\
(\mathrm{kN})\end{array}$ & $\begin{array}{c}N_{c 1} \\
(\mathrm{kN})\end{array}$ & $\begin{array}{c}N_{c 2} \\
(\mathrm{kN})\end{array}$ & $N_{c 1} / N_{e}$ & $N_{c 2} / N_{e}$ \\
\hline ES4-4-71 & 3.5 & 306 & 0.957 & 1524 & 1636.9 & 1501.2 & 1.074 & 0.985 \\
\hline ES4-6-71 & 5.8 & 340 & 0.958 & 1895.6 & 1899.4 & 1827.7 & 1.002 & 0.964 \\
\hline ES6-4-71 & 3.5 & 306 & 0.909 & 1548.4 & 1546.3 & 1406.1 & 0.999 & 0.908 \\
\hline ES6-6-71 & 5.8 & 340 & 0.913 & 1844.9 & 1818.2 & 1722.7 & 0.986 & 0.934 \\
\hline ES8-4-71 & 3.5 & 306 & 0.863 & 1516.5 & 1455.4 & 1314.4 & 0.96 & 0.867 \\
\hline ES8-6-71 & 5.8 & 340 & 0.869 & 1717.3 & 1738.4 & 1619.2 & 1.012 & 0.943 \\
\hline
\end{tabular}

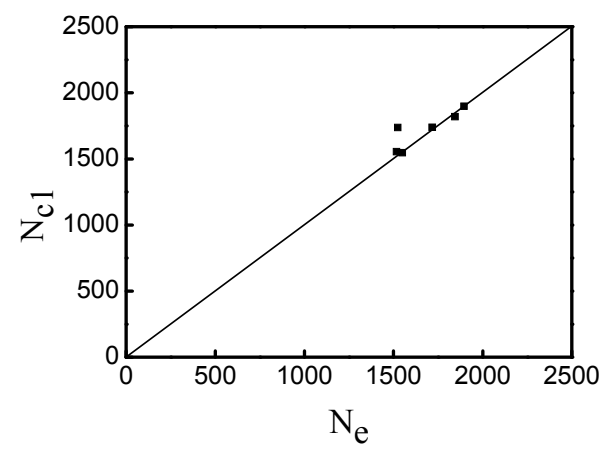

Figure 14. Comparisons of Finite Element Results Versus Test Results

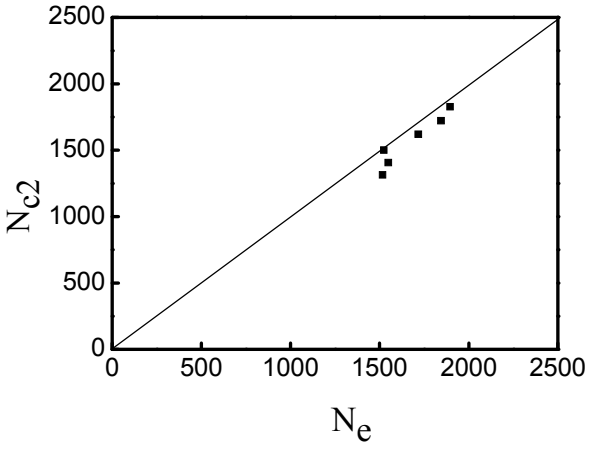

Figure 15. Comparison of Results of Simplified Method and Test Results 


\section{SIMPLIFIED METHOD OF BEARING CAPACITY}

Paper [1] proposed a simplified formula which is applied to predict the stability bearing capacity of CFST under bi-axial eccentric loading. The formula fits the condition that confinement coefficient $\xi=0.2 \sim 5$, yield strength of steel $f_{y}=200 \sim 700 \mathrm{MPa}$, cubic compressive strength of concrete $f_{c u}=30 \sim 120 \mathrm{MPa}$, steel ratio $\alpha=0.03 \sim 0.2$, slenderness ratio $\lambda=10 \sim 200$. Formula can be expressed as follows:

When $N / N_{u} \geq \varphi_{x}^{3} 2 \eta_{0}$

$\frac{N}{\varphi_{x y} N_{u}}+\frac{a}{d}\left[\left(\frac{M_{x}}{M_{u x}}\right)^{1.8}+\left(\frac{M_{y}}{M_{u y}}\right)^{1.8}\right]^{1 / 1.8} \leq 1$

When $N / N_{u}<2 \varphi_{x}^{3} \eta_{0}$

$-b \frac{N^{2}}{N_{u}^{2}}-c \frac{N}{N_{u}}+\frac{1}{d}\left[\left(\frac{M_{x}}{M_{u x}}\right)^{1.8}+\left(\frac{M_{y}}{M_{u y}}\right)^{1.8}\right]^{1 / 1.8} \leq 1$

Where $N_{u}$ is ultimate axial compressive strength of CFST; $\varphi_{x y}$ is stability coefficient of CFST under bi-axial eccentric loading; $M_{x}$ and $M_{y}$ are bending moment along the x-axis and y-axis respectively, which are given by $M_{x}=N e_{x}$ and $M_{y}=N e_{y}$; In this paper, the loading angle is $45^{\circ}$, and $e_{x}=e_{y}=50 \mathrm{~mm}$; $M_{u x}$ and $M_{u y}$ are flexural bearing capacity along the x-axis and y-axis respectively; Where a, b, c, d is calculating coefficient, $1 / \mathrm{d}$ is amplification factor of the bending moment considering the second-order effect. The detailed calculations of these parameters are given by paper [1].

The stability bearing capacity of test specimen was calculated with the simplified formula. Figures 15 shows calculation results $\left(N_{c 2}\right)$ and measured values $\left(N_{e}\right)$. The ratio of $N_{c 2} / N_{e}$ is listed in Table 2 whose average is 0.934 , standard deviation is 0.004 . It can be seen that the calculation results agree well with test data. It means that the simplified formula can be referred to calculate the bearing capacity of HCFST within the parameters of this test.

\section{PARAMETER ANALYSIS}

\section{$5.1 \quad$ Steel Ratio}

With a constant slenderness ratio and the steel ratio changing from $7 \%$ to $13 \%$, the ultimate bearing capacity of growth rates are $24.4 \%, 19.2 \%$ and $13.2 \%$ respectively. Table 2 shows that steel ratio is an important factor to influence ultimate bearing capacity. In addition, as slenderness ratio increases, the growth rate of the ultimate bearing capacity decreases.

\section{$5.2 \quad$ Slenderness Ratio}

Figure 16 shows the relationship of the load and slenderness ratios. When the steel ratio and eccentricity are constant, the bigger slenderness ratio is, the smaller the ultimate load bearing capacity is, because the stability coefficient $\varphi_{x y}$ reduces with the increasing of the slenderness ratio. In addition, Table 2 shows that with a constant slenderness ratio, the greater the steel ratio is, the bigger stability coefficient is. 
Figure 17 is the interaction curve of slenderness ratio and deflection. Steel ratio imposes little influence on the mid-span deflection when the slenderness ratio is 13.86 . With the increasing of slenderness ratio, the impact of steel ratio becomes obvious, because the bigger steel ratio and the greater stiffness of the specimen result in a small deflection of mid-span under the ultimate bearing capacity.

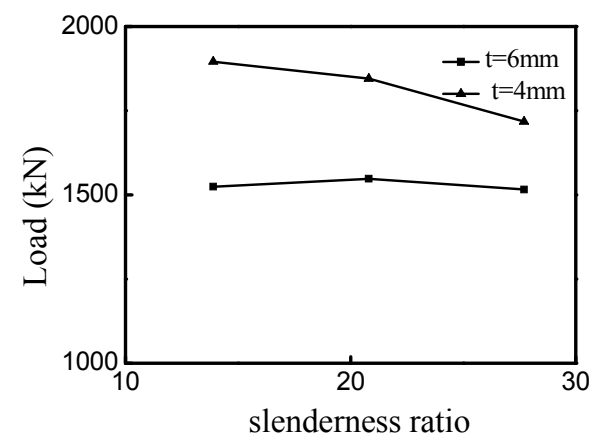

Figure 16. The Relationship between Load and Slenderness Ratios

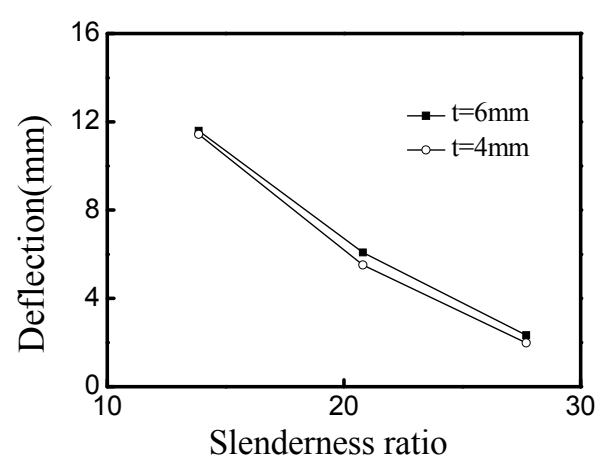

Figure 17 The Slenderness Ratio and Deflection Interaction Curves

\section{CONLUSIONS}

(1) The HCFST columns subjected to bi-axial eccentric loading failed to work because of instability, and showed a certain degree of ductility.

(2) The deflection curves of test fit the ideal half-sine-wave curves well. The strain curves of specimen are consistent with plane-section assumption.

(3) The ultimate bearing capacity of HCFST subjected to bi-axial eccentric loading resulted from analyzing with finite element software ABAQUS shows good agreements with the test data the numerical method is verified to be reliable in predicting the load versus deformation relationships.

(4) The simplified formula was used to calculate bearing capacity of the test specimens, and the calculation results agree well with test data. The simplified formula can be referred to calculate the bearing capacity of HCFST within the parameters of this test.

\section{ACKNOWLEDGEMENTS}

This project was supported by National Science Found of China (50678106), Shenyang Talent Development Fund (2009140403038) and Liaoning BaiQianWan Talents Program. 


\section{REFERENCES}

[1] Han, L.H., "Concrete-Filled Steel Tube Structure-Theory and Practice (Second Edition)", Science Press, 2008.

[2] Shosuke, M. and Keigo, T., "Design and Construction of Concrete-Filled Steel Tube Column System in Japan”, Earthquake Engineering and Engineering Seismology, 2003, Vol. 4, No. 1, pp. 51-73.

[3] Toshiaki, F, Akiyoshi, M, Isao, N. and Kenji, S., "Behavior of Eccentrically Loaded Concrete-Filled Steel Tubular Columns", Journal of Structural Engineering, 2004, Vol. 130, No. 2, pp. 203-212

[4] Han, L.H, Zbao, X.L. and Tao, Z., "Tests and Mechanics Model for Concrete-Filled and Beam-Columns", Steel and Composite Structures-An International Journal, 2001, Vol. 1, No. 1, pp. 51-74.

[5] Campione, G. and Scibilia, N., Beam-Column Behavior of Concrete Filled Steel Tubes", Steel and Composite Structures, 2002, Vol. 2, No. 4, pp. 259-276.

[6] Zegbicbe, J, Cbaoui K., "An Experimental Behaviour of Concrete-Filled Steel Tubular Columns", Journal of Constructional Steel Research, 2005, Vol. 61, No. 1, pp. 53-66.

[7] Mursi, M and Uy, B., "Behaviour and Design of Fabricated High Strength Steel Columns Subjected to Biaxial Bending, Part 1: Experiments", International Journal of Advanced Steel Construction, Hong Kong Institute of Steel Construction, 2006, Vol. 2, No. 4, pp. 286-315.

[8] Mursi, M. and Uy, B., "Behaviour and Design of Fabricated High Strength Steel Columns Subjected to Biaxial Bending, Part 2: Analysis and Design Codes", International Journal of Advanced Steel Construction, Hong Kong Institute of Steel Construction, 2006, Vol. 2, No. 4, pp. 316-54.

[9] Tokgoz, S. and Dundar, C., "Experimental Study on Steel Tubular Columns In-Filled with Plain and Steel Fiber Reinforced Concrete", Thin Walled Structure, 2010, doi:10.1016/j.tws.2010.01.009.

[10] Guo, L.H, Zhang, S.M. and Liu, J.P., "Experimental and Theoretical Analysis of Concrete-filled RHS Under Bi-axial Bending Moment”, Building Structure, 2008, Vol. 38, No. 3, pp. 22-28 (in Chinese).

[11] Bridge, R.Q., "Concrete Filled Steel Tubular Columns Report”, No. 8283, School of Civil Engineering, University, Sydney, Australia, 1976.

[12] Shakir-Khalil, H., "Further Tests on Concrete-Filled Rectangular Hollow-Section Columns", Structural Engineering, 1990, Vol. 68, No. 20, pp. 405-413.

[13] Al-Rodan, A. and Al-Tarawnab, S., "Fe Analysis of the Flexural Behavior of Rectangular Tubular Sections Filled with High-Strength Concrete", Emirates Journal for Engineering Research, 2003, Vol. 8, No. 1, pp. 71-77.

[14] Hu, H.T., Huang, C.S., Wu, M.H. and Wu, Y.M., "Nonlinear Analysis of Axially Loaded Concrete-Filled Tube Columns with Confinement Effect", Journal of Structural Engineering, 2003, Vol. 129, pp. 10, pp. 1322-1329.

[15] Hu, H.T. and Huang, C.S., "Finite Element Analysis of CFT Columns Subjected to An Anal Compressive Force and Bending Moment in Combination", Journal of Constructional Steel Research, 2005, Vol. 61, No. 12, pp. 1692-1712.

[16] Abdel-Rabman, N. and Sivakumaran, K.S., "Material Properties Models for Analysis of Cold-Formed Steel Members", Journal of Structural Engineering, 1997, Vol. 123, No. 9, pp. 1135-1143.

[17] Hillerborg, A., Modeer, M. and Petersson, P.E., “Analysis of Crack Formation and Crack Growth in Concrete by Means of Fracture Mechanics and Finite Elements, Cement and Concrete Research". 1976, Vol. 6, No. 6, pp. 773-782. 


\title{
LOAD-CARRYING CAPACITY AND PRACTICAL DESIGN METHOD OF WELDED HOLLOW SPHERICAL JOINTS IN SPACE LATTICED STRUCTURES
}

\author{
Xing Li \\ School of Civil Engineering, Zhejiang Shuren University, Hangzhou 310015, China \\ E-mail:xingli_sru@126.com
}

Received: 31 January 2010; Revised: 7 June 2010; Accepted: 25 June 2010

\begin{abstract}
A newly developed space structure, the polyhedron space frame based on the bubble theory, is adopted in Chinese National Swimming Center-the Water Cube for 2008 Beijing $29^{\text {th }}$ Olympic Games. Circular hollow sections, square hollow sections and rectangular hollow sections are employed as structural members, while welded hollow spherical joints are employed to connect the members. However, for welded hollow spherical joints connected with rectangular/square steel tubes, no previous study has been reported and no design criterion has been established. This paper investigates the structural behavior and load-carrying capacity of the joints subject to axial forces, bending moments and combined loading of the two. Based on the elastic-perfectly plastic model and the Von-Mises yield criterion, a finite element model for the analysis of the joints is established, in which the effect of geometric nonlinearity is taken into account. A major parametric study is then carried out employing this model. Experiments on ten typical full-scale joints are conducted to understand directly the structural behavior and the collapse mechanism of the joint, and also to validate the finite element model. A simplified theoretical solution is also derived for the loading-carrying capacity of the joint based on the punching shear failure model, and the basic form for the design equation is obtained. Finally, by utilizing the results from the simplified theoretical solution, finite element analysis and experimental study, the practical design method is established for the load-carrying capacity of the joints subject to axial forces, bending moments and the combined loading. The results from this study can be applied for direct design use, and also provide a reference for the revision of relevant design codes
\end{abstract}

Keywords: Space structure; welded hollow spherical joints; rectangular steel tubes; load-carrying capacity; finite element analysis; material nonlinearity; geometrical nonlinearity

\section{INTRODUCTION}

A newly developed space structure, the polyhedron space frame based on the bubble theory, is adopted in Chinese National Swimming Center-the Water Cube for 2008 Beijing $29^{\text {th }}$ Olympic Games. Water cube is located in the central area of the Olympic Green, it is a cubic with the size of $177 m \times 177 m \times 31 m$, with a total architectural area of $80,000 m^{2}$, as is shown in Figure 1 . It has a seating capacity of 11,000 plus 6000 temporary seats, and served as the centrepiece of 2008 Olympic Games venue for swimming, diving, synchronised swimming and water polo events. It also provided multifunctional recreation, sports and fitness services for the public after the Event. The project was completed on time, despite its complexity and a fast-track schedule of design and construction. The interior view of the project in construction is shown in Figure 2. Three types of steel hollow sections are applied in the space frame: the circular hollow section, the square hollow section and the rectangular hollow section. Herein, the circular hollow section is used in the internal members and the square or rectangular hollow section is used for members on the opposite surfaces of roofs and walls for convenience of connection with the ETFE air pillow (Figure 2). 
Two kinds of joint for rigid connection of the steel hollow section members are proposed by Chinese relevant Code or Specifications [1,2,3]: the welded hollow spherical joints (WHSJ), and the intersecting joint. The welded hollow spherical joints, which are popular for the domestic latticed structure for recent years, are mainly employed for connections of the members in this project. At present, studies on structural properties and load carrying capacity of WHSJ are aimed at the connections with the circular hollow pipes $[4,5,6]$. Ultimate bearing capacity of the WHSJ connected with circular pipes was investigated by Han et al [4]. The strength collapse criterion and ultimate criterion were put forward by the numerical analysis of the experimental data. It was indicated that the collapse was a strength problem under axial tension load while it was elasto-plastic buckling collapse under axial compressive load, and both failure mode are related to the design strength of the material. The practical design method was also proposed for the load-carrying capacity of the joints connected with circular hollow section members [5]. Based on the elastic-perfectly plastic model and the Von Mises yield criterion, a finite element model for analysis of welded hollow spherical joints subject to planar tri-directional loading of axial force or planar tri-directional combined loading of axial force and bending moment was established, the results showed that shows that load carrying capacity of welded hollow spherical joints mainly depends on the diameter ratio of steel tube and joint, the joint thickness and the load ratio [6]. Analytical and experimental researches on structural behavior of the intersecting joints were also performed during the past several decades and the design criterion were also proposed [7-12].

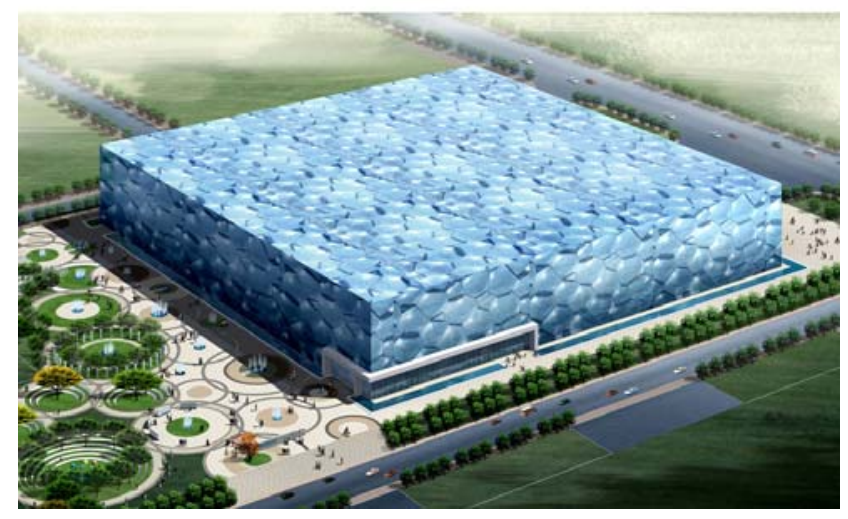

Figure 1. Water Cube for 2008 Beijing $29^{\text {th }}$ Olympic Games, China

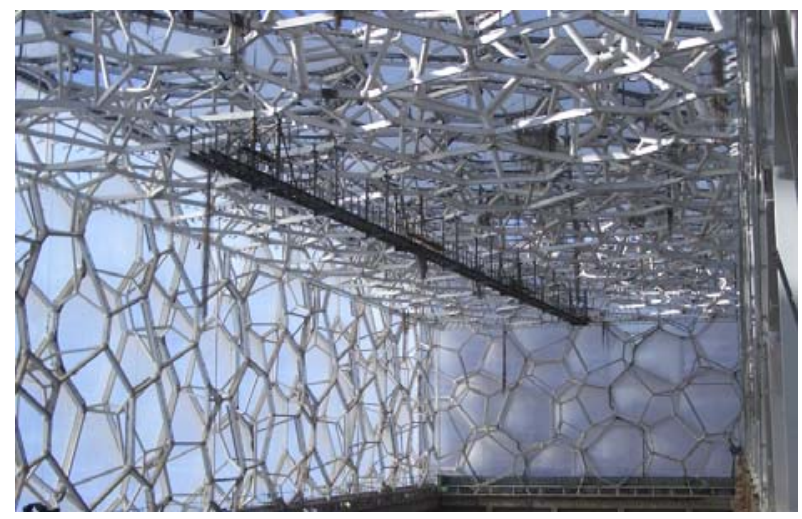

Figure 2. Interior view of Water Cube (in construction)

Whilst the WHSJ connected with rectangular hollow section members has been extensively applied in the practical engineering, few studies have explored the structural behavior of joint under load (axial force, bending moment, and the combination of the two, etc), and the practical design methods have received even less attention. In particular, members in Water Cube are subject to not only the axial force but also very large bending moment, where it is much different from members carrying mainly the axial force in common reticulated structure or trussed structure. Accordingly, the effects of pure bending moment or combined axial force and the bending moment should be taken into consideration for researches on load carrying capacity of WHSJ connected with rectangular/square section member and practical calculation method, besides the common joints subject only to axial force.

This paper is focused on the structural behavior and load carrying capacity of WHSJ connected with rectangular/square tubes subject to axial force, bending moment and combination of the two, based on the three ways: the finite element (FE) analyses, the experimental study and the simplified theoretical solution. The Practical design method for joint load-carrying capacity is also presented for direct engineering design use in the end. 


\section{FINITE ELEMENT ANALYSIS}

\section{$2.1 \quad$ Finite Element Model}

It is shown by the test [5] that the collapse load of WHSJ connected with circular pipes under uniaxial and biaxial force are very close. The design criterion in Chinese specification for trussed structure (JGJ 7-91) is also deduced from the uniaxial loading test. The whole FE model including the steel hollow tube and the spherical joint is established on the basis of uniaxial loading. The analyses are carried out using the commercial general purpose finite element package ANSYS. For the simplification of calculation, one quarter of the whole model is chosen for symmetry in the analyses. In order to make full comprehension of stress distribution along the thickness in the sphere when loading, and the stress concentration in the junction of the sphere and the tube, the eight-node isoparametric solid element SOLID45 is used for discretization of the model. The finite element mesh is shown in Figure 3.

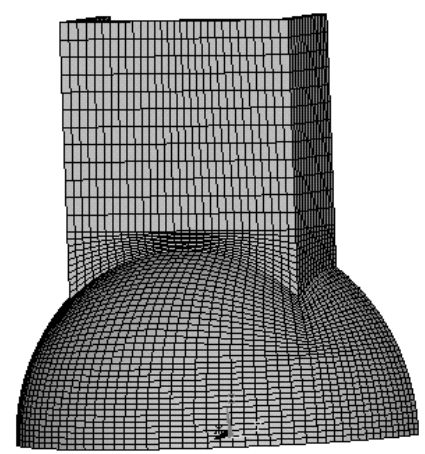

Figure 3. Finite Element Meshes

The perfect elasto-plastic stress-strain relation and the Von-Mise yielding criterion are adopted in the paper and the load-displacement curve is traced down by the arc-length iterative technology. The precision of the FE mesh is firstly investigated prior to the analyses. It is indicated that four-layered mesh along the thickness of the tube and the sphere, producing about 10,000 elements, will satisfy the precision. Mesh precision of the type is applicable to all the following analyses, except if it is specifically stated. Furthermore, influences of geometric nonlinearity on joints under combined axial tension or bending moment and under combined axial compression and bending moment are investigated through typical joint analyses. It shows good agreement with the results in Ref. [5]. Namely, geometric nonlinearity is favorable for joints under combined tension and bending, and unfavorable for joints under combined compression and bending. But the differences should be small as a whole. With a view to practicability and reliability in the practical engineering, the differences between tension and compression are usually disregarded as too large deformation is not allowed in the joints. The analyses are based consistently on the results of combined compression and bending. The peak value of the load-displacement curve is taken as the collapse load for the geometrically imperfect joints under combined axial compression and bending moment. It is expected to be conservative for joints under combing axial tension and bending moment, but is always on the safe side.

\subsection{Stress Distribution in the Punching Area of Joint subject to Axial Compression}

Structural properties of thirty groups of joints subject to axial compression are firstly investigated with the geometry covering a large extent: diameter of sphere ranging from $300 \mathrm{~mm}$ to $1000 \mathrm{~mm}$ : $300 \mathrm{~mm} \leqslant D \leqslant 1000 \mathrm{~mm}$, ratio of diameter to thickness of sphere up to $35: D / t \leqslant 35$, ratio of long side of tube to diameter of sphere ranging from 0.2 to $0.6: 0.2 \leqslant a / D \leqslant 0.6$, ratio of long side to short 
side of tube up to 0.2. To avoid buckling collapse of joint subject to compression, ratio of diameter to thickness of sphere is strictly defined according to the structural measures to the WHSJ specified in Chinese Specification of reticulated structure (JGJ 61-2003).

The WHSJ D500x18 connected with rectangular tube $300 \times 210$ is taken as the example for investigating stress distribution in the punching area (shown in Figure 4 (a)) where the steel tube meets the sphere. Normal stress $\sigma_{x}, \sigma_{y}, \sigma_{z}$ and shear stress $\tau_{x y}, \tau_{x z}, \tau_{y z}$ exist as a rule in the punching area. The stress distributions along the height of punching area are shown in Figure 4(b) together with the Von-Mises equivalent stress curve. It is revealed that normal stresses are usually larger compared to shear stresses, but are close to each other, and shear stresses $\tau_{x y}, \tau_{y z}$ are near to zero. The Von-Mises equivalent stress may be estimated by the following expression:

$$
\sigma_{\text {Mises }}=\sqrt{\frac{1}{2}\left[\left(\sigma_{x}-\sigma_{y}\right)^{2}+\left(\sigma_{y}-\sigma_{z}\right)^{2}+\left(\sigma_{z}-\sigma_{x}\right)\right]+3\left(\tau_{x y}^{2}+\tau_{x z}^{2}+\tau_{y z}^{2}\right)} \approx \sqrt{3} \tau_{x z}
$$

It is indicated that shear stress $\tau_{x z}$ is the dominant stress for punching shear design. Shear stress $\tau_{x z}$ curve is parallel on the whole to that of Von-Mises stress, and the Von-Mises stress is about $\sqrt{3}$ times of shear stress in the same node, which could also be observed from Figure 4 (b). It is also indicated from the analyses that stress distribution of joints under axial tension is consistent with that under axial compression, only different sign of stress produced, and shear stress $\tau_{x z}$ dominates also the punching shear design.

The main factors which have influence on load carrying capacity of joints under axial compression could be derived from the studies on collapse load of the 60 groups of joints, which are listed as follows: the outer diameter of sphere $D$, sphere thickness $t$, side lengths of tube $a, b$. The load carrying capacity increases with the increase of sphere thickness $t$ and side lengths of tube $a, b$, decreases with the increase of sphere diameter $D$, and is almost independent of the thickness of tube.

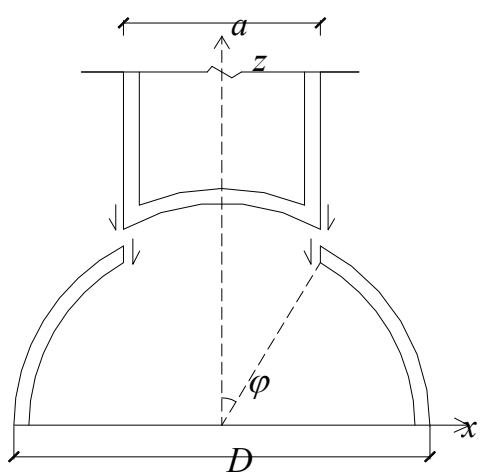

(a) Punching Section

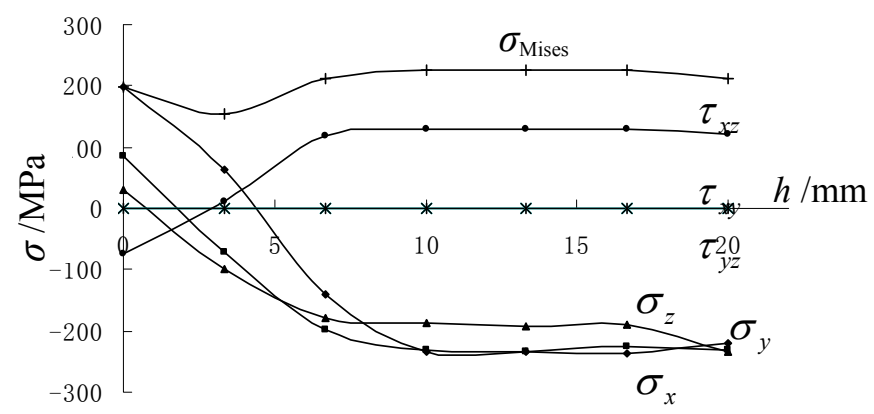

(b) Stress Distribution in Punching Section

Figure 4. Punching Section and Its Stress Distribution

\subsection{Joints subject to Combined Compression and Bending}

The geometries of models are in the same range as that studied before, typical joint with sphere D400x14 and rectangular tube 100x150 is also adopted as the illustrative example. The stress contour and deformation of the collapsed joint are shown in Figure 5 (a). Radial and hoop stresses of typical section numbered in Figure 5 (b), on external surface of the sphere, are illustrated in 
Figure 5. (c) $\sim 5(\mathrm{f})$ respectively. Herein, the tensile stress is marked outside the surface and the compressive stress is marked inside the surface. Moreover, curves are stress distribution for the load $40 \mathrm{kN}$ time FE result, and the dots are stress distribution or the load $40 \mathrm{kN}$ time test result. As the load acts antisymmetrically about Sec.3 (Figure 5 (b)) on the joint, stresses in the section are so small as to be omitted, the distribution is not given in the figures. In the adjacent area where the sphere and the tube meet, not only membrane stress but also very large bending stress is induced for joint under axial compression. The effect of stress concentration in the area above is visible, area A near the conjunction is concave and area $\mathrm{B}$ a little far from the conjunction is convex, as is shown in Figure 5 (a). For most area of the sphere, the radial stress is compressive, and the hoop stress is tensile (compressive only in local area near the conjunction). The external surface near the conjunction yields originally in the course of loading, bringing forth plastic area which is expanded to the inner surface gradually. Area B turns to be plastic with the increase of load, and the plasticity is expanded progressively to area $\mathrm{A}$. When plastic area $\mathrm{A}$ is expanded to the inner surface and coincides with plastic area $\mathrm{B}$, large deformation is induced in the sphere, and the joint reaches its ultimate limit state.

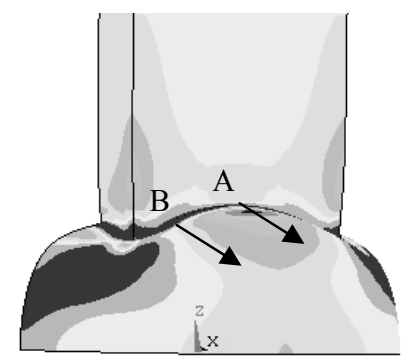

(a) Collapsed Deformation and Stress Contour

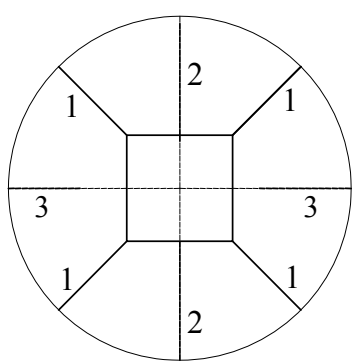

(b) Section Number

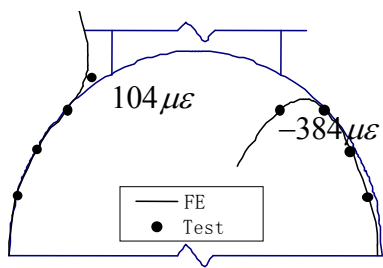

(c) Sec.1 Outside Radial Stress

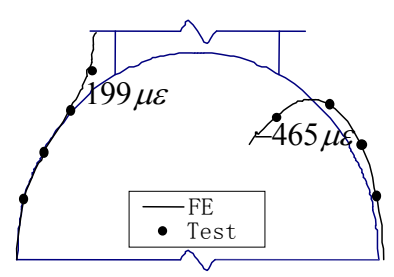

(d) Sec.1 Outside Hoop Stress

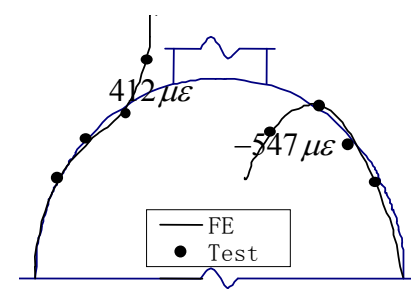

(e) Sec. 2 Outside Radial Stress

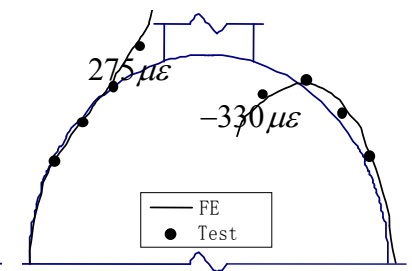

(f) Sec.2 Outside Hoop Stress

Figure 5. Stress Distribution and Deformed Shape of Joint under Combined Compression and Bending

\subsection{Correlation between Axial Compression and Bending Moment}

Seven groups of typical joints (listed in Figure 6) are chosen for analyses among 60 groups referred in Section 2.2. Eight to nine combinations of axial force and bending moment are specified for each group, then structural behavior is investigated for joint subject to combined axial compression and bending moment, i.e. various eccentricities $e$ are taken into consideration when loading, $e=M / N$, where, $M$ is the bending moment and $N$ is the axial force. Different combinations of loads are applied at the end of the tube. As pure bending might be regarded as the combination of axial tension and axial compression, the combined axial compression and bending could be consequently regarded as the combination of axial tension and axial compression, and also as the transition from axial compression to pure bending. The stress distribution is also very similar from the FE results. 


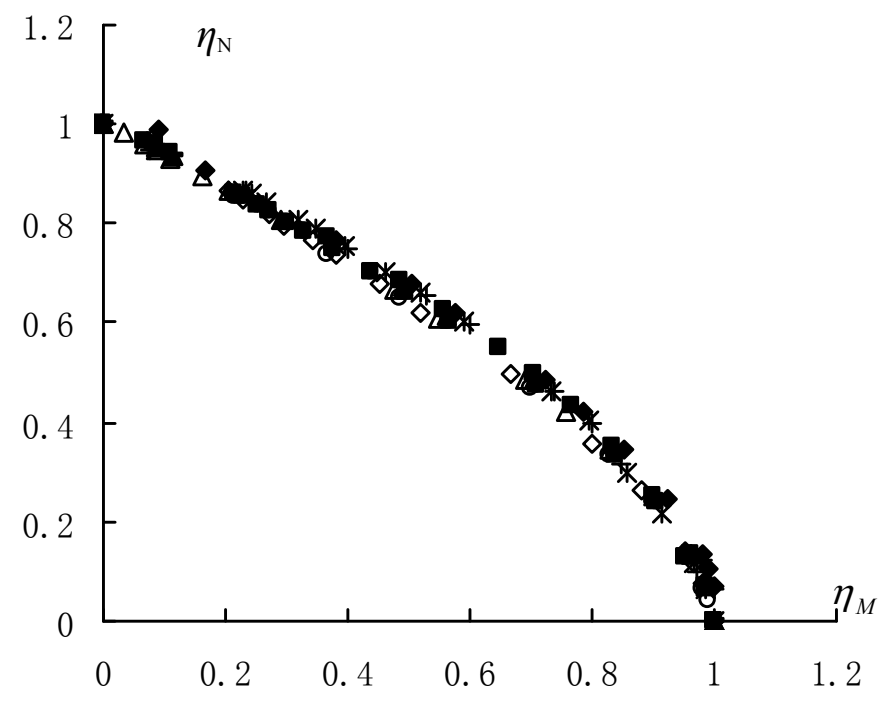

$$
\begin{aligned}
& \diamond \mathrm{S} 350 \times 14 \mathrm{~T} 200 \times 200-\mathrm{S} 400 \times 14 \mathrm{~T} 150 \times 100 \\
& \Delta \mathrm{S} 500 \times 20 \mathrm{~T} 270 \times 180 \Delta \mathrm{S} 500 \times 20 \mathrm{~T} 300 \times 200 \\
& \mathrm{OS} 500 \times 18 \mathrm{~T} 300 \times 210 \bullet \mathrm{S} 500 \times 16 \mathrm{~T} 300 \times 300 \\
& \text { - } \mathrm{S} 550 \times 16 \mathrm{~T} 300 \times 300 * \mathrm{~S} 600 \times 16 \mathrm{~T} 300 \times 300 \\
& -\mathrm{S} 600 \times 20 \mathrm{~T} 300 \times 270-\mathrm{S} 600 \times 20 \mathrm{~T} 300 \times 400 \\
& +\mathrm{S} 650 \times 20 \mathrm{~T} 300 \times 400
\end{aligned}
$$

Figure 6. Dimensionless Axial Force - Bending Moment Correlation for Joints under Combined Compression and Bending (Note: S- Hollow Sphere; T-Rectangular Tube)

For joint under combined compression and bending, the correlation between axial compression and bending moment is the issue which we most concerned with. Only if making the correlation clear could we provide further evidence for the setup of practical calculation method. The axial compression $N$ and bending moment $M$ of joint when collapsed are made dimensionless using the relevant load carrying capacity $N_{\max }$ and $M_{\max }$ (both FE results). The dimensionless parameters $\eta_{N}, \eta_{M}$ are introduced as Expression (2).

$\eta_{N}=\frac{N}{N_{\max }}, \quad \eta_{M}=\frac{M}{M_{\max }}$

The correlation of dimensionless axial compression-bending moment is shown in Figure 6, where $\eta_{N}, \eta_{M}$ are the vertical and horizontal coordinates respectively. It may be found that the results data are concentrated in the same curve for various joints with various eccentricities. That is to say, correlations of axial force and bending moment among different joints are consistent, and the correlations are independent of joint geometries, including sphere diameter and thickness, side length of tube. The property shows good agreement with that of WHSJ connected with circular pipe [5]. It is so important as to simplify, to a large extent, the calculation method of load carrying capacity of joint subject to combined axial force and bending moment. 


\section{EXPERIMENTAL STUDY}

\subsection{General of the Experiment}

Experiments on ten typical full-scale joints as are listed in Table 1 are conducted to understand directly the structural behavior and the collapse mechanism of the joint connected with rectangular tube, and to validate the finite element model, and also to provide the most reliable proofs for practical calculation method. Two types of welded hollow sphere are adopted, where Specimen 1 and Specimen 2 are identical in geometry with bending moments in different orientation acting on them. As the experiment is carried out primarily to investigate the collapse mechanics of joints, and meanwhile the thickness of steel tube has little influence on joint load carrying capacity, steel tubes with larger wall thickness (steel tube geometries: $150 \mathrm{~mm} \times 100 \mathrm{~mm} \times 16 \mathrm{~mm}, 200 \mathrm{~mm} \times 200 \mathrm{~mm} \times$ $16 \mathrm{~mm}, 300 \mathrm{~mm} \times 200 \mathrm{~mm} \times 22 \mathrm{~mm}, 300 \mathrm{~mm} \times 300 \mathrm{~mm} \times 22 \mathrm{~mm}$, welded with four steel plates) are adopted to assure that the steel tubes would not collapse prior to the sphere. Four full-scale specimens are load with different eccentricities, where Specimen 3 and 5 is loaded with no eccentricity, i.e., axial compression. As experiment with infinite eccentricity is impossible to perform in the laboratory, pure bending loading test is not carried out here.

Experiment is conducted with 500-ton compression testing machine in Civil Engineering Testing Center of Zhejiang University. Overall view of the experimental setup is shown in Figure 7. Schematic loading and testing station are shown in Figure 8. Various eccentricities are produced by changing the loading position on the specimen. Rigid box beams are welded to both ends of the specimen to ensure that the combined axial force and bending moment acting on the sphere are accurately simulated by eccentric loading on the box beams. Strain rosettes are arranged on the surface of sphere to measure the spherical outside strains, and strain gauges are arranged longitudinally on the tube surface to verify whether the loads are centrally directed and check the eccentricities. In addition, the dial indicators are used to measure displacements in various positions of the specimen.

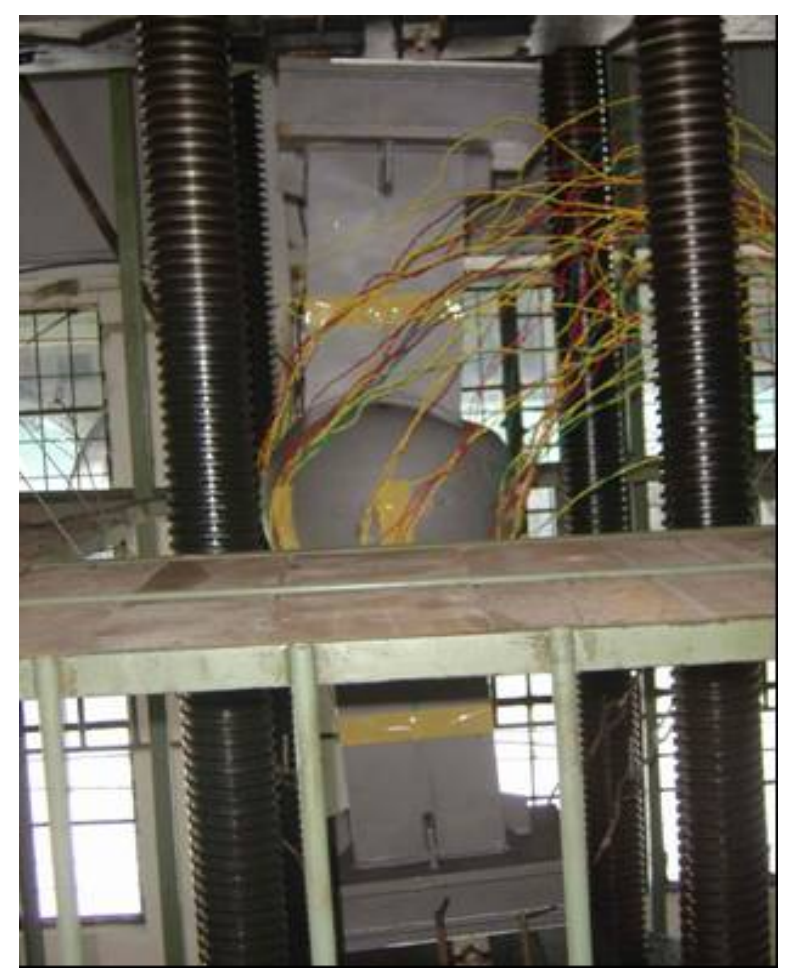

Figure 7. Overall View of the Experiment 
Table 1. Specimen Geometries and Summary of Experimental Results

\begin{tabular}{cccccccccc}
\hline \multirow{2}{*}{$\begin{array}{c}\text { Specimen } \\
\text { No. }\end{array}$} & $\begin{array}{c}\text { Sphere } D \times t \\
(\mathrm{~mm} \times \mathrm{mm})\end{array}$ & $\begin{array}{c}\text { Tube } a \mathrm{x} b \\
(\mathrm{~mm} \times \mathrm{mm})\end{array}$ & $\begin{array}{c}\text { Moment } \\
\text { direction }\end{array}$ & $\begin{array}{c}e \\
(\mathrm{~mm})\end{array}$ & $\begin{array}{c}F_{s} \\
(\mathrm{kN})\end{array}$ & $F_{y}(\mathrm{kN})$ & $F_{s} / F_{y}$ & & \\
\hline 1 & $\mathrm{D} 400 \times 14$ & $150 \times 100$ & Dir.1 & 160 & 240 & 251 & 200 & 0.96 & 1.2 \\
2 & $\mathrm{D} 400 \times 14$ & $150 \times 100$ & Dir.2 & 160 & 282 & 294 & 256 & 0.96 & 1.10 \\
3 & $\mathrm{D} 400 \times 14$ & $200 \times 200$ & Dir.3 & 0 & 1910 & 1846 & - & 1.03 & - \\
4 & $\mathrm{D} 400 \times 14$ & $200 \times 200$ & Dir.4 & 160 & 760 & 763 & 661 & 0.996 & 1.15 \\
5 & $\mathrm{D} 500 \times 20$ & $300 \times 200$ & Dir.3 & 0 & 3500 & 3326 & 3308 & 1.05 & 1.06 \\
6 & $\mathrm{D} 500 \times 20$ & $300 \times 200$ & Dir.2 & 60 & 2260 & 2405 & 2216 & 0.92 & 1.02 \\
7 & $\mathrm{D} 500 \times 20$ & $300 \times 300$ & Dir.1 & 180 & 2095 & 2073 & 1853 & 1.01 & 1.13 \\
8 & $\mathrm{D} 600 \times 20$ & $300 \times 300$ & Dir.1 & 40 & 3080 & 3270 & 3006 & 0.94 & 1.02 \\
9 & $\mathrm{D} 600 \times 20$ & $300 \times 300$ & Dir.1 & 100 & 2400 & 2481 & 2251 & 0.97 & 1.07 \\
10 & $\mathrm{D} 600 \times 20$ & $300 \times 300$ & Dir.4 & 30 & 3350 & 3410 & 3160 & 0.98 & 1.06 \\
\hline
\end{tabular}

Note: Dir.1-along tube short side; Dir.2-along tube long side; Dir.3-along compression;

Dir.4-along tube diagonal line.

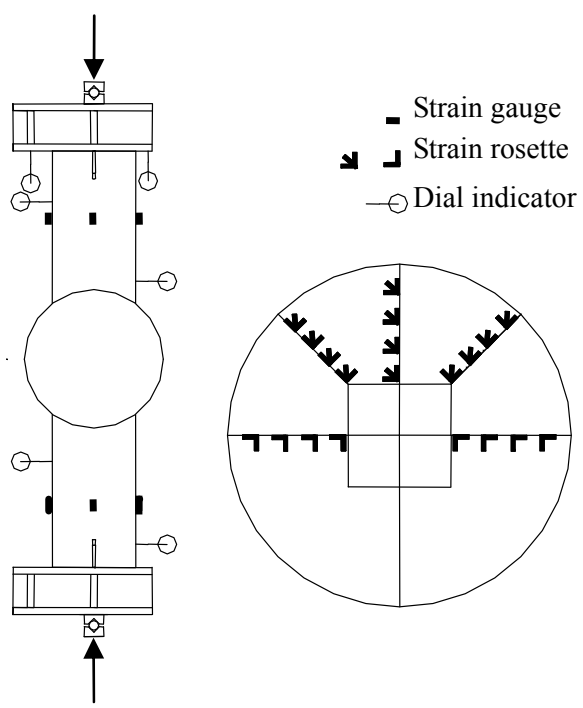

Figure 8. Schematic of Loading and Instrumentation

\subsection{Experimental Results and Analyzing}

Large numbers of data for strain and displacement are recorded during the testing. Herein, specimen 4 is only used for short as the illustrative example to elucidate the main testing results. Load-displacement curves for specimen 4 are shown in Figure 9 with $\theta$ as horizontal coordinates. The nominal angular displacement $\theta$ of joint under bending moment is estimated by the measured translational displacement with the dial indicator, provided that no bending deformation of steel tube is induced during loading. It could be observed from the curves that the displacement approximately increases linearly with the increase of load in the initial stage of loading, and the displacement subsequently increases nonlinearly. Plasticity in local area of the hollow sphere is meantime induced and the plastic area is enlarged gradually. The displacement increase rapidly with small increase of loading in the final stage, and continues to increase rapidly with the decrease of loading after collapse. As the experiment is conducted without servo loading, the curves during unloading are not recorded. Deformed shape of specimen 1 after failure is shown in Figure 10. It could be obviously observed from the photo that collapse of joint is chiefly induced by the large 
plastic deformation in local compressive area of spherical wall where the steel tube and hollow sphere meet. Great concave deformation is very clear as is shown in the photo. The collapsed load of specimens is listed in Table 1 , where $e$ indicates the eccentricity, $F_{s}$ indicates result from testing, and $F_{y}$ indicates finite element result.

Specimens are also simulated for finite element analyses. Perfect elasto-plastic stress-strain relation is adopted in the preceding parametric analyses, and herein, the practical stress-strain relation (stress stiffness stage included) obtained by the material testing is adopted for accurate simulation of the experiment. In addition, the eccentric load acting on the end of specimen is always parallel to the axis of the steel tube in the preceding parametric analyses, and the eccentricity keeps unchanged during loading, i.e., the bending moment acting on joint keeps unchanged. This is actually true in the practical engineering. Nevertheless, the eccentric load acting on the end of specimen is always vertically downwards during the experiment, and the eccentricity would increase with the increasing deflection, corresponding to an additional eccentricity introduced. Accordingly, the actual bending moment acting on joints increases constantly. Two kinds of simulations of loading for each specimen are carried out in order to take account of the influence of additional eccentricity in the finite element analysis. The eccentric load acting on specimen is made parallel to the axis of the steel tube in the first simulation (i.e. taking no additional eccentricity into account), and the specimen is loaded vertically downwards in the end for the second simulation (i.e. taking account of the additional eccentricity). Load-displacement curves for specimen 1 of two types of loading are shown in Figure 9. In the initial stage of loading, the deformation in specimen is small, and the two curves almost coincide. With increasing loading, large deformation is induced in specimen, and the effect of additional eccentricity becomes notable. Load carrying capacity of joint without regard to additional eccentricity is obvious higher than that with regard to additional eccentricity. Moreover, the FE load-displacement curve agrees well with the experimental results in the initial loading stage. With increasing loading, differences between two curves become larger and larger especially in the elasto-plastic stage. It is probably because elasto-plastic stress-strain relation adopted in finite element analysis is impracticable to be exactly equal to that of the tensile specimen in the testing. Two groups of FE collapse load of specimens are listed in Table 1. The additional eccentricity has little influence on joint under axial compression. For joint under combined axial compression and bending, load carrying capacity without regard to additional eccentricity is obviously improved, averagely by $15 \%$.

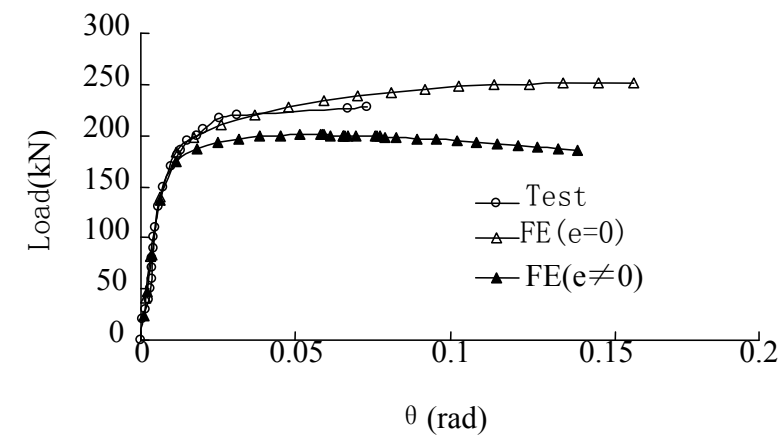

Figure 9. Load-displacement Curves for Specimen 4 after Failure
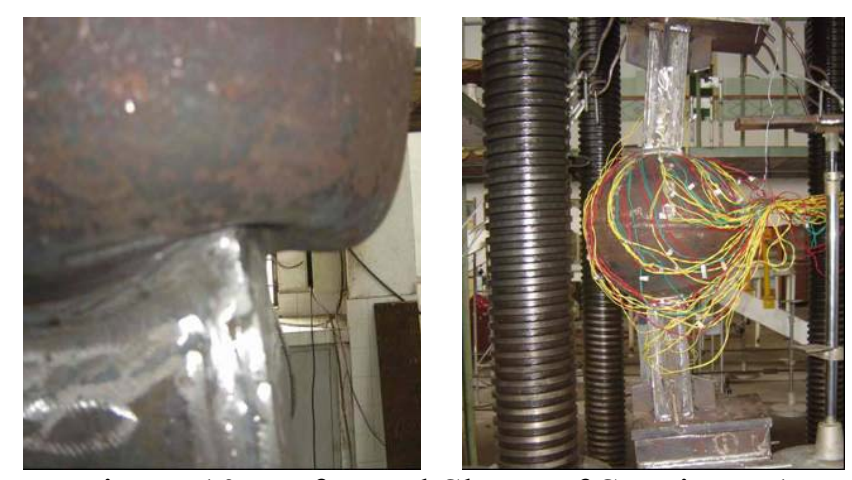

Figure 10. Deformed Shape of Specimen 1

It is shown in Table 1 that the FE collapse load of specimen is close to that from experiment. But, the experimental result is slightly larger than that from FE results of joint with regard to additional eccentricity. Main possible factors making the differences are as follows: (1) Fillet welds besides butt welds exist in the conjunction where the tube and the hollow sphere meet, whereas the effects are disregarded in the FE simulations; (2) The material strength of weld is normally higher than that of the parent material, whereas strengths of both types are regarded to be identical in FE analysis. 
Furthermore, material properties of hollow sphere may vary during machining, and the testing instruments and measurements may also introduce certain errors, making differences between them. As a whole, the FE model established in the paper can present accurately structural property and collapsed load, thus be used for parametric analyses on a large scale. It should be pointed out that the additional eccentricity is supposed to be regarded, for accurate simulation of experimental condition, for joint subject to combined axial compression and bending (additional eccentricity disregarded for joint under axial compression). Additional eccentricity may be disregarded for parametric analysis of practical engineering.

\section{SIMPLIFIED THEORETICAL SOLUTION}

\subsection{Simplified Theoretical Solution of Joint subject to Axial Compression}

It is indicated by the previous studies that ultimate collapse of WHSJ with circular pipe has the feature of punching shear failure [5]. The WHSJ with rectangular tube is addressed in the paper, of which stress distribution in the area where the tube and hollow sphere meet is even more complicated. It has been shown from stress analyses in Section 3 that ultimate collapse of joint of such type has also the feature of punching shear failure. Simplified theoretical solution in the paper is based accordingly on punching shear failure model. Shear stress in punching section may be assumed to be $k f$ for hollow spherical joint (as is shown in Figure 11(a)) under axial compression, where, $f$ is the design tensile strength of joint material, and $k$ is a coefficient to be specially determined in Section 4.2. When side length of tube is less small, punching shear failure is greatly obvious. On basis of Von-Mises yield criterion, failure shear stress tends to be $f / \sqrt{3}$, i.e., $k=1 / \sqrt{3}$ ( $k=1 / 2$ base on Tresca yield criterion). When side length of tube is quite large, especially identical in geometry to sphere diameter, tensile stress (or compressive stress) instead of shear stress will be dominant, and the value tends to be $f$.

On ground of FE stress analysis, WHSJ with rectangular tube under axial compression yield originally in the corners, inducing plastic area, and plastic area are expanded gradually to the side. Expanding course of plasticity from the corners to the side centers is shown in Figure 11 (b). Figure 11 (c) shows the final stage of expanding plasticity with whole section permeated. The dimensionless parameters are introduced,

$\xi=\frac{x}{a}, \quad \eta=\frac{y}{b}, \quad \Delta=\frac{a}{b}$

where, $a, b$ is the side length of rectangular tube; $\Delta$ is the aspect ratio of rectangular tube ( $\mathrm{a}=\mathrm{b}$, square tube).In the expanding stage of plasticity, the relation between axial compression acting on joint and shear stress in punching section is given by:

$N=4 k\left[a \int_{\frac{1}{2}}^{\xi} f t d \xi+b \int_{\frac{1}{2}}^{\eta} f t d \eta\right]$

where, $t$ is the wall thickness of hollow sphere. In the final stage when plasticity expands to the whole area, the axial compression reaches its maximum value, in which $\eta$ varies from $1 / 2$ to 0 and $\xi$ varies from $1 / 2$ to 0 .

$N=N_{\max }=k 2(a+b) t f$ 


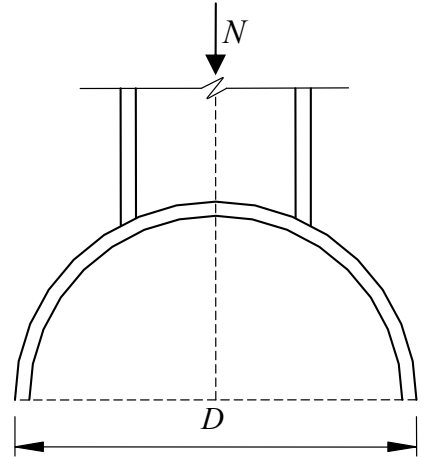

(a) Joint under Axial Compression (b)
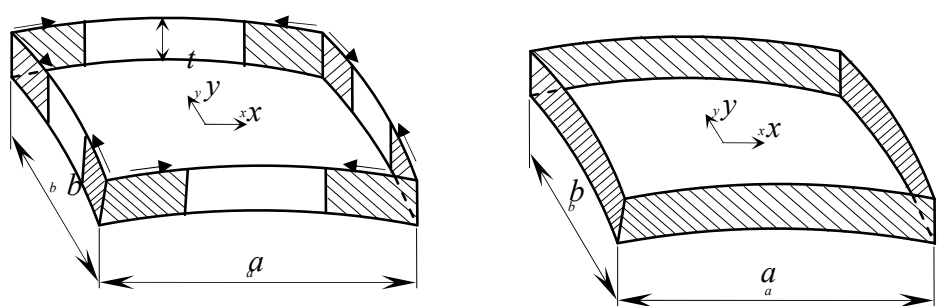

(b) Plastic Area Expansion (c) Final Stage of Plastic Expansion

Figure 11. Model for Simplified Theoretical Solution for Axial Force

\subsection{Simplified Theoretical Solution of Joint subject to Combined Axial Compression and Bending}

For joint under combined axial compression and bending, as is shown in Figure 12a ( $M$ acts in the plane where long side $a$ of tube lies), the expanding course of shear stress in punching section may be divided into two stages. In the first stage, upward shear stress is induced in part area of the punching section which is numbered 1 and without shadow, as is shown in Figure 12b-1, while downward shear stress is induced in other part which is numbered 2 and with shadow. The boundary area of upward and downward shear stress depends on the ratio of axial compression and bending moment.

Based on the force equilibrium in the first stage, bending moment $M$ is resultant from the upward shear stress in Area 1 and downward shear stress in Area 2, and the remainder downward shear stress composes the axial compression $N$. the axial compression $N$ and the bending moment $M$ could be easily obtained by the definite integral of shear stress in punching section.

$$
\begin{aligned}
& N=k 4 t f\left(\frac{1}{2} a+b \eta\right) \\
& M=4 k t f \int_{\eta}^{\frac{1}{2}} \frac{a}{2} b d \eta
\end{aligned}
$$

where, $a$ is the long side length of rectangular tube in the plane where the moment acts, $b$ is the out of plane length.

When the ratio $M / N$ of bending moment to axial compression increases, upward shear stress in Area 1 expands gradually from the corners to the side centers, till the shear stress in the side turns wholly upward, as is shown in Figure 12 b-2. This is the dividing line between the first and second stage. When the ratio $M / N$ further increase, upward shear stress turns around the corner to adjacent side and expands to the side center, as is shown in Figure $12 \mathrm{c}-1$. Herein, the second stage is reached, and the relation between the resultant force $N, M$ and the shear stress in punching section may be derived from the following expressions. 


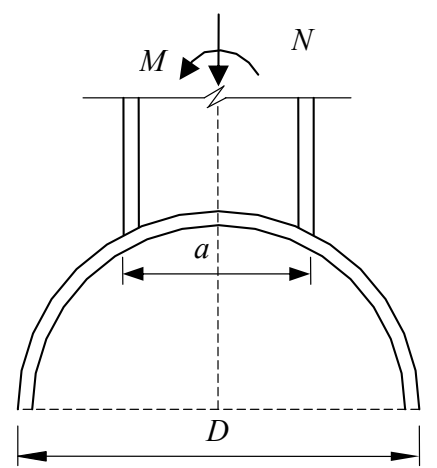

(a) Joint under Combined Axial Compression and Bending

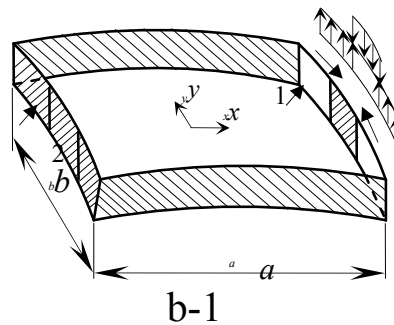

(b) First Stage

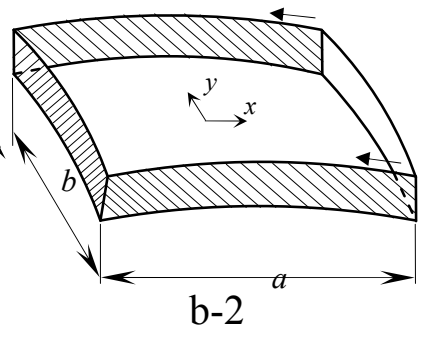

b-2
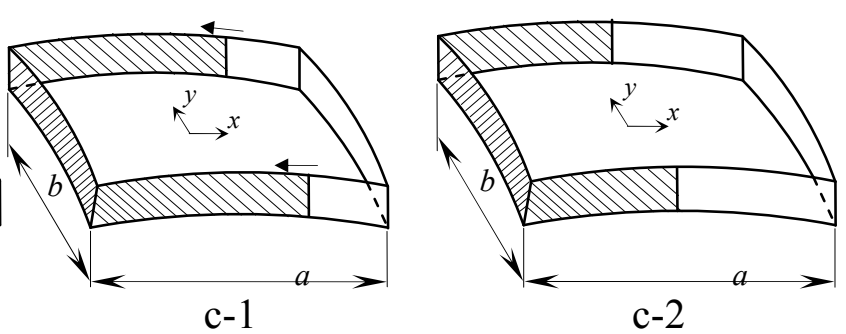

(c) Second Stage

Figure 12. Model for Simplified Theoretical Solution for Combined Axial Force and Bending Moment

$N=k 4 a t f \xi$

$M=4 k t f\left(\int_{0}^{\frac{1}{2}} \frac{a}{2} b d \eta+\int_{\xi}^{\frac{1}{2}} a \xi a d \xi\right)$

When dividing line lies in the middle of the section side, as in shown in Figure $12 \mathrm{c}-2$, the bending moment reaches its maximum value, namely pure bending without axial force.

$M=M_{\max }=4 k t f\left(\int_{0}^{\frac{1}{2}} \frac{a}{2} b d \eta+\int_{0}^{\frac{1}{2}} a \xi a d \xi\right)=a b k t f\left(1+\frac{1}{2} \Delta\right)$

The dimensionless parameters are introduced,

$\eta_{N}=\frac{N}{N_{\max }}, \quad \eta_{M}=\frac{M}{M_{\max }}$

In the first stage, the following expressions can be deduced from Eq. 5, 6, 7, 8, 10 ,

$$
\begin{aligned}
& \eta_{N}=\frac{N}{N_{\max }}=\frac{2 \eta+\Delta}{1+\Delta} \\
& \eta_{M}=\frac{M}{M_{\max }}=\frac{1-2 \eta}{1+\frac{1}{2} \Delta}
\end{aligned}
$$


In the first stage, the following expressions can be deduced from Eq. 5, 8, 9, 10,

$$
\begin{aligned}
& \eta_{N}=\frac{N}{N_{\max }}=\frac{2 \xi}{1+\frac{1}{\Delta}} \\
& \eta_{M}=\frac{M}{M_{\max }}=1-\frac{2 \Delta \xi^{2}}{1+\frac{\Delta}{2}}
\end{aligned}
$$

The relation between $\eta_{N}$ and $\eta_{M}$ may be derived from Eq. $12 \sim 15$.

$$
\begin{aligned}
& \left\{\begin{array}{cc}
\eta_{N}=1-\frac{1+\frac{\Delta}{2}}{1+\Delta} \eta_{M} & 0 \leq \eta_{M} \leq \frac{1}{1+\frac{\Delta}{2}} \\
\eta_{N}=\frac{1}{1+\frac{1}{\Delta}} \sqrt{\left(\frac{2}{\Delta}+1\right)\left(1-\eta_{M}\right)} \frac{1}{1+\frac{\Delta}{2}}<\eta_{M} \leq 1
\end{array}\right. \\
& \begin{array}{l}
0.8 \\
0.4 \\
0.2 \\
0
\end{array}
\end{aligned}
$$

Figure 13. Dimensionless Axial Force - Bending Moment Correlation for Joints under Combined Compression and Bending (Note: S- hollow Sphere; T-rectangular Tube)

It is indicated from Eq. 16 that, for hollow sphere joint under combined axial compression and bending in given aspect ratio $\Delta$ of tube, the load carrying capacity correlation between axial compression and bending moment can be expressed as a line combined with a parabolic curve with $\eta_{M}=1 /(1+\Delta / 2)$ as the dividing point. Dimensionless axial force-bending moment correlation for joints under combined compression and bending is shown in Figure 13, where the simplified theoretical solution is illustrated for $\Delta=1.5$ as example. Meanwhile, large numbers of FE results are also expressed in Figure 13. It can be found that results of the two show good agreement. In practice, when the ratio $\Delta$ varies in the common range, curves determined by Eq. 16 are nearly equal. The FE results for various ratios $\Delta$ are actually covered in Figure 13. The correlation of axial force-bending moment is proved theoretically to be independent of the geometric parameters of joint on the one hand, and on the other hand FE results are also proved to be rational. It can also be found from Eq. 16 and Figure 13 that the axial compression decreases with the increase of bending moment. 
It is found out from Eq. 12, 13 that the relevant expression about $\eta$ should be primarily solved to obtain $\eta_{N}, \eta_{M}$ in the first stage. Eq. 6 and Eq. 7 may be rewritten as:

$$
\begin{aligned}
& k t f=\frac{N}{2 a+4 b \eta} \\
& k t f=\frac{M}{a b-2 a b \eta}
\end{aligned}
$$

Combined Eq. 17 and Eq. 18, expression about $\eta$ can be derived:

$$
\eta=\frac{N-\frac{2 M}{b}}{2 N+\frac{4 M}{b}}
$$

It is indicated in the above equation that $\eta$ is equal to $1 / 2$ for $M=0$, and $\eta$ is equal to 0 for $N=2 M / b$. Thereby, the first stage is characterized by $N \geq 2 M / b$. It is found out from Eq. 14, 15 that the relevant expression about $\xi$ should be primarily solved to obtain $\eta_{N}, \eta_{M}$ in the second stage. Eq. 8 and Eq. 9 may be rewritten as:

$$
\begin{aligned}
& k t f=\frac{N}{4 a \xi} \\
& k t f=\frac{M}{a b+\frac{1}{2} a^{2}-2 a^{2} \xi^{2}}
\end{aligned}
$$

Combined Eq. 20 and Eq. 21, expression about $\xi$ can be obtained:

$$
\xi=-\frac{M}{N a}+\sqrt{\left(\frac{M}{N a}\right)^{2}+\left(\frac{1}{2 \Delta}+\frac{1}{4}\right)}
$$

For joint under combined axial force $N$ and bending moment $M$, it should primarily determine which stage the joint falls into based on $N, M$ and side length $b$ of tube. For $N \geq 2 M / b$, the joint belongs to the first stage, and for $N<2 M / b$, the joint belongs to the second stage. In the first stage, expression about $\eta$ is determined by Eq. 19, and the corresponding expressions about $\eta_{N}, \eta_{M}$ are obtained accordingly by Eq. 12 and Eq. 13. In the second stage, expression about $\xi$ is determined by Eq. 22 , and the corresponding expressions about $\eta_{N}, \eta_{M}$ are obtained accordingly by Eq. 14 and Eq. 15. Finally, the load carrying capacity of joint may be determined based on the axial force:

$$
N=\eta_{N} k 2(a+b) t f
$$

and may also be determined based on the bending moment:

$$
M=\eta_{M} k\left(1+\frac{1}{2} \Delta\right) a b t f
$$


The two expressions are equivalent. The physical meanings of $\eta_{N}, \eta_{M}$ are rather definite from Eq. 23 and 24, where $\eta_{N}$ is the influence coefficient of axial force with regard to bending moment, and $\eta_{M}$ is the influence coefficient of bending moment with regard to axial force.

\subsection{Simplified Theoretical Solution of Joint subject to Combined Axial Compression and Biaxially Equivalent Bending}

For joint under combined axial compression and biaxially equivalent bending, the upward shear stress is induced in part area of the punching section (numbered 1 and without shadow, shown in Figure 14b-1) and spreads from the corner to the midpoints, while downward shear stress is induced in other part (numbered 2). The boundary area of upward and downward shear stress depends on the ratio of axial compression and bending moment. For case $a=b$, the equivalent moment $M$ acts in the diagonal plane of the section. Based on the force equilibrium, bending moment $M$ is resultant from the upward shear stress in Area 1 and downward shear stress in Area 2, and the remainder downward shear stress composes the axial compression $N$. The axial compression $N$ and the bending moment $M$ could be easily obtained by the definite integral of shear stress in punching section.

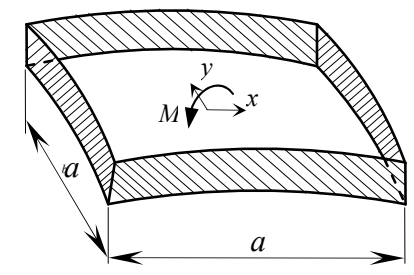

(a)

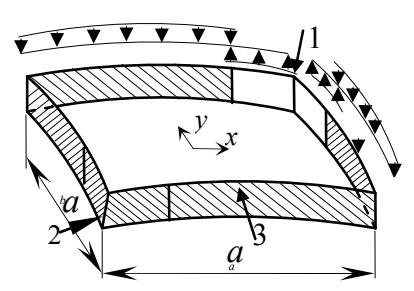

(b)

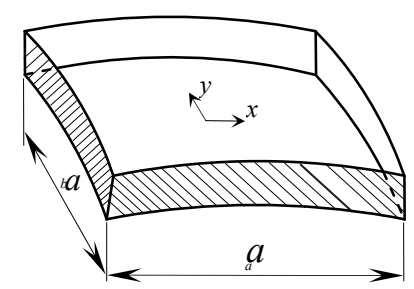

(c)

Figure 14. Model for Simplified Theoretical Solution for Combined Axial Force and Biaxially Rquivalent Bending Moment

$$
\begin{aligned}
& N=k 4 a t f \int_{-\frac{1}{2}}^{\xi} d \xi=k 4 a t f\left(\xi+\frac{1}{2}\right) \\
& M=k 4 \int_{\xi}^{\frac{1}{2}}\left(\frac{1}{2}+\xi\right) a^{2} t f d \xi \sin 45^{\circ}=k \sqrt{2} a^{2} t f\left(\frac{3}{4}-\xi-\xi^{2}\right)
\end{aligned}
$$

For $\xi=1 / 2$, the upward shear stress is actually inexistent in Area 1 (shown in Figure 14a), while only the downward shear stress is induced in the section. The axial force reaches its maximum value, namely pure compression or pure tension without bending.

$$
N^{\prime}=N_{\max }=k 4 a t f \int_{-\frac{1}{2}}^{\frac{1}{2}} d \xi=k 4 a t f
$$

For $\xi=-1 / 2$, the dividing line of the upward and downward shear stress lies in the middle of the section side, as in shown in Figure 14c, and the length of Area 3 becomes zero. The bending moment reaches its maximum value, namely pure bending without axial force.

$$
M^{\prime}=M_{\max }=k 4 \int_{-\frac{1}{2}}^{\frac{1}{2}}\left(\frac{1}{2}+\xi\right) a^{2} t f \sin 45^{\circ} d \xi=k 2 \sqrt{2} a^{2} t f\left[\frac{1}{2} \xi+\frac{1}{2} \xi^{2}\right]_{-\frac{1}{2}}^{\frac{1}{2}}=k \sqrt{2} a^{2} t f
$$


Combining Eq. 25 and Eq. 27,

$\eta_{N}=\frac{N}{N_{\max }}=\xi+\frac{1}{2}$

Combining Eq. 26 and Eq. 28,

$\eta_{M}=\frac{M}{M_{\max }}=\frac{3}{4}-\xi-\xi^{2}$

The relation between $\eta_{N}$ and $\eta_{M}$ may be derived from Eq. 29, Eq. 30.

$\eta_{N}=\sqrt{1-\eta_{M}}$

It is indicated from the above equation that, for hollow sphere joint under combined axial compression and biaxially equivalent bending, the load carrying capacity correlation between axial compression and bending moment can be expressed as a parabolic curve, as is shown in Figure 15. Meanwhile, the results show good agreement with the obtained FE results. The correlation of axial force-bending moment is proved theoretically to be independent of the geometric parameters of joint on the one hand, and on the other hand FE results are also proved to be rational. It can also be found from Eq. 14 and Figure 15 that the axial compression decreases with the increase of bending moment.

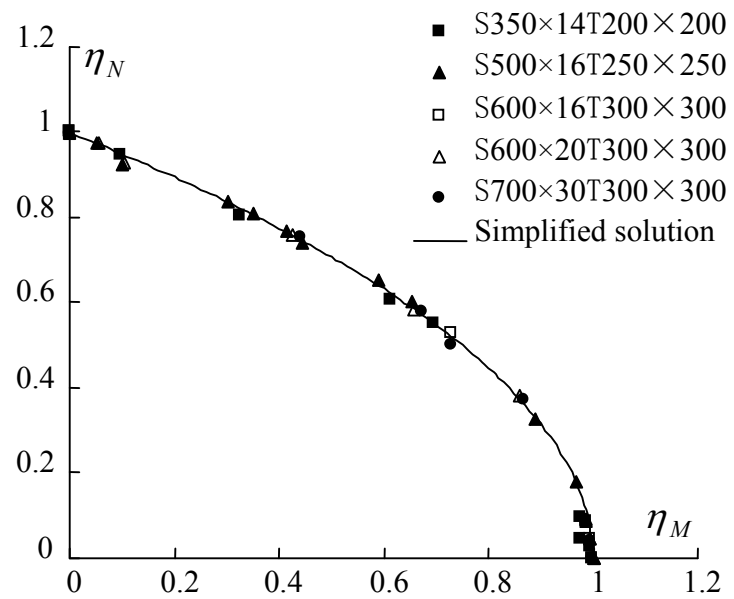

Figure 15. Dimensionless Axial Force-Bending Moment Correlation for Joints under Combined Compression and Biaxially Equivalent Bending

It is found out from Eq. 29, Eq. 30 that the relevant expression about $\xi$ should be primarily solved to obtain $\eta_{N}, \eta_{M}$ in the first stage. Eq. 4 and Eq. 5 may be rewritten as:

$$
k a t f=\frac{N}{4\left(\xi+\frac{1}{2}\right)}
$$

From Eq. 26, the following equation can be obtained, 


$$
k a t f=\frac{M}{\sqrt{2} a\left(\frac{3}{4}-\xi-\xi^{2}\right)}
$$

Combining Eq. 32, Eq. 33

$$
\xi^{2}+\left(1+\frac{2 \sqrt{2} M}{N a}\right) \xi+\frac{\sqrt{2} M}{N a}-\frac{3}{4}=0
$$

Solving the above equation, $\xi$ can be obtained,

$$
\xi=-\left(\frac{1}{2}+\frac{\sqrt{2} M}{N a}\right)+\sqrt{1+\left(\frac{\sqrt{2} M}{N a}\right)^{2}}
$$

For joint under combined axial force $N$ and bending moment $M$ acting in the diagonal plane of section, $\xi$ can be obtained by Eq. 35 when M, N and a are given. The corresponding expressions about $\eta_{N}, \eta_{M}$ are obtained accordingly by Eq. 29 and Eq. 30. The load carrying capacity of joint may be determined based on the axial force:

$$
N_{\mathrm{R}}=\eta_{N} N_{\max }=\eta_{N} k 4 a t f
$$

and may also be determined based on the bending moment:

$$
M_{\mathrm{R}}=\eta_{M} M_{\max }=\eta_{M} k \sqrt{2} a^{2} t f
$$

The two expressions are equivalent. The physical meanings of $\eta_{N}, \eta_{M}$ are the same with that defined in the above expressions, where $\eta_{N}$ is the influence coefficient of axial force with regard to bending moment, and $\eta_{M}$ is the influence coefficient of bending moment with regard to axial force.

\section{PRACTICAL DESIGN METHOD FOR LOAD CARRYING CAPACITY}

The load carrying capacity of WHSJ with rectangular/square steel tube under combined axial compression and bending has been discussed based on the simplified theoretical solution, as is shown in Eq. 23 and Eq. 24. Load carrying capacity will be further evaluated in this section to establish the practical calculation method, with the FE analyses and experimental results. Calculation methods for axial compression and bending moment are established respectively, and calculation method for combined axial compression and bending is accordingly established.

For consistency with the current specification for latticed shells [3] and design criterion of WHSJ with circular pipe under combined axial force and bending [5], load carrying capacity of joints under axial force is given by Eq. 5 in the following expression.

$$
N_{R}=\left(A+B \frac{\sqrt{a b}}{D}\right) 2(a+b) t f
$$


The expression in the first bracket corresponds to the coefficient $k$ discussed in Section 4.1. Similarly, load carrying capacity of joints under bending is given by Eq. 10 in the following expression.

$M_{R}=\left(A^{\prime}+B^{\prime} \frac{\sqrt{a b}}{D}\right)\left(1+\frac{1}{2} \Delta\right) a b t f$

In Eq. 38, 39, $A, B, A^{\prime}, B^{\prime}$ are coefficients to be determined based on the $\mathrm{FE}$ and experimental results. For joint under axial force, load carrying capacity made dimensionless by $2(a+b) t f$ is used as the vertical coordinate, while $\sqrt{a b} / D$ as the horizontal coordinate. The correlation is shown in Figure 16 which is used to determined coefficients $A, B$. The lower envelop of FE results shown by the real line in Figure 16 is chosen as the design line for safety. The coefficients are then determined, $A=0.3, B=0.57$, for consistency with the design criterion of WHSJ with circular pipe [5]. Namely the design criterion is $0.3+0.57 \sqrt{a b} / D$. For tubes and hollow spheres in practical engineering, $\sqrt{a b} / D$ usually ranges from 0.25 to 0.60 , and $\mathrm{k}$ ranges correspondingly from 0.44 to 0.64 , which is equal to that determined by Mises or Tresca yield criterion. It is indicated that collapse of the type is characterized by shear punching failure.

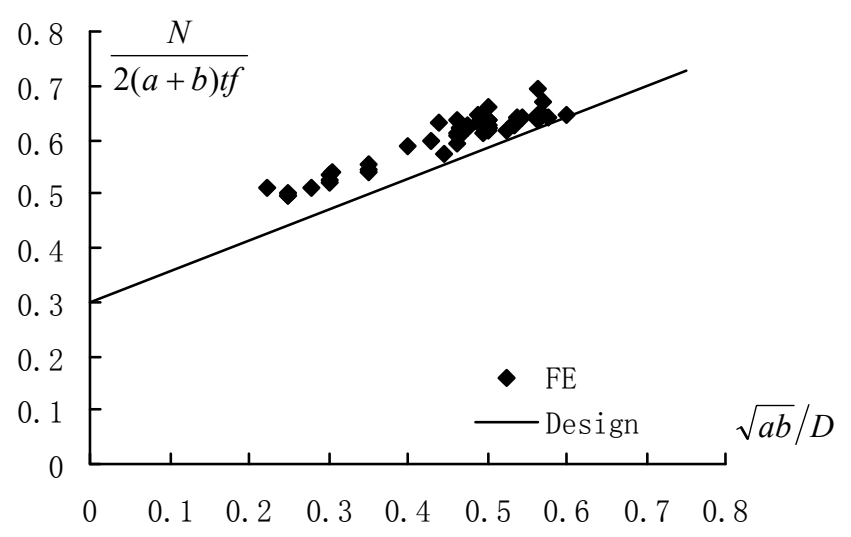

Figure 16. Determination of Coefficients in Formula for Axial Force

For joint under pure bending, load carrying capacity made dimensionless by $a b(1+0.5 \Delta) t f$ is used as the vertical coordinate, and the correlation with $\sqrt{a b} / D$ is shown in Figure 17 which is used to determined coefficients $A^{\prime}, B^{\prime}$. It is found that design equation determined by $A^{\prime}=A=0.3$ 、 $B^{\prime}=B=0.57$ can also regard to be the lower envelop for FE results. In this way design equations of load carrying capacity are normalized and simplified for axial force and pure bending. 


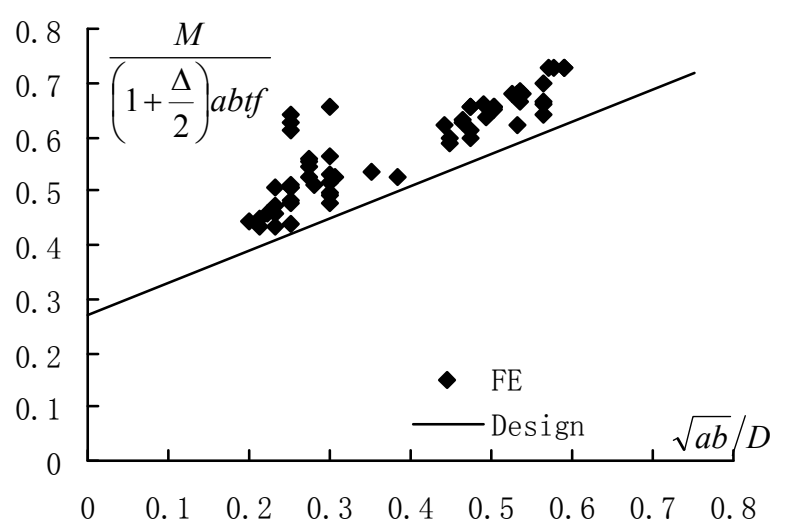

Figure 17. Determination of Coefficients in Formula for Bending Moment

For joint under combined axial force and bending moment, as is mentioned before, load carrying capacity of joint may be determined based on the axial force taking account of the corresponding influence coefficient $\eta_{N}$, and also on the bending moment taking account of $\eta_{M}$. The design equation based on axial force is given in Eq. 40.

$$
N_{R}=\eta_{N}\left(A+B \frac{\sqrt{a b}}{D}\right) 2(a+b) t f
$$

and design equation based on bending moment is given in Eq. 41 .

$$
M_{R}=\eta_{M}\left(A+B \frac{\sqrt{a b}}{D}\right)\left(1+\frac{1}{2} \Delta\right) a b t f
$$

The simplified theoretical solutions by Eq. 40 and Eq. 41 coincide in format with that by Eq. 23 and Eq. 24. The coefficients are also chosen as $A=0.3, B=0.57$. The FE load carrying capacity based on axial force is made dimensionless by $\eta_{N} 2(a+b) t f$, and the correlation with $\sqrt{a b} / D$ is shown in Figure 18, in which $\eta_{N}$ is determined by Eq. 12 or Eq. 14. It is found that design equation determined by $0.3+0.57 \sqrt{a b} / D$ is also applicable for the lower envelop of FE results.

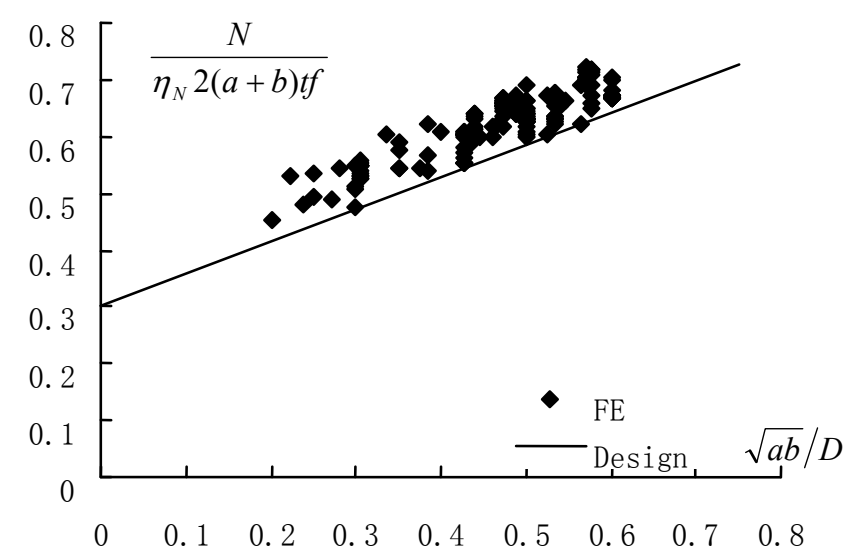

Figure 18. Determination of Coefficients in Formula for

Combined Axial Force and bending moment 
Comparisons of collapsed load between the experimental results and the design formula are made, as is shown in Table 2. The safety factor in the design formula is about 1.47 which is smaller than that (about 1.6) specified in Chinese Specifications [JGJ 61-2003]. It has been shown from studies on WHSJ with circular pipe in Ref. [5] that the eccentricity would increase with the increasing deflection, corresponding to an additional eccentricity introduced. Namely, the actual collapsed bending moment acting on joints is larger than the designed value. When load carrying capacity is determined by the design formula, the influence coefficient $\eta_{M}$ is obtained by the design bending moment. The influence coefficient is consequently larger, and the corresponding design load carrying capacity is higher. Load carrying capacity without regard to additional eccentricity is obviously larger than that with regard to additional eccentricity, improved averagely by $15 \%$. The safety factor of experimental results in the paper for evaluation of proposed formula is smaller, where it is mainly caused by the inescapable additional eccentricity. As additional eccentricity is actually inexistent in practical engineering, design formula proposed in this paper is regarded to have the equivalent safety factor with that specified in the current specification [JGJ 61-2003].

Table 2. Evaluation of Proposed Formula

\begin{tabular}{cccccc}
\hline No. & $\begin{array}{c}\text { Sphere } \\
(\mathrm{mm} \times \mathrm{mm})\end{array}$ & $\begin{array}{c}\text { Tube } \\
(\mathrm{mm} \times \mathrm{mm})\end{array}$ & $\begin{array}{c}\text { Test } \\
\text { value } \\
(\mathrm{kN})\end{array}$ & $\begin{array}{c}\text { Design } \\
(\mathrm{kN})\end{array}$ & $\begin{array}{c}\text { Test } / \\
\text { Design }\end{array}$ \\
\hline 1 & $\mathrm{D} 400 \times 14$ & $100 \times 150$ & 240 & 164 & 1.46 \\
2 & $\mathrm{D} 400 \times 14$ & $150 \times 100$ & 282 & 210 & 1.34 \\
3 & $\mathrm{D} 400 \times 14$ & $200 \times 200$ & 1910 & 1409 & 1.36 \\
4 & $\mathrm{D} 400 \times 14$ & $200 \times 200$ & 760 & 533 & 1.36 \\
5 & $\mathrm{D} 500 \times 20$ & $300 \times 200$ & 3500 & 2375 & 1.47 \\
6 & $\mathrm{D} 500 \times 20$ & $300 \times 200$ & 2260 & 1662 & 1.36 \\
7 & $\mathrm{D} 500 \times 20$ & $300 \times 300$ & 2095 & 1433 & 1.46 \\
8 & $\mathrm{D} 600 \times 20$ & $300 \times 300$ & 3080 & 2272 & 1.36 \\
9 & $\mathrm{D} 600 \times 20$ & $300 \times 300$ & 2400 & 1727 & 1.39 \\
10 & $\mathrm{D} 600 \times 20$ & $300 \times 300$ & 3350 & 2500 & 1.34 \\
\hline
\end{tabular}

In summary, practical calculation methods of load carrying capacity for WHSJ with rectangular tube are given in following expressions.

For joint under axial force:

$$
N_{R}=\left(0.3+0.57 \frac{\sqrt{a b}}{D}\right) 2(a+b) t f
$$

For joint under pure bending:

$$
M_{R}=\left(0.3+0.57 \frac{\sqrt{a b}}{D}\right)\left(1+\frac{1}{2} \frac{a}{b}\right) a b t f
$$

For joint under combined axial force and bending:

$$
N_{R}=\eta_{N}\left(0.3+0.57 \frac{\sqrt{a b}}{D}\right) 2(a+b) t f \quad(\text { based on axial force })
$$


$M_{R}=\eta_{M}\left(0.3+0.57 \frac{\sqrt{a b}}{D}\right)\left(1+\frac{1}{2} \frac{a}{b}\right) a b t f \quad$ (based on bending moment)

Where, $D$ is the sphere diameter, $t$ is sphere wall thickness, $a, b$ is the side length of tube respectively (when $a=b$, the tube is the square tube ), $f$ is the design tensile strength of steel, $\eta_{N}, \eta_{M}$ are the influence coefficients.

The design steps are as follows for joints under combined axial force and bending.

1) Determine which stage the joint falls into based on $N, M$ and side length $b$ of tube. For $N \geq 2 M / b$, the joint belongs to the first stage, and for $N<2 M / b$, the joint belongs to the second stage.

2) In the first stage, expression about $\eta$ is determined by Eq. 19, and the corresponding expressions about $\eta_{N}, \eta_{M}$ are obtained accordingly by Eq. 12 and Eq. 13. In the second stage, expression about $\xi$ is determined by Eq. 22, and the corresponding expressions about $\eta_{N}, \eta_{M}$ are obtained accordingly by Eq. 14 and Eq. 15 .

3) For given $\eta_{N}, \eta_{M}$, the load carrying capacity of joint may be determined based on the axial force by Eq. 44 or on the bending moment by Eq. 45 .

The FE analyses and experiment in this paper are aimed at WHSJ under uniaxial force. For WHSJ under biaxial or spatial force, preliminary FE results show that structural behavior of the type has little difference with the uniaxial joint. In addition, influence of stiffener is not taken into account in the paper. As no experimental results about influences of stiffener on load carrying capacity of joint under bending has been reported, and measures can hardly be taken to insure the stiffener fixed in the plane in which the bending moment acts, effect of stiffener may be disregarded for safety for joint under large bending moment. For the case where the axial force is dominant, the load carrying capacity can also be improved according to coefficients specified in Chinese Specifications [2, 3] (i.e., 1.4 for compressive sphere, and 1.1 for tensile sphere).

\section{SIMPLIFIED DESIGN METHOD FOR COMBINED AXIAL FORCES AND BIAXIAL BENDING MOMENTS}

The practical design method for load carrying capacity is presented for WHSJ under combined axial force and bending in this section. Whereas, biaxial bending moment usually acts on elements in the practical engineering, i.e., bending moments $M_{x}, M_{y}$ act in two main planes, where $M_{x}$ acts in $x z$ plane, and $M_{y}$ acts in $y z$ plane. The resultant bending moment of $M_{x}, M_{y}$ (Figure 19a) is given by Eq. 46.

$M=\sqrt{M_{x}^{2}+M_{y}^{2}}$

An angle of $\theta$ is staggered between the resultant moment and $x$-axial,

$\theta=\arctan \frac{M_{y}}{M_{x}}$

For $\theta=0$ or $\pi / 2$, it corresponds to the uniaxial bending. For biaxial bending, $\theta$ ranges randomly from 0 to $\pi / 2$. For cases of the type, following the simplified design method is put forward: The 
resultant bending moment $M$ obtained by Eq. 46 acts in two main planes of tube respectively, as are shown in Figure 19b, Figure 19c. As load carrying capacity for joint under combined axial force and uniaxial bending is established in the previous study, practical load carrying capacity can be obtained by linear interpolation. Namely, solution to $\theta$ which ranges from 0 to $\pi / 2$ may be obtained by linear interpolation of the results for $\theta=0$ and $\theta=\pi / 2$.

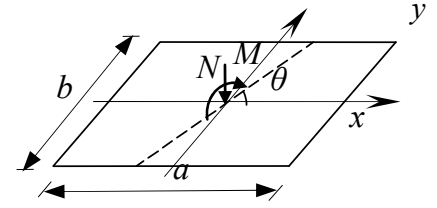

(a) Resultant of Biaxial Bending

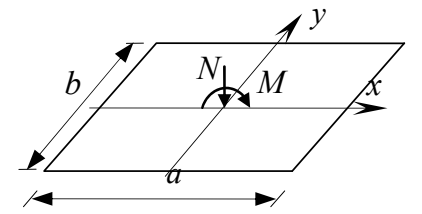

(b) Resultant Bending in $x z$ Plane

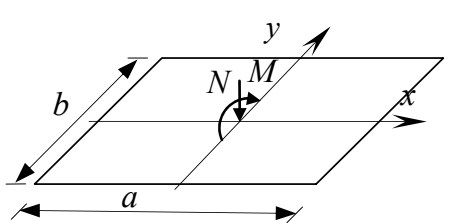

(c) Resultant Bending in $y z$ Plane

Figure 19. Simplified Calculation for Biaxial Bending

For joint under combined axial force and biaxial bending, the load carrying capacity can also be determined based on the axial force or the bending moment. It is revealed from Eq. 44 that the influence coefficient $\eta_{N}$ is only needed for interpolation when design of joint is based on the axial force. It is also revealed from Eq. 45 that not only the influence coefficient $\eta_{N}$ but the expression $(1+a / 2 b)$ is needed for interpolation when design of joint is based on the bending moment. As bending moment acts in different plane, expression $(1+a / 2 b)$ should be converted to $(1+b / 2 a)$. Hereby joint design based on axial force is simpler. Detailed design steps based on axial force are presented as follows.

1) The resultant bending moment $M$ is obtained by composition of $M_{x}, M_{y}, \theta$ from Eq. 46, 47.

2) The resultant moment $M$ is supposed to act in $x z$ plane (where the long side $a$ of tube lies). Determine which stage the joint falls into based on $N, M$ and side length $a$ of tube. For $N \geq 2 M / b$, the joint belongs to the first stage, expression about $\eta$ is determined by Eq. 19, and the corresponding expressions about $\eta_{N}$ are obtained accordingly by Eq. 12. And for $N<2 M / b$, the joint belongs to the second stage. Expression about $\xi$ is determined by Eq. 22, and the corresponding expressions about $\eta_{N}$ are obtained accordingly by Eq. 14. It should be notified that $\Delta=a / b$ in above expressions $(12,14,19,22)$. Herein, $\eta_{N}$ is signified as $\eta_{N x}$.

3 ) The resultant moment $M$ is supposed to act in $y z$ plane (where the long side $b$ of tube lies). Determine which stage the joint falls into based on $N, M$ and side length $b$ of tube. For $N \geq 2 M / b$, the joint belongs to the first stage, expression about $\eta$ and $\eta_{N}$ are obtained accordingly by Eq. 19 and 12. And for $N<2 M / b$, the joint belongs to the second stage. Expressions about $\xi, \eta_{N}$ are obtained accordingly by Eq. 22 and 14. It should be notified that $\Delta=b / a$ in above expressions. Herein, $\eta_{N}$ is signified as $\eta_{N y}$.

4) For given $\eta_{N x}, \eta_{N y}$, the influence coefficient $\eta_{N}$ for biaxial bending can be obtained by the interpolation formula, as is shown in Eq. 48.

$$
\eta_{N}=\frac{\frac{\pi}{2}-\theta}{\frac{\pi}{2}} \eta_{N x}+\frac{\theta}{\frac{\pi}{2}} \eta_{N y}
$$


5) Load carrying capacity is determined by Eq. 44.

The above simplified design method is an approximate solution for random combination of biaxial bending moment, and the physical meanings are definite. For case $\mathrm{a}=\mathrm{b}$ (i.e. the square section), the result for $0<\theta<\pi / 4$ can be obtained by linear interpolation of that for $\theta=0$ and $\theta=\pi / 4$.

The correlation of $\eta_{N}, \eta_{M}$ (aspect ratio $\Delta=1.5$ ) is plotted in Figure 20 where $\theta=0, \theta=\pi / 2$ corresponds to resultant bending moment $M$ acting in two main plane $x z, y z$. For angle $\theta$ ranging from 0 to $\pi / 2$, correlation of $\eta_{N}, \eta_{M}$ is supposed to fall into the region whose boundary is marked by the two curves. As discrepancy between two curves is not large, enclosing a narrow region, linear interpolation is supposed to be rational for the solution. For instance, the correlation of $\eta_{N}, \eta_{M}$ for $\theta=0$ is composed of a line and a curve with $(4 / 7,3 / 5)$ as the dividing point. The physical meaning corresponding to the point is $N=2 M / b$. Similarly, dividing point $(0.6,0.52)$ corresponds to $\theta=\pi / 2$. The dividing point $(0.586,0.560)$ can be obtained by interpolation for $\theta=\pi / 4$. The correlations are plotted in Figure 20. It can be observed clearly that results for $\theta=\pi / 4$ falls in the region whose boundary is marked by the two curves for $\theta=0$ and $\theta=\pi / 2$.

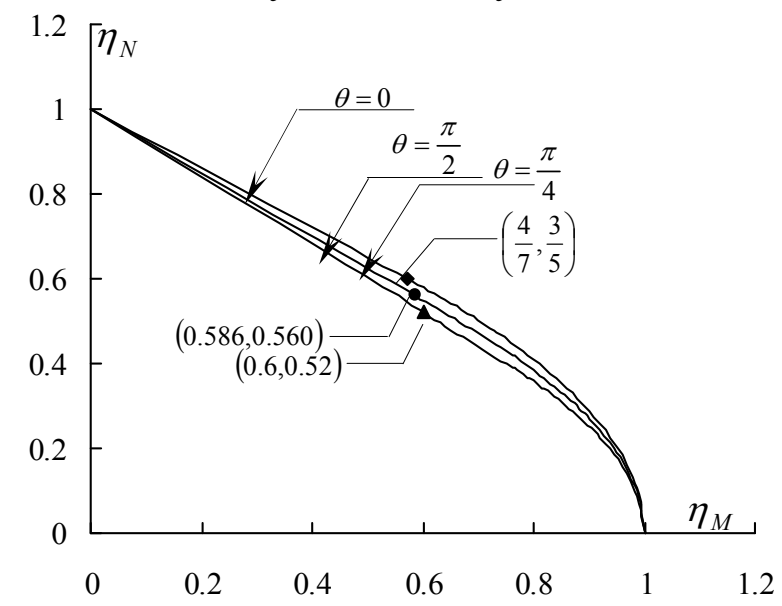

Figure 20. Simplified Calculation Method for Combined Axial Forces and Biaxial Bending Moments

In order to validate further the simplified design method, the results from the FE analysis and that from the simplified design method for $\theta=0.694738$ and $\theta=0.588003$ are obtained and plotted in Figure 21. It is shown in the figure that the results show good agreement, and the linear interpolation method is validated to be feasible.

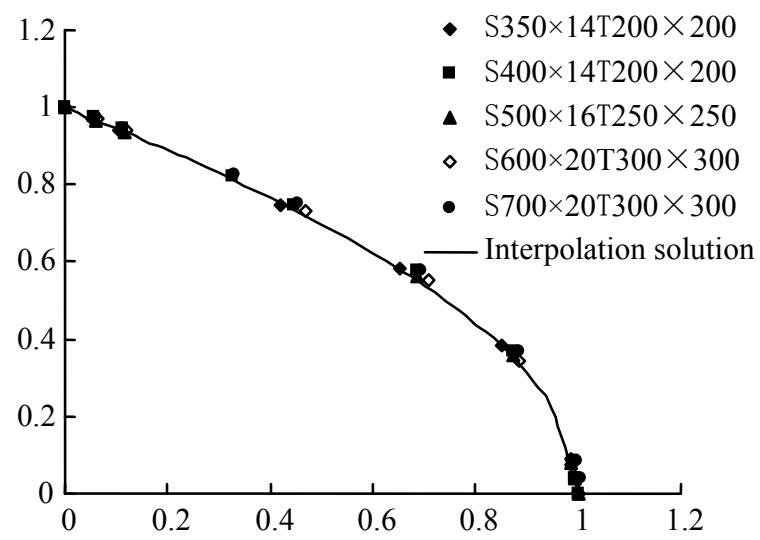

Figure 21. Dimensionless Axial Force-Bending Moment Correlation for Joints under Combined Compression and Biaxially Random Bending $(\theta=0.694738)$ 


\section{CONCLUSIONS}

1) Based on the elastic-perfectly plastic model and the Von-Mises yield criterion, a finite element model for the analysis of these joints is established, in which the effect of geometric nonlinearity is taken into account. Great deal of FE parametric analyses are carried out by the model for WHSJ with rectangular tube under axial force, bending moment and combination of the two. The main factors which have influence on load carrying capacity are investigated.

2) Experiments on ten typical full-scale joints under axial force, bending moment and combination of the two are conducted to understand directly the structural behavior and the collapse mechanism of the joint connected with rectangular tube, and to validate the finite element model.

3 ) For joint subject to combined axial force and bending moment, FE analysis shows that axial force-bending moment correlation is independent of joint geometries, including sphere diameter and thickness, side length of tube. The property is further proved by the simplified theoretical solution. It is so important as to simplify, to a large extent, the calculation method of load carrying capacity.

4) Based on simplified theoretical solution and the FE, experimental results, calculation methods for axial compression, bending moment and combination of the two are established respectively. For joint subject to combined axial force and bending moment, the concept of influence coefficient is put forward for joint design based on axial force with respect to influence of bending moment (or on bending moment with respect to influence of axial force). The calculation method for influence coefficient is also presented. It is noteworthy that the above proposed design formulas are approximate evaluations for joint design, which are suggested to be used in the preliminary design stage for rough results. For more precise results, the finite element analyses are indispensable to joint design in the practical engineering.

5) For joint under combined axial force and biaxial bending, simplified calculation method is proposed in which load carrying capacity can be derived from linear interpolation of the results obtained by resultant bending moment acting in two main planes respectively.

6) In the present design code, design method is only provided for joint (circular tube with WHS) under axial force. The proposed design method has extended the application range of joint design to a great extent that is applicable to the load-carrying capacity of the joints subject to axial forces, bending moments and the combined loading. The results from the studies can be applied for direct design use, and also provide a reference for the revision of relevant design codes.

\section{ACKNOWLEDGMENT}

The author gratefully acknowledges the support of the Technological Project Foundation of Zhejiang Province (No. 2008C21149). The author also wishes to thank the anonymous reviewers for their constructive comments and suggestions. 


\section{REFERENCES}

[1] GB 50017-2003, "Code for Design of Steel Structures”, Chinese Planning Press, Beijing (in Chinese).

[2] JGJ 7-91, "Specification for Design and Construction of Reticulated Structures", China Architecture \& Building Press, Beijing, 1991 (in Chinese).

[3] JGJ 61-2003, “Technical Specification for Latticed Shells”, China Architecture \& Building Press, Beijing, 2003. (in Chinese).

[4] Han, Q.H. and Liu, X.L., "Ultimate Bearing Capacity of the Welded Hollow Spherical Joints in Spatial Reticulated Structures", Engineering Structures, 2004, Vol. 26, No. 2, pp.73-82.

[5] Dong, S.L., et al, "Load-carrying Capacity and Practical Calculation Method of Welded Hollow Spherical Joints Subject to Combined Axial Force and Bending Moment", China Civil Engineering Journal, 2005, Vol. 38, No. 1, pp. 21-30 (in Chinese).

[6] Yuan, X.F., Pei, Z.L., et al, "Load-Carrying Capacity of Welded Hollow Spherical Joints Subject to Combined Planar Tri-Directional Axial Force and Bending Moment", Journal of Zhejiang University (Engineering Science), 2007, Vol. 41, No. 9, pp.1436-42 (in Chinese).

[7] Lie, S.T., Lee, C.K. and Wong, S.M., "Model and Mesh Generation of Cracked Tubular Y-Joints", Engineering Fracture Mechanics, 2003, Vol. 70, pp. 161-184.

[8] Lee, C.K., et al, "Numerical Models Verification of Cracked Tubular T, Y and K-Joints under Combined Loads", Engineering Fracture Mechanics, 2005, Vol. 72, pp. 983-1009.

[9] Lee, M.M.K., "Strength, Stress and Fracture Analyses of Offshore Tubular Joints Using Finite Elements" Journal of Constructional Steel Research, 1999, Vol. 51, pp. 265-286.

[10] A. N'Diaye, et al, "Stress Concentration Factor Analysis for Welded, Notched Tubular T-joints under Combined Axial, Bending and Dynamic Loading”, International Journal of Fatigue, 2009, Vol. 31, pp. 367-374.

[11] Zhu Shi-zhe, et al, "Experimental Investigation of X-joint in Double-arch Structure", Journal of Zhejiang University (Engineering Science), 2008, Vol. 42, No. 1, pp. 99-104 (in Chinese).

[12] Wang Ying-chuan, et al, "Analysis of Ultimate Bearing Capacity of Spatial Steel Tubular Joint”, Spatial Structures, 2007, Vol. 13, No. 4, pp. 25-27(in Chinese). 


\title{
BOND TESTS OF PARTIALLY ENCASED COMPOSITE COLUMNS
}

\author{
Marisa Pecce* and Francesca Ceroni \\ Department of Engineering, University of Sannio \\ Piazza Roma 21, 82100, Benevento, Italy \\ *(Corresponding author: E-mail: pecce@unisannio.it and ceroni@unisannio.it)
}

Received: 31 December 2007; Revised: 22 July 2008; Accepted: 28 July 2008

\begin{abstract}
This paper deals with bond behaviour at the steel-concrete interface of partially encased composite columns. The topic is especially interesting to determine the stress transfer between the two materials at sections where composite structural elements are connected, such as in a beam-column joint, and to ensure a short transfer length to attain the strength of the composite section. The few experimental tests in the technical literature usually concern other types of composite columns. The Authors therefore designed and carried out experimental bond tests to investigate the transfer mechanism and ascertain the reliability of some code provisions (Eurocode 4 [5]; New Italian Code [8]) concerning the design value of bond strength for partially encased columns. A suitable test set-up was designed to measure the shear stresses transferred to the steel profile and the slip between the two materials, allowing compression or tension to be applied to concrete according to monotonic or cyclic load history. The test results give interesting information about the bond stress-slip relationship and bond strength; the cyclic tests highlight the effect of seismic action and indicate considerable degradation of strength and stiffness.
\end{abstract}

Keywords: Composite Columns, Steel-Concrete Structures, Bond Strength

\section{INTRODUCTION}

Steel concrete composite constructions can offer many benefits in structural performance due to technical solutions that allow problems of both RC and steel structures to be solved. However, the design approach still needs suitable procedures and code provisions (Cosenza and Zandonini [1]) since the structural behaviour of steel-concrete composite elements is due to the interaction mechanism between the two materials based on suitable mechanical devices or bond at the interface. In particular the bond between steel profile and concrete is usually completely neglected in the design of beams made of a steel profile and a concrete slab, where the stress transfer is entrusted to mechanical devices (connectors). By contrast, in composite columns the contribution of the bond at the steel-concrete interface can be taken into account in the calculation because the contact surface is wider and the concrete is completely or partially encased in the steel profile, that gives a beneficial confinement effect. A large contact surface usually leads to low bond strengths but allows total interaction of the two materials to be obtained. The composite section can then reach its plastic bending moment; this can happen particularly for sections where the centroids of the concrete and steel section coincide.

The bond mechanism in composite columns is complex and depends on many geometrical and mechanical parameters discussed elsewhere (Virdi and Bowling [2]; Hamdan and Hunaiti [3]; Hunaiti [4]). Behaviour depends on the type of composite column (partially or fully encased, concrete-filled), the shape of the section (rectangular, square, circular), the loading procedure (on concrete, on steel, on both materials), the type of load condition (axial load, bending, tension, cyclic loads), the concrete properties (class, age, shrinkage, creep, temperature). Design values of bond strength are suggested by international codes, such as Eurocode 4 [5] and AISC [6], and Italian codes, such as CNR 10016 [7], and now also by the new technical instructions for constructions in Italy (NTC, DM 14 [8]). 
Clearly, bond capacity is an essential matter in order to ensure suitable stress transfer in the zones where structural elements are connected. Although composite joints can be achieved with various systems, it would be preferable to choose solutions where both materials are loaded in order to transfer the stresses from one element to another more efficiently and attain full composite action. This result can be reached by ensuring sufficient bond capacity to guarantee short transfer lengths or by using mechanical connectors.

The threshold values of bond strength suggested by codes are based on a few experimental results of monotonic tests on concrete-filled composite columns (Khalil [9]; Hunaiti [4]; Kilpatrick and Rangan [10]; Johansson and Gylltoft [11]; Mouli and Khelafi [12]). Some details concerning Khalil's [9]) tests are discussed in section 4 in order to underline the different bond behaviour of concrete in filled and partially encased composite columns. For applications under seismic action, information on the effect of cyclic loads is required to evaluate the severe degradation of strength and stiffness.

In order to study the bond behaviour of partially encased composite columns, tests were designed and carried out at the Laboratory of the University of Sannio at Benevento, Italy. The specimens are made of HEB (double $\mathrm{T}$ wide flange) steel profiles partially encased with concrete, with and without longitudinal and transversal steel rebars. The influence of the interface roughness was tested by spreading the interface with oil in some cases; some tests under cyclic loads were also performed. The test results are presented below; some comparisons with code limits and the results of other researchers on concrete-filled columns are also made.

\section{EXPERIMENTAL PROGRAM}

The tested specimens were made of steel profiles HEB 180 (flange thickness $t_{\mathrm{f}}=14 \mathrm{~mm}$, web thickness $\mathrm{t}_{\mathrm{w}}=8.5 \mathrm{~mm}$, width and height of the section $\mathrm{H}=\mathrm{B}=180 \mathrm{~mm}$ ) $630 \mathrm{~mm}$ long with a bond length of $450 \mathrm{~mm}$. The profile HEB 180 (Figure 1a) was chosen in order to have as the maximum dimensions, significant for composite columns in buildings, compatible with the testing machine frame and allow correct positioning of the loading plates and instruments. Bond length was established as 2.5 times the section width.
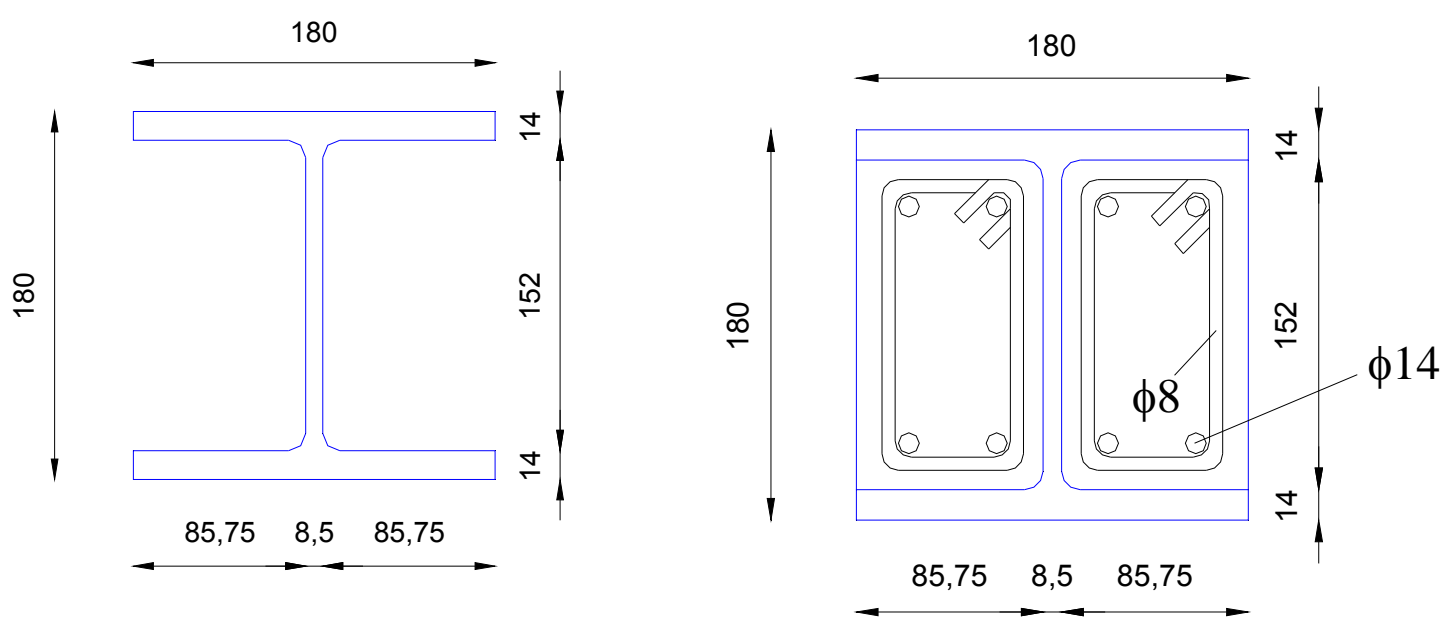

Figure 1. Section of the Specimen:

a) Steel Profile; b) Steel Profile with RC Reinforcement (Measures in mm) 
The experimental program includes specimens with and without steel reinforcement, oil along the interface before casting, monotonic and cyclic loading histories in compression and tension. Application of compressive, tensile and cyclic loads was aimed at investigating the seismic performance of the system also when, under cyclic action, load reversal can occur.

In Table $1 \mathrm{a}$ list of specimens with the following characteristics is reported: the type of load, the presence of steel reinforcement (Figure 1b) and oil along the interfaces, the mean compressive strength of concrete, $\mathrm{R}_{\mathrm{cm}}$, evaluated on three cubes (side $150 \mathrm{~mm}$ ) for each casting. The profiles were made of steel type S275 (yielding strength $275 \mathrm{MPa}$ ) and the internal rebars were type Fe430 (yielding strength $430 \mathrm{MPa}$ ); in these tests the mechanical characteristics of steel were not experimentally evaluated since stresses were very low and far from yielding.

Each specimen was designed and constructed with the concrete part staggered from the steel one longitudinally by $50 \mathrm{~mm}$ at both ends (Figure 2a) in order to allow stress transfer between the two materials. Tests were carried out by placing the specimens in an electro-mechanical universal testing machine with a capacity of $300 \mathrm{kN}$ and anchoring the profile to a stiff steel plate at the base (Figure 3a). Using another stiff steel plate the compressive load was applied directly on the concrete; the tensile load was applied by gripping steel re-bars embedded in concrete, even in the presence of internal steel reinforcement (Figures $2 \mathrm{~b}$ and $3 \mathrm{~b}$ ).

Table 1. Data of Specimens for Bond Tests

\begin{tabular}{|c|c|c|c|c|c|}
\hline Specimen & Stress & Load & Internal steel & Oil & $\mathrm{R}_{\mathrm{cm}}[\mathrm{MPa}]$ \\
\hline C1 & Compression & Monotonic & - & - & 22 \\
\hline C2 & Compression & Monotonic & - & - & 22 \\
\hline C3 & Compression & Monotonic & - & - & 35 \\
\hline C4 & Compression & Monotonic & - & - & 35 \\
\hline C5 & Compression (on steel) & Monotonic & - & - & 35 \\
\hline Ca1 & Compression & Monotonic & Yes & - & 22 \\
\hline Co1 & Compression & Monotonic & - & Yes & 22 \\
\hline T1 & Tension & Monotonic & - & - & 22 \\
\hline T2 & Tension & Monotonic & - & - & 22 \\
\hline Ta1 & Tension & Monotonic & Yes & - & 22 \\
\hline To1 & Tension & Monotonic & - & Yes & 22 \\
\hline CYC1 & Compression-Tension & Cyclic & - & - & 35 \\
\hline CYCa1 & Tension-Compression & Cyclic & Yes & - & 35 \\
\hline CYCo1 & Tension-Compression & Cyclic & - & Yes & 35 \\
\hline
\end{tabular}

When the load is applied to the specimen (either in compression by the steel plate or in tension by the steel re-bars), the concrete blocks move with respect to the steel profile in which they are embedded; this activates the load transfer mechanism from concrete to steel with development of bond stress at the interfaces. For tests in compression in one case (specimen C5) the load was applied directly on the steel profile by turning the specimen over.

In all cases the stress transfer from the concrete blocks to the steel profile was measured and analysed. Thirteen strain gauges were glued on the steel profile along the interfaces before casting and on the outer surface of the flanges to measure strain distributions (Figures 4 - 5). Four displacement transducers were applied: two were placed vertically to measure the slip between the concrete and steel; the other two were positioned horizontally on two opposite sides to check the effects of accidental load eccentricity (Figure 3a). In Figures 4a and b specimens before casting with and without oil at the interfaces are depicted; in Figures $4 \mathrm{c}$ and $4 \mathrm{~d}$ the specimens arranged for the tensile tests with and without internal reinforcement are reported. 

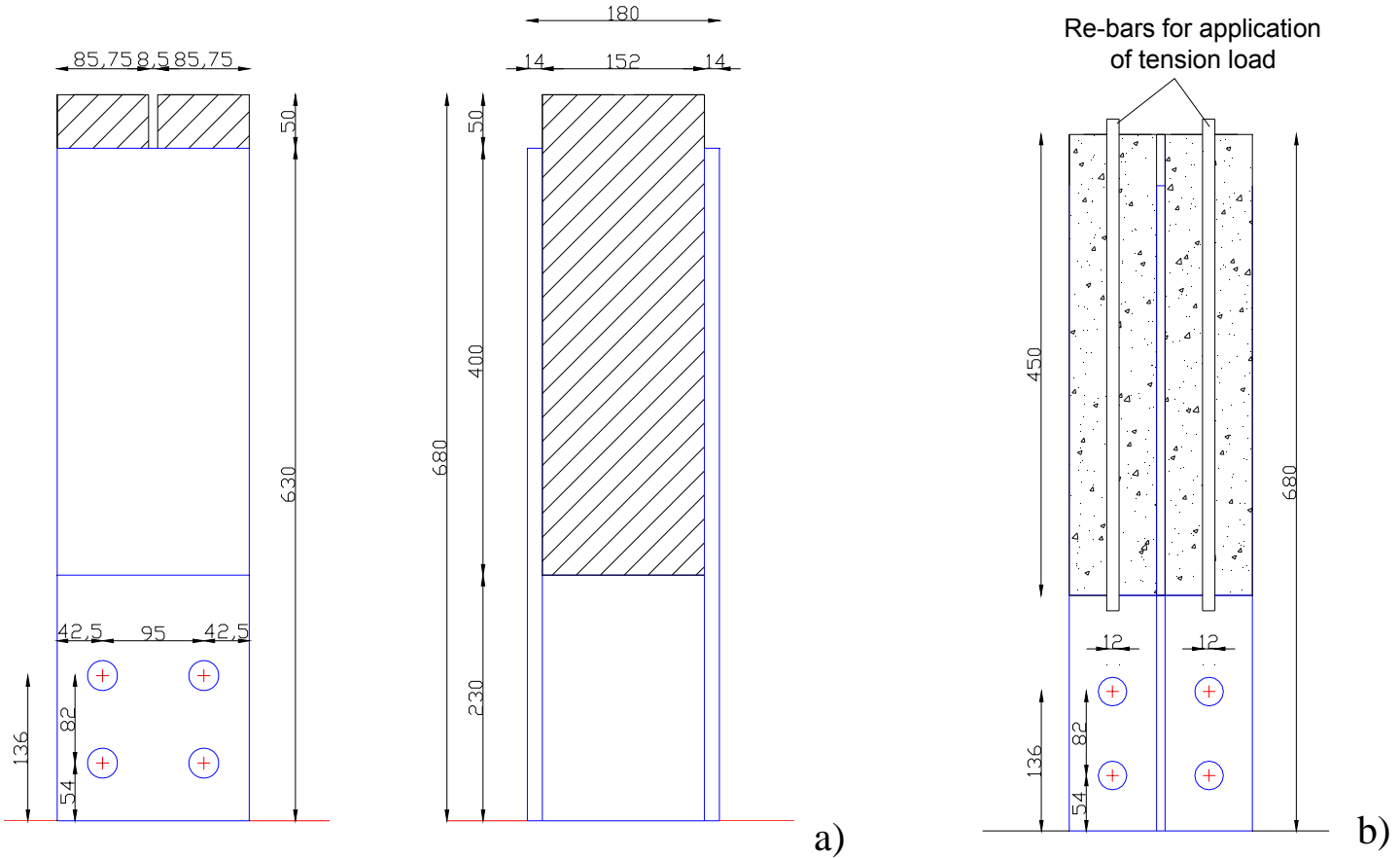

Figure 2. Specimen Geometry: a) Element in Compression; b) Element in Tension

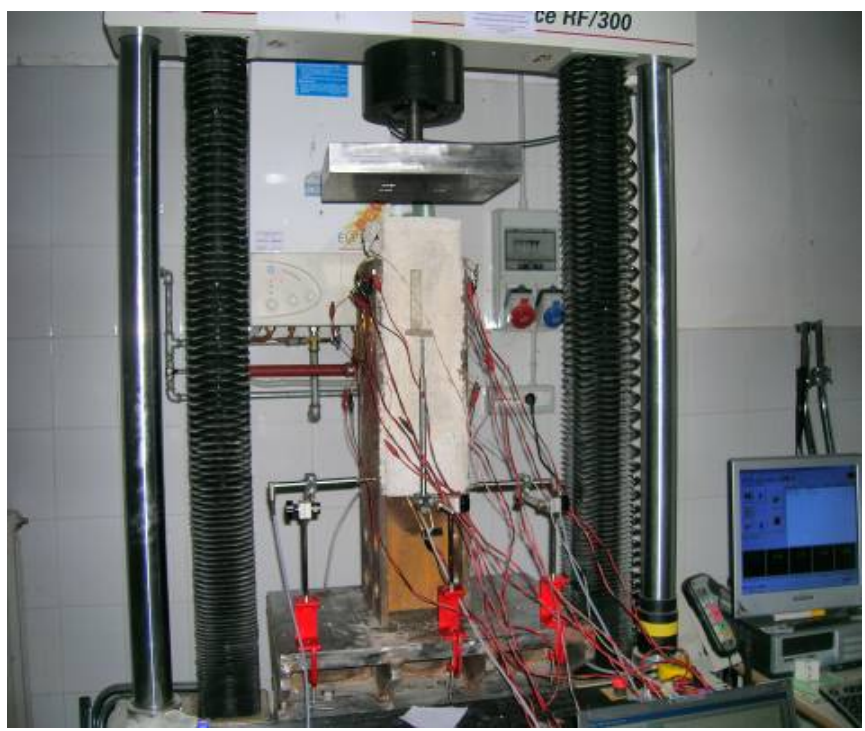

(a)

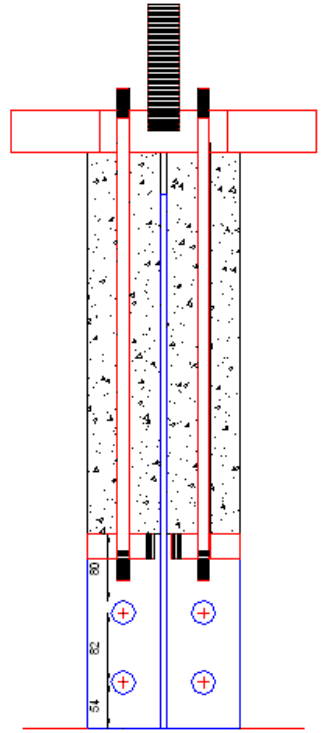

(b)

Figure 3. Set-up for Bond Tests on Composite Elements: a) Plate at the Base and Transducers; b) Plate at the Top and Rebars for Tensile Tests 

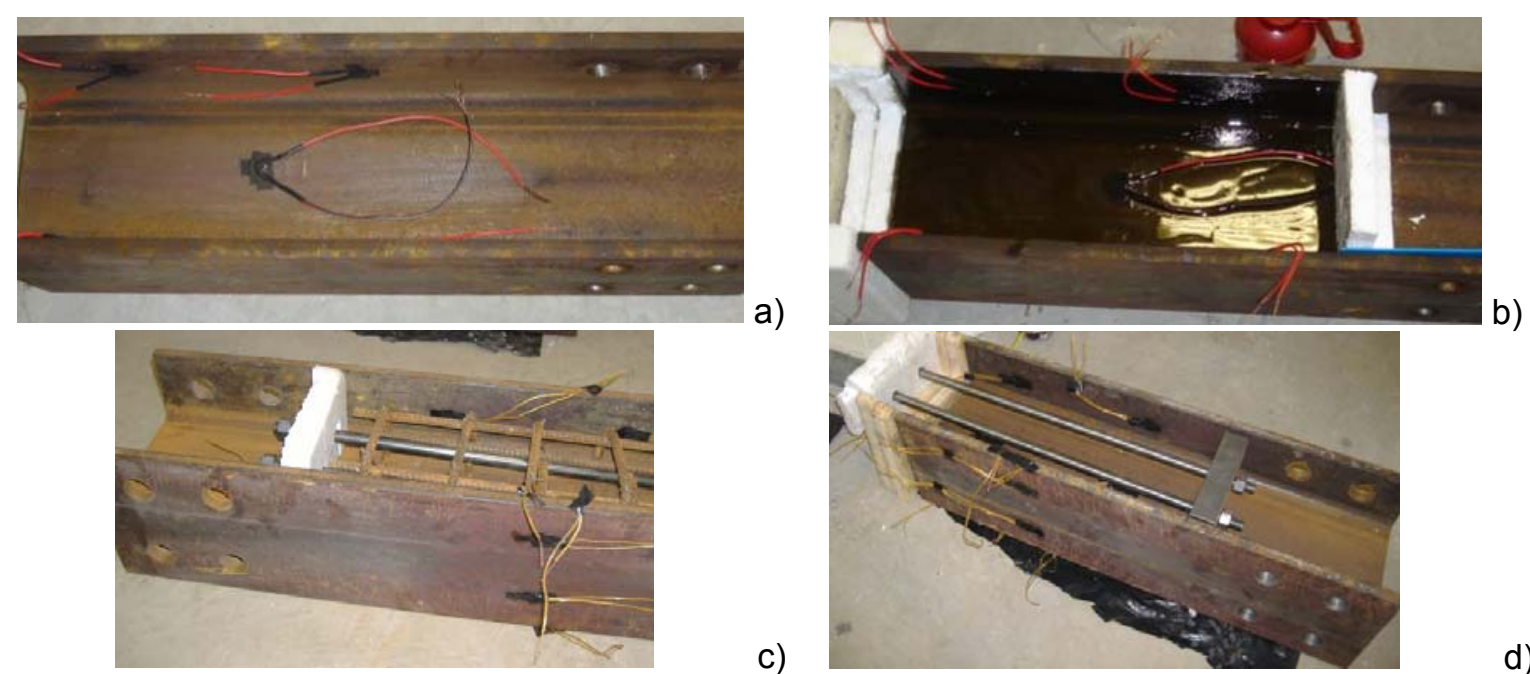

a)

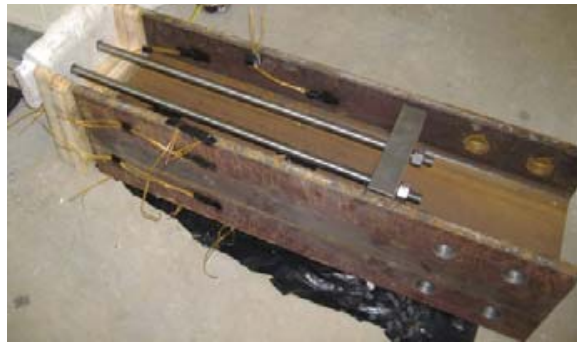

b)

c)

d)

Figure 4. a) Specimen for Compression Test; b) Specimen with Oil for Compression Test; c) Specimen with Internal Rebars and Reinforcement for Tensile Tests;

d) Specimen with Rebars for Tensile Tests

external side of flanges

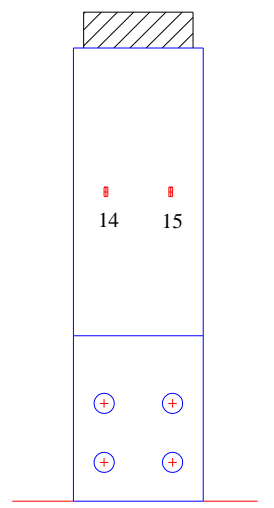

internale side of web

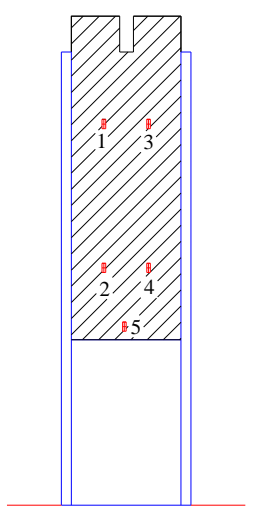

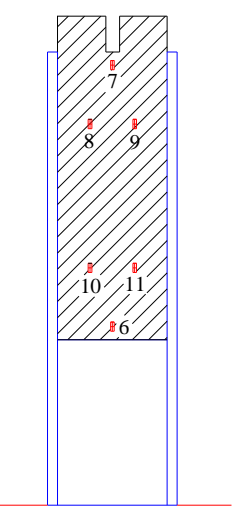

Figure 5. Position and Number of Strain Gauges

\section{EXPERIMENTAL RESULTS}

\subsection{Compression Tests}

The experimental load is plotted against slip curves obtained by monotonic tests in compression in Figures 6a-b; the slip is obtained as the mean value of the measures of the two vertical transducers. The elements marked C1 to C4 are characterized by two different castings of concrete with different compressive strengths (22 MPa for casting 1, 35 MPa for casting 2); element C5 (casting 2) was tested by applying the compressive load directly on the steel profile.

The bond-slip relations of specimens C1 and C2 (casting 1, Figure 6a) have a three-branch shape; the beginning of the curves shows a stiff behaviour without slip up to a peak bond strength, then there is a steep descending branch and finally a stable, practically horizontal, branch as far as great slips with a residual strength that is about $40 \%$ of peak stress. 

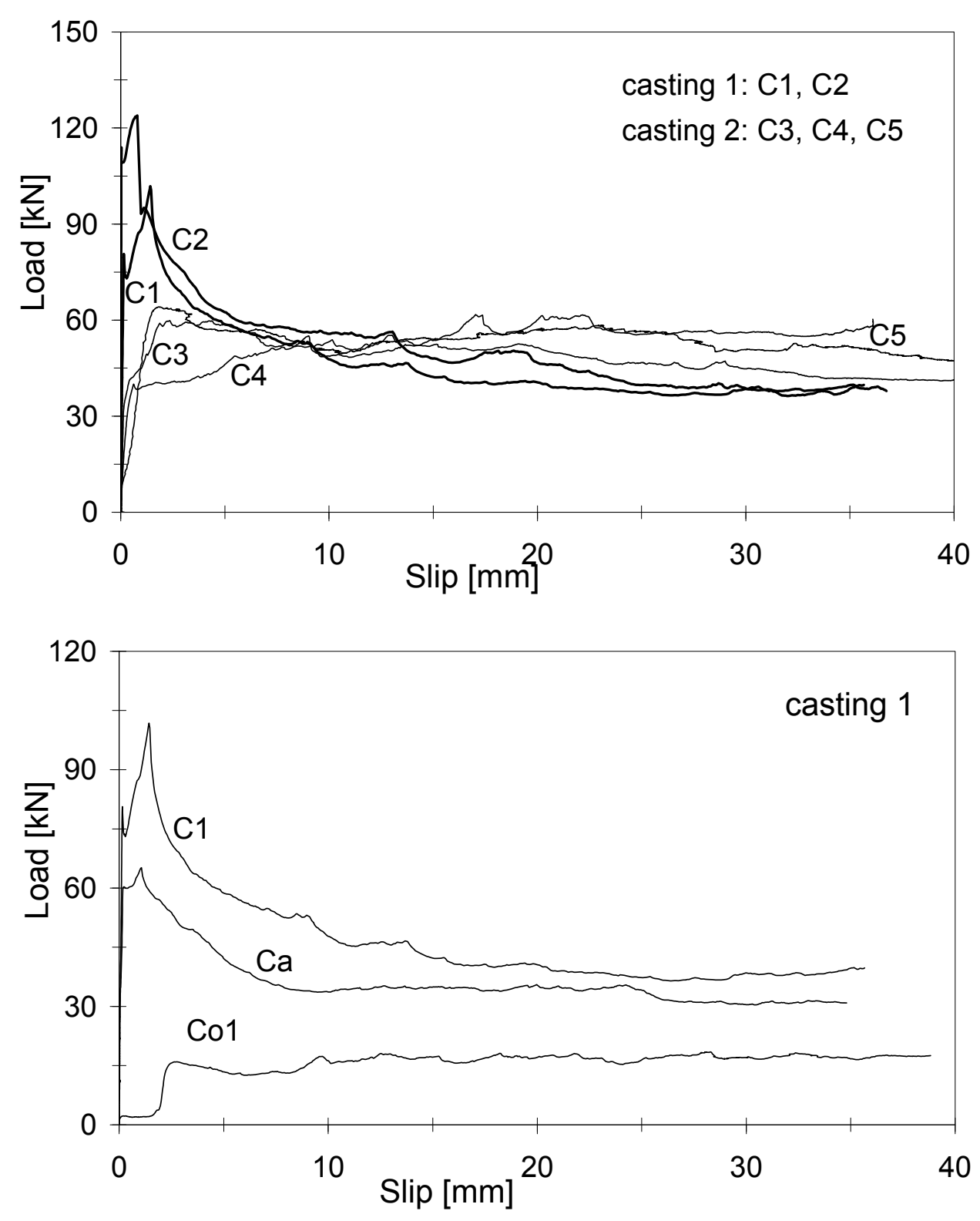

a)

b)

Figure 6. Load-slip Relationship for Specimens in Compression:

a) Standard Specimens; b) Specimens with Oil and Internal Reinforcement

The experimental curves of specimens C3 and C4 (casting 2, Figure 6a) have a different shape from the previous ones: small slips occur from the beginning, there is no peak of stress, the maximum load is attained in the horizontal branch (mean value $=50 \mathrm{kN}$ ) and is greater than the residual strength of specimens C1 and C2 (mean value $=30 \mathrm{kN}$ ) of about $24 \%$. For specimen C5, tested (same casting 2) by applying the compressive load on the steel profile, the result is similar with slips from the beginning and the same value of residual strength $(50 \mathrm{kN})$.

The different shapes of the $\tau$-s curves at the beginning up to the descending branch, on varying the concrete casting, point to the sensitivity of the phenomenon to concrete quality, environmental conditions (humidity and temperature) during hardening (the second casting was done in summer) and shrinkage effect; furthermore in the first mixer a suitable additive to reduce shrinkage was used. The residual strength after peak depends on average upon concrete strength: the greater concrete strength of the second casting causes an enhancement of the residual strength. 
In Figure $6 \mathrm{~b}$ the reference specimen $\mathrm{C} 1$ is compared with specimens $\mathrm{Co} 1$ and $\mathrm{Ca} 1$, belonging to the same casting, with oil at the interface and internal steel reinforcement, respectively. The surface treatment with oil eliminates the initial effect of adhesion, the horizontal branch is reached without a peak and the maximum load is about $25 \%$ of that of the specimen without oil. A negative effect of internal steel reinforcement appears with a load reduction both at the peak and horizontal branch, the residual load being about 15\% lower than standard specimens. This last result may well be due to a lower concrete quality since it is more difficult to vibrate concrete in the presence of steel rebars to have homogeneity; concrete thickness $(20-30 \mathrm{~mm})$ between the steel rebars and the profile surface, that govern the interface bond, could be particularly influenced by inefficient vibration. The detrimental effects of internal reinforcement on bond performance could definitely be reduced in real composite columns characterized by greater dimensions of the concrete section which, due to the thicker cover of the steel rebars, allow better concrete quality particularly along the steel profile interfaces.

In conclusion, the shape of the $\tau$-s curve is sensitive to the quality of concrete depending on several factors (casting and hardening conditions, shrinkage, internal reinforcement), and the effective bond shear strength can be identified as that corresponding to the horizontal branch after the peak. This value is less than proportional to concrete strength (when compressive strength increases by $50 \%$, bond strength increases by $24 \%$ ), but depends heavily on surface roughness, since it falls below $50 \%$ when steel surfaces are impregnated with oil.

\subsection{Tensile Tests}

The experimental results of bond tests on specimens loaded in tension are presented in Figure 7a; the bond-slip curves of these specimens are compared with those tested in compression (C1, C2) and belonging to the same casting (casting 1). The experimental relations show that adhesion and friction phenomena at the beginning are much lower than in compression tests and slips are considerable also for low loads. The shape of the curve is similar to that in compression with a peak and a sharp descending branch, after which the almost horizontal line gives about the same residual strength ( $40 \%$ of peak) as that recorded in compression.

The different behaviour in compression and tension at the beginning of the test is related essentially to the development of greater slip when the tensile load is applied. This result is probably due to the beneficial lateral expansion of concrete in the compression test that improves the friction contribution. After the friction effect wears off, bond behaviour becomes similar for both tensile and compressive loading conditions.

In Figure 7b specimen $\mathrm{T} 1$ is compared with the other two of the same casting, but treated with oil at the interface and with internal steel reinforcement. Reduction in surface roughness due to oil has the same effect observed in the compression test: the peak disappears and the residual strength reduces to $25 \%$ of the reference specimen without oil. Analogously the internal reinforcement, as in the compression test, reduces bond efficiency, eliminating the peak and decreasing the residual strength to $70 \%$ of the reference specimens (T1). Effects of oil and internal reinforcement are related to the same phenomena already described for the compression tests.

Finally, the bond tests carried out by applying tensile loads to the concrete blocks confirm the results obtained in compression tests, highlighting appreciable effects of friction at the steel-concrete interfaces that are drastically reduced by oil or concrete quality. 


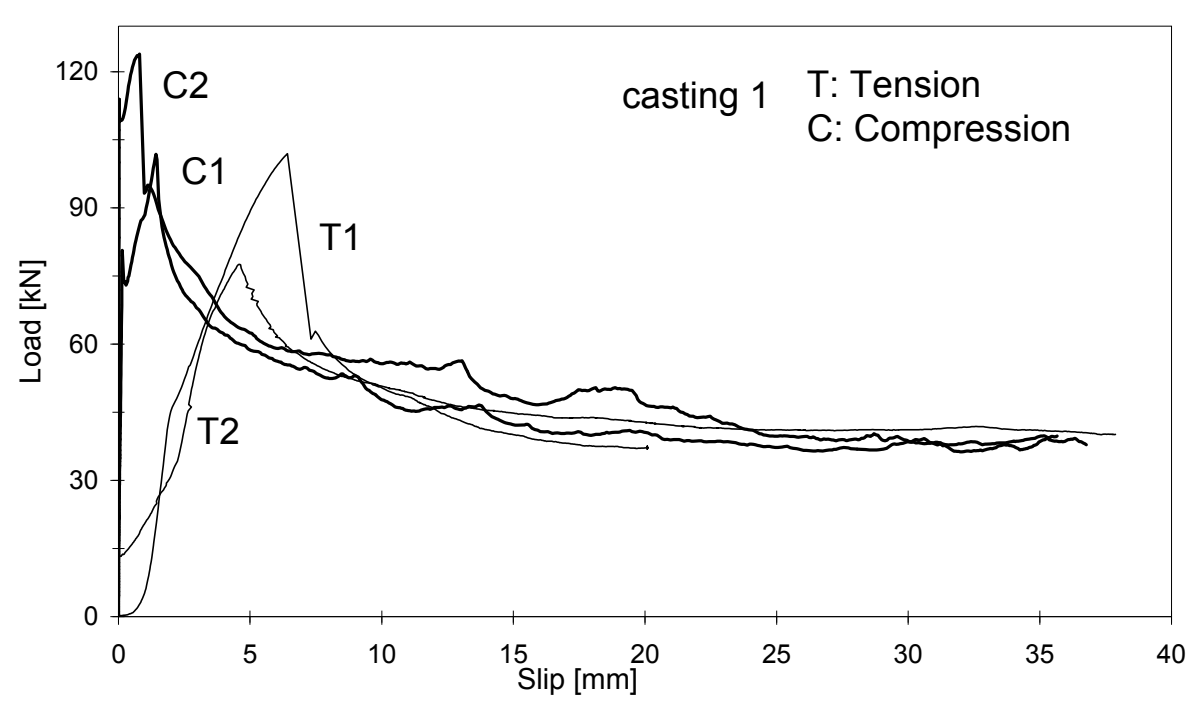

a)

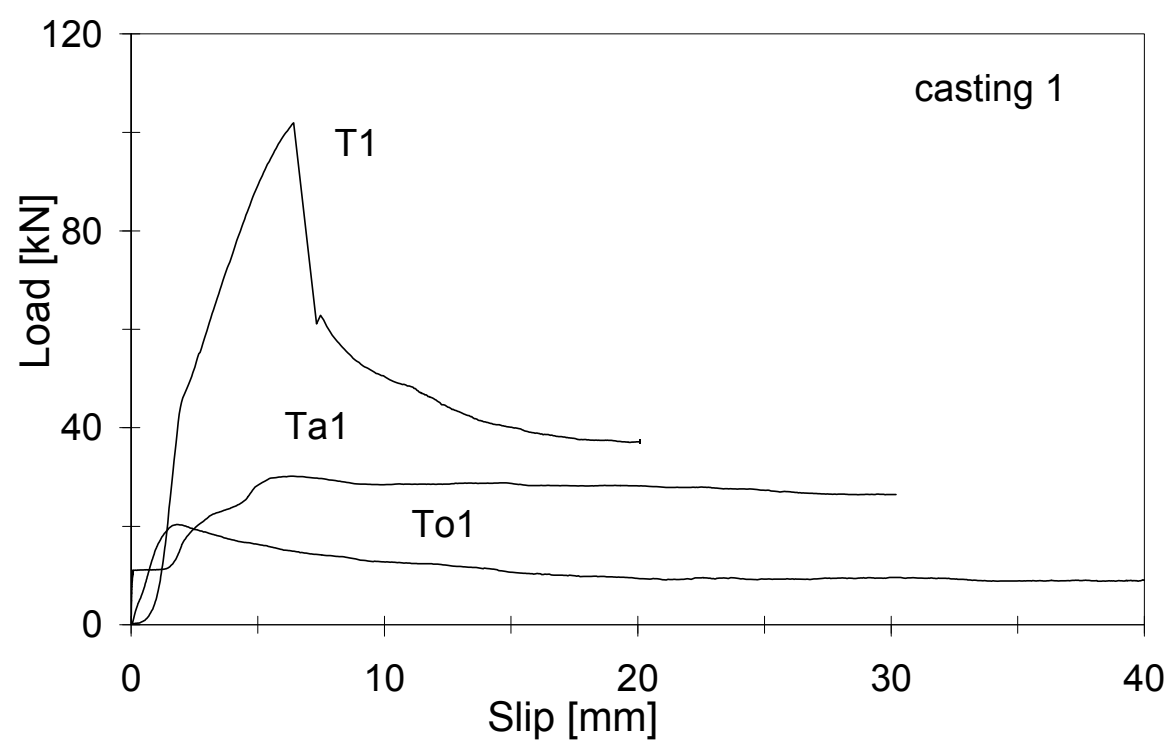

b)

Figure 7. Load-slip Relation for Specimens Tested in Tension: a) Standard Specimens Tested in Tension and Compression; b) Specimens with Internal Reinforcement and Oil

\subsection{Cyclic Tests}

As regards the three cyclic tests, aimed to analyse the structural response under seismic actions, the first (CYC1, casting 2) was carried out by first applying a monotonic compression load history, five cycles were then done between $+20 \mathrm{kN}$ and $-20 \mathrm{kN}$, a monotonic compression load was applied up to a slip of $17 \mathrm{~mm}$ and finally the load was reversed to achieve a zero slip (Figure 8a).

Interestingly, during the five cycles at a load equal to about $40 \%$ of the monotonic strength (specimens C3 and C4 belonging to the same casting) when the load becomes zero, the slip is not recovered and higher slip values are required to regain the same load. An evident phenomenon of pinching occurs and the load is regained only when slip becomes as higher as concrete is able to contrast again the steel profile along the interfaces where friction is not yet overcame. Pinching is typical of bond mechanisms under cyclic loads that is well-known for the bond-slip behaviour of steel bars in reinforced concrete elements or more in general in all phenomena where strength is based on a shear stress transfer between separate components (i.e. at the interfaces of shear cracks in concrete elements). 


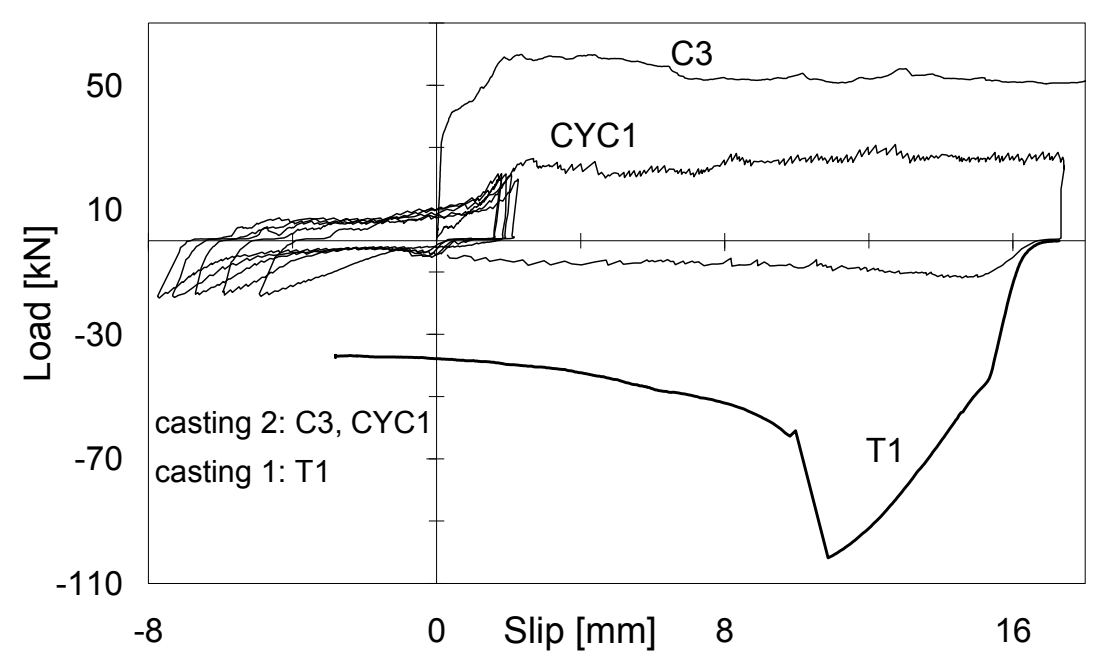

a)

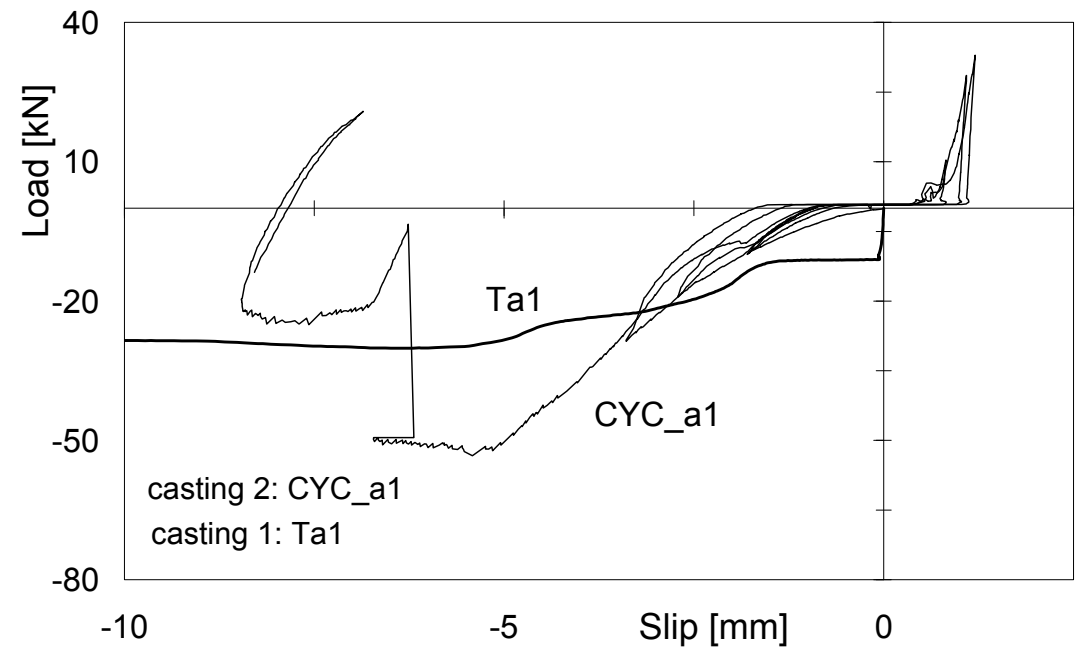

b)

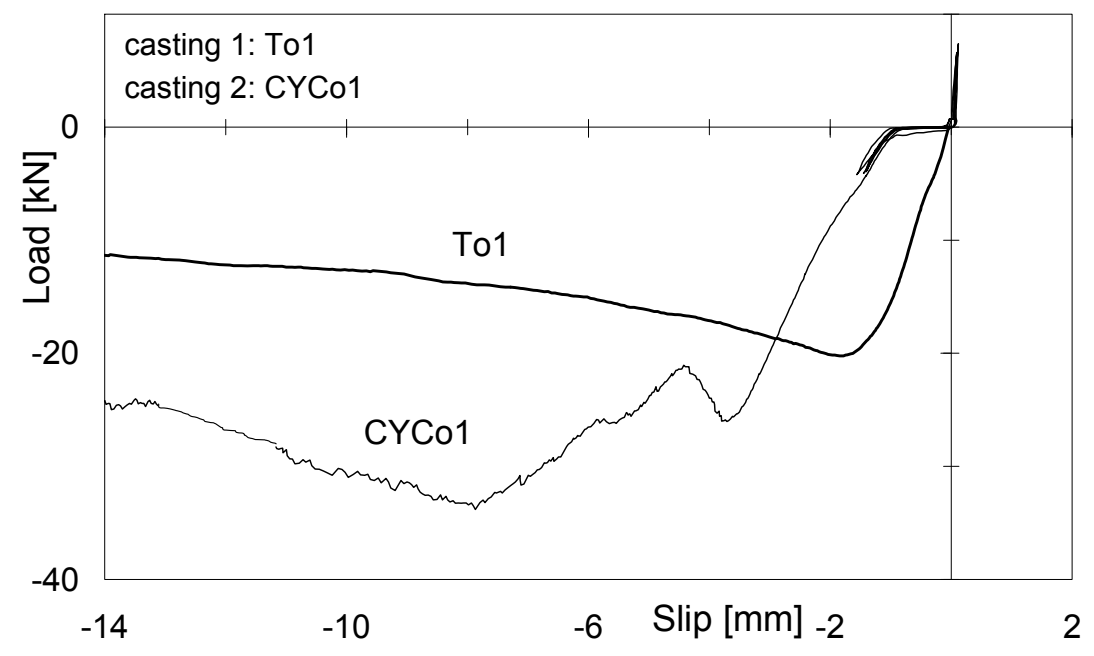

c)

Figure 8. Load-slip Relationship for Cyclic Tests: a) Test Started in Compression;

b) Test Started in Tension; c) Test on Specimen with Oil 
Comparison of the cyclic curves with the monotonic one of a similar specimen belonging to the same casting (C3) shows that residual strength after 5 cycles is about half the monotonic. In the last branch in tension the cyclic curve shows a higher strength reduction than the monotonic, that still refers to a specimen T1 (casting 1) with a concrete strength (22 MPa) lower than that (35 MPa) used for the cyclic tests (casting 2).

In Figure 8b the experimental load vs. slip curve is depicted for a cyclic test on specimen CYCa1 (casting 2) with internal steel reinforcement and loaded first in tension. In this case five cycles were imposed between $+30 \mathrm{kN}$ and $-30 \mathrm{kN}$. The same pinching effect is evidenced and the residual strength reduces by about $18 \%$ against the same specimen (Ta1) loaded monotonically, but belonging to casting 1 with a lower strength (22 MPa).

Finally, Figure 8c shows the result of a cyclic test on specimen CYCo1 treated with oil at the interface. This test was started by loading the specimen first in tension, and then five cycles between $+5 \mathrm{kN}$ and $-5 \mathrm{kN}$ were applied; the test was completed by applying monotonically the load until a residual constant strength was attained. Comparison of the cyclic with the monotonic curve (specimen To1, made of lower strength concrete $22 \mathrm{MPa}$ ) shows there is no reduction in strength due to cyclic loads since the influence of friction, that strongly degrades under cyclic loads, is already reduced by oil.

\section{COMPARISON OF EXPERIMENTAL RESULTS AND CODE PROVISIONS}

\subsection{Code Provisions}

The capacity of composite elements to avoid slip between concrete and steel is related to suitable bond stresses at the interface or to mechanical connections. The Italian code (NTC, 2008) gives the following bond strengths to design composite columns, according to the type of element:

- fully encased: $0.30 \mathrm{MPa}$

- circular concrete-filled: $0.55 \mathrm{MPa}$

- rectangular concrete-filled: $0.40 \mathrm{MPa}$

- for the flanges of partially encased: $0.20 \mathrm{MPa}$

- for the web of partially encased: $0.00 \mathrm{MPa}$

If these limits are exceeded, the entire load has to be transferred by connectors. The same limits are also recommended by Eurocode 4 [5], and similar values were provided in the previous edition of Eurocode 4 and in the Italian guidelines devoted to composite elements (CNR 10016 [7]); in these instructions it was clearly stated that in the joints between elements the transfer length must be no greater than twice the smallest dimension of the cross section. The American code (AISC [6]) gives similar values for concrete-filled columns $(0.40 \mathrm{MPa})$, supplies suggestions about the transfer length at joints, and recommends to neglect bonds for partially encased columns.

The Italian code (NTC [8]) states that for structures under seismic action the transfer of shear stresses by bond mechanism can be not sufficient so that mechanical connectors have to be introduced to guarantee the composite action. In the European code for seismic constructions (Eurocode 8 [13]) the transfer of stresses is not dealt with, but constructive details and geometrical limits have to be applied in the design to assume active collaboration between materials and to develop the required ductility. In columns partially encased with double T profiles, the concrete between flanges can be connected to the web with steel stirrups or rebars in order to form a clear transfer mechanism between the concrete and the steel web. 


\subsection{Experimental Shear Stresses}

In the hypothesis that bond interaction is effective along the entire interface, the mean values of experimental shear stresses are evaluated by dividing the applied load (tensile or compressive) by the entire interface area of the steel profile $\left(\tau=N / A_{p}\right.$ with $\left.A_{p}=29.910^{4} \mathrm{~mm}^{2}\right)$. In Figure 9 the shear stresses are plotted versus slips for all the monotonic tests. Clearly, bond strength (the value indicated by the horizontal branch) is always lower than the limit of $0.2 \mathrm{MPa}$ laid down by EC4 for flanges but higher than zero suggested for the web.

In order to compare the experimental results with the code limits, it seems more appropriate to take into account only the flange interfaces since most codes neglect the web contribution; hence shear stress is re-calculated by dividing the applied load by the interface area of flanges $\left(\tau=N / A_{f l}\right.$ with $\mathrm{A}_{\mathrm{fl}}=16.210^{4} \mathrm{~mm}^{2}$ ). The bonded area of the flanges alone is about half the entire bonded area, such that the bond stresses are about double those previously evaluated, as shown in Figure 9. In Figure 10 the new mean shear stresses are plotted versus slips. All compressive tests, except the specimen treated with oil, show a residual strength greater than $0.2 \mathrm{MPa}$; for tensile tests the specimens with oil and internal reinforcement give values below this limit.

The strain gauges glued on each specimen allowed local shear stresses to be calculated. If the measured strains are multiplied by the elastic modulus of steel the stresses in the profile can be determined neglecting the transversal stresses induced by the transversal deformation of the embedded concrete blocks; this assumption was confirmed by the negligible values of transversal strains in the steel profiles measured by two transducers positioned orthogonally to the specimen axis (Figure 3 a). The difference between stresses in steel at two consecutive points gives the load transferred in this length which, divided by the interface area, gives the shear stress. Shear stresses can be calculated on the flanges or on the web where the strain gauges are glued; the following formula is used to determine shear stress along the flanges:

$$
\tau(x)=t_{f} \cdot B \cdot E_{s} \cdot \frac{\Delta \varepsilon_{i}}{\left(B-t_{w}\right) \cdot \Delta x_{i}}
$$

$t_{f}$ being the thickness and $B$ the width of the flange, $t_{w}$ the thickness of the web, and $\Delta x_{i}$ the distance between two consecutive strain gauges.

In Figure 11a showing an example (specimen C1) of shear stress distribution, the flanges demonstrate a greater transfer between points placed at $100 \mathrm{~mm}$ and $200 \mathrm{~mm}$ from the loaded end (the end of the steel profile). Furthermore, normal stresses increase going away from the loaded end $(\mathrm{x}=0 \mathrm{~mm})$. In Figure 11b the comparison between local bond stresses $\left(\tau_{1}\right.$ and $\tau_{2}$, respectively, at position $100 \mathrm{~mm}$ and $200 \mathrm{~mm}$ from the loaded end) and mean bond stress ( $\tau=\mathrm{N} / \mathrm{A}_{\mathrm{p}}$, with $A_{p}$ of flanges) shows good agreement.

Evaluation of local stresses in steel is useful to accurately determine the distribution of load between the profile components and to define the length necessary to transfer the entire load. The steel stresses in the web and the flanges at $300 \mathrm{~mm}$ from the loaded end are multiplied by the respective area to calculate the force sustained by each sub-component. In Figure 12 the sum of both contributions is compared with the entire applied load: good agreement is shown until the maximum load is reached. This proves that the flanges play the main role supporting almost the entire force, even if the bonded area of web and flange is about the same. This last observation seems to re-confirm the recommendation of Italian and European codes to neglect the bond strength of the web. It is also worth noting that the load transfer is exhausted in the length between the 
measuring points (200 mm and $300 \mathrm{~mm}$ ), since it proved complete at $300 \mathrm{~mm}$ from the loaded end. After the peak the contributions of the sub-components decline, while the applied load remains quite constant. This means that the bond strength was exceeded in the first part of the bonded length and the transfer of shear stresses moved to the remaining undamaged interface (not instrumented) that is still sufficient to sustain a slightly lower than maximum load.

In Figures 13a and 13b the stress-slip curves of Khalil [9] related to concrete-filled square hollow sections (side $h_{a}=150 \mathrm{~mm}$ and thickness $t=5 \mathrm{~mm}$ ) are plotted; the compressive strength of concrete was about $50 \mathrm{MPa}$. The specimens were realized with and without oil and are characterized by three different bond lengths (250, 450, and $600 \mathrm{~mm})$. The results of specimens without oil show that both peak and residual strengths exceed the Italian code threshold (NTC [8]) for concrete-filled rectangular sections (0.40 MPa) only for a bond length of $250 \mathrm{~mm}$; for greater bond lengths the mean experimental value is $0.30 \mathrm{MPa}$. In the presence of oiled surfaces, the strength declines considerably (about 50\%) for all the bonded lengths tested.

In Figures 14a and 14b the experimental results presented herein for partially encased elements are compared with those of Khalil [9], already introduced, and the others of Mouli and Khelafi [12] realized on concrete-filled rectangular sections (mean strength of $45 \mathrm{MPa}$ ) with a bond length of $450 \mathrm{~mm}$. For these tests both the results without (Figure 14a) and with oil (Figure 14b) are analysed. It can be observed that the code limits are not safe for concrete-filled columns and safe, albeit with a low margin, for the partially encased ones. For specimens treated with oil, residual strength is strongly reduced in both types of columns once again indicating the importance of roughness upon the bond stress transfer mechanism.

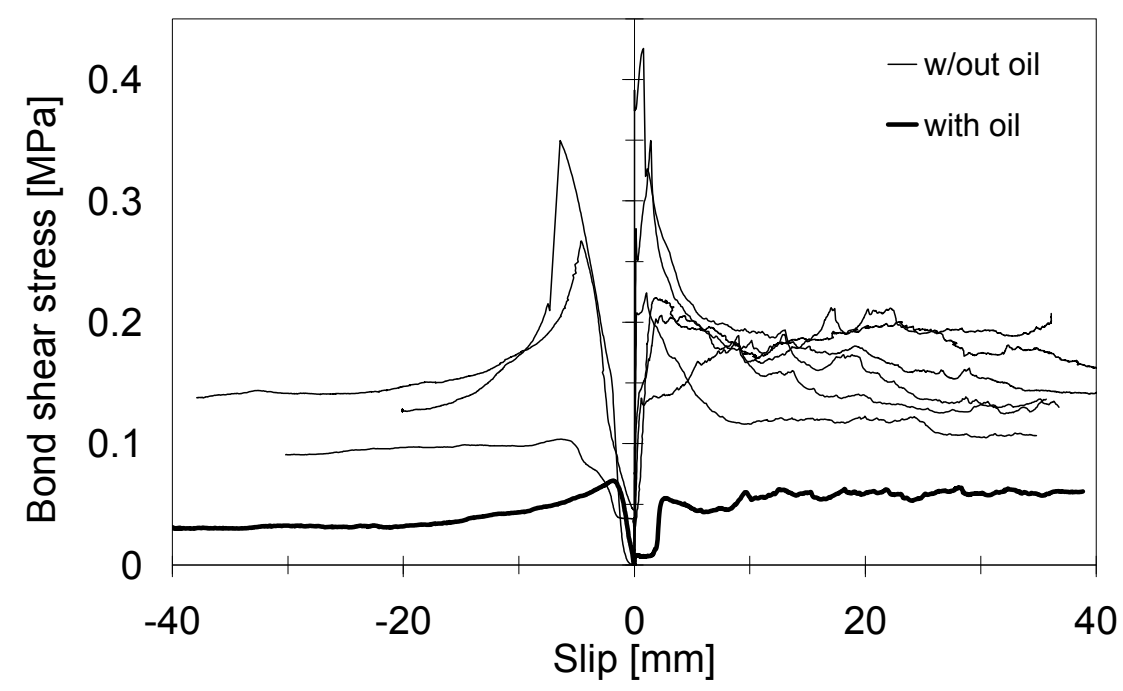

Figure 9. Shear Stress-slip Relationship for All Monotonic Tests 


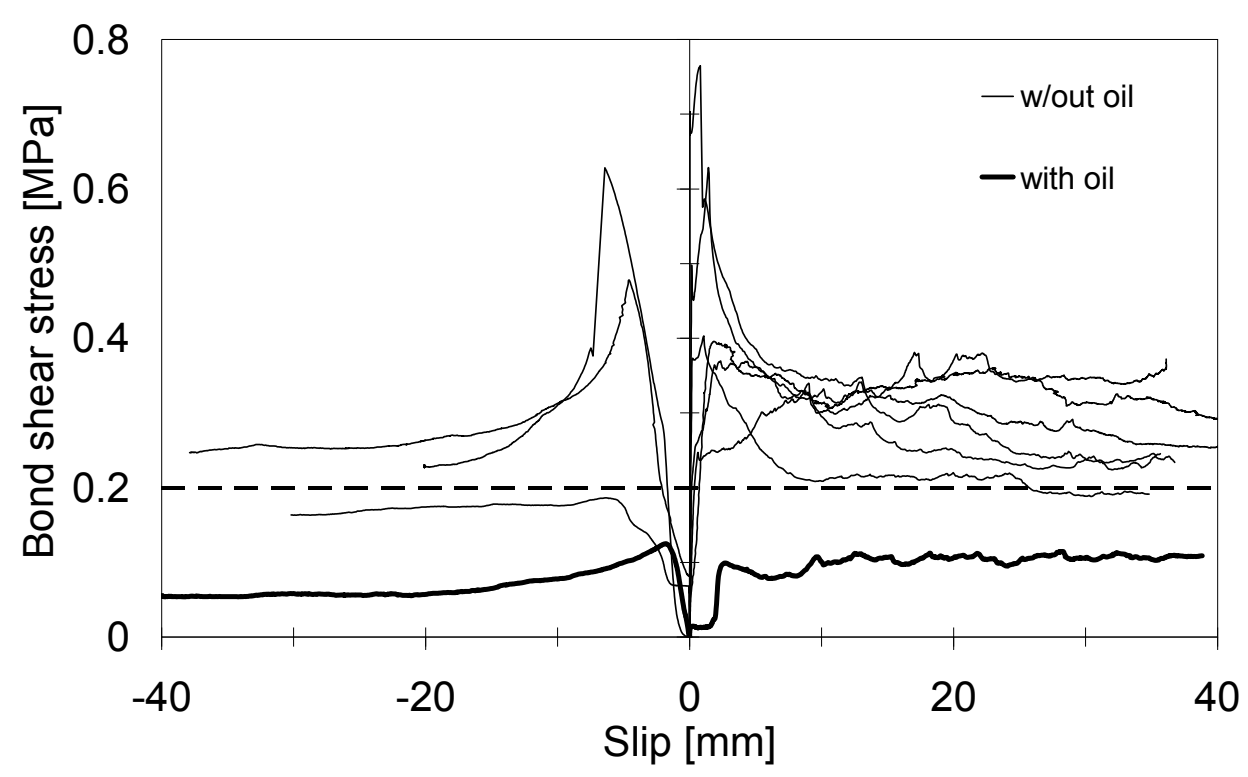

Figure 10. Bond Stress-slip Relationship of All Monotonic Tests assuming only the Flanges Adherent

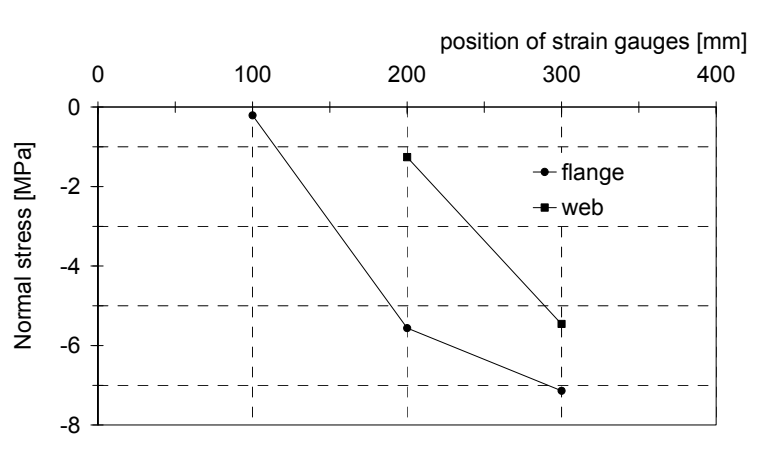

a)

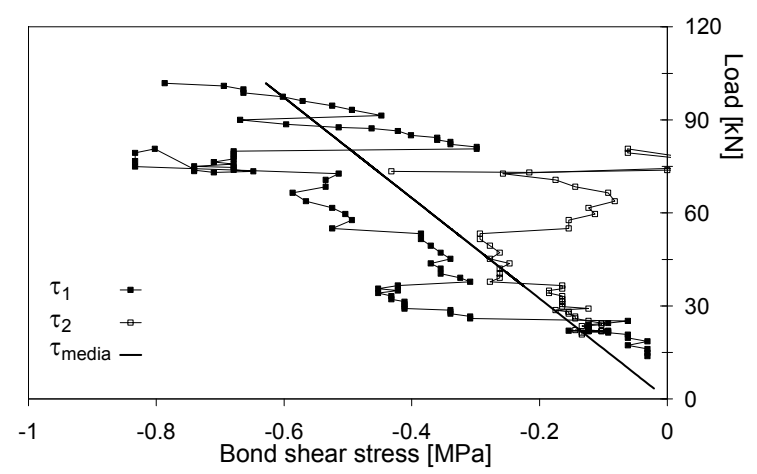

b)

Figure 11. a) Variation of the Bond Stresses along the Flange and the Web of Specimen C1; b) Comparison of Local and Mean Values of Bond Strength for Specimen C1 


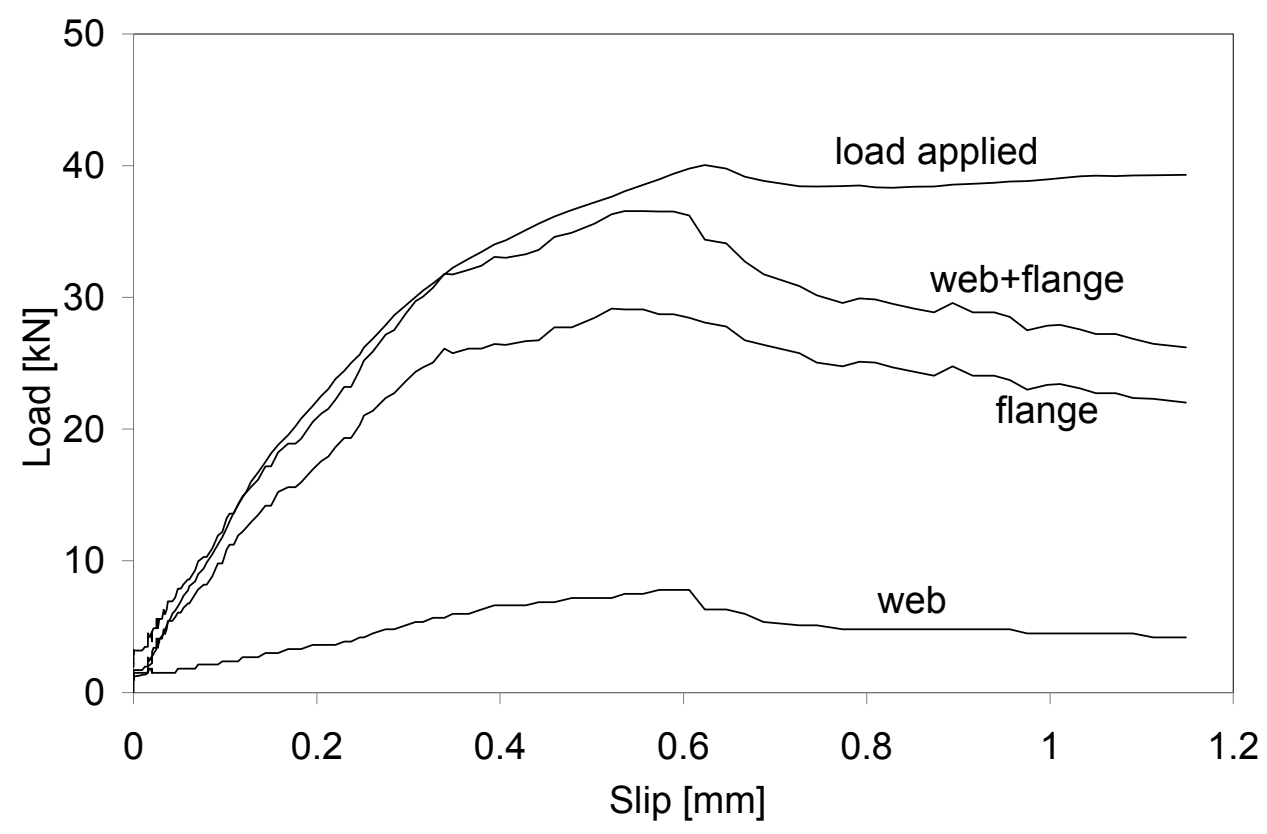

Figure 12. Contributions of the components 

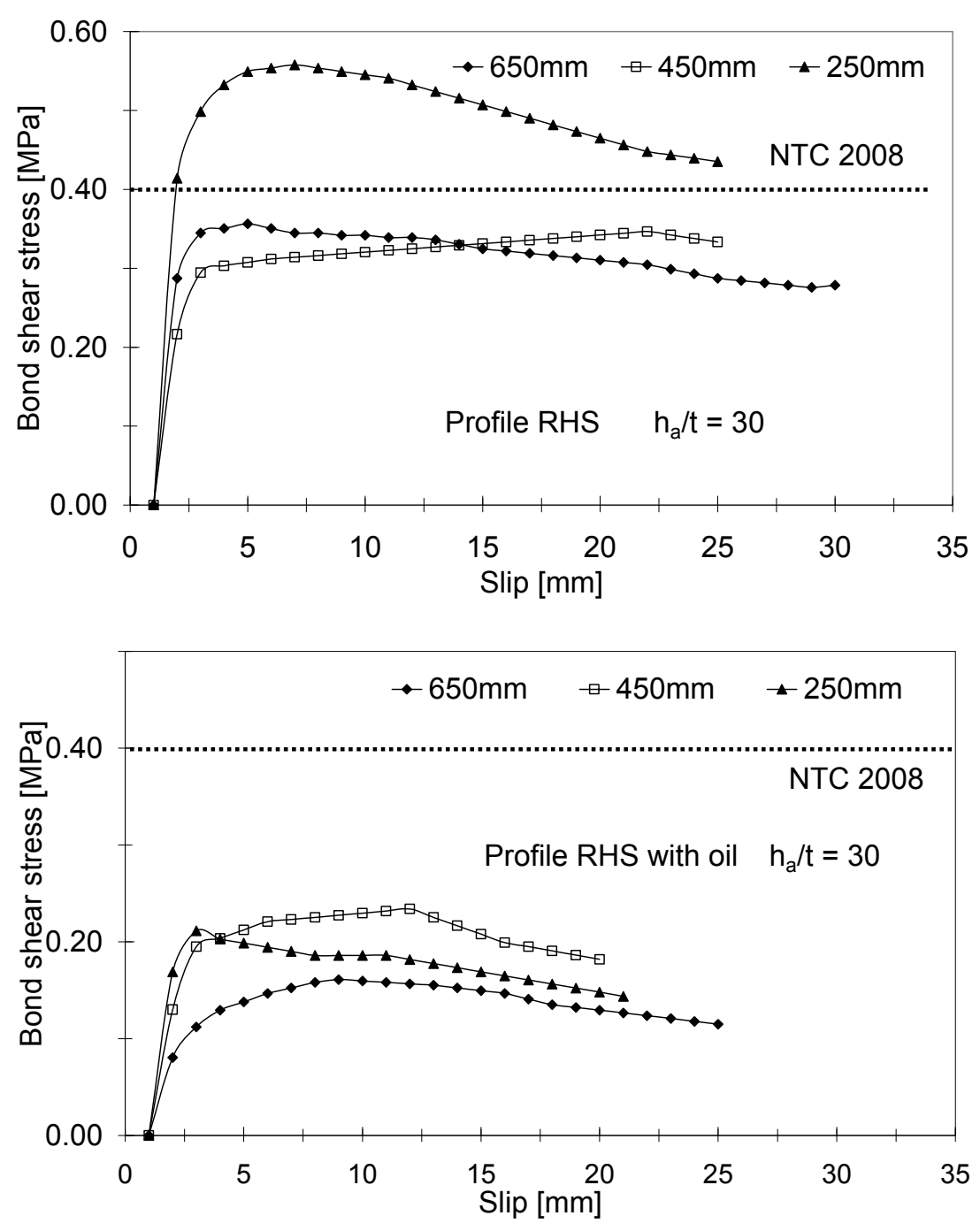

a)

b)

Figure 13. Bond Stress-slip Relationships of Tests by Khalil (1993): a) Concrete-filled Square Sections; b) Concrete-filled Square Sections with Oil at the Interface 


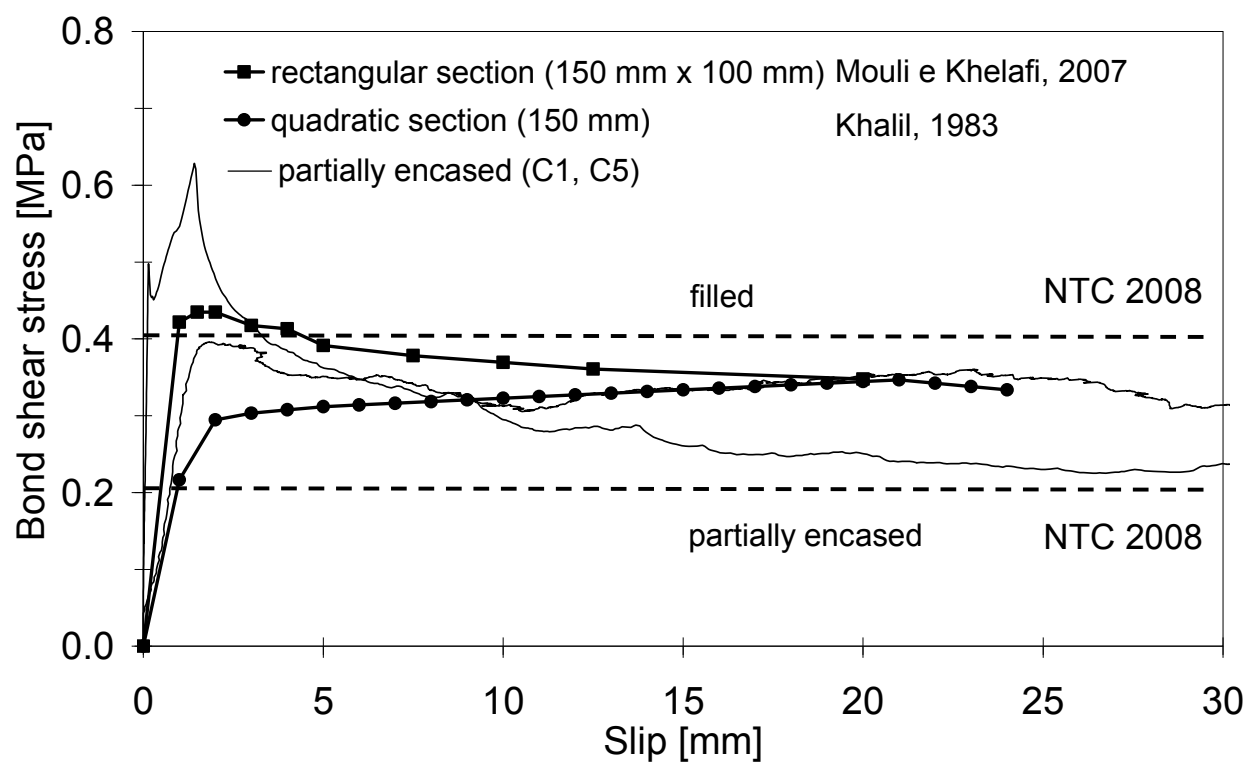

a)

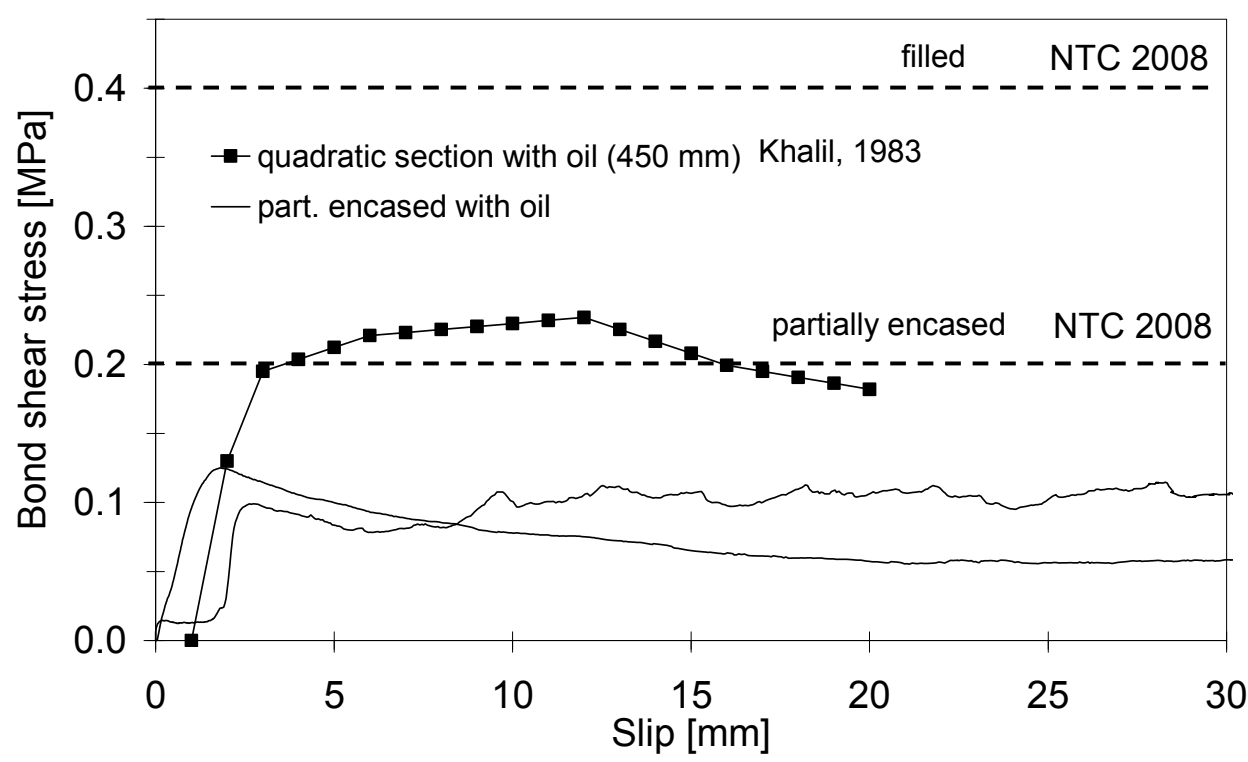

b)

Figure 14. Comparison of the Experimental Results on Partially Filled Columns with those of Khalil [9] and Mouli and Khelafi [12]: a) Specimens without Oil; b) Specimens with Oil 


\section{CONCLUSIONS}

The bond tests carried out to study bond behaviour at the steel-concrete interface in partially encased composite columns provided much information that was hitherto lacking in the technical literature. The first part of the bond-slip relationship is strongly influenced by adhesion and friction, that can result in a very stiff initial branch up to a peak followed by a sharp descending branch and a last horizontal branch with a constant residual bond stress. In other cases, depending on the casting condition of concrete, the behaviour at the beginning is less stiff and the horizontal branch occurs without a peak being reached before. Evidently, bond strength is defined by the horizontal line that allows large slip values to develop.

Application of compressive or tensile loads does not change the residual value of bond strength, that is also invariable if the load is applied on concrete or steel, even though this aspect was analyzed in only one test. The compressive strength of concrete influences the bond strength according to a lower than proportional dependence. Hence concrete strength does not appear a relevant parameter, as already assumed in the codes that set a limit value of bond strength depending only on column type. The specimens with oil at the interfaces showed a reduction in bond strength to less than $50 \%$ that of the reference ones, confirming the importance of friction related to the roughness of the contact surfaces.

A reduction in bond strength of about $10-20 \%$ is also due to the presence of internal steel reinforcement made of longitudinal steel rebars and stirrups, that influence the quality of concrete due to practical difficulties in vibrating the concrete homogeneously in the reduced thickness between the rebars and the surface of the steel profile. Application of tensile load highlights a negligible effect on bond strength and a lower friction effect in the ascending branch due to the absence of transversal dilatation of concrete when tension is applied.

Analysis of the local measures on the web and flanges confirms the higher collaboration of flanges, as suggested by the Italian and European codes. Measurements of the transferred stresses also suggest the transfer length is between $200-300 \mathrm{~mm}$, i.e. 3 times the width of the steel flanges.

The comparison of the results obtained in this experimental program with those of other authors on concrete-filled columns points out that friction is more important in partially encased columns, since the reduction in roughness by treating surfaces with oil causes a larger decrease in bond strength with respect to concrete-filled elements. Finally, the few tests executed according to cyclic load histories show a strong degradation of stiffness and strength in the bond-slip relationship due to the reduction of the fundamental effect of friction.

As regards design provisions, the experimental values of bond strength are always higher than the limit established by Italian and European codes, if the web contribution is neglected and the stress transfer is attributed only to the flanges, as codes suggest. However, since the experimental results show that the limits of the codes do not guarantee a safety factor, the approach of AISC which neglects bond strength in partially encased columns seems sound. Overall, the recommended limits in European and Italian codes need to be reviewed with a view to a reduction, and details about surface conditions may well have to be introduced. Furthermore, in seismic areas the bond contribution has surely to be neglected and suitable connectors have to be applied to guarantee strength and stiffness under cyclic action. 


\section{ACKNOWLEDGEMENTS}

The experimental tests presented in this paper were carried out by the research unit of the University of Sannio for the RELUIS project - task 5 financed by the Civil Protection Department in the period 2005-2008.

\section{REFERENCES}

[1] Cosenza, E. and Zandonini, R., “Composite Construction”, Handbook of Structural Engineering - W.F. Chen Ed., CRC. Boca Raton, Florida, 1997.

[2] Virdi, K.S. and Dowling, P.J., "Bond Strength in Concrete Filled Steel Tubes", Proc. of the IABSE Periodica, 1980, pp. 125-130.

[3] Hamdam, H. and Hunaiti, Y., "Factors Affecting Bond Strength in Composite Columns", Proceedings of the $3^{\text {rd }}$ International Conference on Steel-Concrete Composite Structures, Fukuoka, Japan, 1991, pp. 213-218.

[4] Hunaiti, Y.M., "Aging Effect on Bond Strength in Composite Sections”, Journal of Materials in Civil Engineering, 1994, Vol. 6, No. 4, pp. 469-473.

[5] Eurocode 4, "Design of Composite Steel and Concrete Structures - Part 1.1: General Rules and Rules for Buildings”, European Committee for Standardization, 2004, Brussels, Belgium.

[6] American Institute of Steel Construction, "Specification for Structural Steel Buildings", ANSI/AISC, 2005, 360-05, Illinois, Chicago.

[7] CNR 10016, "Strutture Composte di acciaio e Calcestruzzo Istruzioni per l'impiego Nelle Costruzioni”, CNR Bollettino Ufficiale no. 194 - Norme tecniche, Parte IV, 1999, Roma.

[8] Min.LL.PP, DM 14 gennaio, "Norme Tecniche per le Costruzioni (NTC)”, Gazzetta Ufficiale della Repubblica Italiana, 2008, No. 29 (in Italian).

[9] Khalil, H.S., "Push-out Strength of Concrete-filled Steel Hollow Sections", The Structural Engineer, 1993, Vol. 71, No. 13, pp. 230-233.

[10] Kilpatrick, A.E. and Rangan, B.V., "Influence of Interfacial Shear Transfer on behavior of Concrete-filled Steel Tubular Columns”, ACI Structural Journal, 1999, Vol. 96, S72, pp. 642-648.

[11] Johansson, M. and Gylltoft, K., "Mechanical Behavior of Circular Steel-Concrete Composite Stub Columns”, Journal of Structural Engineering, 2002, Vol. 128, No. 8, pp. 1073-1080.

[12] Mouli, M. and Khelafi, H., "Strength of Short Composite Rectangular Hollow Section Columns Filled with Lightweight Aggregate Concrete”, Engineering Structures, 2007, Vol. 29, No. 8, pp. 1791-1797.

[13] Eurocode 8, "Design of Structures for Earthquake Resistance - Part 1: General Rules, Seismic Actions and Rules for Buildings”, European Committee for Standardization, 2003, Brussels, Belgium. 


\title{
ADVANCED ANALYSIS AND PERFORMANCE BASED EVALUATION OF CONCRTE FILLED TUBE (CFT) COLUMNS
}

\author{
Jong Wan $\mathrm{Hu}^{1, *}$, Joonam Park ${ }^{2}$, and Roberto T. Leon ${ }^{3}$ \\ ${ }^{1}$ Associate Research Fellow, Office of National R\&D Investment Strategy and Analysis, \\ Korea Institute of S\&T Evaluation and Planning (KISTEP), Seoul, 137-130, South-Korea \\ ${ }^{2}$ Senior Researcher, Korea Railroad Research Institute, Ui-Wang City, Kyung-gi, 437-757, South-Korea \\ ${ }^{3}$ Professor, School of Civil and Environmental Engineering, \\ Georgia Institute of Technology, Atlanta, GA, 30332, USA \\ *(Corresponding author: E-mail: jongp24@kistep.re.kr; fax number: +82-2-589-2191)
}

Received: 5 July 2010; Revised: 6 August 2010; Accepted: 23 August 2010

\begin{abstract}
This paper discusses the design of such composite structures which are based on the advanced methods introduced in the 2005 AISC Specification and the 2005 Seismic Provisions. The 2005 AISC specification explicitly allows the use of the full plastic capacities of concrete-filled tube (CFT) columns for members with slender steel walls and provides substantially larger bending capacities than previous specifications. This study focuses particularly on seismic design following the nonlinear method. The paper begins with an examination of pseudo-elastic design interaction equations and the ductility demand ratios due to combined axial compressive force and bending moment in CFT members. Based on advanced computational simulations for a series of low-rise composite-moment frames, this paper then investigates both building performance and new techniques in an effort to evaluate building damage during a strong earthquake. It is shown that 2 dimensional (2D) equivalent static analyses can provide good design approximations to the force distributions in moment frames subjected to large inelastic lateral loads. Dynamic analyses utilizing strong ground motions generally produce higher strength ratios than those from equivalent static analyses, but on more localized basis. Finally, ductility ratios obtained from nonlinear dynamic analyses are also sufficient to detect which CFT columns undergo significant deformations.
\end{abstract}

Keywords: CFT columns; Interaction ratio; Dynamic loads; Ductility; Composite-moment frames; Frame Analyses

\section{INTRODUCTION}

In the last two decades, concrete-filled steel tubes (CFTs) have received widespread acceptance in many parts of the world, particularly, in Japan and other countries in Southeast Asia. CFTs are used as composite columns in multi-story buildings as well as bridge piers because of their superior ductility and toughness. These outstanding performance characteristics are associated with the synergetic action of its ductile steel and high compressive strength concrete components (e.g. Roder [1]). Some of the advantages of CFT columns over other either steel or reinforced concrete systems include (e.g. Azizinamini and Schneider [2]; Hajjar [3]):

- The use of the stiffening action from concrete to prevent the local buckling of slendersteel wall elements and to permit the efficient utilization of thin steel tubes.

- The use of the confining action by the steel walls to increase both the concrete strength (primarily for circular columns or CCFTs) and its ductility (in both CCFTs and rectangular CTFs, or RCFTs).

- The use of concrete as a heat sink in case of fire so that the CFT element can be erected without any fire-proofing, if minimal reinforcement in the form of bars is incorporated.

- The use of the steel section as the formwork that considerably reduces construction costs and that speeds the completion of the building.

Composite CFT columns are especially suited for moment resisting frames in high seismic areas because they (a) have a high strength to weight ratio due to the confinement effect of concrete core, (b) provide excellent monotonic and dynamic resistance under biaxial bending plus axial force, and 
(c) improve damping behavior (e.g. Hu et al. [4]; Rassati et al. [5]; Green et al. [6]). Composite CFT frames consisting of steel I girder and either rectangular or circular CFT columns can be classified into fully restrained (FR) composite frames when welded connections are used at the panel zones.

Design provisions based on the full plastic behavior of composite members and systems are particularly useful in limit state calculations for both non-seismic and seismic resistant design. The new USA code provisions for composite construction - namely, the American Institute of Steel Construction 2005 Specification for Structural Steel Buildings (e.g. AISC Specification [7]) and the Seismic Provisions for Structural Steel Buildings (e.g. AISC Seismic Provision [8]) - present designers with new guidance on the analysis and design of composite columns and moment resisting frames. The current AISC Specification for composite columns is appropriate for predicting the ultimate capacity of CFT beam-columns determined by means of a simplified full plastic stress distribution. The full plastic interaction diagram for a cross section can be easily generated through exact or piece-wise linear approximations so that any combination of axial load and moment can be easily checked in design. The stress distribution used to evaluate the capacity of composite columns can be considered as a simplified approximation on the ground that the tensile capacities of concrete and, in particular, any tension stiffening effects are ignored. It is also because materials are assumed to behave in a bilinear elasto-plastic manner.

The purpose of this research is two-fold. First, it examines the monotonic and cyclic behavior of CFT beam-columns subjected to both axial and moment loading in an attempt to estimate both the maximum strength and ductility for doubly-symmetric and axisymmetric composite cross sections. Moreover, the ultimate capacities for rectangular/circular CFT beam-columns can be estimated with reasonable accuracy by means of the axial and moment (P-M) interaction formulas provided by 2005 AISC Specification for composite systems. Second, based on the analytical study of CFT cross-sectional strength and ductility, advanced computational simulations are carried out on a series of five story composite-moment resisting frames. The primary aim of this portion of the study is to develop preliminarily performance based damage assessment methods for CFT columns in the low-rise composite-moment frames which are designed in accordance with the 2005 Seismic Provisions when subjected to large seismic loads.

\section{METHODOLOGY}

The case studies in this paper comprise both cross-sectional analyses (composite CFT cross section) on 1D nonlinear beam-column elements with 2D fiber cross sections and nonlinear frame analyses. The numerical experiments are performed using a nonlinear structural analysis program, OpenSEES v.1.7.2 (e.g. Mazzoni et al. [9]). The cross-sectional analyses include both circular and rectangular concrete-filled steel tube (CCFT or RCFT) columns. The cross-sectional specimens were subjected to simulations that first applied a constant axial load and then monotonically increased the bending moments while holding the axial load constant. The simulations utilized fiber models consisting of steel and concrete two-dimensional fiber elements available in the OpenSEES program. The mid-height moment-curvature response $(M-\phi)$ of cross-sectional specimens was extracted in order to estimate the overall rotational capacity of CFT columns. The initial P-M interaction curves were also formulated by cross-sectional analyses. These studies verified that the P-M interaction formulas from 2005 AISC Specification are able to accurately predict the capacity of the CFT beam-columns. These analytical results were used to determine the available curvature ductility ratios for CFT columns (e.g. Varma et al. [10]), and these ratios were employed to assess the performance of composite frames that undergo considerable deformations. 
The assessment methods implemented for composite CFT beam-columns as described above can be extended to the nonlinear frame analyses. Within these frame analyses, both static pushover analyses and nonlinear dynamic time history analyses were performed on $2 \mathrm{D}$ composite-moment resisting frames. Two primary indices were employed to quantify expected performance. The first index, which was used for the static pushover and nonlinear dynamic analysis, will be labeled the elastic strength ratio (ESR) and compares the bending plus axial load ratio generated from the frame analyses to that provided by the section selected in the design process. The second index, which will be only used for the non-linear dynamic analysis, results in the inelastic curvature ductility ratio (ICDR) and compares the required rotational ductility given by the frame analyses with the yield ductility predicted by the cross-section one.

\section{OVERVIEW OF APPLICABLE DESIGN GUIDELINES}

The current 2005 AISC Specification includes design guidelines for composite columns consisting of rolled or built-up structural steel shapes, pipe or hollow steel section (HSS) and structural concrete component acting together as a composite member. To qualify as a concrete filled composite column, the following requirements should be satisfied:

- The cross sectional area of HSS shall be at least 1 percent of the total composite cross section.

- The maximum width-thickness ratio for a rectangular HSS shall be less than or equal to $2.26 \sqrt{E_{s} / F_{y}}$.

- The maximum diameter-thickness ratio for a circular HSS filled with concrete shall be equal to $0.15 E_{s} / F_{y}$.

- Larger slenderness are permitted in the practical design when verified by either experimental tests or advanced analyses.

The 2005 AISC Specification endorses the use of the full plastic stress distribution to calculate cross-sectional strength. The calculations are based on the assumption of linear strain across the section height and perfectly elasto-plastic behavior. The nominal strength is estimated by assuming that the steel has reached its yield stress under either tension or compression and that the concrete has reached its crushing strength under only compression as shown in Figure 1. The corresponding stress on an equivalent concrete stress block is taken as $0.85 f_{c}^{\prime}$ and $0.95 f_{c}^{\prime}$ for RCFT columns and CCFT columns, respectively.

The P-M interaction diagram (see Figure 1) for a composite section, which is based on a full plastic stress distribution, can be generated as a conservative linear interpolation between five points (see Table 1) (e.g. Galambos [11]). Point (A) and Point (B) indicate the plastic axial strength and flexural strength of the section, respectively. Point (C) is anchored to the same flexural capacity as Point (B), but its axial resistance comes from the concrete portion in compression only. Point (D) corresponds to the balanced failure condition, giving the maximum flexural strength for the section and an axial capacity equal to one half of that determined for Point (C). Point (E) is an additional, arbitrarily located point to better capture any bulges in the interaction diagram region corresponding to high axial loads. All five points are defined according to Table 1. For design, a simplified bilinear interpolation may be used between Point (A), ( $\left.\mathrm{D}^{\prime}\right)$ and $(\mathrm{B})$ as also shown in Figure 1. The simplified equations shown in Table 2 can be used for determining an index to use as the member capacity in the computation of the elastic strength ratios (ESRs) of composite beam-columns. This approach is reasonably accurate for steel columns and should provide a conservative estimate for composite structures. 
In so far as the frame designs are concerned, those are governed by the Seismic Provisions (e.g. 2005 AISC Seismic Provision [8]). 4 potential classes of composite moment frame (C-MF) are identified in the Part II of the Seismic Provisions as shown in Table 3. For this study, composite-special moment frames (C-SMF), the most ductile system, were selected for the design of several trial low-rise moment frames. Five-story buildings with long bays (36 ft. or $11 \mathrm{~m})$ and perimeter moment resisting systems were used because the intent is to demonstrate the economy of this system for the market segment that constitutes about $90 \%$ of the steel frame construction in the USA. The buildings were designed to the loading prescribed by the ASCE 7-05 (e.g. ASCE [12]). The primary purpose of the ASCE 7-05 standard is to provide information useful to determine the required strength, inter-story drift, and seismic use group for a given structure type and geographical location. The seismic design category (SDC) assigned to a building is a classification based upon the occupancy class and the seismicity of the site. SDC A, B and C generally correspond to structures with the moderate seismic risk or low importance, while SDC D, E, and F require special seismic detailing in the areas of high seismic risk or for critical structures. The designs herein satisfy all the requirements of C-SMF for SDC D in terms of the allowable inter-story drift and the stability limit (e.g. ASCE [12]).

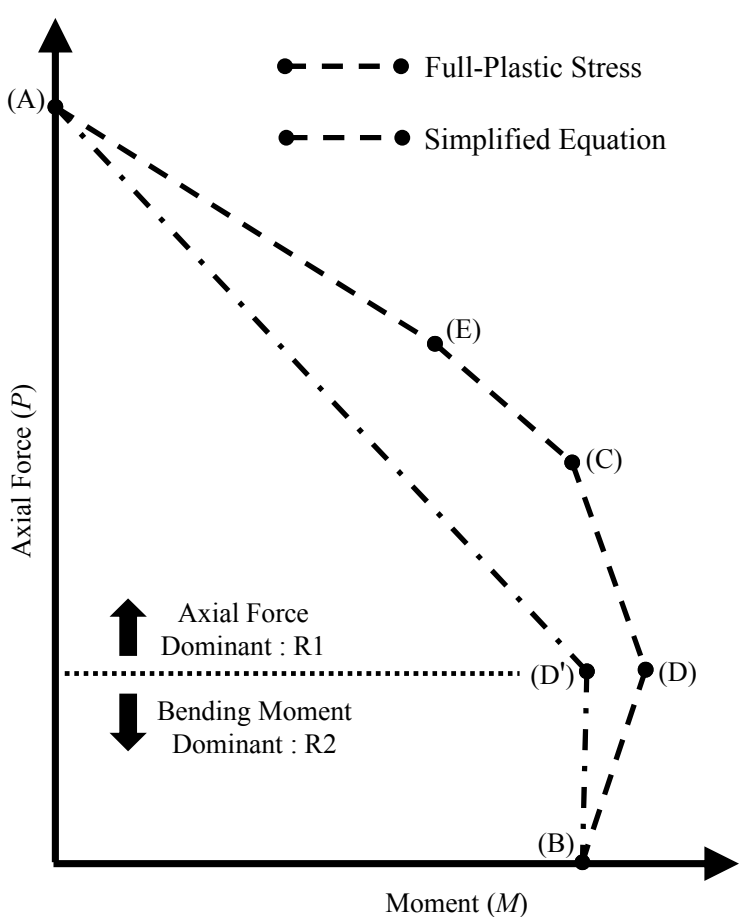

(a) P-M interaction diagrams for composite beam-columns

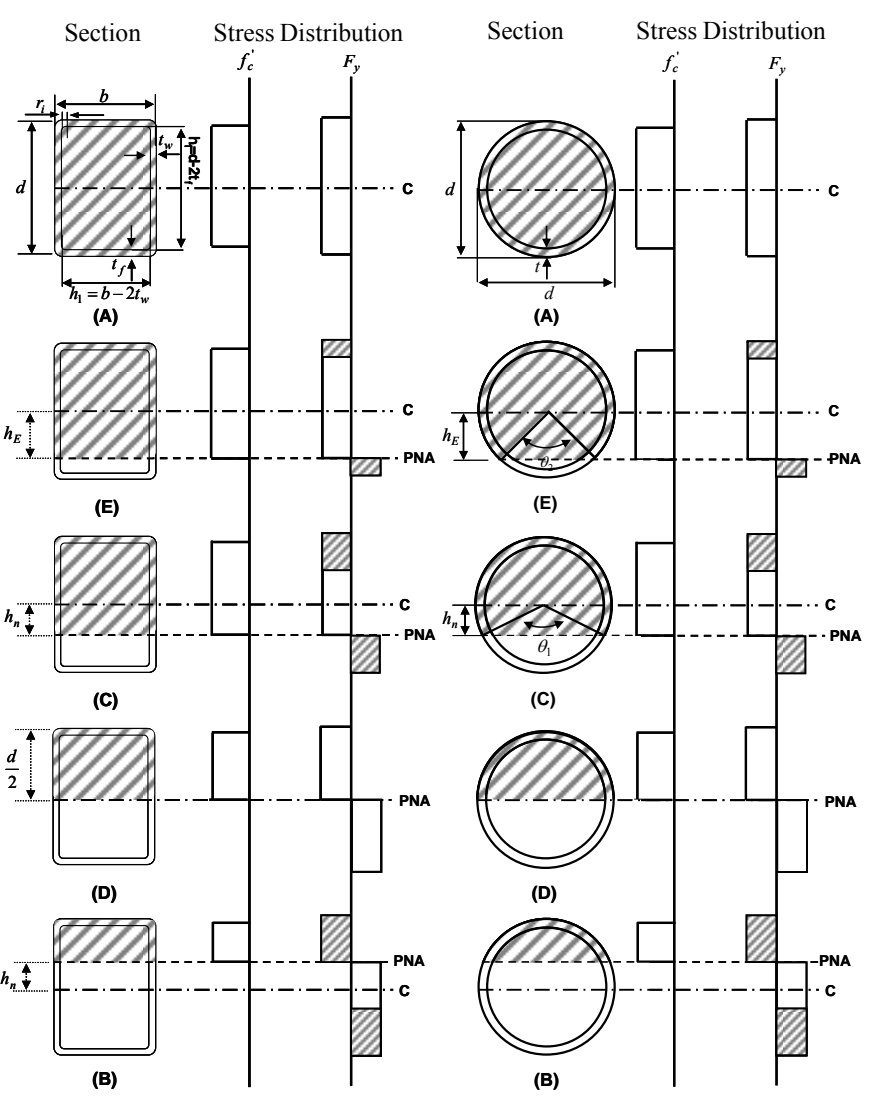

(b) Full plastic stress distributions for RCFT and CCFT at point A to D

Figure 1. P-M Interaction Diagram for the Composite CFT Section and Full Plastic Stress Distribution Over the Section Height at Five Specific Points 


\section{CFT BEAM-COLUMN ANALYSES}

Two CFT relatively stocky cross sections were modeled as numerical fiber sections using the OpenSEES program as shown in Figure 2. The rectangular tube (HSS16X16X625) has a wall slenderness of 24.5 which is well below the limit of 56.7 allowed by the 2005 AISC specification. Similarly, the circular tube (HSS18X500) has a slenderness of 36 which is also below the limit of 103.6 allowed by this specification. The rectangular tube was designed with A572-Gr. 50 steel material $\left(F_{y}=320 \mathrm{MPa}\right.$ or $\left.46 \mathrm{ksi}\right)$, while the circular one was designed with A500-Gr.B steel material ( $F_{y}=290 \mathrm{MPa}$ or $42 \mathrm{ksi}$ ) as specified in the AISC-LRFD code (e.g. AISC [13]). The inside core was modeled as the confined concrete with $f_{c}^{\prime}=27.9 \mathrm{MPa}$.

Table 1. P-M Interaction Strength Formulas for Five Specific Points

\begin{tabular}{|c|c|c|}
\hline Point & Equation for RCFT & Equation for CCFT \\
\hline (A) & $\begin{array}{l}P_{A}=A_{S} F_{y}+A_{c}\left(0.85 f_{c}^{\prime}\right) \\
M_{A}=0 \\
A_{s}=\text { area of steel shape } \\
A_{c}=h_{1} h_{2}-0.858 r_{i}^{2}\end{array}$ & $\begin{array}{llrl}P_{A} & =A_{S} F_{y}+0.85 f_{c}^{\prime} A_{c}^{*} & r_{m} & =\frac{d-t}{2} \\
M_{A} & =0 & A_{c} & =\frac{\pi h^{2}}{4} \\
A_{s}=\pi r_{m} t & & \end{array}$ \\
\hline (E) & $\begin{array}{l}P_{E}=\frac{1}{2}\left(0.85 f_{C}^{\prime}\right) A_{C}+0.85 f_{c}^{\prime} h_{1} h_{E}+4 F_{y} t_{w} h_{E} \\
M_{E}=M_{\max }-\Delta M_{E} \\
Z_{s E}=b h_{E}^{2}-Z_{c E} \quad Z_{c E}=h_{1} h_{E}^{2} \\
\Delta M_{E}=Z_{s E} F_{y}+1 / 2 Z_{c E}\left(0.85 f_{C}^{\prime}\right) \\
h_{E}=\frac{h_{n}}{2}+\frac{d}{4}\end{array}$ & $\begin{aligned} P_{E}= & \left(0.85 f_{C}^{\prime} A_{C}+F_{y} A_{s}\right)-1 / 2\left[F_{y}\left(d^{2}-h^{2}\right)+1 / 2\left(0.85 f_{C}^{\prime}\right) h^{2}\right]\left[\theta_{2} / 2-\sin \theta_{2} / 2\right. \\
M_{E} & =Z_{S E} F_{y}+1 / 2 Z_{C E}\left(0.85 f_{C}^{\prime}\right) \\
h_{E} & =\frac{h_{n}}{2}+\frac{d}{4} \quad h=d-2 t \\
Z_{S E} & =\frac{d^{3} \sin ^{3}\left(\theta_{2} / 2\right)}{6}-Z_{C E} \quad Z_{C E}=\frac{h^{3} \sin ^{3}\left(\theta_{2} / 2\right)}{6} \\
\theta_{2} & =\pi-2 \arcsin \left(2 h_{E} / h\right)\end{aligned}$ \\
\hline (C) & $\begin{aligned} P_{C} & =A_{c}\left(0.85 f_{c}^{\prime}\right) \\
M_{C} & =M_{B}\end{aligned}$ & $\begin{array}{l}P_{C}=0.85 f_{c}^{\prime} A_{c} \\
M_{C}=M_{B}\end{array}$ \\
\hline (D) & $\begin{aligned} P_{D} & =\frac{0.85 f_{c}^{\prime} A_{c}}{2} \\
M_{D} & =Z_{s} F_{y}+1 / 2 Z_{c}\left(0.85 f_{c}^{\prime}\right) \\
Z_{s} & =\text { full y-axis plastic section modulus of steel shape } \\
Z_{c} & =\frac{h_{1} h_{2}^{2}}{4}-0.192 r_{i}^{3}\end{aligned}$ & $\begin{array}{l}P_{D}=\frac{0.85 f_{c}^{\prime} A_{c}}{2} \\
M_{D}=Z_{s} F_{y}+1 / 2 Z_{c}\left(0.85 f_{c}^{\prime}\right) \quad h=d-2 t \\
Z_{s}=\text { plastic section modulus of steel shape }=\frac{d^{3}}{6}-Z_{c} \\
Z_{c}=\frac{h^{3}}{6}\end{array}$ \\
\hline (B) & $\begin{aligned} P_{B} & =0 \\
M_{B} & =M_{D}-Z_{s n} F_{y}-1 / 2 Z_{c n}\left(0.85 f_{c}^{\prime}\right) \\
Z_{s n} & =2 t_{w} h_{n}^{2} \\
Z_{c n} & =h_{1} h_{n}^{2} \\
h_{n} & =\frac{0.85 f_{c}^{\prime} A_{c}}{2\left[0.85 f_{c}^{\prime} h_{1}+4 t_{w} F_{y}\right]} \leq \frac{h_{2}}{2}\end{aligned}$ & $\begin{array}{l}P_{B}=0 \\
M_{B}=Z_{s B} F_{y}+1 / 2 Z_{c B}\left(0.85 f_{c}^{\prime}\right) \\
Z_{s B}=\frac{d^{3} \sin ^{3}\left(\frac{\theta}{2}\right)}{6}-Z_{c B} \quad \begin{array}{l}K_{c}=f_{c}^{\prime} h^{2} \\
K_{s}=F_{y} r_{m} t\end{array} \\
Z_{c B}=\frac{h^{3} \sin ^{3}\left(\frac{\theta}{2}\right)}{6} \quad h_{n}=\frac{h}{2} \sin \left(\frac{\pi-\theta}{2}\right) \leq \frac{h}{2} \\
\theta_{1}=\frac{0.0260 K_{c}-2 K_{s}}{0.0848 K_{c}}+\frac{\sqrt{\left(0.0260 K_{C}+2 K_{S}\right)^{2}+0.857 K_{C} K_{S}}}{0.0848 K_{C}}\end{array}$ \\
\hline
\end{tabular}

The numerical CFT beam-column specimens are made up of flexible elements based on nonlinear stress-strain material response with discrete fiber sub-regions (e.g. quadrilateral, circular and triangular shapes). The material properties for CFT columns were simulated utilizing the effects of isotropic strain hardening, Bauschinger behavior, and biaxial stress for the steel tube and the uniaxial compressive Kent-Scott-Park stress-strain behavior model for confined concrete. The latter includes the effects of stress degradation and crack opening and closing (e.g. Mazzoni et al. [9]). 
Table 2. Simplified Equations Determined for ESRs

\begin{tabular}{|c|c|}
\hline Prior condition & Simplified equation \\
\hline$P_{r}<P_{D}$ & $\frac{M_{r}}{M_{B}}<1$ \\
\hline$P_{r} \geq P_{D}$ & $\frac{P_{r}-P_{D}}{P_{A}-P_{D}}+\frac{M_{r}}{M_{D^{\prime}}} \leq 1$ \\
\hline
\end{tabular}

The numerical test setup for a fiber based nonlinear beam-column element is shown in Figure 3 (a). Both element deformations and forces were recorded at each integration point. These integration points can be converted into simple zero-length section elements to extract the force-deformation relationship (i.e. $P-\varepsilon$ or $M-\phi$ ) for the composite cross section (e.g. Mazzoni et al. [9]; Varma et al. [10]). This section element is defined by the two nodes at the same position and discrete fiber based section as shown in Figure 3 (b). The test section model was subjected to various levels for the axial force, roughly corresponding to the axial load levels of five interpolation points given by the code provisions. Therefore, the fiber section analyses were conducted on the section elements based on the loading control that the constant axial load level as applied first and then the moment was continuously increased.

Table 3. Summarize Table for C-MF Structures

\begin{tabular}{|c|c|c|c|c|}
\hline C-MF Type & $\begin{array}{l}\text { Yield Shape and Main } \\
\text { Deformation }\end{array}$ & SDC & Moment Connections & Other System Requirements \\
\hline C-PRMF & $\begin{array}{l}\text { Limited yielding occurs in } \\
\text { column base and main yielding } \\
\text { occurs in the ductile components. }\end{array}$ & $\begin{array}{c}\mathrm{C} \\
\text { or } \\
\text { below }\end{array}$ & $\begin{array}{l}\text { A nominal strength is at least equal to } 50 \\
\text { percent of } \mathrm{M}_{\mathrm{p}} \text {. Connections shall be } \\
\text { capable of sustaining the total inter-story } \\
\text { drift of } 0.04 \mathrm{rad} \text {. }\end{array}$ & $\begin{array}{l}\text { Composite beams shall be encased } \\
\text { and fully composite. The stiffness of } \\
\text { beams shall be determined by } E I_{\text {eff }} \\
\text { for the composite section. }\end{array}$ \\
\hline C-SMF & $\begin{array}{l}\text { Limited inelastic deformations } \\
\text { occur in the columns and/or } \\
\text { connections and main yielding } \\
\text { occurs in the beams. }\end{array}$ & $\begin{array}{c}\mathrm{D} \\
\text { and } \\
\text { above }\end{array}$ & $\begin{array}{l}\text { The required strength shall be determined } \\
\text { with the expected flexural strength }\left(R_{y} \mathrm{M}_{\mathrm{n}}\right) \text {. } \\
\text { Connections shall be capable of sustaining } \\
\text { the total inter-story drift of } 0.04 \mathrm{rad} \text {. }\end{array}$ & $\begin{array}{l}\text { Composite columns shall meet the } \\
\text { requirement of the special seismic } \\
\text { systems of Sec. } 6.4 \text { or Sec. } 6.5 \text { (e.g. } \\
\text { ANSI. } 360-05 \text { [7]), as appropriate. }\end{array}$ \\
\hline C-IMF & $\begin{array}{l}\text { Moderate inelastic deformations } \\
\text { occurs in the columns and/or } \\
\text { connections and main yielding } \\
\text { occurs in the beams }\end{array}$ & $\begin{array}{c}\mathrm{C} \\
\text { and } \\
\text { below }\end{array}$ & $\begin{array}{l}\text { The required strength of connections shall } \\
\text { be based on the plastic capacity of steel } \\
\text { beams. Connections can sustain the total } \\
\text { inter-story drift of } 0.03 \mathrm{rad} \text {. }\end{array}$ & $\begin{array}{l}\text { Composite columns shall meet the } \\
\text { requirement of the intermediate } \\
\text { seismic systems of Sec. } 6.4 \text { or Sec. } \\
6.5 \text {, as appropriate. }\end{array}$ \\
\hline C-OMF & $\begin{array}{l}\text { The limited inelastic action will } \\
\text { occur in the beam, columns } \\
\text { and/or connections }\end{array}$ & $\begin{array}{c}\mathrm{A} \\
\text { and } \mathrm{B}\end{array}$ & $\begin{array}{l}\text { Connections can sustain the total inter- } \\
\text { story drift of } 0.02 \mathrm{rad} \text {. }\end{array}$ & $\begin{array}{l}\text { Composite columns shall meet the } \\
\text { requirement of the ordinary seismic } \\
\text { systems of Sec. } 6.4 \text { or Sec. } 6.5 \text {. }\end{array}$ \\
\hline
\end{tabular}

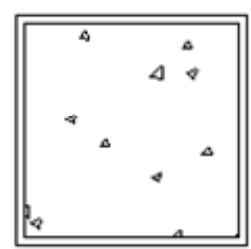

RCFT:HSS16X16X625

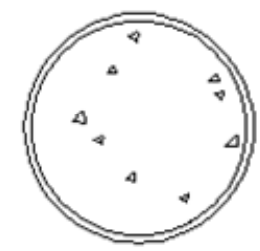

CCFT:HSS18X500
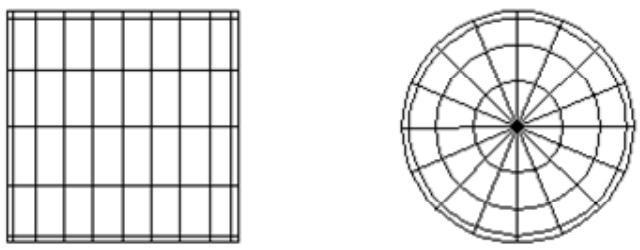

Fiber based beam column elements

Figure 2. Cross Sections for CFT Columns and Idealized Fiber Section Models for Numerical Experiments 
The analytical test results plotted as the moment and curvature response for composite CFT sections are shown in Figure 4 for the case where the zero-length section elements are subjected to the eccentric load. It is composed of a constant axial load corresponding to the axial resistance from half of the pure concrete part (i.e. $P_{D}$ at the Point D shown in Figure 1) and consecutively increasing bending moment. The plastic moment curvature can be captured on the point determined by the computation by dividing the yield stain of the steel tube into the half width of inside concrete, such that $\phi_{P}=2 \varepsilon_{y} / h_{1}$. The plastic moment based on the full plastic yield stress of the steel tube $\left(M_{P}\right)$ is obtained on the plastic moment curvature at the moment and curvature curve (see Figures 4 (a) and (b)). Therefore, the plastic moment capacities of composite CFT sections under each axial force level are able to be estimated through the fiber section analyses (e.g. $M_{P}=M_{D}=1260 \mathrm{kN}-\mathrm{m}$ for HSS16X16X625 section under $P=P_{D}=1644 \mathrm{kN}$; see Figure 4 (a)).

Since the strain hardening effect was assigned into the steel tube sections, the extra section capacity from the plastic yield moment to the ultimate moment $\left(M_{u}\right)$ was provided as shown in the curves. The envelope of the post-yield section behavior can be used to develop the inelastic curvature ductility ratio (ICDR). The proportional slope $\left(K_{i}\right)$ is defined as the initial secant flexural stiffness corresponding to the serviceability level of the moment generally taken as $0.6 M_{u}$ (see Figure (4)). The ICDR is defined as $\phi_{u}$ divided by $\phi_{y} . \phi_{y}$ denotes the curvature at the nominal yield defined as $M_{u}$ divided by $K_{i} . \phi_{u}$ indicates the ultimate curvature. The degree of the post-yield response is well expressed by this ratio. On the other hand, the index defined as the ductility ratio at the structural behavior can change in accordance with the amount of the material strain hardening.
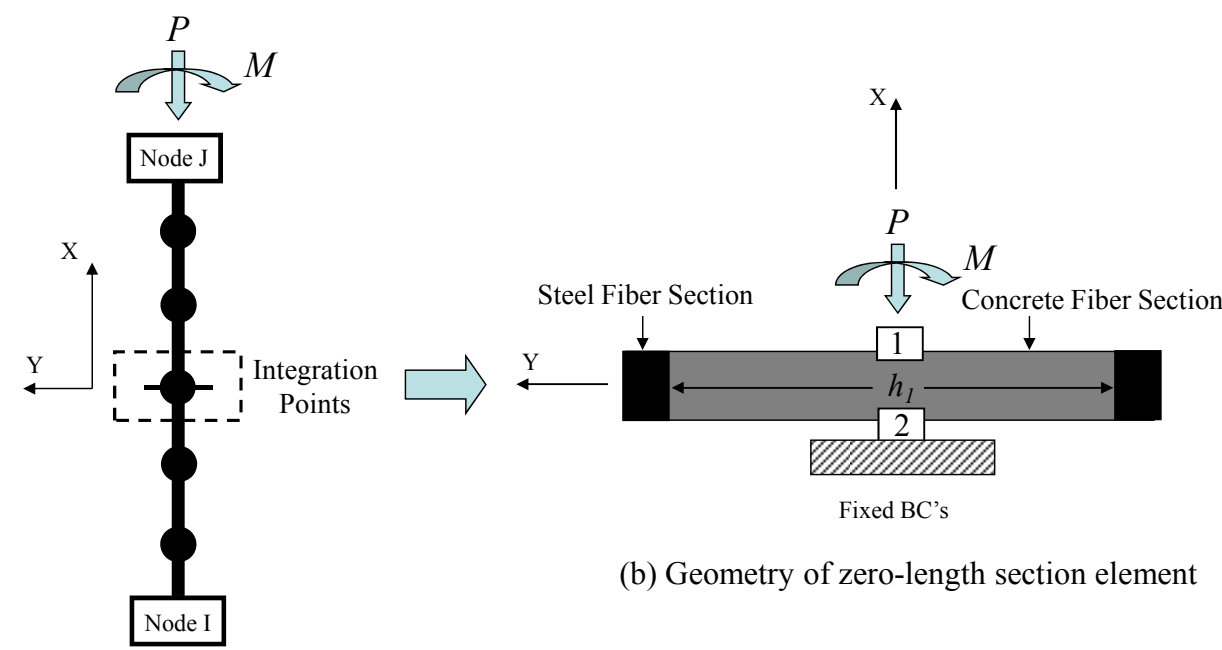

(b) Geometry of zero-length section element

(a) Element for beam-column

Figure 3. Test Setup for the Nonlinear Beam-column Element and Zero-length Section Element

The P-M interaction diagrams resulting from the fiber section analyses are compared with those from the equations listed in Table 1. Comparisons between two diagrams are shown in Figure 5. In addition to the overall plastic yield of steel tube sections, the points obtained by the fiber section analyses are equivalent to the achievement of the maximum concrete strength. P-M interaction diagrams compared to each other show good agreement, indicating that the analytical results are adequate to estimate the capacity of the composite CFT sections with considerable accuracy. 


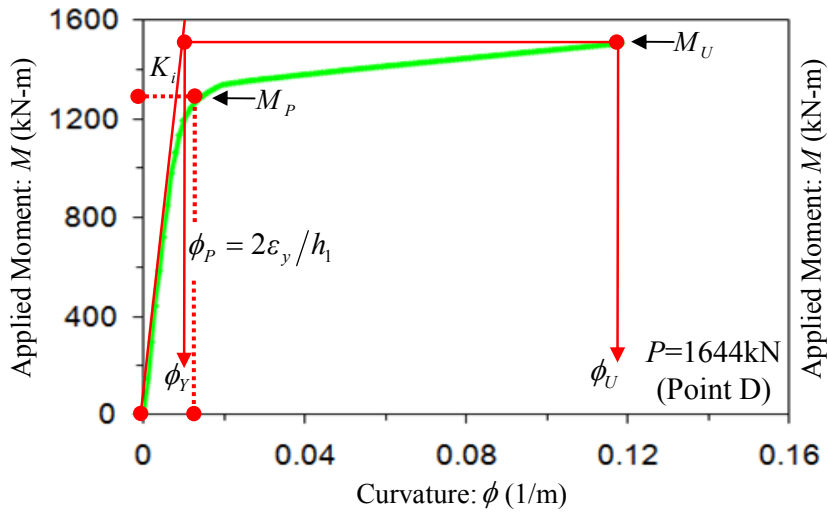

(a) RCFT Column (HSS16X16X625)

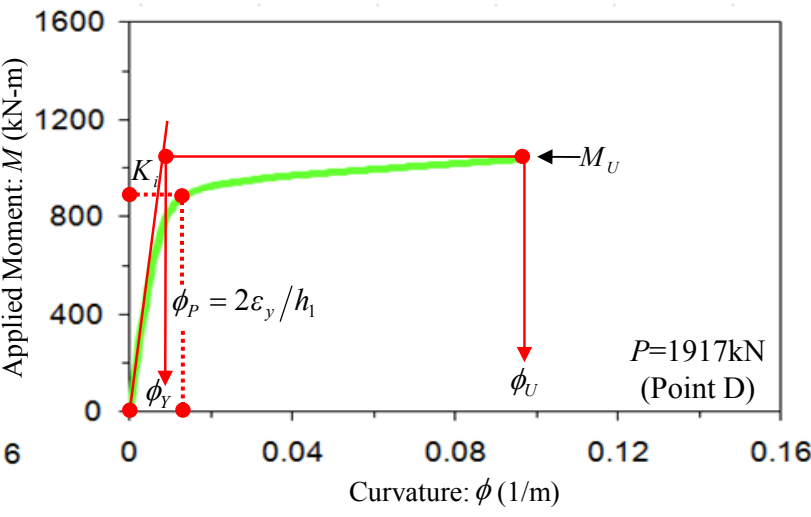

(b) CCFT Column (HSS18X500)

Figure 4. Moment and Curvature response for the composite CFT sections under the axial force $P_{D}$

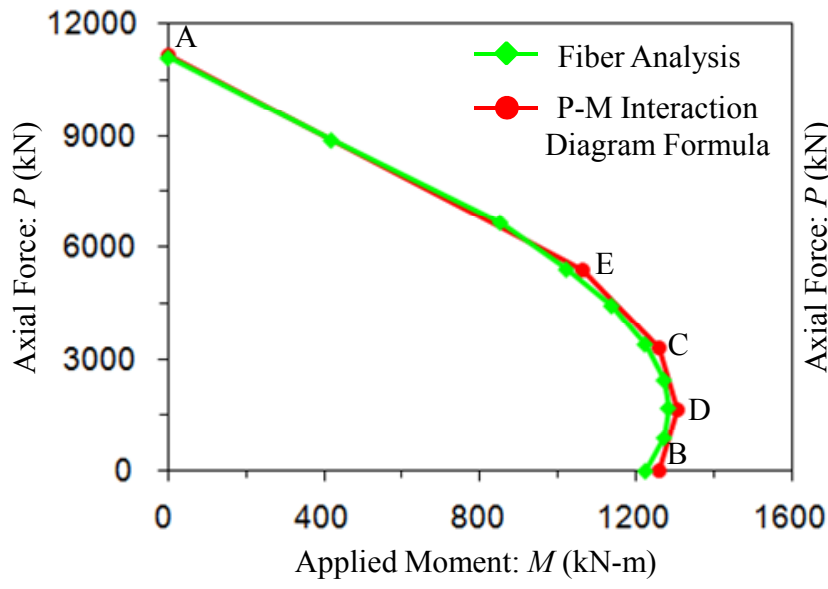

(a) RCFT Column (HSS16X16X625)

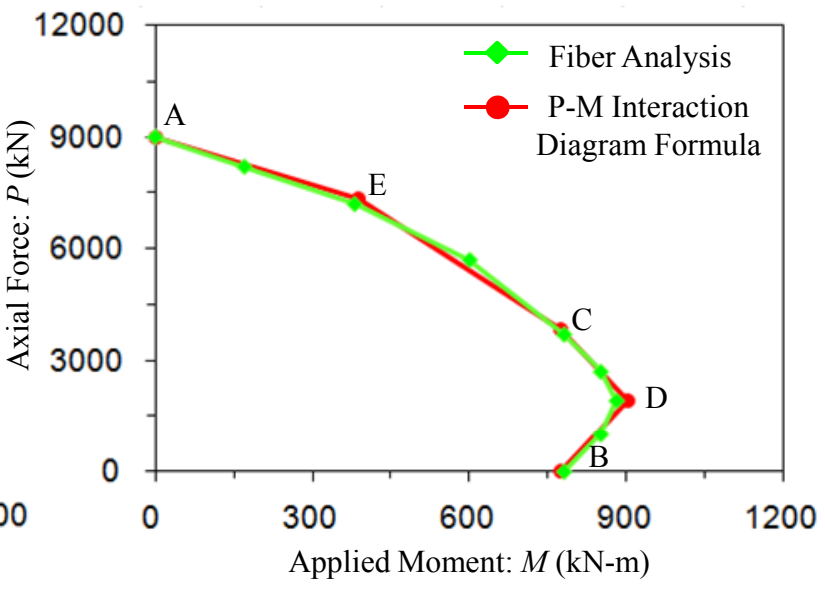

(b) CCFT Column (HSS18X500)

Figure 5. Comparisons of P-M Interaction Diagrams

\section{NONLINEAR FRAME ANALYSES}

For nonlinear frame analyses, five-story composite moment frames were designed with either RCFT columns (5SRCFT model) or CCFT columns (5SCCFT model). These structures were first evaluated using an equivalent static lateral load procedure (pushover) and then using nonlinear dynamic analysis for a ground motion taken from the 1994 Northridge earthquake. Thus, the structures were assumed to be located in LA area with high seismicity corresponding to SDC D and a soil site (e.g. ASCE [12]) and designed by using the mapped spectrum accelerations corresponding to $S_{S}=1.60 \mathrm{~g}$ for the short period and $S_{I}=0.6 \mathrm{~g}$ for 1 second period. The geometric nonlinearity (i.e. P-Delta effect) was included in the frame model. The equivalent lateral loads $\left(E_{a}\right)$ used in the static analysis are based upon the code-calculated period of vibration $(0.79 \mathrm{sec}$.) and not the actual ones $(1.28 \mathrm{sec}$. for the RCFT structure and 1.25 for the CCFT one). The frame models were designed as a composite-special moment frame (C-SMF) for ordinary occupancy and a target story drift limit of 0.02 radians for the 2 percent probability of exceedance in 50 year seismic hazard level. The frame models were detailed in accordance with the Section 10 of the 2005 Seismic Provisions, and overall dimensions and member sizes are shown in Figure 6. The design of this frame was governed by drift considerations, resulting in members with a substantial over-strength factor $(\Omega)$ compared to that required from the strength design case. The frame with RCFT columns was designed with longer bay length along the NS direction than that with CCFT 
columns (11m for the 5SRCFT model and 9m for the 5SCCFT model) because the composite sections used for RCFT columns can accommodate more member capacity as shown in the P-M interaction diagrams (see Figure 5).

For the static pushover analyses, factored dead loads $(D)$ and live loads $(L)$ along with the earthquake loads were applied at the joints using the dominant load combination (i.e. LC5: $1.2 D+1.0 L+1.0 E_{a}$ ) specified in the ASCE07-05. For the dynamic analyses, the unscaled EW base accelerations from the Tarzana station (see Figure 7) recorded during the 1994 Northridge were used. The peak ground acceleration (PGA) for this record is $1.78 \mathrm{~g}$ and this ground motion includes strong directional effects. In the non-linear analyses, a dead load factor of 1.0 and live load factor of 0.2 were used to provide a realistic gravity loading.

The nonlinear frame analyses were performed by the OpenSEES program with all members modeled as nonlinear beam-column elements with discrete fiber sections. The steel beams and composite columns extended from centerline to centerline and met together at a node, and rigid end-offset corresponding to the panel zone was used in the beam elements. All analyses utilized the Newton-Raphson iteration algorithm to ensure equilibrium at each time step. Static pushover analyses were conducted using load a control method, while dynamic analyses were performed by implicit integration using the Newmark-Beta constant acceleration method. For the dynamic analyses, the structural damping ratio was assumed to be 0.025 and the equivalent point masses were applied at the joints as specified in FEMA 355C (e.g. FEMA [14]).

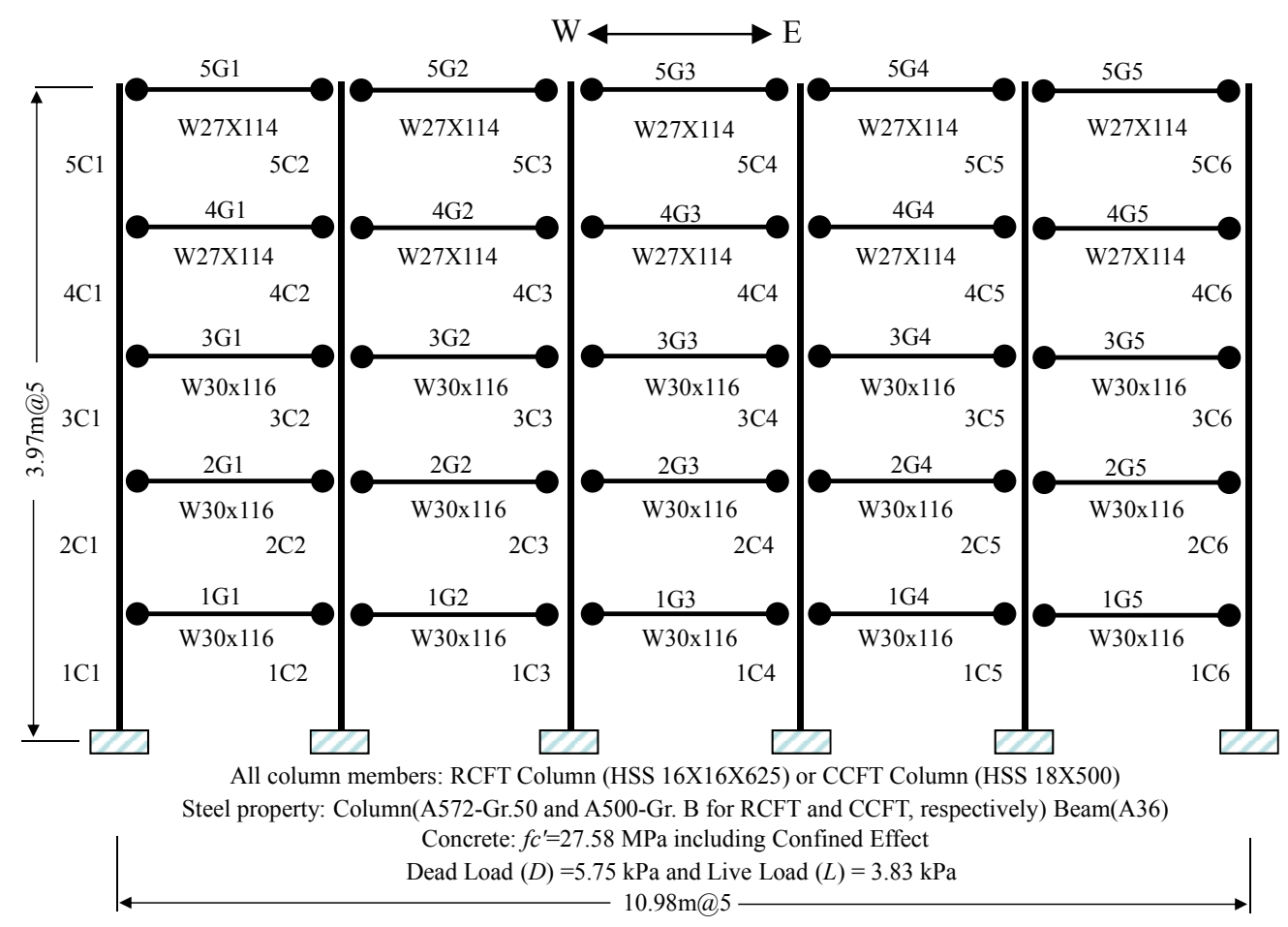

Figure 6. Front View of the 5 Story Composite Moment Frame Model 


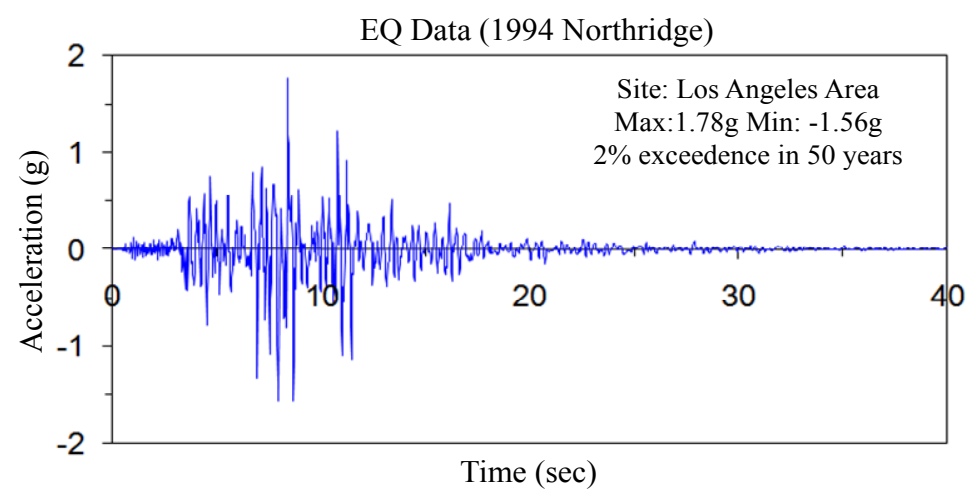

Figure 7. Ground Motion Used for the Nonlinear Dynamic Analysis

The resulting static pushover curves plotted in terms of the story drift ratio (SDR) at the roof level vs. the base shear force normalized by the seismic design base shear force $\left(V / V_{\text {design }}\right)$ are shown in Figure 8. The seismic design base shear force is defined as the summation of the equivalent lateral loads $\left(V_{\text {design }}=\Sigma E_{a}\right)$. The design base shear forces for the 5SRCFT and 5SCCFT model are $1570 \mathrm{kN}$ and $1310 \mathrm{kN}$, respectively. The over-strength ratio was defined as the ratio of the ultimate base shear force to the seismic design base shear force $\left(\Omega=V_{u} / V_{\text {design }}\right)$. This over-strength ratio can be easily observed through the static pushover analyses with displacement control increment and is very useful to examine the strength of the moment frame for the seismic evaluation. The over-strength ratios at both frame models are in close proximity to the value of 3.0 which the guideline recommends during the seismic design (e.g. ASCE [12]). The design point level $\left(\mathrm{V} / V_{\text {design }}=1.0\right)$ is located on the proportionally elastic range.

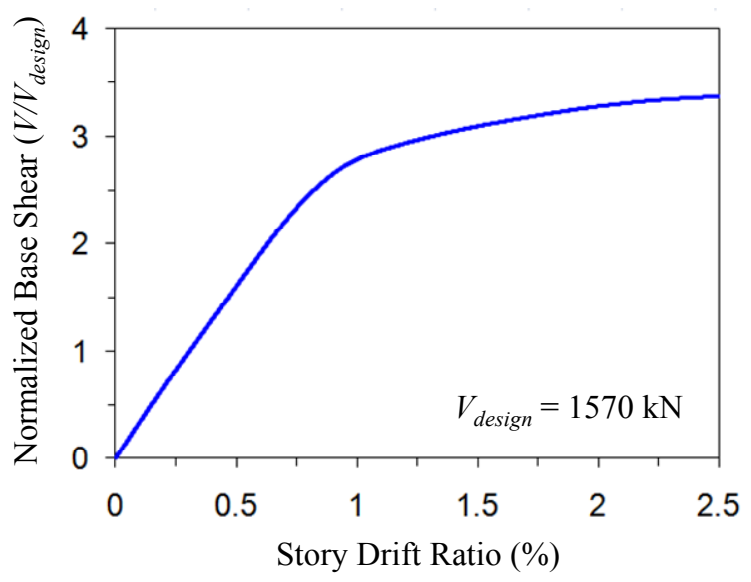

(a) 5SRCFT

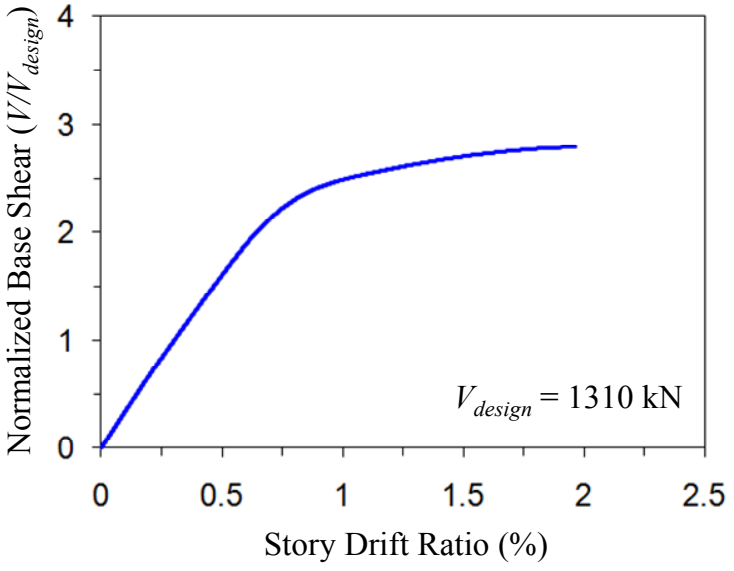

(b) $5 \mathrm{SCCFT}$

Figure 8. Resulting Static Pushover Curves

The results of nonlinear dynamic analyses are shown in Figure 9. The resulting curves are also plotted as the story drift ratio (SDR) at the roof level vs. the base shear force normalized by the seismic design base shear force. Under the ground motion (see Figure 7), the peak roof displacement for the 5SRCFT and 5SCCFT model are roughly $218 \mathrm{~mm}$ and $208 \mathrm{~mm}$, respectively, corresponding to the roof SDR of 1.10 and 1.05 percents. The outbreak time for each peak value slightly lagged behind the time of the PGA (approximately 0.2 second time lag). Overall, the nonlinear dynamic analyses generate slightly larger base shear forces (around 3\%) in comparison with the static pushover analyses at the 1\% SDR level. Based on these nonlinear frame analysis results, the performance based damage evaluation for composite-moment frames is introduced in the next section. 


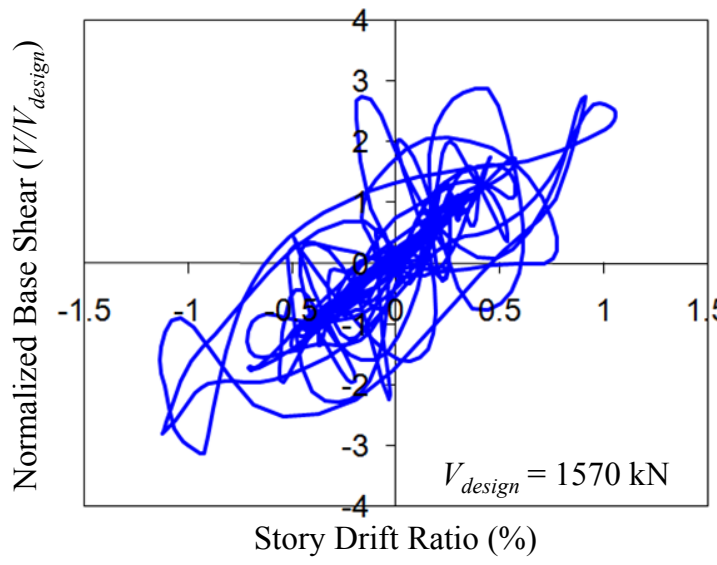

(a) $5 \mathrm{SRCFT}$

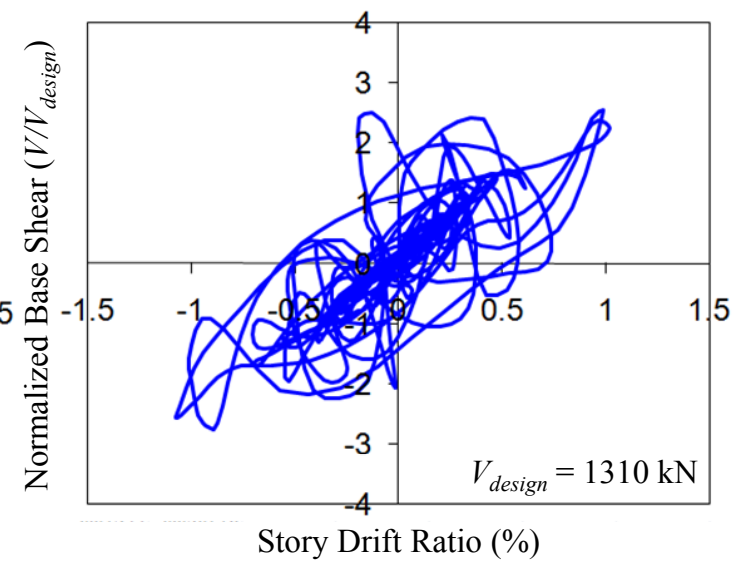

(b) $5 \mathrm{SCCFT}$

Figure 9. Results of Nonlinear Dynamic Analyses

\section{DAMAGE EVALUATION}

The excess of the ultimate limit state in the columns indicates the severe failure state of the building so it leads to the complete collapse. Moreover, there were no available design programs which provide the performance based design check for composite CFT sections. In lieu of the structural beams, the investigation of the structural damage for the composite columns under the seismic loads is emphasized in this study because of these reasons.

There are two steps in proceeding with the damage evaluation, first step associated with determining the capacity and second one with estimating the demand. The member capacity was computed by the P-M interaction diagram for the composite sections based on a full plastic yield stress distribution. To accomplish the second step, the demand at the composite columns must be established from nonlinear frame analyses, which were carried out on a series of entire composite moment frame structures.

The structural damage was estimated in this study through the comparisons of the elastic strength ratios (ESR), which were defined as the ratios of the demand to the strength capacity for the member cross section. Thus, the value of the ESR can be determined by the position of the required strength on the domain of a simplified P-M interaction diagram. Two regions can be identified insofar as axial strength is concerned (see Figure 1). If the required axial strength is low (R2), the behavior of CFT columns is controlled by yielding in tension due to the bending moments. The behavior in this region will be very ductile. It the required axial load is high (R1), the behavior of CFT columns will be dominated by compression due to the axial loads. This will result in only limited ductile behavior. The ESR is defined with the combination of the required axial load $\left(P_{r}\right)$ and bending moment $\left(M_{r}\right)$ as summarized in Table 2. Once P-M interaction forces acting on the CFT columns under seismic loading exceed the conservative limit state referred to as the simplified P-M interaction diagram, the value of the ESR is greater than 1.0. It indicates that the possibility of the plastic yield failure is relatively higher. As mentioned above, the ICDR is another method to estimate the structural damage with respect to the plastic deformation. 
After the nonlinear frame analyses, the performance based damage evaluations referred to as ESRs and ICDRs are summarized in Figs. 10 and 11. The ESRs under the seismic design force level obtained from the static pushover analysis $\left(V / V_{\text {design }}=1.0\right)$ cannot exceed 1.0 even at the bases of CFT columns (e.g. ESR $=0.47$ at the $1 \mathrm{C} 1$ column of 5SRCFT model) because these frame structures satisfied the code requirement for the seismic design. It means that the required member forces of CFT columns subjected to the design earthquake force still exist under the proportional strength limit.

The maximum ESRs and ICDRs resulting from the nonlinear dynamic analysis were computed at the peak member forces under a real ground motion used in this study. The ESRs under the seismic design force level are considerably smaller than those under the peak response from the nonlinear dynamic analysis. Therefore, extensive member failure and overall frame damage can occur due to the actual strong seismic ground motion. A symbol "-" in Figures 10 and 11 indicates that the member force did not exceed the yield point. An ESR of over 0.95 under dynamic loads indicates that the observed member exceeded its yield point and will potentially be subject to a large ductility demand. Overall, the relatively higher ESRs are distributed over the lower story levels because of the larger lumped masses converted from the gravity loads plus the partial live loads. The higher ICDRs also concentrate on the lower story level. Especially, the peak values generally occur at the bases of interior columns $(1 \mathrm{C} 2 \mathrm{~B}, 1 \mathrm{C} 3 \mathrm{~B}, 1 \mathrm{C} 4 \mathrm{~B}$, and $1 \mathrm{C} 5 \mathrm{~B})$. This implies that the composite columns located in the lower story levels are susceptible to severe plastic deformations under this ground motion. Both indies for the damage evaluation decrease as the story level moves up the frame. The values of ESRs less than 1.0 were distributed over more than third story level, and so the possibility of the failure at the upper floor level is relatively lower. All frame models are symmetric in plan and subjected to uniform gravity loads along all bays and stories. Therefore, the values for damage evaluation show a similar distribution along the exterior or interior CFT column lines (e.g. $1 \mathrm{C} 1$ to $5 \mathrm{C} 1$ and $1 \mathrm{C} 6$ to $5 \mathrm{C} 6$ for an exterior column line; $1 \mathrm{C} 3$ to $5 \mathrm{C} 3$ and $1 \mathrm{C} 4$ to $5 \mathrm{C} 4$ for an exterior column line).

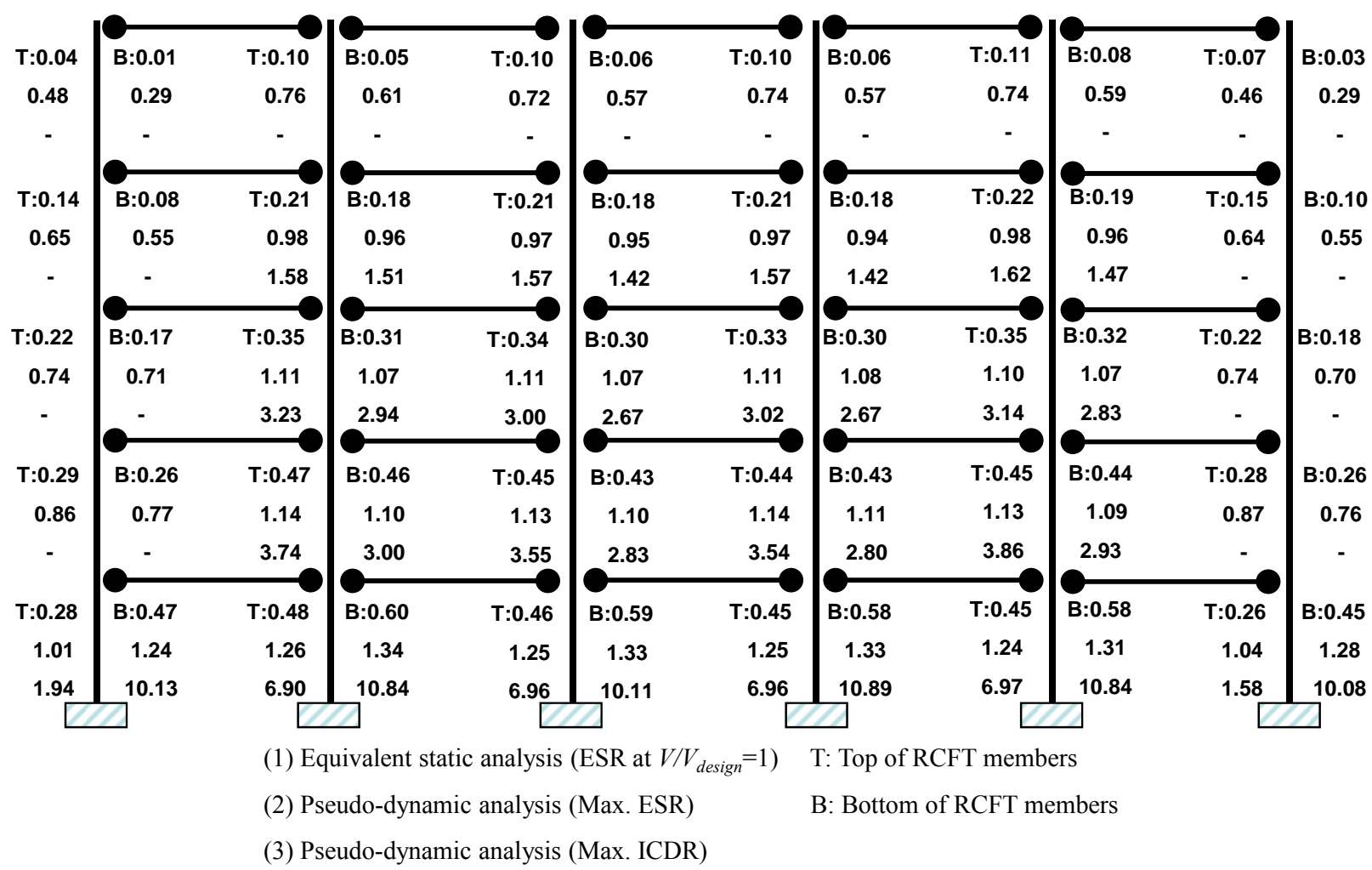

Figure 10. ESRs and ICDRs Distributed Over the 5SRCFT Model 


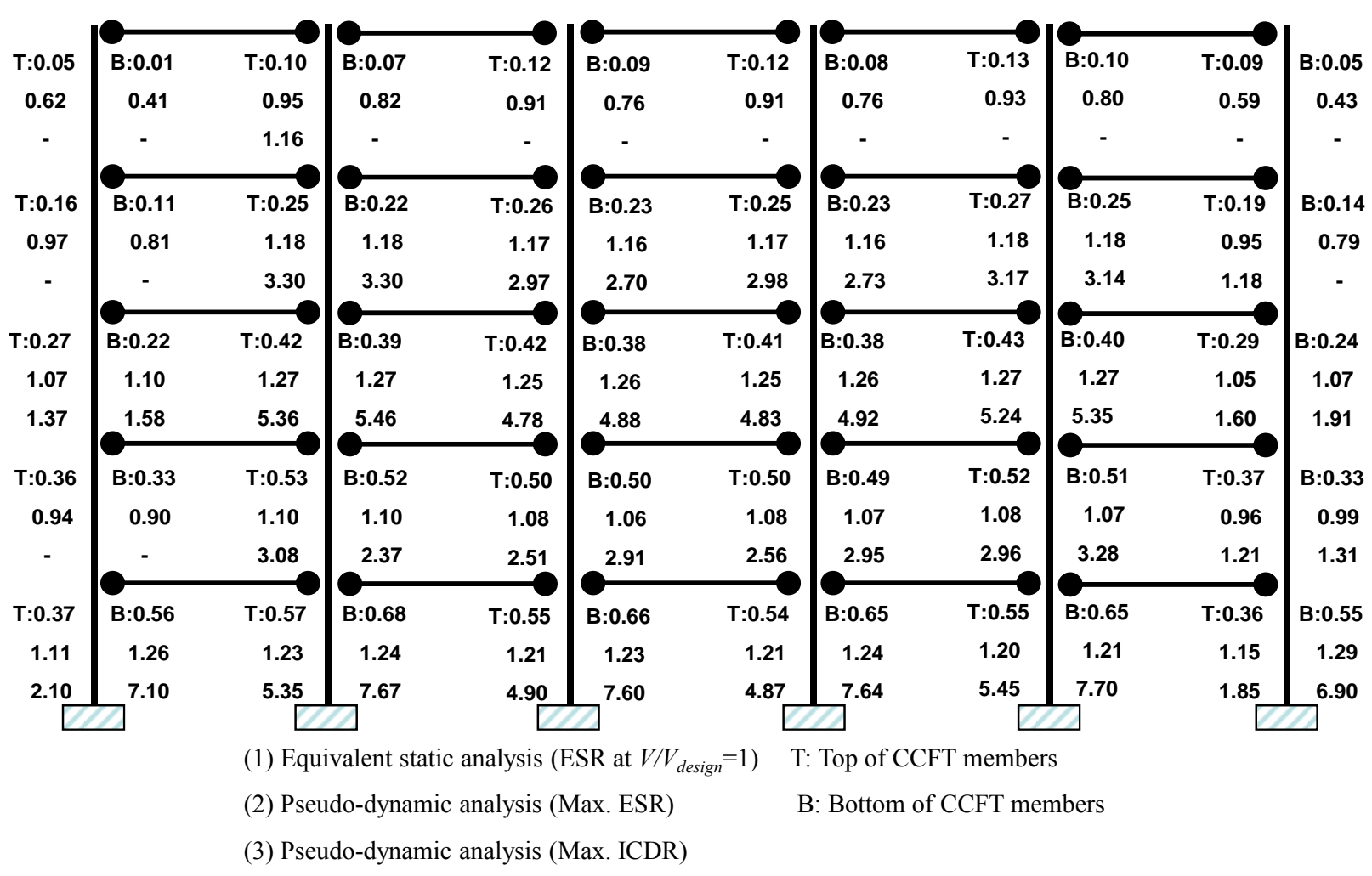

Figure 11. ESRs and ICDRs Distributed over the 5SCCFT Model

\section{CONCLUDING REMARKS}

The new 2005 AISC Specification was used to estimate P-M interaction diagrams for composite CFT beam-columns and the 2005 Seismic Provisions were used for the design of several low-rise composite-moment frame structures. The comparisons between fiber analysis results obtained by numerical experiments and interaction diagrams obtained by AISC design formulas indicate that full plastic capacities by this new design code are quite reasonable for predicting the interaction strength for composite beam-columns.

For the nonlinear frame analyses, both ESRs and ICDRs obtained from nonlinear dynamic analyses show significant correlation with predicted damage based on the excessive deformation. Similar numerical distribution trends between ESRs and ICDRs are observed in both RCFT frame and CCFT frame structures and larger values are found in interior CFT columns of the lower floors when structure models are subjected to either static or dynamic loading. ESR and ICDR values decrease moderately with increasing building story, so damage in the upper floor columns is not expected.

Finally, it is concluded with these reasonable proofs that the evaluation approaches proposed herein are convenient and accurate to check the damage of the entire frame structures subjected to the seismic loads. 


\section{ACKNOWLEDGEMENTS}

The first author would like to also sincerely thank the National Science Foundation (NSF) for six years of financial support (US Grant No. 0324542) as a research assistantship and a post-doctorate fellowship at Georgia Tech.

\section{NOTATIONS}

$A_{c}$ : Cross section area of a concrete core

$A_{s}$ : Cross section area of a steel tube

$E_{s}$ : Elastic modulus of steel

$F_{y}$ : Yield stress of steel (e.g. $F_{y}=350 \mathrm{MPa}$ for A572-Gr.50 carbon steel)

$F_{u}$ : Ultimate stress of steel (e.g. $F_{u}=590 \mathrm{MPa}$ for A572-Gr.50 carbon steel)

$M$ : Applied moment

$M_{A}=\ldots=M_{E}$ : Available flexural strength (Capital subscript indicates the observed point)

$P$ : Applied axial force

$P_{A}=\ldots=P_{F}$ : Available axial strength (Capital subscript indicates the observed point)

$Z_{S B}=Z_{S E}$ : Plastic section modulus of steel shape at Points (B) and (E)

$Z_{c B}=Z_{c E}$ : Plastic section modulus of concrete shape at Points (B) and (E)

$b:$ Width of the composite section

$d$ : Depth or diameter of the composite section

$d_{b}$ : Depth of the steel beam

$d_{c}$ : Depth of the composite column

$f_{c}^{\prime}$ : Crushing strength of concrete

$h$ : Height of the concrete core (e.g. $h_{2}=d-2 t_{f}$ )

$h_{n}=h_{E}$ : Equivalent height of the composite section between center and PNA

$r_{m}:$ Effective radius of the CFT section

$t$ : Thickness of the steel tube

$t_{w}$ : Thickness of the web of the steel tube

$t_{f}$ : Thickness of the flange of the steel tube

$\varepsilon_{c}^{\prime}$ : Uni-axial compressive strain of concrete corresponding to $f_{c}^{\prime}$

$\varepsilon_{y}:$ Yield strain of the steel tube

$\phi$ : Moment curvature of the composite section

$\phi_{p}$ : Plastic moment curvature of the composite section

$\phi_{u}$ : Ultimate moment curvature of the composite section

$\theta$ : Arc angle 


\section{REFERENCES}

[1] Roeder, C.W., "Seismic Behavior of Steel Braced Frame Connections to Composite Columns", Connections in Steel Structure 4, AISC, 2000, pp. 51-62.

[2] Azizinamini, A. and Schneider, S P., "Moment Connections to Circular Concrete-filled Steel Tube Columns", Journal of Structural Engineering, ASCE, 2004, Vol. 130, No. 2, pp. 213-222.

[3] Hajjar, J.F., "Composite Steel and Concrete Structural Systems for Seismic Engineering” Journal of Constructional Steel Research, 2002, Vol. 58, pp. 703-723.

[4] Hu, J.W., Kang, Y.S., Choi, D.H. and Park, T., "Seismic Design, Performance, and Behavior of Composite-moment Frames with Steel Beam-to-concrete Filled Tube Column Connections", International Journal of Steel Structures, KSSC, 2010, Vol. 10, No. 2, pp. 177-191.

[5] Rassati, G.A., Leon, R.T. and Noe, S., "Component Modeling of Partially Restrained Composite Joints under Cyclic and Dynamic Loading”, Journal of Structural Engineering, ASCE, 2004, Vol. 130, No. 2, pp. 343-351.

[6] Green, T.P., Leon, R.T. and Rassati, G.A., "Bidirectional Tests on Partially Restrained, Composite Beam-column Connections", Journal of Structural Engineering, ASCE, 2004, Vol. 130, No. 2, pp. 320-327.

[7] 2005 AISC Specification, "Specification for Structural Steel Buildings (ANSI/AISC 360-05)", 2005, Chicago, IL.

[8] 2005 AISC Seismic Provision, "Seismic Provisions for Structural Steel Buildings (ANSI/AISC 341-05)", 2005, Chicago, IL.

[9] Mazzoni, S., Mckenna, F. and Fenves, G.L., "OpenSEES Command Language Manual”, Department of Civil Environmental Engineering, 2005, University of California, Berkley, CA.

[10] Varma, A.H. et al., "Seismic Behavior and Design of High-strength Square Concrete-filled Steel Tube Beam Columns" Journal of Structural Engineering, ASCE, 2004, Vol. 130, No. 2, pp. 169-179.

[11] Galambos, T.V., "Guide to Stability Design Criteria for Steel Structures, Structural Stability Research Council", $5^{\text {th }}$ Edition, John Wiley and Sons, 1998, New York, NY.

[12] American Society of Civil Engineers (ASCE), "Minimum Design Loads for Buildings and Other Structures" ASCE 7-05, 2005.

[13] American Institute of Steel Contraction (AISC), "Manual of Steel Construction, Load, and Resistance Factor Design (LRFD)", $3^{\text {rd }}$ Edition, 2001, Chicago, IL.

[14] Federal Emergency Management Agency (FEMA), "State of the Art Report on Systems Performance of Steel Moment Frames Subjected to Earthquake Ground Shaking", Rep. No. FEMA-355C, 2000, Washington, DC. 


\title{
TENSILE BEHAVIOR OF WELDED TEE END CONNECTION FOR CIRCULAR HOLLOW MEMBERS
}

\author{
Vittorio Nascè ${ }^{1}$ and Francesco Tondolo, ${ }^{2, *}$ \\ ${ }^{1}$ Full Professor, Politecnico di Torino, Department of structural and Geotechnical Engineering, \\ corso Duca degli Abruzzi, 24, 10129, Torino, Italy \\ $2,{ }^{2}$ Research Assistant, Politecnico di Torino, Department of structural and Geotechnical Engineering, \\ corso Duca degli Abruzzi, 24, 10129, Torino, Italy \\ *(Corresponding author: E-mail: francesco.tondolo@polito.it)
}

Received: 8 August 2010; Revised: 23 September 2010; Accepted: 2 October 2010

\begin{abstract}
The structural behavior of welded tee end connections used for circular hollow sections (CHS), depends on the number and the position of the tee webs. International specifications, such as ANSI/AICS and CIDECT Design Guide, provide design rules for joints made with one or two parallel tee webs, whereas the use of cross tee webs is not taken into consideration. However, the performance of such extensively employed connections cannot directly be referred to that of single tee web connection, as confirmed by the uniaxial tensile tests presented in this paper. A numerical model, based on a nonlinear Finite Element approach, is also introduced to show the influence of some geometrical parameters on the structural efficiency of the joints. As a result, a possible extension of the current design rules for CHS connections is also suggested.
\end{abstract}

Keywords: Circular Hollow Section, Welded Tee End Connection, Uniaxial Tensile Test, FEM Analysis, Code Formulation

\section{INTRODUCTION}

The design of connections has always been a key point for steel constructions; during the recent years design codes have addressed an increasing attention on the design rules. The best choice is generally a compromise among architectural, static and constructive requirements. In the case of plane and spatial steel truss structures, circular hollow sections (CHS) are frequently connected by joints hidden inside the element [1]. Possible connections for CHS in tension are described in the Chapter 8 of the CIDECT Design Guide [2] (section "Bolted joints") and are reported in Figure 1.

The first two connections, illustrated in Figures $1 \mathrm{a}$ and $1 \mathrm{~b}$ present respectively one or two parallel webs welded to a cap plate, which is connected to the tube by a fillet weld. Conversely, Figure 1c shows a different connection. It consists of a slotted end connection and a gusset plate welded to the tube by means of a corner weld. For this connection all the design rules reported in International Specifications are based on a consolidated literature [3-5]. From the structural point of view it is certainly more efficient but also more expensive than the connections showed in Figures $1 \mathrm{a}$ and $1 \mathrm{~b}$.

Several tests performed on the welded tee end connections depicted in Figure 1a can be found in the current literature [6-7]. In these works, tube and cap plate are generally joined with a fillet weld. They are designed by assuming the presence of a stress diffusion zone between tube and tee web, even if high tensile stresses are localized in the zone where tube, cap plate and tee web converge. Starting from each face of the tee web, stresses are spread into the cap plate (with an angle $\alpha$ ) and produce dispersed effective load width $1_{\mathrm{e}}$ on the tube (see Figure 2a). In the CIDECT Design Guide [2], a similar load diffusion is assumed for designing the tee web $\left(l_{d}=\right.$ dispersed effective load width on the tee web). 

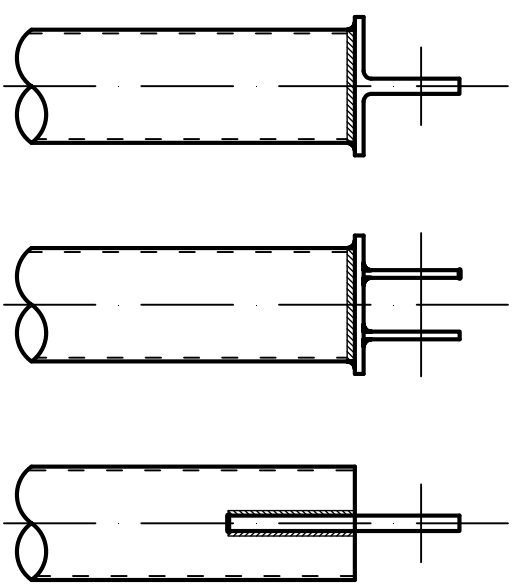

Figure 1. Bolted End Connections [2]
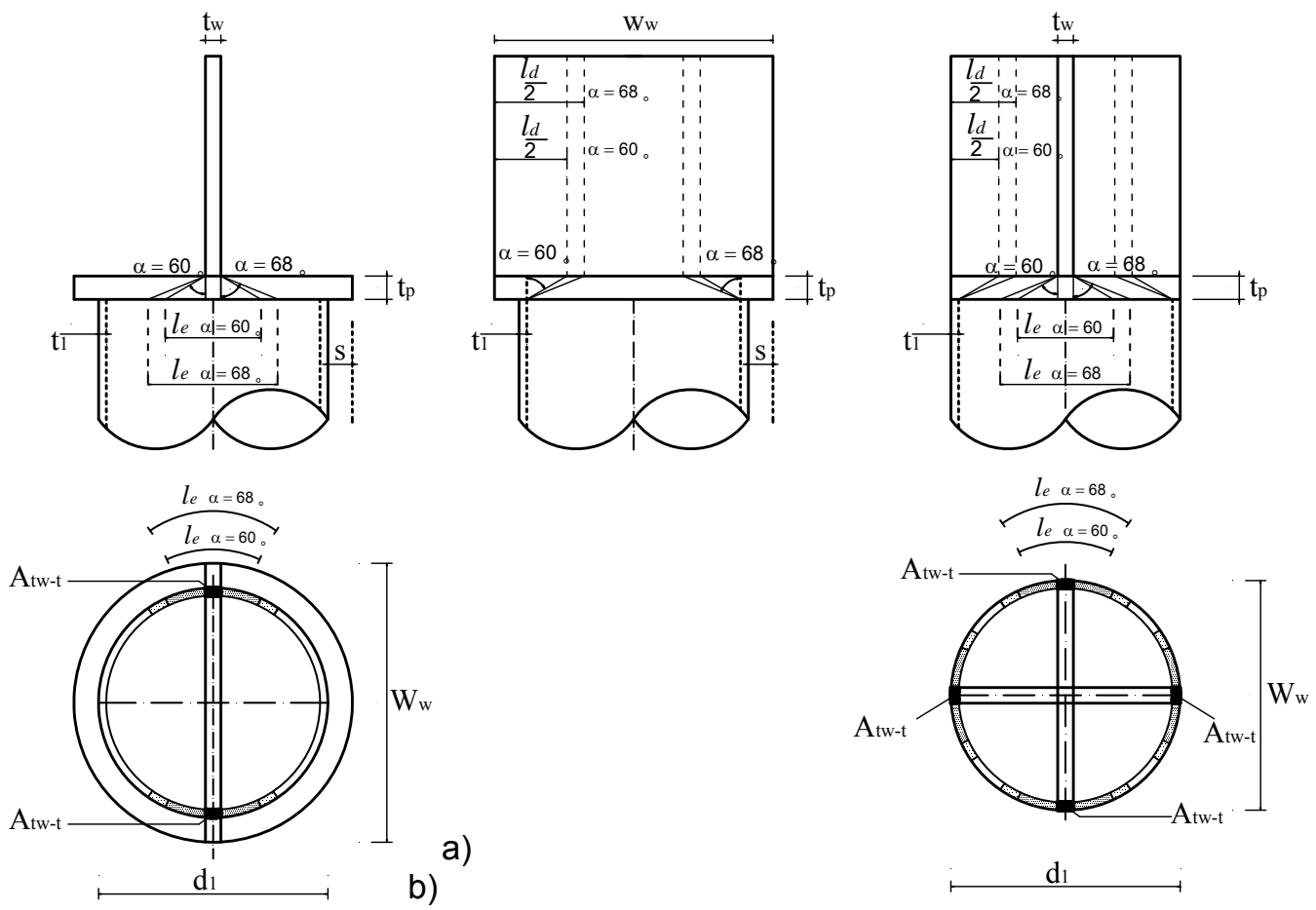

Figure 2. Load Dispersion Mechanism for Tube and Tee Web Resistance for Tee Joints with Diffusion Slopes of $60^{\circ}$ and $68^{\circ}$ for Welded-Tee end Connections with a) One b) Two Tee Webs

If two cross tee webs are used, the stress transfer mechanism changes because the distribution element (i.e. the cap plate) is stiffer. As a consequence, the state of stress within the structural elements is completely different. In fact, the points of contact increase from 2 to 4 , thus new rules need to be introduced for designing these joints. This is remarked in the present work, in which the structural behavior of CHS connection, obtained with one or two cross tee webs, are numerically and experimentally compared. 


\section{DESIGNING WELDED TEE END CONNECTION}

Design Guides for welded tee end connections (Figure 1a) with one tee web are included in some International Specifications [3]. They are the results of several researches such as those developed by Kitipornchai and Traves [6] and by Stevens and Kitipornchai [7] at Queensland University (Australia). These works were taken as references by the American Institute for Steel Construction [3] (see Commentary to section "k"). Before 1989, design guidelines for "welded-tee end connections" for circular hollow tubes were reported in the Specifications of the American Institute of Steel Construction [8] and in design codes of Australian Standard Association [9]. In both the codes, stresses in the tube are calculated assuming a load diffusion slope of $60^{\circ}$ within the thickness of the cap plate (Figure 2a). However, according to other authors [4-8], the assumption of a distribution slope equal to 2.5:1 [2] have to be used and therefore the diffusion angle of $68^{\circ}$ is used. Independently from the diffusion angle, the effective length for load diffusion $l_{e}$ can be computed by the following equation:

$$
\mathrm{l}_{\mathrm{e}}=\mathrm{t}_{\mathrm{w}}+\mathrm{m} \cdot \mathrm{t}_{\mathrm{p}}
$$

where $t_{\mathrm{w}}=$ thickness of the tee web; $t_{\mathrm{p}}=$ thickness of the cap plate; $\mathrm{m}=$ coefficient (if the diffusion angle is $68^{\circ}, \mathrm{m}=5$; if the diffusion angle is equal to $60^{\circ}, \mathrm{m}=3.5$ ). Consequently it is possible to define the design load resistance $\mathrm{N}_{1}$ for the tube of the CHS connection:

$\mathrm{N}_{1}=2 \cdot \mathrm{f}_{\mathrm{y} 1} \cdot \mathrm{t}_{1} \cdot \mathrm{l}_{\mathrm{e}}$

where $f_{\mathrm{y} 1}=$ yielding stress of the tube and $t_{1}=$ thickness of the tube. In the Design Guide by Wardenier et al. [2], an equation for designing load of the tee web $\mathrm{N}_{\mathrm{i}}$ is also suggested. It is based on a slope diffusion similar to that adopted for the bearing capacity of the tube (Eq. 2). If the web width and the diameter of the cap plate are the same (and equal to $d_{i}+2 s$ ), the design load $\mathrm{N}_{i}$ may be calculated as:

$$
N_{i}=2 \cdot f_{y w} \cdot t_{w} \cdot\left(t_{1}+m / 2 \cdot t_{p}+s\right)
$$

where $f_{\mathrm{yw}}=$ yielding stress of the tee web; $\mathrm{s}=$ edge distance of a cap plate (i.e. radius of the cap plate minus radius of the tube). The coefficient 2, which appears into the Eqs. 2 and 3, is due to the two areas $A_{t w-t}$ (see Figure $2 a$ ) that connect the tee web and the tube. Eq. 3 is only valid for $\mathrm{s} \leq \mathrm{m} / 2 \cdot \mathrm{t}_{\mathrm{p}}$ and the maximum design load for the tee web results:

$\mathrm{N}_{\mathrm{i}, \mathrm{max}}=2 \cdot \mathrm{f}_{\mathrm{yw}} \cdot \mathrm{t}_{\mathrm{w}} \cdot\left(\mathrm{t}_{1}+\mathrm{m} \cdot \mathrm{t}_{\mathrm{p}}\right)$

If two cross tee webs are used (see Figure $2 \mathrm{~b}$ ), there are 4 areas of contact $\left(\mathrm{A}_{\mathrm{tw}-\mathrm{t}}\right)$ and therefore the efficiency of the joint increases. However, as confirmed by the experimental analysis reported in the next section, Eqs. 2-3 cannot be simply extended to designing the connection depicted in Figure $2 b$. 


\section{EXPERIMENTAL ANALYSIS}

\subsection{Specimens Description}

The structural behavior of one tee web connection in tension (Figure 3a), is experimentally compared with that made by two cross tee webs (Figure 3b). The specimens, named $\mathrm{M}_{1} 9 \mathrm{x} 6$ and $\mathrm{M}_{2} 9 \mathrm{x} 6$, are respectively shown in Figures $3 \mathrm{c}$ and $3 \mathrm{~d}$. They consist of welded tee joints, having $\mathrm{s}=0$, whose dimensions (see Table 1) are chosen in accordance with those tested by Kitipornchai and Traves [6]. In particular, the tube has a diameter of $88.9 \mathrm{~mm}$, a length of $350 \mathrm{~mm}$ and a thickness of $3 \mathrm{~mm}$. The ratio between the diameter and the thickness of the tube is a value commonly used in steel construction.

One of the ends of the specimen $\mathrm{M}_{1} 9 \times 6$ is made with a cap plate and a tee web, having a thickness of 9 and $6 \mathrm{~mm}$, respectively. In this manner, the ratio between the thicknesses of the cap plate $t_{p}$ and tube diameter $d_{1}$ is equal to 0.1 . The opposite end is designed to be stronger. More precisely, a thick plate $(12 \mathrm{~mm}$ ) slotted into the tube for a length of $150 \mathrm{~mm}$ (see Figure 3a) is welded as depicted in Figure 1c. The distance between the two ends, measured along the tube, is equal to $200 \mathrm{~mm}$. The specimen named $\mathrm{M}_{2} 9 \times 6$ (Figure 3b) is assembled with two cross tee webs (thickness $6 \mathrm{~mm}$ ) and with a cap plate (thickness of $9 \mathrm{~mm}$ ). To simplify the clamping jaw action, only a single tee web is extended of $135 \mathrm{~mm}$, and its thickness is doubled in order to ensure the same resisting section area.

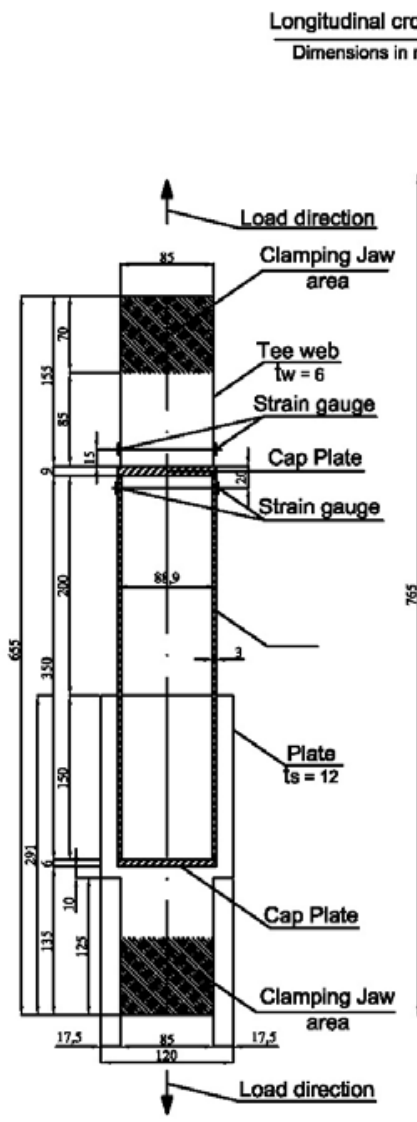

a)

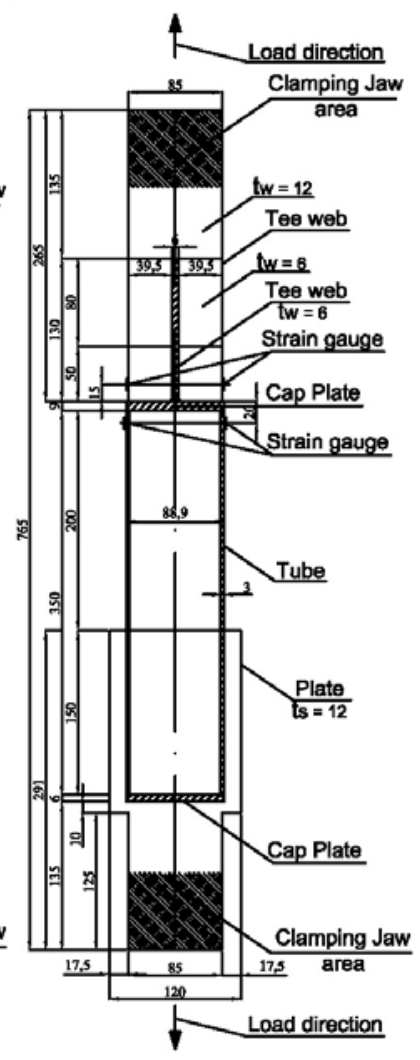

b)

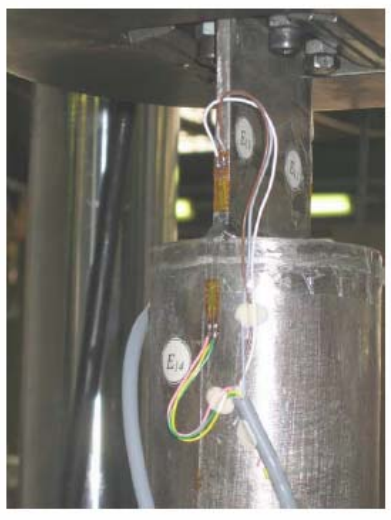

c)

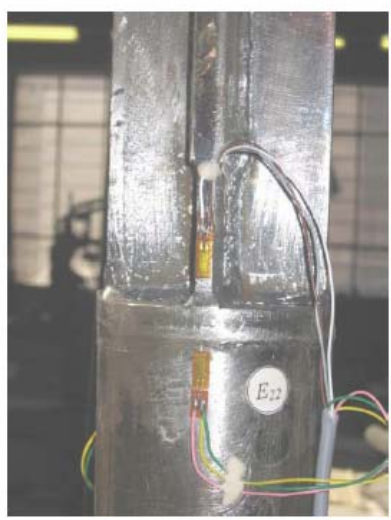

d)

Figure 3. Test Specimens Prepared in the Laboratory with a), c) One Tee Web $M_{1} 9 \times 6$ and b), d) Two Tee Webs $M_{2} 9 \times 6$ 
Table 1. Geometrical Characteristics of Experimental Tests

\begin{tabular}{ccc|ccc|ccccc} 
& \multicolumn{2}{c|}{ Tube } & \multicolumn{4}{c|}{ Cap Plate } & \multicolumn{5}{c}{ Tee Web } \\
\cline { 2 - 10 } & $\begin{array}{c}\mathrm{d}_{1} \\
{[\mathrm{~mm}]}\end{array}$ & $\begin{array}{c}\mathrm{t}_{1} \\
{[\mathrm{~mm}]}\end{array}$ & $\begin{array}{c}\mathrm{W}_{\mathrm{p}} \\
{[\mathrm{mm}]}\end{array}$ & $\begin{array}{c}\mathrm{t}_{\mathrm{p}} \\
{[\mathrm{mm}]}\end{array}$ & $\begin{array}{c}\mathrm{t}_{\mathrm{p}} / \mathrm{d}_{1} \\
{[-]}\end{array}$ & $\begin{array}{c}\mathrm{W}_{\mathrm{w}} \\
{[\mathrm{mm}]}\end{array}$ & $\begin{array}{c}\mathrm{W}_{\mathrm{w}} / \mathrm{d}_{1} \\
{[\mathrm{~mm}]}\end{array}$ & $\begin{array}{c}\mathrm{t}_{\mathrm{w}} \\
{[\mathrm{mm}]}\end{array}$ & $\begin{array}{c}\mathrm{t}_{\mathrm{w}} / \mathrm{d}_{1} \\
{[\mathrm{~mm}]}\end{array}$ & $\begin{array}{c}\text { Area } \\
{\left[\mathrm{mm}^{2}\right]}\end{array}$ \\
\hline $\mathrm{M}_{1} 9 \times 6$ & 88.9 & 3 & 88.9 & 9 & 0.10 & 85 & 0.96 & 6 & 0.07 & 510 \\
\hline $\mathrm{M}_{2} 9 \times 6$ & 88.9 & 3 & 88.9 & 9 & 0.10 & 85 & 0.96 & 6 & 0.07 & 984 \\
\hline
\end{tabular}
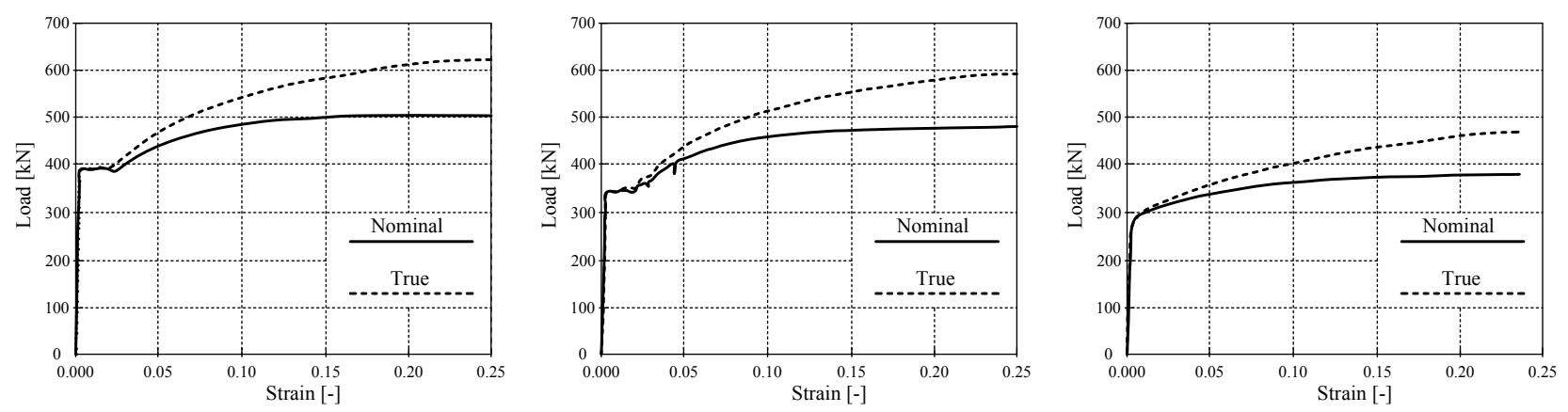

Figure 4. Stress-Strain Curve and Nominal Stress Strain Curve for

a) Cap Plate, b) Tee Web, c) Tube

The tube is cold formed whereas the cap plate and the tee webs are obtained by hot rolling. The mechanical properties of the elements are listed in Table 2. They are measured from the stress strain relationships (see Figure 4) from coupon tests. All the weldings are arc welded by means of a semi automatic procedure. Double bevel tee welding is used between the tee webs and the cap plate. A single vee corner connection is used to join the cap plate and the tube.

Quasi static loads are applied to the specimens (Figures 3a and 3b) through a MTS machine having a bearing capacity of $1000 \mathrm{kN}$. A displacement control procedure with a rate of $7.8 \cdot 10^{-4} \mathrm{~mm} / \mathrm{s}$ is imposed during the elastic stage. This rate is increased to $5 \cdot 10^{-2}$ as soon as the nonlinear response becomes evident. The test, conducted up to the global collapse of the joint, were performed at the Department of Structural and Geotechnical Engineering of Politecnico di Torino (Italy).

In order to measure the local longitudinal strains, two couples of strain gauges (width $6 \mathrm{~mm}$, length $10 \mathrm{~mm}$, and maximum strain capacity 1\%) are applied on the surfaces of each specimens. One couple is positioned on tee web at a distance of $15 \mathrm{~mm}$ from the cap plate (see Figures $3 \mathrm{a}-\mathrm{b}$ ), while the other couple is positioned on the external surface of the tube at a distance of $20 \mathrm{~mm}$ from the cap plate.

Table 2. Mechanical Properties of Materials for the Elements

\begin{tabular}{c|c|c|c|c|} 
& $\begin{array}{c}\text { Yeld stress } \\
{[\mathrm{MPa}]}\end{array}$ & $\begin{array}{c}\text { Ultimate stress } \\
{[\mathrm{MPa}]}\end{array}$ & $\begin{array}{c}\text { Ultimate deformation } \\
{[\%]}\end{array}$ & $\begin{array}{c}\text { Elastic modulus } \\
{[\mathrm{MPa}]}\end{array}$ \\
\hline Tee web & 343 & 476 & 34 & 204500 \\
\hline Tube & 287 & 378 & 27.3 & 199400 \\
\hline Cap plate & 391 & 502 & 33.2 & 202700 \\
\hline
\end{tabular}




\section{TEST RESULTS}

The results of the tests, in terms of load-total displacement, are reported in Figure 5. For the specimen $\mathrm{M}_{1} 9 \mathrm{x} 6$ with one tee web, a yielding load (i.e. deviation from the linear behavior as the ideal point corresponding to the load level where the linear and the plastic branch converge) equal to $150 \mathrm{kN}$ and an ultimate load of $193 \mathrm{kN}$ are observed. In the same way, for the specimen $\mathrm{M}_{2} 9 \times 6$, having two cross tee webs, the global yielding is reached $210 \mathrm{kN}$ while the collapse occurs at $263 \mathrm{kN}$. The specimens show different failure mechanisms. $\mathrm{M}_{1} 9 \mathrm{x} 6$ collapses after the cracking of the tee web close to the cap plate (Figure 6a). At the failure, the total elongation of the specimen is $10 \mathrm{~mm}$. The tee web shows a slight necking and the cap plate presents a large curvature.

The specimen named $\mathrm{M}_{2} 9 \times 6$ reaches the ultimate state with an elongation of about $40 \mathrm{~mm}$ (see Figure 5b) which involved the whole tube and produces a necking on it. As a result, a large pseudo-plastic stage is showed in Figure 5. Moreover, at the collapse, a crack on the interface between the cap plate and the tube appears (Figure 6b). In the same structural element, the increase of mechanical strength (about 36\%) can be ascribed to a tightening of the cap plate, and, consequently, to a more uniform stress within the tube. However in this case, the ultimate and yielding loads do not double with respect to those measured in one tee web joint, although the cross sectional area is doubled, as it could be obtained with the application of the rules of Eq. 2 and 3 of the design code. It is also probably due to a more restrained condition for the joint with two tee webs that determine a multiaxial state of stress and a consequent reduction of the plastic resources in the critical zone. In Figure 5 the increment of load level within the first millimeters of deformation, that can be associated with the joint, show a lower increase of load level for the specimen $\mathrm{M}_{2} 9 \times 6$ if compared to the specimen $\mathrm{M}_{1} 9 \mathrm{x} 6$.

The diagrams loads vs. strain, measured by the strain gauges glued on the specimen M19x6, are reported in Figure 7a. In this Figure, the continuous curve reproduces the average strain of the tee web, whereas the dashed line indicates the average strains of the tube. Similarly, for the specimen $\mathrm{M}_{2} 9 \times 6$ the load-strain curves of the tube (dashed line) and the tee web (continuous line) are depicted in Figure 7b. In these Figures a different structural behavior appears. While in the specimen $\mathrm{M}_{1} 9 \times 6$ the nonlinear behavior of the tube and the tee web simultaneously occurs, in the specimen $\mathrm{M}_{2} 9 \times 6$ the deviation from the linearity begins initially in the tube for a load (about 20\%) lower than the yielding load of the tee web.

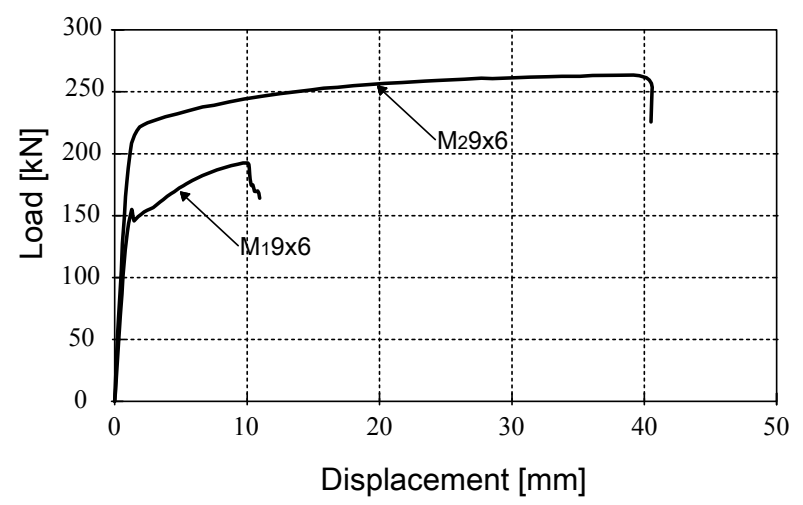

Figure 5. Load-displacement Curves for Tests $\mathrm{M}_{1} 9 \mathrm{x} 6$ and $\mathrm{M}_{2} 9 \mathrm{x} 6$ 


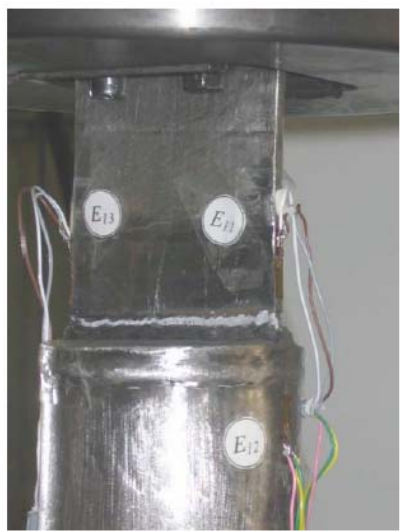

a)

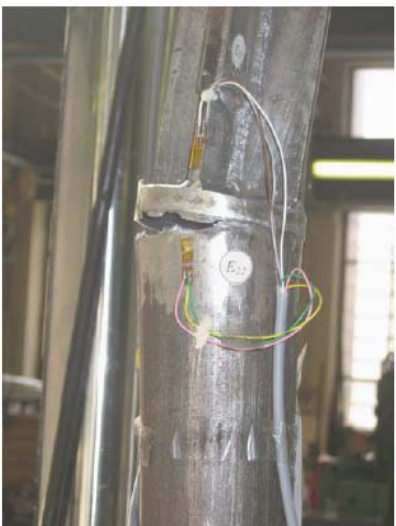

b)

Figure 6. Detail of the Rupture in the Two Test Specimens:

a) Test with One Tee Web, b) Test with Two Tee Webs

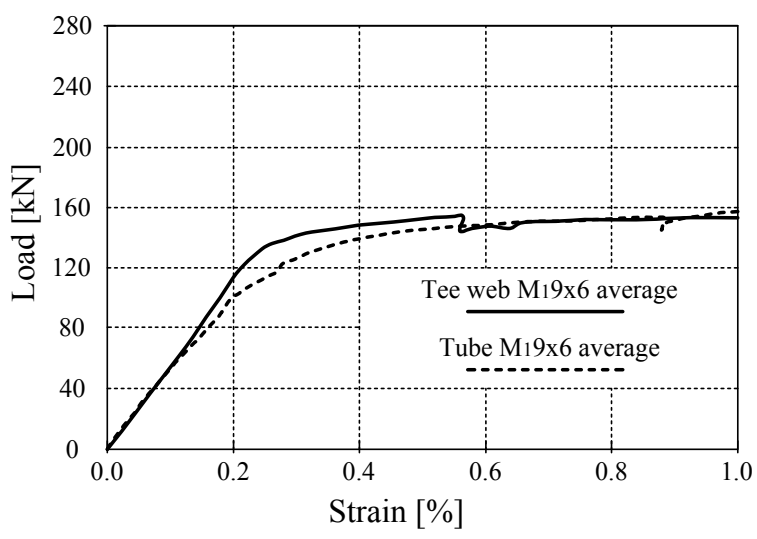

a)

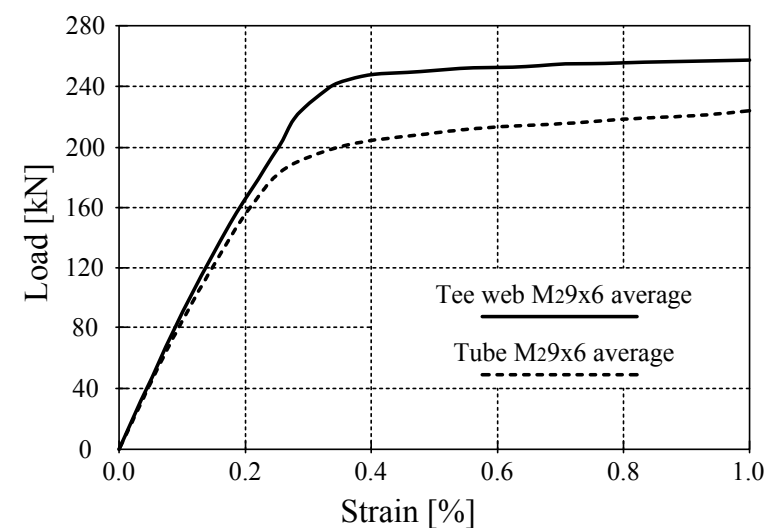

b)

Figure 7. Load-deformation Curves Recorded by the Strain Gauges Placed on the Tube and on the Tee Web for a) One Tee Web Joint and b) Two Tee Webs Joint

\section{NUMERICAL MODEL}

Together with the experimental tests, the structural behavior of the joints is modeled with a finite element analysis (FEM). Tri-dimensional isoparametric elements, having 20 nodes, three translational degrees of freedom, and able to encompass large strains, are adopted by using ADINA v8.3 program [10]. Nominal stresses and strains in the tee webs, the cap plate, and the tube, are defined by the following equations:

$\varepsilon_{\mathrm{r}}=\ln \left(1+\varepsilon_{\mathrm{n}}\right)$

$\sigma_{\mathrm{r}}=\sigma_{\mathrm{n}}\left(1+\varepsilon_{\mathrm{n}}\right)$

with

$\varepsilon_{\mathrm{n}}=\frac{\mathrm{I}-\mathrm{I}_{0}}{\mathrm{I}_{0}}$ 
Where $\varepsilon_{\mathrm{n}}, \sigma_{\mathrm{n}}=$ nominal strains and stresses, $\varepsilon_{\mathrm{r}}, \sigma_{\mathrm{r}}=$ true strains and stresses, $1_{0}=$ reference length, and 1 = final length. The curves of nominal and true stress vs. nominal and true strain, obtained with Eq. 5 and 6 are reported in Figure 4. The nonlinear analysis is based on the Von-Mises flow rule with the isotropic hardening assumption; the rupture plastic strain corresponds to the effective plastic strain at the last point input for the stress strain curve for the materials (Figure 4).

Due to the double symmetry of joint with respect to load and constraints, only a quarter of the entire structure is modeled (Figure 8). In particular, the finite element mesh regards the tee webs, the cap plate and a part of the tube. The analysis is performed by imposing displacements on the free end of each model and computing the corresponding tensile load from the reaction. The FEM models are shown in Figure 8a for the specimen $\mathrm{M}_{1}$ 9x6 and in Figure $8 \mathrm{~b}$ for the specimen $\mathrm{M}_{2} 9 \times 6$.

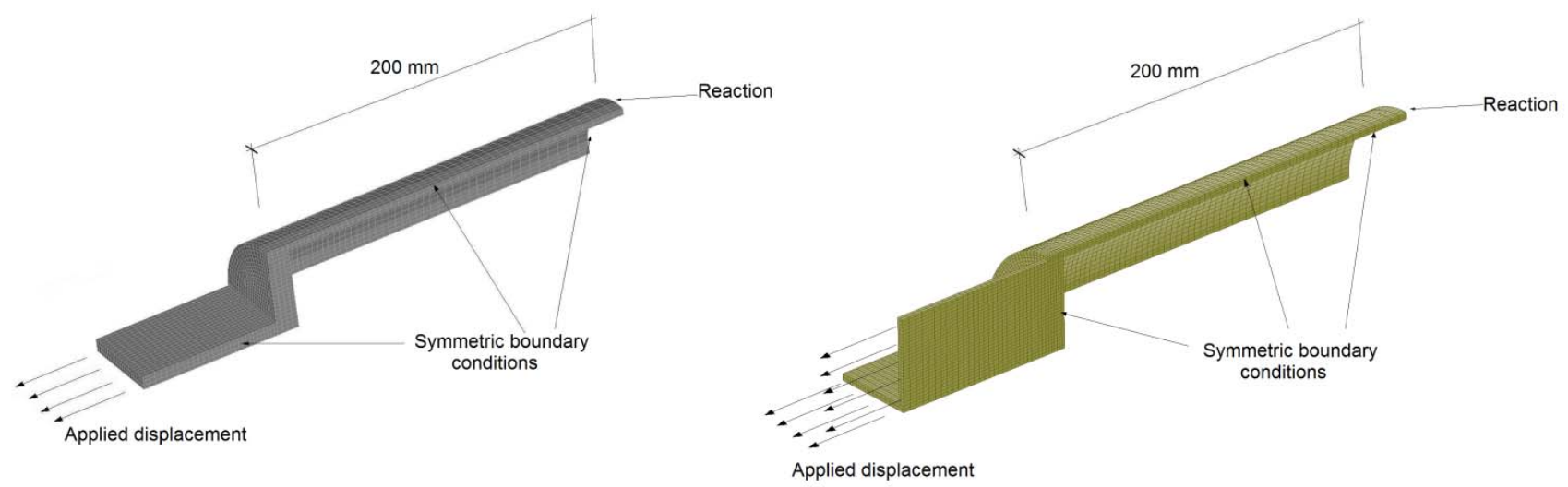

Figure 8. Boundary Conditions for the Model

a) FE1 that Simulates Test $M_{1} 9 \times 6$ and b) FE2 that Simulates $M_{2} 9 \times 6$

The results of the numerical analysis, in terms of load displacement, are called FE1 and FE2 for the specimens $M_{1} 9 \times 6$ and $M_{2} 9 \times 6$, respectively. They are reported in Figure 9, whereas Figure 10 shows some images of the plastic strains. For the specimen $M_{1} 9 \times 6$ the measured load displacement diagram is in good agreement with the numerical results of the analysis FE1. From these diagrams, the nonlinear behavior of the whole joint appears at $125 \mathrm{kN}$. However, if lower loads are applied, the joint is in the linear elastic regime, although the edges of the tee web show plastic deformations at the connection with the cap plate. This is evident in Figure 10a, where the plastic strain distribution of step I, which corresponds to a load $\mathrm{N}=100 \mathrm{kN}$ (see Figure 9) is reported. For loads higher than $125 \mathrm{kN}$ (step II in Figure 10a) a more extended plastic zone can be observed between the tee web and the cap plate, which is also subjected to bending action. The failure (step III in Figure 10a), which appears at $\mathrm{N}=179 \mathrm{kN}$, is finally localized around the connection between tee web and cap plate, as obtained in the experimental results (Figure 6a).

In the case of the specimen $\mathrm{M}_{2} 9 \times 6$, the load-displacement curve obtained with the numerical analysis (model FE2), is able to predict with good accuracy the yielding and the collapse loads experimentally measured (Figure 9). The nonlinear behavior is evident for $\mathrm{N}>200 \mathrm{kN}$, even if plastic zones are generated for lower loads (step I in Figure 10b). However, with respect to FE1 (step I in Figure 10a), these zones are located in few elements at the connection between the tee webs and the cap plate. If the load is increased (step II in Figure 10b) plastic strains affect a larger area. Nevertheless, due to a more uniform distribution, maximum strains are lower than those obtained with FE1 analysis (step II in Figure 10a). As illustrated in Figure 10b, during step III, wide plastic strains affect both the interface between cap plate and tee webs, and between tube and cap plate. In these zones the failure might occur. This explains the discrepancy between the numerical results of FE2, in which a failure on the interface between tee web and cap plate occurs 
(load $\mathrm{N}=247 \mathrm{kN}$, step III in Figure 10b) and the observed failure in the tube (Figure 4b). It is sufficient a little variations of the material characteristics or small and localized defects (e.g., an incomplete penetration of the weld between cap plate and tube) to obtain one of the possible failure mechanisms.

In Figure 11a the strains measured by the gauges glued on the tube of each specimen are compared with the FEM results. In both the cases, FE1 and FE2 analyses provide, respectively, a good approximation of the local strains in the tube. In the same way, the strains measured on the tee webs are compared with those in Figure $11 \mathrm{~b}$ with those numerically computed. In all the diagrams of Figure 11, the higher load bearing capacity of the joint $\mathrm{M}_{2} 9 \mathrm{x} 6$ is clearly evident.

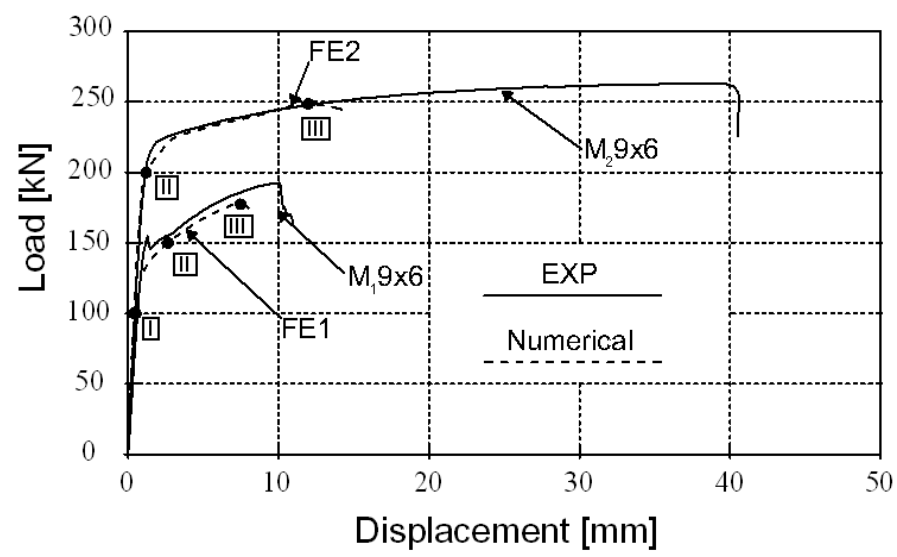

Figure 9. Load-displacement Curves for Tests and Numerical Models

(S tep I)

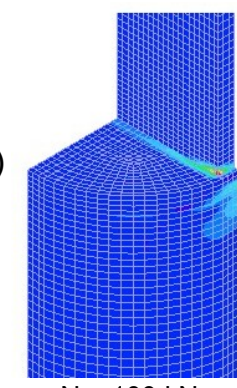

$\mathrm{N}=100 \mathrm{kN}$

(S tep I)

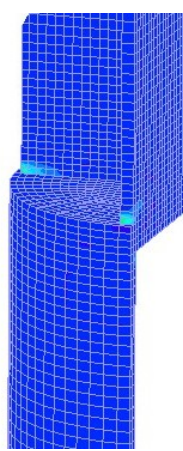

$\mathrm{N}=100 \mathrm{kN}$
(S tep II)

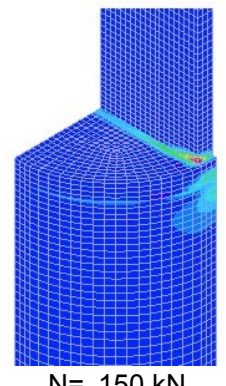

(S tep II)

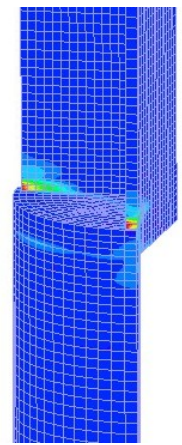

$\mathrm{N}=200 \mathrm{kN}$
(S tep III)
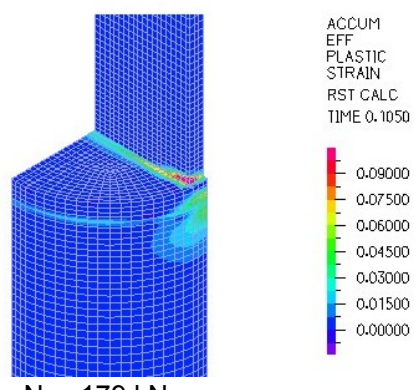

(S tep III)

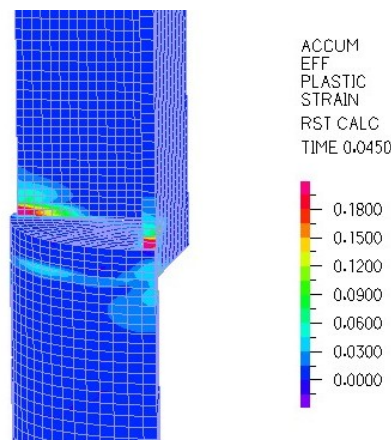

$\mathrm{N}=247 \mathrm{kN}$

Figure 10. Plastic Strain Concentration for Increasing Load a) One Tee Web Model and b) Two Cross Tee Webs Model 


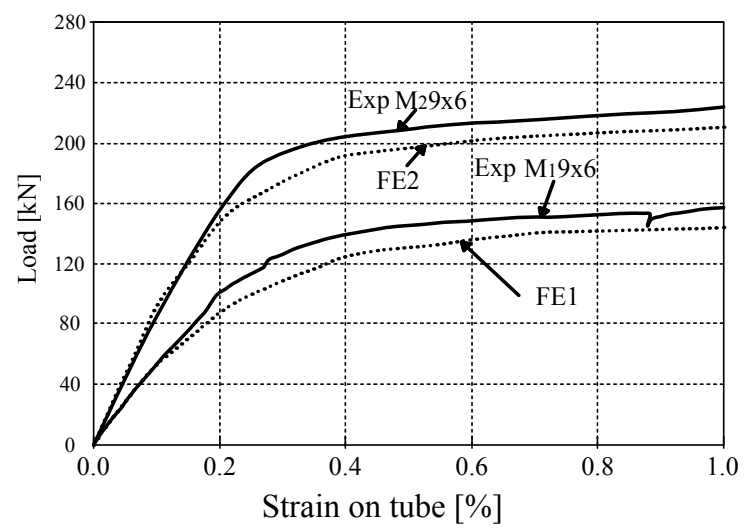

a)

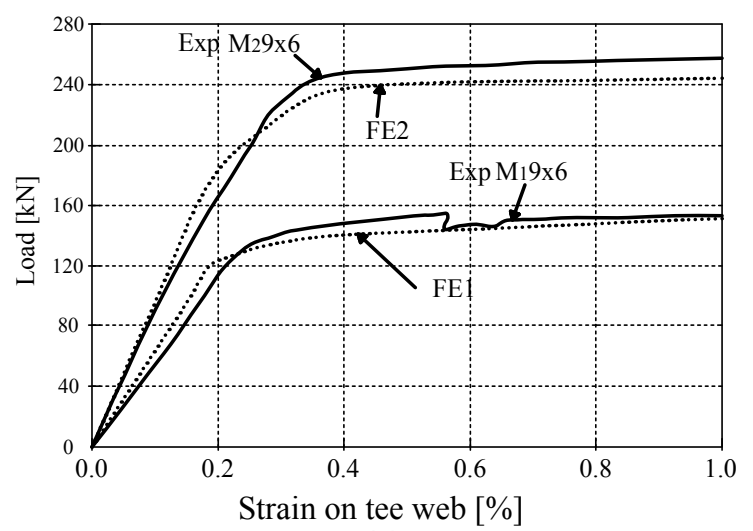

b)

Figure 11. Comparison between the Numerical and Experimental Results of the Strain Gauge Readings a) on the Tubes and b) on the Tee Web of the Specimens and the Fem Models

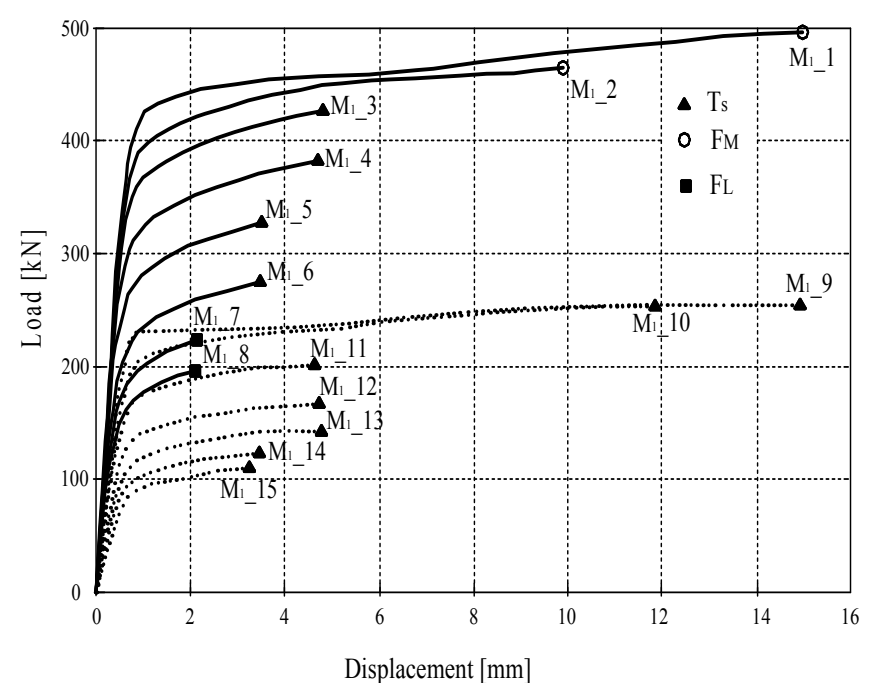

a)
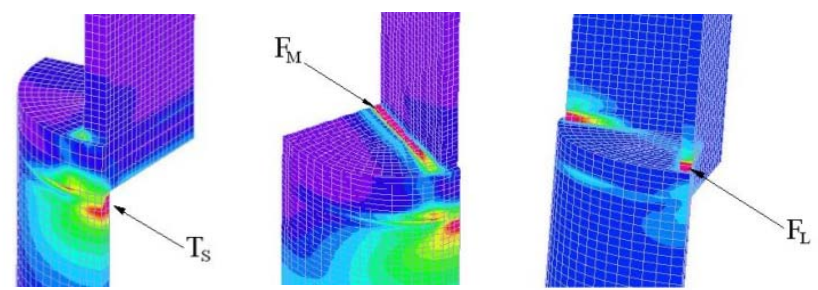

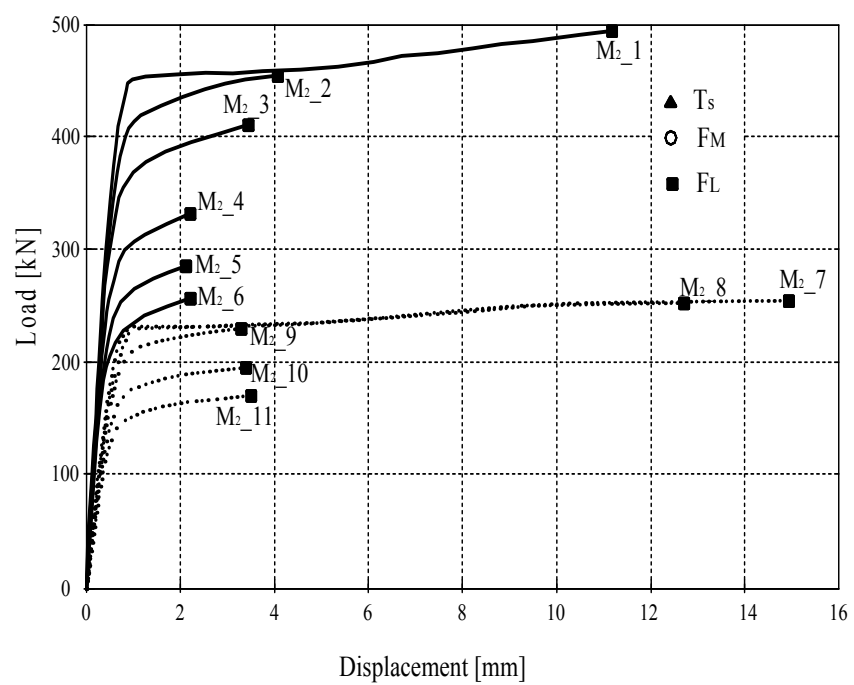

b)
$\mathrm{T}_{\mathrm{s}}=$ Initiation of crack on the tube towards the tee web

$\mathrm{FM}=$ Intermediate initiation of crack between the tee web and the cap plate $\mathrm{FL}=$ Initiation of Crack on the lateral edge of the tee web

Figure 12. Load Displacement Curves and Type of Crack Initiation for the Models of Parametric Analysis with a) One Tee Web and b) Two Tee Webs; c) Point of Rupture Initiation 


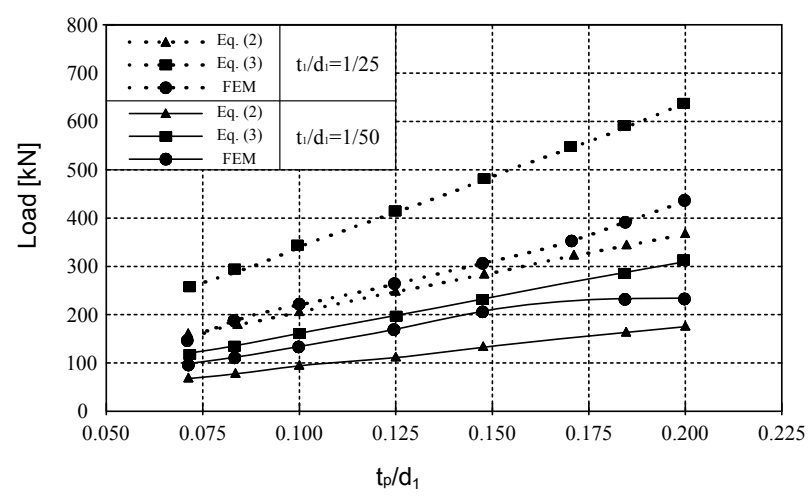

a)

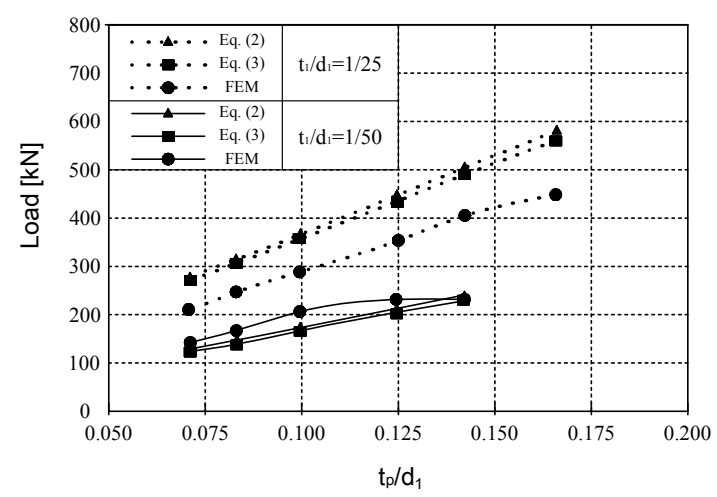

b)

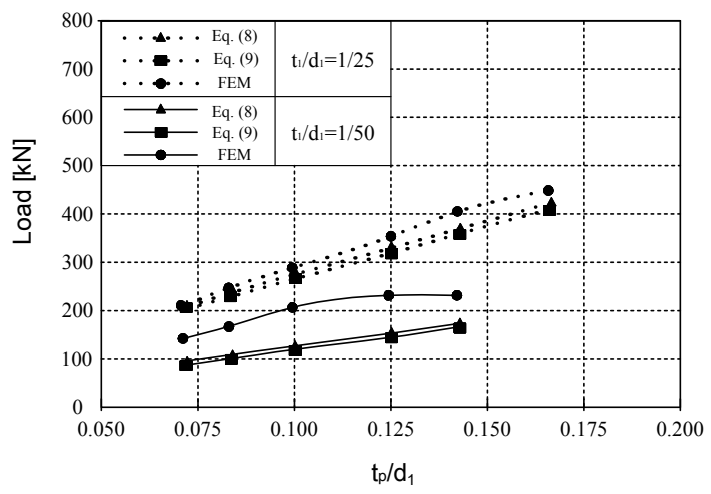

c)

Figure 13. Loads of Non-linearity Behavior for Joints for Models with

a) One Tee Web $\left(\alpha=68^{\circ}\right)$, b) Two Tee Webs $\left(\alpha=68^{\circ}\right)$ and c) Two Tee Webs $\left(\alpha=60^{\circ}\right)$

\section{PARAMETRIC ANALYSIS AND DESIGN FORMULAE}

Starting from the good agreement between the test results and the numerical evaluation of the bearing capacity a parametric analysis is performed. By means of the numerical models previously introduced, it is possible to analyze the influence of some parameters such as the ratios $t_{1} / d_{1}$ and $t_{p} / d_{1}$ on the mechanical response of the joints with one or two tee webs. These ratios were also considered in the analysis made by Kitipornchai and Traves [6] and by Stevens and Kitipornchai [7] for one tee web joints.

If the tube diameter is fixed at $d_{1}=100 \mathrm{~mm}$, the ratios $t_{1} / d_{1}$ and $t_{p} / d_{1}$ for the joint with one tee web (named $\mathrm{M}_{1}$ ) have been varied as listed in Table 3. In the same manner, for joints with two tee webs (named $\mathrm{M}_{2}$ ) the parameters have been modified according to Table 4. In total, 15 models with one tee web (named from $\mathrm{M}_{1} 1$ to $\mathrm{M}_{1} 15$ ) and 11 models with two tee webs (named from $\mathrm{M}_{2} 1$ to $\mathrm{M}_{2} 11$ ) have been analyzed. For all the elements the thicknesses of the tee webs are designed in order to have a cross sectional area higher than the cross-sectional area of the tube of about $15 \%$. An area increase like that is generally used in bolted lap joints to compensate the reduction produced by the holes.

The ratios $t_{1} / d_{1}=1 / 25$ and $t_{1} / d_{1}=1 / 50$ corresponds to tubular elements with a medium and thin thickness, respectively. The numerical results in term of load displacement curves are reported in Figure 12a (models $\mathrm{M}_{1}$ ) and in Figure $12 \mathrm{~b}$ (models $\mathrm{M}_{2}$ ). They are obtained by assuming the constitutive relationship of materials of Figure 4. In the same Figures, different points of failure are also reported. They are named $\mathrm{T}_{\mathrm{s}}, \mathrm{F}_{\mathrm{M}}$, and $\mathrm{F}_{\mathrm{L}}$, if the ultimate strain is reached respectively in the tube, in the internal part of the tee web, or on the edge of the tee web (see Figure 12c). 
Table 3. Thicknesses for One Tee Web Joints with $d_{1}$ Equal to $100 \mathrm{~mm}$

\begin{tabular}{c|c} 
Joint & $\mathrm{t}_{\mathrm{p}} / \mathrm{d}_{1}$ \\
\hline $\mathrm{M}_{1 \_} 1$ & $1 / 5$ \\
\hline $\mathrm{M}_{1 \_} 2$ & $18.5 / 100$ \\
\hline $\mathrm{M}_{1 \_} 3$ & $17.1 / 100$ \\
\hline $\mathrm{M}_{1 \_} 4$ & $14.8 / 100$ \\
\hline $\mathrm{M}_{1 \_} 5$ & $1 / 8$ \\
\hline $\mathrm{M}_{1 \_} 6$ & $1 / 10$ \\
\hline $\mathrm{M}_{1 \_} 7$ & $1 / 12$ \\
\hline $\mathrm{M}_{1 \_} 8$ & $1 / 14$ \\
\hline $\mathrm{t}_{1} / \mathrm{d}_{1}=1 / 25$ & $\mathrm{t}_{\mathrm{w}}=14.7 \mathrm{~mm}$
\end{tabular}

\begin{tabular}{c|c} 
Joint & $\mathrm{t}_{\mathrm{p}} / \mathrm{d}_{1}$ \\
\hline $\mathrm{M}_{1 \_} 9$ & $1 / 5$ \\
\hline $\mathrm{M}_{1 \_} 10$ & $18.5 / 100$ \\
\hline $\mathrm{M}_{1 \_11}$ & $14.8 / 100$ \\
\hline $\mathrm{M}_{1 \_} 12$ & $1 / 8$ \\
\hline $\mathrm{M}_{1 \_} 13$ & $1 / 10$ \\
\hline $\mathrm{M}_{1 \_14}$ & $1 / 12$ \\
\hline $\mathrm{M}_{1 \_} 15$ & $1 / 14$ \\
\hline \multicolumn{2}{|c}{} \\
$\mathrm{t}_{1} / \mathrm{d}_{1}=1 / 50$ & $\mathrm{t}_{\mathrm{w}}=7.4 \mathrm{~mm}$
\end{tabular}

Table 4. Thicknesses for two tee web joints with $\mathrm{d}_{1}$ equal to $100 \mathrm{~mm}$

\begin{tabular}{c|c} 
Joint & $\mathrm{t}_{\mathrm{p}} / \mathrm{d}_{1}$ \\
\hline $\mathrm{M}_{2 \_} 1$ & $1 / 6$ \\
\hline $\mathrm{M}_{2 \_} 2$ & $1 / 7$ \\
\hline $\mathrm{M}_{2 \_} 3$ & $1 / 8$ \\
\hline $\mathrm{M}_{2 \_} 4$ & $1 / 10$ \\
\hline $\mathrm{M}_{2 \_} 5$ & $1 / 12$ \\
\hline $\mathrm{M}_{2 \_} 6$ & $1 / 14$ \\
\hline $\mathrm{t}_{1} / \mathrm{d}_{1}=1 / 25$ & $\mathrm{t}_{\mathrm{w}}=7.7 \mathrm{~mm}$
\end{tabular}

\begin{tabular}{c|c} 
Joint & $\mathrm{t}_{\mathrm{p}} / \mathrm{d}_{1}$ \\
\hline $\mathrm{M}_{2} \_$ & $1 / 7$ \\
\hline $\mathrm{M}_{2 \_} 8$ & $1 / 8$ \\
\hline $\mathrm{M}_{2} 9$ & $1 / 10$ \\
\hline $\mathrm{M}_{2 \_} 10$ & $1 / 12$ \\
\hline $\mathrm{M}_{2 \_} 11$ & $1 / 14$ \\
\hline
\end{tabular}

$\mathrm{t}_{1} / \mathrm{d}_{1}=1 / 50 \quad \mathrm{t}_{\mathrm{w}}=3.8 \mathrm{~mm}$

Increasing the thickness of the cap plate, both the ultimate and yielding loads increase. The presence of two tee webs determines a more uniform stress pattern in the tubes and consequently an increase of their efficiency. For models with two tee webs, the failure is always located on the tee web (close to the cap plate), whereas for joints with one tee web it generally affects the tube, even if in the models $\mathrm{M}_{1} 1, \mathrm{M}_{1} 2, \mathrm{M}_{1} 7$, and $\mathrm{M}_{1} 8$ the concentration of plastic strains regards the tee web.

The yielding loads evaluated with the FEM analysis and those obtained with Eqs. 2 and 3 are compared in Figure 13 for models with one tee web (Figure 13a) and two tee webs (Figure 13b). All the curves are grouped according to the different thicknesses $\left(t_{1} / d_{1}=1 / 25 \div 1 / 50\right)$.

It is not possible to compare directly the results obtained with model of $\mathrm{M}_{1}$ series with model of $M_{2} 1$ series because they have the same ratios $t_{1} / d_{1}$ and $t_{p} / d_{1}$, but they have different thicknesses $t_{w}$ for the tee webs.

For joints with one tee web, the yielding loads computed with numerical models and design approaches [2] increase with the thickness of the cap plate. Both for thick $\left(t_{1} / d_{1}=1 / 25\right)$ and thin tubes $\left(t_{1} / d_{1}=1 / 50\right)$, the Eq. 2 provides a design load lower than Eq. 3, and therefore (Eq. 2) rules the load design capacity of the joint (Figure 13a). The ratio between the yielding load value obtained from FEM analysis and that from Eq. 2 is approximately constant for each type of tube. More precisely, for thin tubes, this ratio is almost equal to 1.4, whereas for thicker tubes it reduces to 1.1. For the specimen $\mathrm{M}_{1} 9 \mathrm{x} 6$, the Design Code with Eq. 2 supplies a design load for the tube equal to $87.8 \mathrm{kN}$, whereas the Eq. 3 provides a design load for the tee web equal to $105.0 \mathrm{kN}$; in this case, in the test the failure is located on the tee web. The ratio between the yielding load measured experimentally and that obtained with the Eq. 2 is equal to 1.7. 
Although they were developed for one tee web joints, Eqs. 2 and 3 are here used also in the case of joints made with two cross tee webs. Precisely, they give substantially the same ultimate loads (see Figure 13b). For thin tubes, the ratio between the yielding load of FEM simulations and those obtained from the Eqs. 2 and 3 is constantly equal to 1.1, and reduces to 0.8 for tubes having $\mathrm{t}_{1} / \mathrm{d}_{1}=1 / 25$. Considering the aforementioned ratios, the design approach can underestimate the yielding load for tube with medium thickness $\left(t_{1} / d_{1}=1 / 25\right)$. For the joint $M_{2} 9 x 6$, the design load obtained with the application of Eq. 2 and Eq. 3 are respectively $175.6 \mathrm{kN}$ and $210.0 \mathrm{kN}$ (i.e. twice the values obtained for joints with one tee web). On the contrary the yielding load measured experimentally is only 1.2 times higher than that observed for specimen $\mathrm{M}_{1} 9 \mathrm{x} 6$.

According to the above observations, the design formulae, if applied to one and two tee webs joints, do not provide the same ratio between the measured and predicted values of design load (Eqs. 2 and 3). In order to ensure similar ratios, for joints with two cross tee webs, a load diffusion angle of $60^{\circ}$ (instead of $68^{\circ}$ ) has to be adopted in the Eq. 2 and Eq. 3. In this way, the design load for the specimen $\mathrm{M}_{2} 9 \times 6$ is reduced to $129 \mathrm{kN}$ and the ratio between the experimentally observed yielding load and that predicted is similar to the ratio of $M_{1} 9 x 6$ (value equal to 1.6). Similarly, the ratio between the yielding loads obtained for the fem simulations and the analytical value calculated by means of a diffusion angle $\alpha=60^{\circ}$, in joints with two tee web, result to be almost the same of those obtained for the elements with one tee web and angle $\alpha=68^{\circ}$. This can be clearly seen from Figure 13c in which the new diffusion angle for two tee web joints is used. In other words, the following equations, which can be considered as an extension of Eqs. 2 and 3 for the two tee web joints, give the design loads:

$$
\begin{aligned}
& N_{1}=4 \cdot f_{y 1} \cdot t_{1} \cdot\left(t_{w}+3.5 \cdot t_{p}\right) \\
& N_{i}=4 \cdot f_{y w} \cdot t_{w} \cdot\left(t_{1}+1.75 \cdot t_{p}\right)
\end{aligned}
$$

\section{CONCLUSIONS}

Some aspects regarding the structural behavior of joints for welded-tee end connections, made with one or two cross tee webs and subjected to tensile load are investigated in the present paper. According to this study, also supported by both the numerical and experimental results, the following conclusion can be drawn:

- The current codes do not supply effective design rules for CHS welded tee end connections, having two cross tee webs. The structural behavior of such connections is remarkably different from those made with one tee web.

- In the case of two cross tee webs joints, the deformation of the tube is constrained by two orthogonal tee webs welded on the cap plate and then the stress diffusion mechanism is different from joints with one tee web

- The analytical formulae reported in the literature, developed for joints with one tee web, seem to overestimate the design load for tube and tee webs, if applied to two cross tee webs joints.

With the aim of a harmonization between the two different types of joints, in terms of ratios between the design load evaluated by mean of the structural response evaluated during experimental and numerical test, and the design formula, a reduction of the assumed spread angle through the cap plate is introduced for two cross tee web joints design equations. 


\section{REFERENCES}

[1] Wardenier, J., "Hollow Sections in Structural Applications", CIDECT Publication, 2001, pp.199.

[2] Wardenier, J., Kurobane, Y., Packer, J.A., van der Vegte, G.J. and Zhao, X.L., "Design Guide for Circular Hollow Section (CHS) Joints under Predominantly Static Loading", CIDECT Publication, preliminary version, November 2007.

[3] ANSI/AISC 360-05, "Specification for Structural Steel Buildings", Chicago: American Institute of Steel Construction (AISC), 2005.

[4] CAN/CSA-S16-01, "Limit States Design of Steel Structures", Toronto: Canadian Standards Association (CSA), 2001.

[5] Martinez-Saucedo, G., Packer, J.A. and Willibald, S., "Parametric Finite Element Study of Slotted End Connections to Circular Hollow Sections", Engineering Structures, 2006, Vol. 28, pp. 1956-1971.

[6] Kitipornchai, S. and Traves, W.H., "Welded-Tee End Connections for Circular Hollow Tubes", Journal of Structural Engineering, ASCE, 1989, Vol. 115, No. 12, pp. 3155-3170.

[7] Stevens, N.J. and Kitipornchai, S., "Limit Analysis of Welded-Tee End Connection For Hollow Tubes", Journal of Structural Engineering, ASCE, 1990, Vol. 116, No. 9, pp. 2309-2323.

[8] "Specification for the Design, Fabrication and Erection of Structural Steel for Buildings", American Institute of Steel Construction, New York, N.Y., 1978.

[9] AS 1250 Steel Structures Code, Standard Association of Australia, Sydney, 1981.

[10] ADINA Finite Element System for Structures, Release 8.3, Watertown, USA, 2003. 